UNIVERSIDADE DE BRASÍLIA

INSTITUTO DE GEOCIÊNCIAS

PÓS-GRADUAÇÃO EM GEOCIÊNCIAS APLICADAS

Dissertação de Mestrado $\mathrm{N}^{\circ} 100$

\title{
ESTUDO DA ESTRUTURA DA CROSTA NO NORTE DO PERU USANDO A FUNÇÃO DO RECEPTOR
}

\author{
Área de concentração: Geofísica Aplicada
}

\section{CRISTOBAL CONDORI QUISPE}

Orientador: Prof. Dr. George Sand Leão Araújo de França (Universidade de Brasília)

Co-orientador: Dr. Hernando Tavera (Instituto Geofísico del Perú)

\section{Brasília-DF}




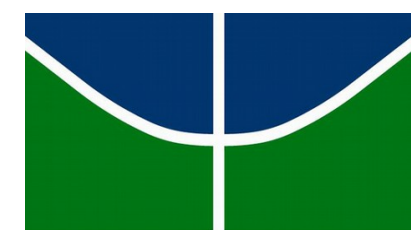

UNIVERSIDADE DE BRASÍLIA

INSTITUTO DE GEOCIÊNCIAS

PÓS-GRADUAÇÃO EM GEOCIÊNCIAS APLICADAS

\title{
ESTUDO DA ESTRUTURA DA CROSTA NO NORTE DO PERU USANDO A FUNÇÃO DO RECEPTOR
}

\author{
Autor* \\ CRISTOBAL CONDORI QUISPE
}

Orientador:

Prof. Dr. George Sand Leão Araújo de França (Universidade de Brasília - Brasil)

Co-orientador:

Dr. Hernando Tavera (Instituto Geofísico del Perú - Perú)

Dissertação apresentada ao Instituto de Geociências da Universidade de Brasília, para a obtenção de Título de Mestre em Geociências Aplicadas, na área de Geofísica Aplicada.

\section{Brasília-DF}

2016

* Este trabalho contou com apoio financeiro da CAPES. 
CRISTOBAL CONDORI QUISPE

\title{
ESTUDO DA ESTRUTURA DA CROSTA NO NORTE DO PERU USANDO A FUNÇÃO DO RECEPTOR
}

\author{
Dissertação apresentada ao Instituto de \\ Geociências da Universidade de Brasília, \\ para a obtenção do Título de Mestre em \\ Geociências Aplicadas, na área de Geofísica \\ Aplicada. \\ Autor: Cristobal Condori Quispe \\ Orientador: Prof. Dr. George Sand Leão \\ Araújo de França (Universidade de Brasília) \\ Co-orientador: Dr. Hernando Tavera \\ (Instituto Geofísico del Perú)
}

\section{Brasília-DF}


Condori Quispe, Cristobal

Estudo da Estrutura da Crosta no Norte do Peru usando a

Função do Receptor.

143 páginas

Dissertação ( Mestrado ) - Instituto de Geociências da

Universidade de Brasília. Observatório Sismológico.

1. Função do Receptor

2. Espessura Crustal

3. Razão de Vp/Vs

4. Região Norte do Peru

I. Universidade de Brasília. Instituto de Geociências. Observatório Sismológico.

COMISSÃO JULGADORA:

Prof. Dr. George Sand Leão Araújo de França - IG/UnB

\author{
Prof. Dr. Marcelo Peres Rocha - IG/UnB \\ Membro Interno
}

Prof. Dr. Marcelo Sousa de Assumpção - IAG/USP

Membro Externo

Brasília, 29 de julho de 2016 
À minha esposa Gloria Inés Ticona, a minha filha Stefanny Guadalupe e o meu filho Gabriel Samín. 


\section{Agradecimentos}

Registro aqui meus sinceros agradecimentos a todas as pessoas que contribuíram para a realização desta Dissertação.

Em primeiro lugar a meu grande Deus por conceder-me a paciência e força necessária para poder continuar crescendo como pessoa e profissional.

A meu orientador Prof. Dr. George Sand, pela amizade e excelente orientação, pelos valiosos ensinamentos, pelas palavras de incentivo e pela confiança que depositou em mim sem me conhecer.

A meu Co-orientador Dr. Hernando Tavera do Instituto Geofísico del Perú (IGP), por sua amizade, pelo seu incentivo, disponibilidade e apoio que sempre demonstrou em minha formação profissional em Sismologia.

Agradeço a CAPES, pelo incentivo, suporte financeiro que foi de fundamental importância paro o desenvolvimento desta Dissertação.

Ao Observatório Sismológico (OBSIS) da Universidade de Brasília pelo ambiente agradável e logística para a elaboração da presente Dissertação.

Agradeço ao IGP pela disponibilização dos dados sísmicos da Rede Sismográfica Nacional. Um especial agradecimento a meus colegas Henry Salas e Efraín Fernandes por toda a sua ajuda na adquisição dos dados sísmicos.

Os meus professores de Pós-Graduação Mônica G. Von Huelsen, Giuliano Sant'Anna, Marcelo Peres Rocha e Roberta Vidotti.

Agradeço também os membros da banca de avaliação por disponibilizarem seu tempo para ler e avaliar este trabalho, dando contribuições significativas para sua conclusão.

A minha querida esposa Gloria por ser tão importante na minha vida, obrigado pela compreensão, paciência, amor e apoio durante este período para que este trabalho pudesse ser concretizado.

Aos meus grandes amores da minha vida, o meu filho Gabriel Samín e a minha filha Stefanny Guadalupe, que são as razões da minha dedicação e fontes de inspiração que me tem dado forças para continuar trabalhando, o que levou muitas vezes a privá-los da minha presença.

Minha eterna gratidão a minha mãe Florentina, ao meu irmão Daniel e irmãs Eufemia, Roxana e Maribel, que sempre se orgulharam de mim e confiaram em meu trabalho. Obrigado pela confiança. 
Ao meu tio José Quispe e ao Reverendo padre Christopher Stanley por apoiarem em minha formação profissional.

A todos os meus amigos e colegas da área de Ciencias de la Tierra Sólida (CTS) do IGP.

Agradeço também a meu amigo Dr. Juan Carlos Villegas da Unidad de Geodesia Espacial do IGP pela sua ajuda e sugestões na Dissertação.

A Susan Beck e Brandon Bishop da University of Arizona por apoiarem na elaboração desta Dissertação.

Aos meus amigos e companheiros de moradia Juan Romero e Jason Jerry Atoche pela amizade e por todos os momentos agradáveis compartilhados.

À senhora Iris Soares pela sua amável atenção em sua casa durante o primeiro mês da minha estadia em Brasília.

A todos os funcionários do OBSIS, pessoas com quem convivi nesses anos, Fernando Paiva, Leonardo Honorato, Daniel Linhares, Sidney e Iago Guilherme.

Finalmente um agradecimento aos amigos e companheiros de Pós-Graduação Umberto José Travaglia Filho, Diogo Farrapo, Magda Oliveira, Paulo Araújo, Márcio Maciel, Chris Fianco, Cintia Rocha, Eduardo Xavier e Jean Vinicius que motivaram, acompanharam e contribuíram para o desenvolvimento do trabalho. Obrigado pelos bons momentos que passei em Brasília. 


\section{Resumo}

Neste estudo foram analisados um total de 981 registros de eventos telessismos detectados por 28 estações sismográficas de banda larga, da Rede Sismográfica Nacional do Instituto Geofísico do Peru (2012-2015), CTBTO (2012-2015) e a rede temporal SisNort (2008-2009), com a finalidade de estudar a estrutura da crosta na região norte do Peru, aplicando os métodos de Funções do Receptor no domínio de tempo e Hk-Stacking. Os resultados mostram que a Zona Costeira possui crosta com espessura variando de 25 a $35 \mathrm{~km}$ e Vp/Vs média de 1,72. A espessura crustal na Cordilheira dos Andes é mais heterogênea e varia entre 45 e 55 km no norte, no entanto, na região central na Cordilheira Ocidental a espessura varia entre 55 e $60 \mathrm{~km}$ com Vp/Vs média de 1,78, e na Cordilheira Oriental a crosta apresenta valores entre 45 e $50 \mathrm{~km}$ e Vp/Vs média de 1,82. Na zona Sub-Andina, a espessura obtida é de 35 a 45 km com razão Vp/Vs de 1,75, e na Bacia Amazônica a espessura é de 35 e $40 \mathrm{~km}$ e Vp/Vs media de 1,76. As Vp/Vs correlacionam-se com as variações de fluxo de calor, espessura da crosta, e topografia, mostrando altos valores de Vp/Vs na Cordilheira Ocidental e Cordilheira Oriental, sugerindo uma crosta com composição máfica, e valores baixos de Vp/Vs na Zona Costeira, Sub-Andina e Bacia Amazônica, com uma crosta de composição

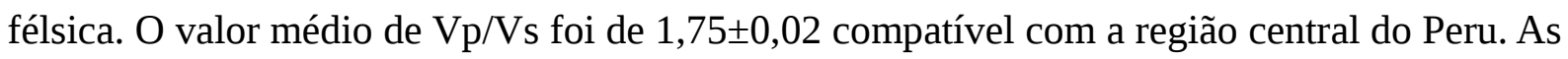
espessuras crustais mostram correlação com as respostas gravimétricas (anomalia Bouguer), indicando um provável equilíbrio isostático, e também mostram que são consistentes com estimativas de espessura para regiões adjacentes, ou estimativas obtidas por outros métodos. 


\begin{abstract}
In this study we analyze 981 teleseismic events recorded by 28 broadband seismic stations from the National Seismographic Network of the Geophysical Institute of Peru (20122015), CTBTO station (2012-2015) and the temporary network SisNort (2008-2009), in order to study the crustal thickness and $\mathrm{Vp} / \mathrm{Vs}$ ratio beneath northern Peru, using time domain Receiver Functions and Hk-Stacking methods. The results show that the Forearc has crust with thickness ranging from $25 \mathrm{~km}$ to $35 \mathrm{~km}$ and an average $\mathrm{Vp} / \mathrm{Vs}$ of 1.72 . The crustal thickness in the Andes Cordillera is more heterogeneous and varies between $45 \mathrm{~km}$ and $55 \mathrm{~km}$ in the north, in the central region the Western Cordillera crustal thickness varies between 55 $\mathrm{km}$ and $60 \mathrm{~km}$ with an average Vp/Vs of 1.78, and the Eastern Cordillera has values from 45 $\mathrm{km}$ to $50 \mathrm{~km}$ and an average $\mathrm{Vp} / \mathrm{Vs}$ of 1.82. In the Sub-Andean zone, we obtain thicknesses from $35 \mathrm{~km}$ to $45 \mathrm{~km}$ with an average $\mathrm{Vp} / \mathrm{Vs}$ ratio of 1.75 , while in the Amazon Basin the thickness is $35 \mathrm{~km}$ to $40 \mathrm{~km}$ and the $\mathrm{Vp} / \mathrm{Vs}$ average is 1.76 . The $\mathrm{Vp} / \mathrm{Vs}$ ratios correlate with the variations in heat flow, crustal thickness, and topography, having high Vp/Vs ratios in the Western Cordillera and Eastern Cordillera suggesting a crust with mafic composition, and lower $\mathrm{Vp} / \mathrm{Vs}$ ratios in the Forearc, Sub-Andean and Amazon Basin having a crust with felsic composition. The average value of $\mathrm{Vp} / \mathrm{Vs}$ for the whole region is $1.75 \pm 0.02$, matching with values for the central region of Peru. Crustal thickness values show good correlation with the gravimetric data (Bouguer anomaly), indicating probable isostatic compensation, and also appear consistent with thickness estimates for adjacent regions or values obtained by other methods.
\end{abstract}




\section{Sumário}

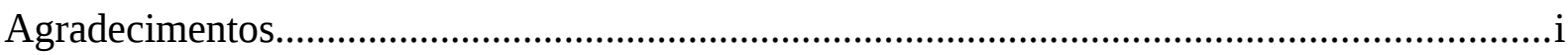

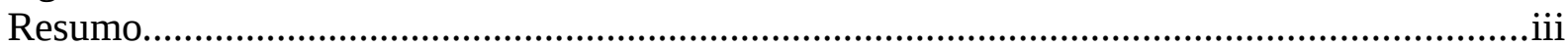

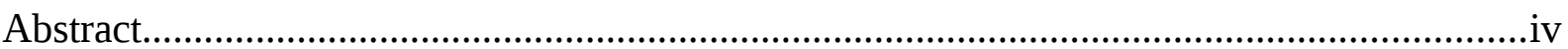

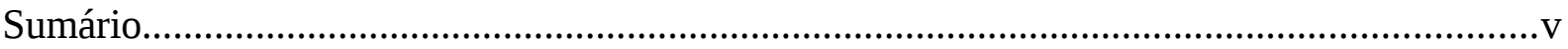

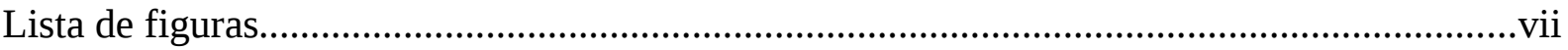

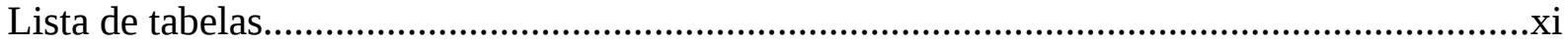

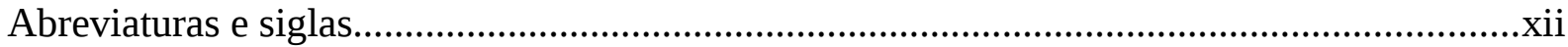

\section{Capítulo 1}

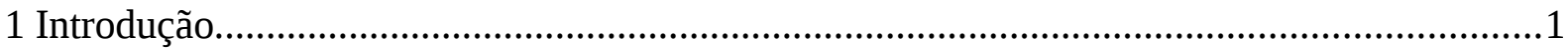

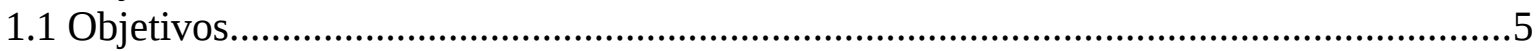

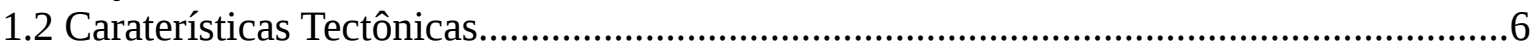

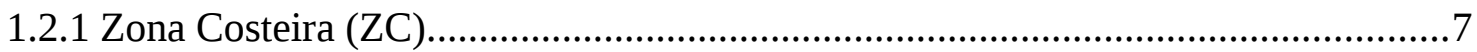

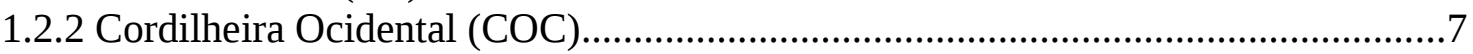

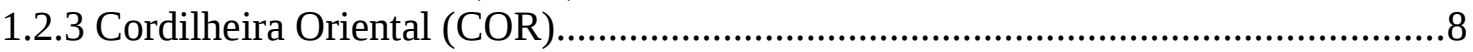

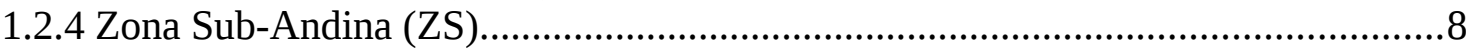

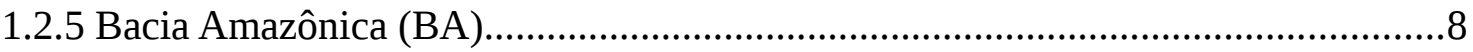

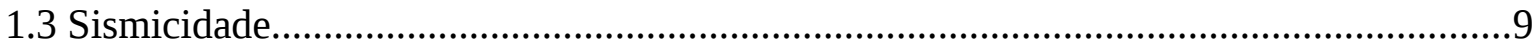

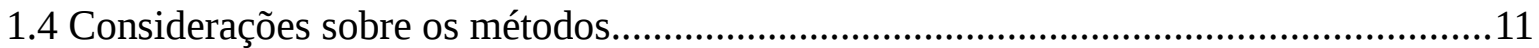

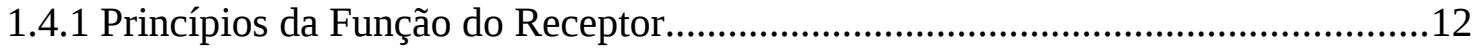

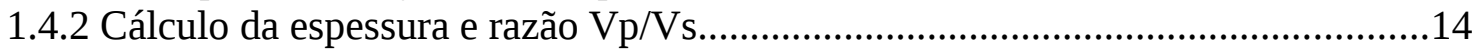

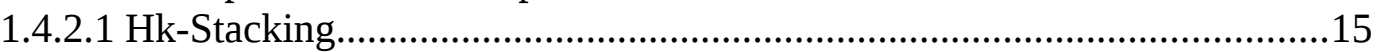

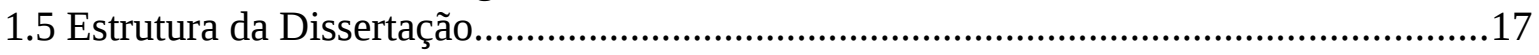

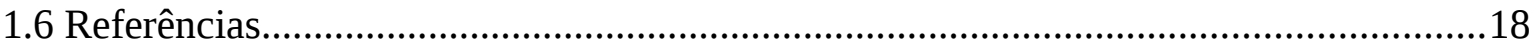

\section{Capítulo 2}

2 Crustal Structure of North Peru from Analysis of Teleseismic Receiver Functions..............23

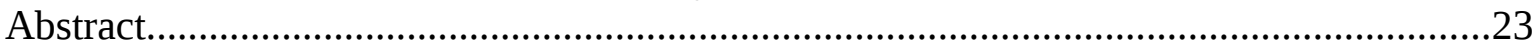

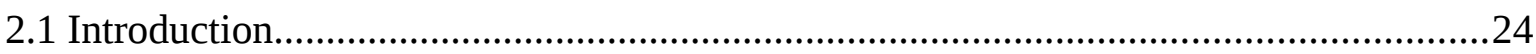

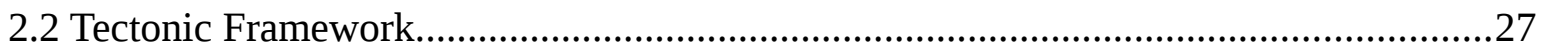

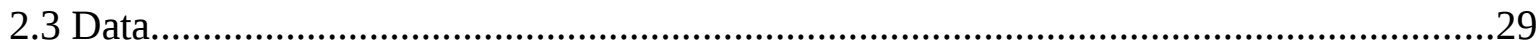

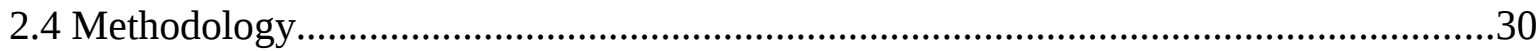

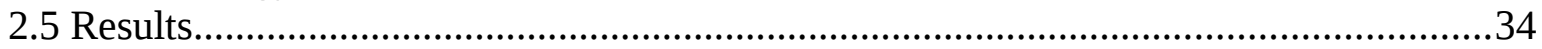

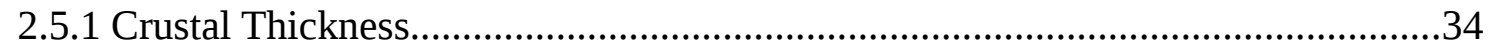

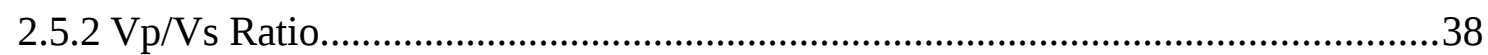

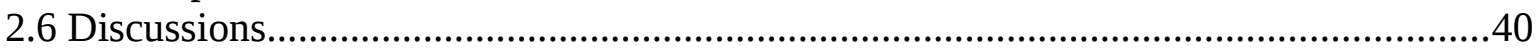

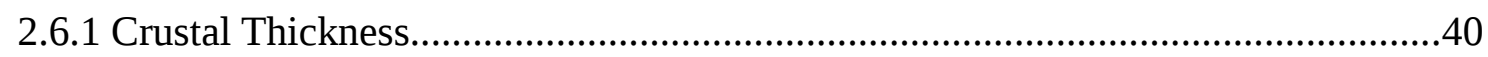

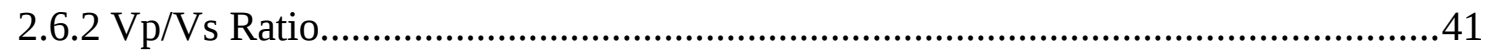

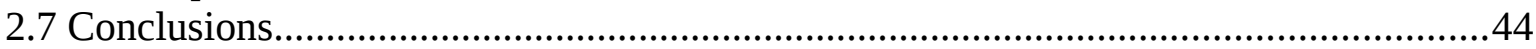

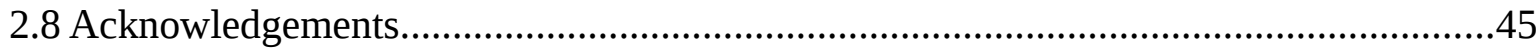

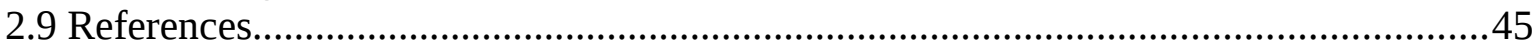

\section{Capítulo 3}

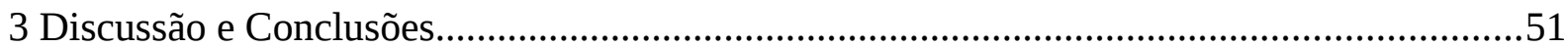




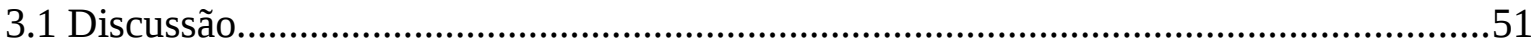

3.1.1 Razão Vp/Vs e Fluxo de Calor Geotérmico..........................................................53

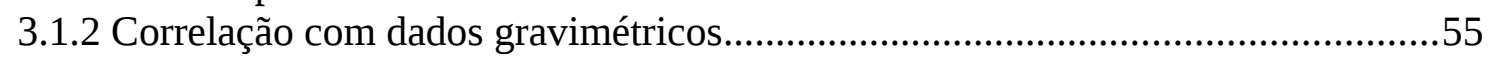

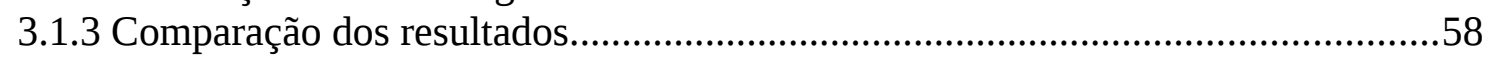

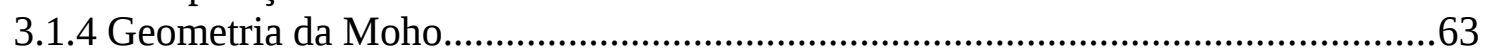

3.1.5 Função do Receptor na Cordilheira dos Andes...................................................64

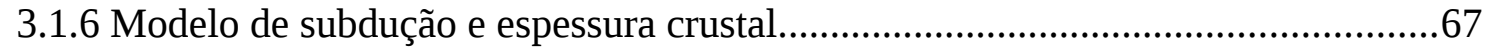

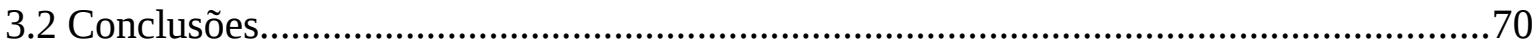

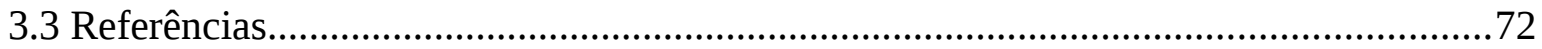

\section{Anexo A}

Coordenadas e período de operatividade das estações sismográficas utilizadas neste estudo..77

\section{Anexo B}

Eventos usados na Função do Receptor em cada estação (Rede SisNort, CTBTO e IGP) para o

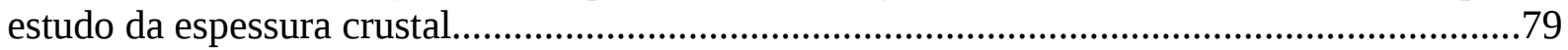

\section{Anexo C}

RF (componente radial) e Hk-stacking para cada estação (Rede SisNort, CTBTO e IGP) ordenadas de acordo com o Back-azimute e Distância............................................................96 


\section{Lista de figuras}

\section{Capítulo 1}

Figura 1.1: Mapa do Peru mostrando as estações sismográficas dos principais projetos realizados no centro e sul. O quadrado vermelho representa a área do estudo e os triângulos representam as estações sismográficas dos projetos: Peru Subduction Experiment (PeruSE), Central Andean Uplif and Geodynamics of High Topography (CAUGHT) e Peru Lithosphere and Slab Experiment (PULSE).....

Figura 1.2: Mapa topográfico mostrando a área do estudo e as estações sismográficas na região norte do Peru. Os quadrados azuis representam as estações da Rede Sísmica Nacional do Instituto Geofísico do Peru. Os triângulos vermelhos representam as estações do Projeto SisNort e o círculo amarelo representa a estação ATH do CTBTO. Maiores detalhes sobre as estações sismográficas e dados nos anexos A e B................................................................

Figura 1.3: Mapa topográfico mostrando as principais caraterísticas tectônicas e geomorfológicas do norte do Peru. As linhas tracejadas de cor azul são os contornos da placa de Nazca determinadas por Hayes et al. (2012). Os polígonos representam as principais unidades geomorfológicas da área de estudo (modificado de Audebaud et al., 1973; Dalmayrac et al., 1980; Tavera e Buforn, 1998).

Figura 1.4: Esquema que mostra as principais unidades tectônicas e geomorfológicas da região norte do Peru (Modificado de Mattauer, 1976).

Figura 1.5: Mapa Sísmico do norte do Peru. a) Distribuição espacial da sismicidade com magnitudes iguais ou maiores que 4,0 Mw no período 1960-2016. O polígono com linha tracejada representa a área dos Andes com menor sismicidade. b) Perfil sísmico A-A'. c) Perfil sísmico B-B'.

Figura 1.6: Diagrama de raio da Função do Receptor (FR). a) Diagrama de raio simplificado mostrando as principais conversões da onda $P$ em onda $S$ que compreende a FR radial para um semi-espaço. b) Registro da FR radial correspondente às reflexões do diagrama em (a). Com exceção da primeira chegada, as letras maiúsculas denotam o percurso para baixo, as letras minúsculas denotam o percurso para cima, $m$ denota a interface de reflexão, por exemplo a Moho. (Modificado de França, 2003).

Figura 1.7: Exemplo de deconvolução pela técnica iterativa no domínio de tempo. a) Pulsos agregados em cada iteração. b) Sismograma sintético resultado da convolução entre o trem de impulsos e a componente vertical do sismograma. Para comparação, mostra-se o sismograma observado (Modificado de Kikuchi e Kanamori, 1982).........................................................14

Figura 1.8: Resultado de espessura crustal e razão Vp/Vs para a estação ATH. a) Diagrama Hk-stacking, calculado com os pesos w1=0,7, w2=0,2 e w3=0,1. b) Traços de FRs radiais mostrando os diferentes tempos de chegada das fases convertidas Ps, PpPms e PpSms+PsPms (em vermelho). 


\section{Capítulo 2}

Figure 2.1: Tectonic map of northern Peru, showing the main tectonic features and local crustal thickness result from previous seismic studies (Hussong et al., 1976; Aranda and Assumpção, 2013), black dotted lines represent contours from the Slab1.0 model (Hayes et al., 2012). Blue lines represent the outline of the Andean Cordillera (600 m elevation contour). Brown dashed lines indicate morphostructural units (modified from Audebaud et al., 1973; Dalmayrac et al., 1987; Tavera and Buforn, 1998). Abbreviations: MFZ: Mendaña Fracture Zone; FA: Forearc; WC: Western Cordillera; EC: Eastern Cordillera; SA: SubAndes; AB: Amazonian Basin; and HD: Huancabamba Deflection, represented by the thick red dashed line.

Figure 2.2: Map showing the location of seismic stations in northern Peru used in this study. Lines AA' correspond to schematic cross-section show in the Figure 2.9.

Figure 2.3: The map in azimuthal projection shows the distribution of teleseismic events with magnitude larger than $5.5 \mathrm{Mb}$ used in this study. Red circles represent earthquake epicenter locations used for the computation of receiver functions, large circles represent the distances of $30^{\circ}$ and $95^{\circ}$ from the center of each seismic station distributed inside the red box, blue lines represent tectonic plate boundaries.

Figure 2.4: Plot of individual radial RFs with different Gaussian filters $(\alpha)$ and time window as a function of back azimuth at three stations located in different tectonic regimes. a) Station FIC of the SisNort Network located close to the coastal Peru-Ecuador border $(\alpha=2.5)$. b) ATH station located in the Andean Cordillera $(\alpha=1.0)$. c) IQT station is located in the Amazonian Basin $(\alpha=2.5)$. Pulses corresponding to the Ps phase from the Moho and multiples (PpPs and PsPs+PpSs) are indicated respectively.

Figure 2.5: Results of $\mathrm{H}-\mathrm{k}$ stacking for three different seismic stations showing the best crustal thickness and $\mathrm{Vp} / \mathrm{Vs}$ ratios at each station. a) Station FIC of the SisNort Network located close to the coastal Peru-Ecuador border. b) ATH station (CTBTO) located in the Andean Cordillera. c) IQT station (NSN) is located in the Amazonian Basin. The grid search was carried out for an assumed average crustal P-wave velocity of $6.1 \mathrm{~km} / \mathrm{s}$. Colors are stacking surface with contours showing percentage values of the objective function and the red line gives the percent confidence ellipse obtained from bootstrapping the dataset.

Figure 2.6: Crustal thickness map in kilometers beneath northern Peru and adjacent areas. In addition to our results, we have also included data from previous studies compiled by Assumpção et al. (2013, 2015). Lines AA' correspond to schematic cross-section showing in Figure 2.9. Contour interval is $5 \mathrm{~km}$

Figure 2.7: $\mathrm{Vp} / \mathrm{Vs}$ ratios for the station analyzed in this study. .38

Figure 2.8: $\mathrm{Vp} / \mathrm{Vs}$ ratio versus crustal thickness for the stations analyzed in this study. Bars associated with each circles represent the estimated uncertainty. See Table 2.1 for numerical values.

Figure 2.9: Cross section showing profiles: (top) topography, (middle) Bouguer anomaly 
interpolate and (bottom) crustal thickness interpolate along the sections A-A' from Figures 2.2 and 2.6.

Figure 2.10: a) Topography showing change in elevation associated with the different geomorphological units in northern Peru. b) Average $\mathrm{Vp} / \mathrm{Vs}$ ratio. c) Average Crustal Thickness and d) Average Geothermal Heat Flow (Cardoso et al., 2010).

\section{Capítulo 3}

Figura 3.1: Mapa topográfico da área de estudo. As cores indicam a elevação em metros, a linha azul indica a geometria da Cordilheira dos Andes (elevação $600 \mathrm{~m}$ ) e as linhas pretas representam as diferentes unidades geomorfológicas. a) Valores de espessura crustal estimados a partir da FR. A linha vermelha representa o perfil A-A' que será mostrado na Figura 3.11. b) Valores de razão de Vp/Vs para cada estação sismográfica.

Figura 3.2: a) Mapa de razão Vp/Vs. b) Mapa do Fluxo de Calor Geotérmico (Modificado de Cardoso et al. 2010). Os quadrados vermelhos e pretos indicam as estações sismográficas e as linhas tracejadas em branco, os limites das unidades geomorfológicas e a linha marrom indica a geometria da Cordilheira dos Andes (elevação 600 m)........................................................54

Figura 3.3: a) Mapa de anomalia Bouguer. b) Mapa de espessura crustal. As linhas tracejadas em branco são os limites das diferentes unidades geomorfológicas e a linha marrom indica a geometria da Cordilheira dos Andes (elevação 600 m)......................................................56

Figura 3.4: a) Variação da anomalia Bouguer com a elevação da estação. b) Variação da espessura crustal com a elevação da estação.

Figura 3.5: Mapa de contorno de espessura crustal para a região norte do Peru proposto por Assumpção et al. (2013, 2015) gerados a partir de dados compilados anteriormente. .59

Figura 3.6: Modelos de espessura crustal. a) Modelo A interpolado com dados de RF calculados neste estudo. b) Modelo B interpolado com dados do Modelo A e com dados compilados por Assumpção et al. $(2013,2015)$.

Figura 3.7: Mapa de espessura crustal a partir do modelo CRUST 1.0 (Laske et al., 2013) para a região norte do Peru.

Figura 3.8: Mapa de contornos de espessura crustal para as regiões centro e sul do Peru proposto por Bishop et al. (2014) a partir de estudos de RF e gravimetria..............................62

Figura 3.9: Diagrama em 3D mostrando a topografia, espessura crustal e a geometria da placa de Nazca (modelo Slab1.0 Hayes et al. 2012) para a região norte do Peru......

Figura 3.10: Traços de Função Receptor gerados pela técnica de deconvolução iterativa no domínio do tempo com dados para as estações: a) YLS (Huaylas), b) PCH (Portachuelo) e c) ATH (Atahuallpa). Todas estão localizadas na Cordilheira dos Andes. 
Figura 3.11: Secção de FR para cada estação ao longo do perfil A-A' (Figura 3.1a) em que os pontos pretos apresentam os epicentros da sismicidade do catálogo sísmico do IGP (19602016). As fases Ps estão marcadas com linha verde e a linha tracejada azul apresenta os traços aproximados da placa de Nazca de acordo com a distribuição da sismicidade em profundidade.

Figura 3.12: a) Modelo de subducção proposto a partir dos resultados das estimativas de espessura crustal e o modelo Slab1.0 (Hayes et al., 2012). b) Correlação com a sismicidade local e regional. Os pontos brancos representam os epicentros da sismicidade com magnitudes 5,0 Mw do catálogo sísmico do IGP (1960-2016).

\section{Anexo A}

Figura A.1: Gráfico mostrando os períodos em que os dados foram obtidos nas estações, barras em vermelho para a Rede SisNort em amarelo a rede CTBTO e em azul para a Rede Sismográfica Nacional do IGP.....

\section{Anexo C}

Figura C.1: RF (Radial) e Hk-stacking para a estação PCM..............................................97

Figura C.2: RF (Radial) e Hk-stacking para a estação CLB................................................98

Figura C.3: RF (Radial) e Hk-stacking para a estação MTP....................................................99

Figura C.4: RF (Radial) e Hk-stacking para a estação LCN..............................................100

Figura C.5: RF (Radial) e Hk-stacking para a estação CHL ................................................101

Figura C.6: RF (Radial) e Hk-stacking para a estação FIC................................................102

Figura C.7: RF (Radial) e Hk-stacking para a estação CLL...............................................103

Figura C.8: RF (Radial) e Hk-stacking para a estação SIG ...................................................104

Figura C.9: RF (Radial) e Hk-stacking para a estação BAG............................................105

Figura C.10: RF (Radial) e Hk-stacking para a estação MOY...........................................106

Figura C.11: RF (Radial) e Hk-stacking para a estação BLV ................................................107

Figura C.12: RF (Radial) e Hk-stacking para a estação BYV ...........................................108

Figura C.13: RF (Radial) e Hk-stacking para a estação ATH...........................................110

Figura C.14: RF (Radial) e Hk-stacking para a estação TMB............................................112

Figura C.15: RF (Radial) e Hk-stacking para a estação YRM............................................113

Figura C.16: RF (Radial) e Hk-stacking para a estação CHO..............................................114

Figura C.17: RF (Radial) e Hk-stacking para a estação NIEV ...........................................115

Figura C.18: RF (Radial) e Hk-stacking para a estação PCH.............................................116

Figura C.19: RF (Radial) e Hk-stacking para a estação CHA...........................................117

Figura C.20: RF (Radial) e Hk-stacking para a estação TAR...............................................118

Figura C.21: RF (Radial) e Hk-stacking para a estação TICA...........................................119

Figura C.22: RF (Radial) e Hk-stacking para a estação CBT...........................................120

Figura C.23: RF (Radial) e Hk-stacking para a estação YANA...........................................121

Figura C.24: RF (Radial) e Hk-stacking para a estação OXA...............................................122

Figura C.25: RF (Radial) e Hk-stacking para a estação PUC.............................................123

Figura C.26: RF (Radial) e Hk-stacking para a estação IQT..............................................124

Figura C.27: RF (Radial) e Hk-stacking para a estação HCO.............................................125

Figura C.28: RF (Radial) e Hk-stacking para a estação HYL.............................................126 


\section{Lista de tabelas}

\section{Capítulo 1}

Tabela 1.1: Valores médios de espessura crustal calculados usando métodos sísmicos e gravimétricos nas regiões Norte, Centro e Sul do Peru.

\section{Capítulo 2}

Table 2.1: Summary of Crustal Thickness and Vp/Vs Ratio and their associated uncertainties from $\mathrm{H}-\mathrm{k}$ stacking for each seismic stations, using $\mathrm{P}$-wave velocity of $6.1 \mathrm{~km} / \mathrm{s}$ and weights of $\mathrm{W}_{1}=0.7, \mathrm{~W}_{2}=0.2$, and $\mathrm{W}_{3}=0.1$ respectively. 36

\section{Anexo A}

Tabela A.1: Coordenadas das estações sismográficas. SN refere-se as estações pertencentes ao projeto SisNort. CTBTO corresponde a rede mundial (Comprehensive Nuclear-Test-Ban Treaty Organization). RSN refere-se as estações pertencentes ao Rede Sismográfica Nacional do Instituto Geofísico do Peru....

\section{Anexo B}

Tabela B.1: Lista de eventos detectados pelas estações da Rede SisNort. .79

Tabela B.2: Lista de eventos detectados pelas estações da Rede SisNort.

Tabela B.3: Lista de eventos detectados pelas estações da Rede SisNort.

Tabela B.4: Lista de eventos detectados pela estação da Rede CTBTO.

Tabela B.5: Lista de eventos detectados pela estação da Rede CTBTO..................................83

Tabela B.6: Lista de eventos detectados pelas estações da Rede do IGP................................84

Tabela B.7: Lista de eventos detectados pelas estações da Rede do IGP...............................85

Tabela B.8: Lista de eventos detectados pelas estações da Rede do IGP...............................86

Tabela B.9: Lista de eventos detectados pelas estações da Rede do IGP..............................87

Tabela B.10: Lista de eventos detectados pelas estações da Rede do IGP.............................88

Tabela B.11: Lista de eventos detectados pelas estações da Rede do IGP..............................89

Tabela B.12: Lista de eventos detectados pelas estações da Rede do IGP.............................90

Tabela B.13: Lista de eventos detectados pelas estações da Rede do IGP............................91

Tabela B.14: Lista de eventos detectados pelas estações da Rede do IGP............................92

Tabela B.15: Lista de eventos detectados pelas estações da Rede do IGP .............................93

Tabela B.16: Lista de eventos detectados pelas estações da Rede do IGP............................94

Tabela B.17: Lista de eventos detectados pelas estações da Rede do IGP............................95 


\section{Abreviaturas e siglas}

$\begin{array}{ll}\text { BA } & \text { Bacia Amazônica } \\ \text { BOP } & \text { Borda Ocidental do Peru } \\ \text { Caltech } & \text { California Institute of Technology } \\ \text { CTBTO } & \text { Comprehensive Nuclear-Tes-Ban Treaty } \\ \text { CAUGHT } & \text { Central Andean Uplif and the Geodynamics of High Topography } \\ \text { COC } & \text { Cordilheira Ocidental } \\ \text { COR } & \text { Cordilheira Oriental } \\ \text { CCPS } & \text { Common Convertion Point Stacking } \\ \text { FR } & \text { Função do Receptor } \\ \text { FCG } & \text { Fluxo de Calor Geotérmico } \\ \text { GPS } & \text { Global Position System } \\ \text { IGP } & \text { Instituto Geofísico del Perú } \\ \text { IRD } & \text { French L'Institut de Recherche pour le Développement } \\ \text { Moho } & \text { Mohorovičić } \\ \text { NSN } & \text { National Seismological Network } \\ \text { NEIC } & \text { National Earthquake Information Center } \\ \text { PDE } & \text { Preliminary Determinations of Epicenters } \\ \text { PeruSE } & \text { Peru Subduction Experiment } \\ \text { PULSE } & \text { Peru Lithosphere and Slab Experiment } \\ \text { ZBV } & \text { Zona de Baixa Velocidade } \\ \text { ZC } & \text { ZS }\end{array}$




\section{Capítulo 1}

\section{Introdução}

O planeta Terra desde sua origem, vem sofrendo inúmeras mudanças geológicas resultante do produto das forças internas que emanam do interior da Terra e são evidenciadas em superfície pela divergência e convergência das placas tectônicas que mantêm em constante movimento os continentes. Uma das consequências importantes deste processo tectônico é a orogênese que envolve encurtamento intraplaca e espessamento crustal.

O Peru encontra-se localizado em uma margem convergente de uma das placas tectônicas mais ativas do mundo e faz parte do chamado Cinturão de Fogo do Pacífico, a região mais sismicamente ativa do mundo, isto é, sua tectônica é através do processo da subducção onde a placa litosférica de Nazca que mergulha sob a placa continental SulAmericana. A placa de Nazca colide com velocidade relativa de 6 a 7 cm/ano (DeMets et al., 1990; Norabuena et al., 1999; Nocquet et al., 2014), apresentando diferentes características geomorfológicas em função da topografia, que varia até 6,000 m acima do nível médio do mar (Dewey e Bird, 1970), com sismicidade e heterogeneidade litológica complexa nas regiões norte, centro e sul do Peru (Lindo, 1993; Tavera e Buforn, 1998).

As informações detalhadas sobre as variações das propriedades da espessura crustal é crucial para a compreensão do mecanismo, evolução crustal e grau isostático (Yuan et al., 2002; Assumpção et al., 2013a; Pavão et al., 2013). A descontinuidade de Mohorovičić (Moho) é a interface limite entre a crosta terrestre e o manto, e representa o maior contraste da velocidade sísmica e composição química (Pacca e McReath, 2000), sendo o local onde a maioria dos processos geológicos dinâmicos acontecem, tais como; terremotos, vulcanismos e orogêneses.

Um dos métodos amplamente aplicados para o estudo da crosta é o denominado Função do Receptor (FR) (Langston, 1979; Owens et al., 1984; Ammon et al., 1990; Ammon, 1991), o qual consiste em utilizar informações das ondas sísmicas de telessismos que fornecem informação sobre a fonte, o percurso pelo manto, e a estrutura local sob a estação 
sismográfica. Quando uma onda P de um sismo distante incide nas camadas abaixo da estação com um ângulo próximo da vertical, podemos retirar os efeitos da fonte e do percurso no manto através da deconvolução da componente radial pela componente vertical. Dessa forma, o sismograma resultante corresponde aproximadamente à função de transferência do meio sob a estação, e é chamada "Função do Receptor" (FR). O traço da FR mostra várias conversões da onda P para onda S, e os tempos de chegada dessas conversões são usados para estimar as descontinuidades no interior da Terra, em especial a crosta, e também a razão Vp/Vs.

No Peru, diversos trabalhos sobre estrutura da crosta foram realizados para entendimento da evolução tectônica da Cordilheira dos Andes, anisotropia do manto e sua relação com a geometria da placa de Nazca, entre os quais podemos citar nas regiões centro e sul: Peru Subduction Experiment-PeruSE (Phillips et al., 2012; Skinner e Clayton, 2013; Ma et al., 2013; Dougherty e Clayton, 2014; Phillips e Clayton, 2014), Central Andean Uplif and Geodynamics of High Topography-CAUGHT (Ryan et al., 2011, 2016; Ward et al., 2013, 2014) e Peru Lithosphere and Slab Experiment-PULSE (Eakin e Long, 2013; Bishop et al., 2014; Eakin et al., 2014, 2015; Antonijevic et al., 2015), (Figura 1.1).

O projeto PeruSE foi desenvolvido em parceria com o Tectonic Observatory do Caltech e o French L'Institut de Recherche pour le Développement (IRD) com o objetivo de estudar principalmente a dinâmica da litosfera dos Andes Orogênicos, os mecanismos que causam a mudança da geometria da placa de Nazca na “zona de transição” de sub-horizontal a normal. Os resultados de FR indicam que a espessura da crosta na região com subducção normal é de $30 \mathrm{~km}$ na costa e de $75 \mathrm{~km}$ embaixo do Altiplano. Além disso, indica a existência de crosta intermediaria a $40 \mathrm{~km}$ de profundidade, que provavelmente indica o Escudo Brasileiro (underplating) (Phillips et al., 2012; Phillips e Clayton, 2014). Por outra parte, o projeto multidisciplinar denominado CAUGHT, foi desenvolvido, principalmente, para estudar os processos geodinâmicos que causaram a formação e evolução do Altiplano nos Andes Centrais do sul do Peru e norte da Bolívia, em que foram instaladas 50 estações de banda larga. Os resultados com o método da RF indicam que a espessura da crosta sob o Altiplano não é uniforme e essa variação, provavelmente, é consequência da delaminação na litosfera e grande precipitação de chuvas ocorridas nos flancos do Altiplano desde o Mioceno (Ryan et al., 2011, 2016). 


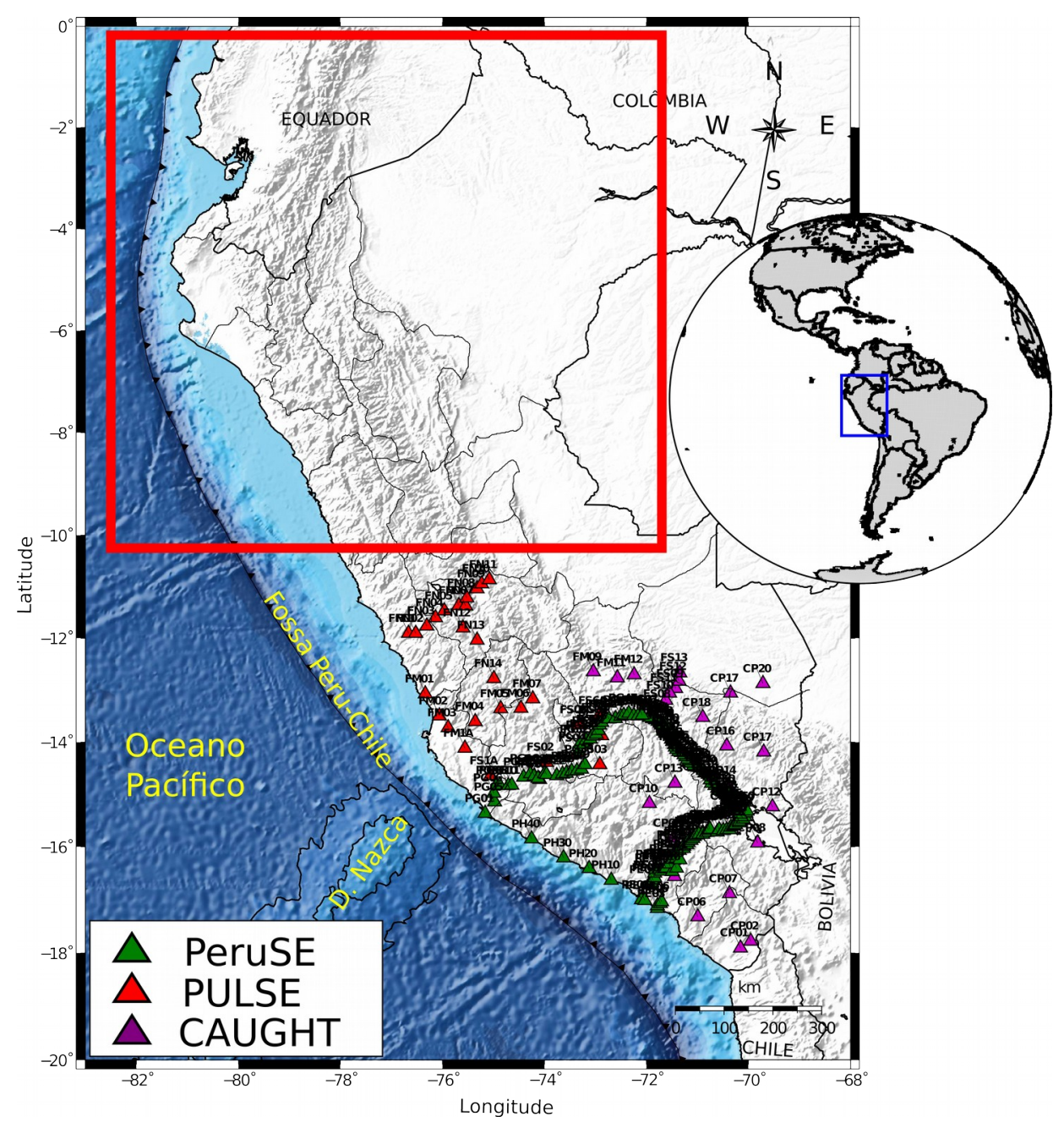

Figura 1.1: Mapa do Peru mostrando as estações sismográficas dos principais projetos realizados no centro e sul. O quadrado vermelho representa a área do estudo e os triângulos representam as estações sismográficas dos projetos: Peru Subduction Experiment (PeruSE), Central Andean Uplif and Geodynamics of High Topography (CAUGHT) e Peru Lithosphere and Slab Experiment (PULSE).

O projeto PULSE foi desenvolvido principalmente para estudar a origem e as causas da estrutura e dinâmica da geometria de tipo sub-horizontal da placa de Nazca na região central do Peru, em que foram utilizadas 40 estações sismográficas de banda larga. Os resultados da anisotropia sísmica indicam que a geometria e deformação da placa subhorizontal é controlada pela migração da Dorsal de Nazca. Por outro lado, a FR indica que a espessura da crosta sob a Dorsal de Nazca é mais fina (45 km) (Eakin e Long, 2013; Bishop et al., 2014). 
A região norte do Peru é caraterizada por apresentar ausência de arco vulcânico e de terremotos com magnitude maior que 8.0 Mw nos últimos 500 anos. Embora existam estudos em escala regional e global, com informações de vários métodos geofísicos sobre a estrutura da crosta (Feng et al., 2007; Lloyd et al., 2010; Pavão et al., 2012; Chulick et al., 2013; Assumpção et al., 2013b, 2015), ainda é pouco conhecida sua estrutura dinâmica da crostamanto (Figura 1.1) e, portanto, é de grande importância entender melhor os aspectos sismotectônicos.

A Tabela 1.1 mostra um resumo dos resultados obtidos nesses trabalhos principalmente nas regiões centro e sul do Peru. Há alguns estudos, como o modelo de crosta inferidos através de modelamento com informações de dados de gravimetria, espessura crustal e sismicidade realizados por Fukao et al. (1989), que mostram espessura média crustal de 45 km para o norte do Peru. Aranda e Assumpção (2013), usando informação de tempos de percurso da onda $\mathrm{P}$ refletidas na superfície de sismicidade com profundidade maior que 60 km, estimaram uma espessura crustal de 40 km no limite da borda Peru-Brasil.

Tabela 1.1: Valores médios de espessura crustal calculados usando métodos sísmicos e gravimétricos nas regiões Norte, Centro e Sul do Peru.

\begin{tabular}{rrrr}
\hline Região & Método & Moho $(\mathrm{km})$ & Referências \\
\hline Norte & Gravimetria & 45 & Fukao et al., 1989, 1999 \\
& Sísmica & 40 & Aranda e Assumpcão, 2013 \\
\hline \multirow{3}{*}{ Centro } & Gravimetria & 55 & Fukao et al., 1989, 1999 \\
& Sísmica & 60 & Tavera, 1990 \\
& Sísmica $-F R$ & 60 & Bishop et al., 2014 \\
\hline Sul & Gravimetria & 65 & Fukao et al., 1989, 1999 \\
& Sísmica & 70 & James, 1971 \\
& Sísmica $-F R$ & 75 & Ocola et al. 1971 \\
& Sísmica $-F R$ & 70 & Bishop et., 2014 \\
& Sísmica $-F R$ & 70 & Phillips e Clayton, 2014 \\
\end{tabular}




\subsection{Objetivos}

Este trabalho foi realizado para dar aporte ao estudo da estrutura tectônica no norte do Peru. Por apresentar uma complexidade tectônica evidenciada em superfície, é importante pesquisar a configuração da crosta e do manto superior para entender a evolução tectônica da região. Dessa forma, o trabalho tem como objetivo estimar a profundidade da descontinuidade Moho e a razão de velocidade (Vp/Vs) sob as estações instaladas no norte do Peru (Figura 1.2), usando a FR com informação de telessismos.

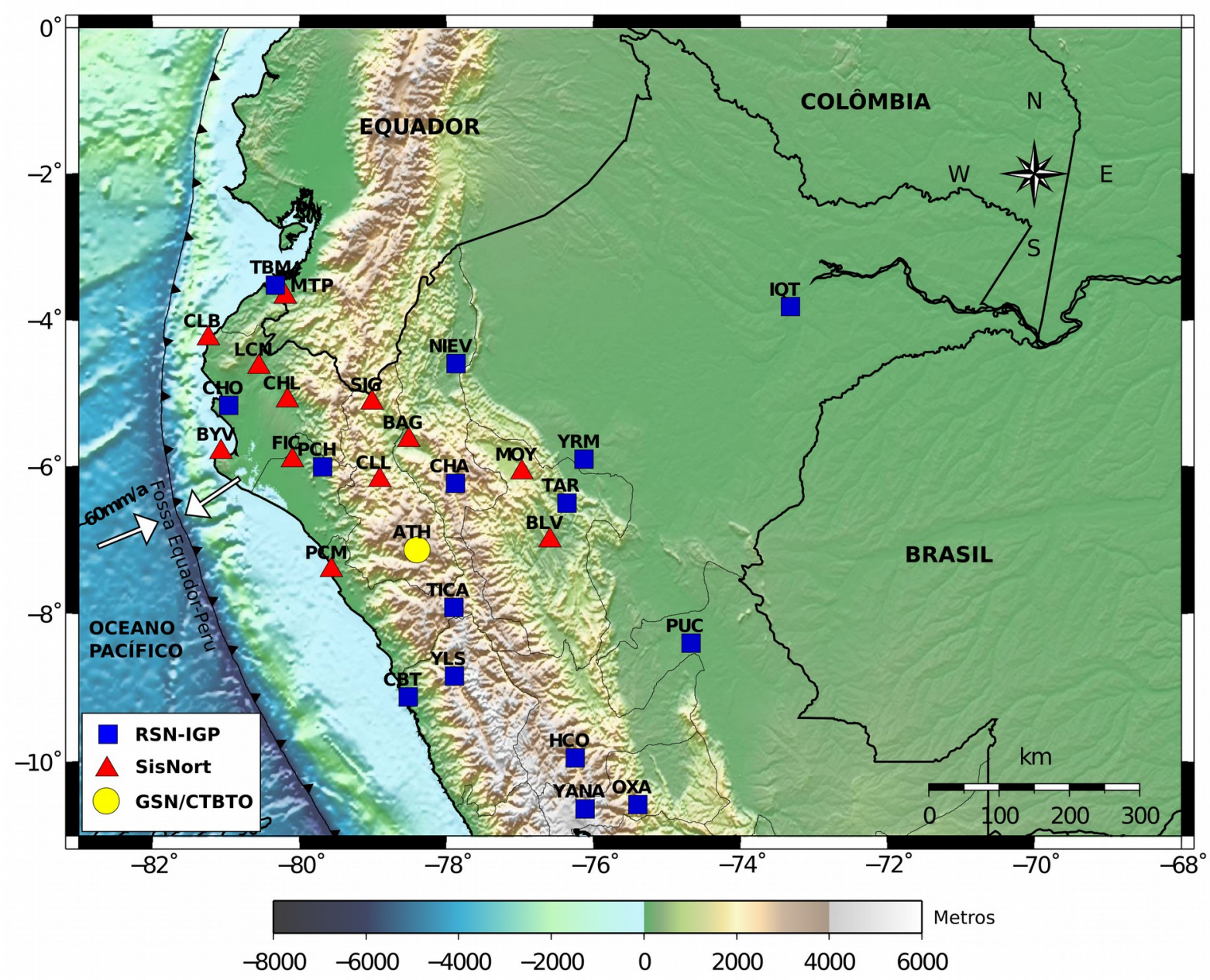

Figura 1.2: Mapa topográfico mostrando a área do estudo e as estações sismográficas na região norte do Peru. Os quadrados azuis representam as estações da Rede Sísmica Nacional do Instituto Geofísico do Peru. Os triângulos vermelhos representam as estações do Projeto SisNort e o círculo amarelo representa a estação ATH do CTBTO. Maiores detalhes sobre as estações sismográficas e dados nos anexos A e B. 


\subsection{Características Tectônicas}

A tectônica atual da região norte do Peru (Figura 1.3) é o resultado de sucessivos ciclos orogênicos produtos de uma forte atividade dinâmica devido à interação das placas de Nazca e Sul-Americana (James, 1971), que convergem de Leste para Oeste com uma velocidade média de 6 a 7 cm/ano (DeMets et al., 1990; Norabuena et al., 1999; Villegas, 2009a). Grandes esforços compressivos e extensivos com magmatismo associado geram uma constante deformação e o soerguimento da cadeia Andina nos últimos 20 milhões de anos (Megard, 1978; Soler e Sébrier, 1990). Esta variedade de processos deu origem a diferentes compartimentações tectônicos com caraterísticas muito particulares.

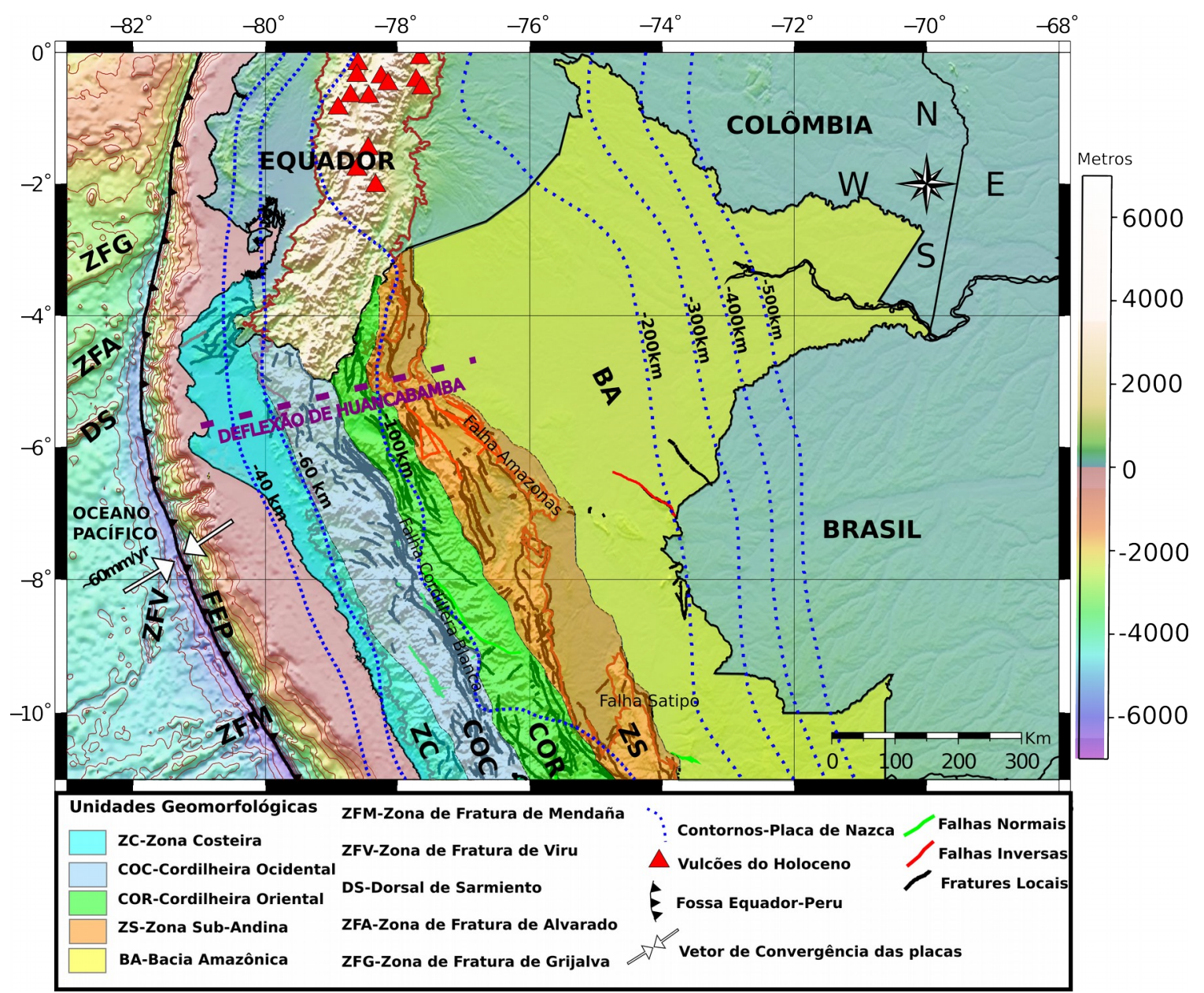

Figura 1.3: Mapa topográfico mostrando as principais caraterísticas tectônicas e geomorfológicas do norte do Peru. As linhas tracejadas de cor azul são os contornos da placa de Nazca determinadas por Hayes et al. (2012). Os polígonos representam as principais unidades geomorfológicas da área de estudo (modificado de Audebaud et al., 1973; Dalmayrac et al., 1980; Tavera e Buforn, 1998). 
As deformações andinas atuais são também evidenciadas pela constante atividade sísmica, resultante da subducção iniciada entre o Triássico Médio e Jurássico Inferior (Mégard, 1987a), sendo, por sua vez, precursora do desenvolvimento dos principais elementos estruturais dos Andes (Figura 1.3). Por outro lado, ocorreram eventos compressionais e distensionais que afetaram a cordilheira de forma geral, sendo que os esforços compressionais se deram nos flancos e os distensionais na porção mais elevada (Dalmayrac et al., 1980; Tavera e Buforn, 1998).

Uma das particularidades mais marcantes da região norte do Peru é a ausência do arco vulcânico devido à geometria da placa de Nazca tipo sub-horizontal (flat-slab), que subducta com um ângulo de 30 graus até uma profundidade de 100 km e depois mantém uma forma sub-horizontal estendendo por vários quilômetros e novamente mergulha no manto (Figura 1.3). No Peru, este processo ocorre a partir da latitude $2^{\circ}$ sul até $15^{\circ}$ sul (Cahill e Isacks, 1992; Gutscher et al., 1999).

Diversos estudos descreveram as estruturas da Cordilheira dos Andes e da Placa de Nazca (Mattauer, 1976; Dalmayrac et al., 1980; Macharé et al., 1986; Mégard, 1987b; Tavera e Buforn, 1998). Com base nestes estudos, são descritas as diferentes unidades geomorfológicas presentes na área de estudo:

1.2.1 Zona Costeira (ZC): é uma zona estreita de aproximadamente $40 \mathrm{~km}$ de largura, que estende-se de norte a sul com altitude média de $700 \mathrm{~m}$ e possui embasamento de rochas PréCambrianas e Paleozóicas e sedimentos Mesozóicos (Palacios et al., 1995). A sul, ocorrem rochas cristalinas fortemente dobradas por causa dos esforços extensionais e compressionais (Figura 1.3).

1.2.2 Cordilheira Ocidental (COC): constitui o batólito plutônico andino de maior volume e contínuo desde a Venezuela até a Terra do Fogo, no Chile. No Peru, está distribuída de norte a sul paralelo à costa. A maior parte dessa cadeia de montanhas (4.200-4.500 m) é formada por rochas do Mesozóico, dobradas e cobertas de maneira heterogênea por rochas vulcânicas do Cenozóico (Figura 1.3). 
No Peru, a Cordilheira Andina apresenta direção principal NW-SE. No entanto, na latitude $6^{\circ}$ sul, sofre uma mudança de orientação conhecida como Deflexão de Huancabamba, seguindo uma nova direção N-S (Figura 1.3).

1.2.3 Cordilheira Oriental (COR): em média, é menos elevada que a Cordilheira Ocidental (3.700-4.000 m) e corresponde principalmente a uma dobra anticlinal regional, formada essencialmente por depósitos intrusivos do Pré-Cambriano na região norte. Na porção sul, esta cordilheira se curva em direção E-W (Figura 1.3) para logo continuar paralela às unidades mencionadas anteriormente.

1.2.4 Zona Sub-Andina (ZS): esta é uma zona de largura variável, onde não ocorrem as estruturas andinas. A zona Sub-Andina localiza-se entre a Cordilheira Andina e a Bacia Amazônica e é formada por uma cobertura de sedimentos do Mesozóico e Cenozóico fortemente afetados por dobras regionais (Figura 1.3).

1.2.5 Bacia Amazônica (BA): limitada a oeste com a zona Sub-Andina, situada entre 80 e $400 \mathrm{~m}$ de altitude e encontra-se depositada sobre o escudo Brasileiro, caracterizado por uma extensa cobertura sedimentar Fanerozóica (Figura 1.3).

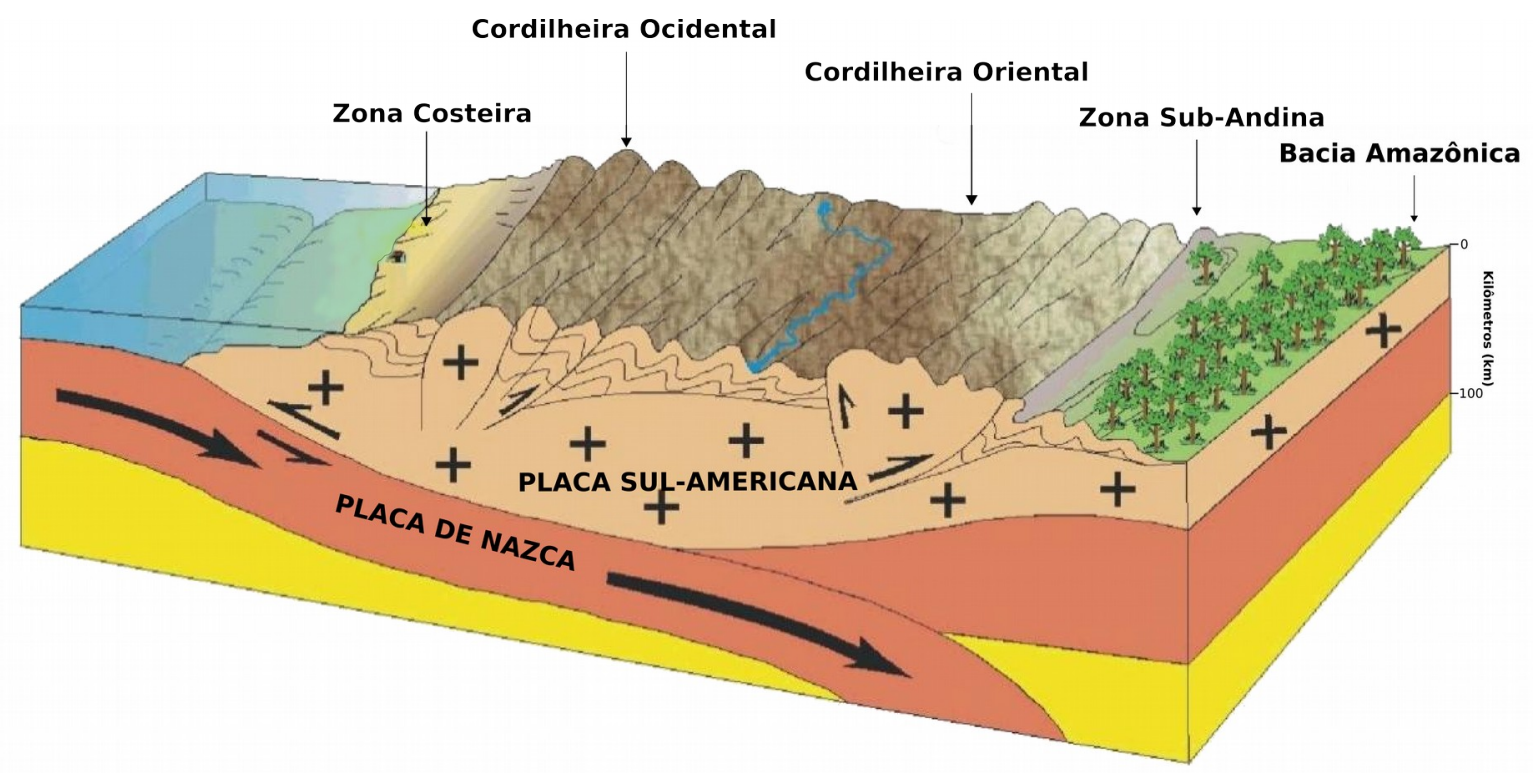

Figura 1.4: Esquema que mostra as principais unidades tectônicas e geomorfológicas da região norte do Peru (Modificado de Mattauer, 1976). 
A Figura 1.4 mostra o esquema tectônico da área de estudo, apresentando as diferentes feições geomorfológicas que representam cada compartimento tectônico descrito acima.

\subsection{Sismicidade}

O processo de subducção da Placa de Nazca (oceânica) sob a Sul-Americana (continental) desenvolve-se na Borda Ocidental do Peru (BOP). Este processo dá origem a uma sismicidade de diversas magnitudes e distribuída em diferentes profundidades (Tavera e Buforn, 1998; Bernal e Tavera, 2002; Tavera, 2014).

A constante recorrência da sismicidade mostra que a região de estudo é por demais complexa e dinamicamente ativa. A região de estudo é caracterizada por uma taxa de sismicidade muito alta, típica de zonas de subducção. Os eventos são classificados, de acordo a profundidade de seus focos, em: superficiais $(\leq 60 \mathrm{~km})$, intermediários $(61-300 \mathrm{~km})$ e profundos ( $\geq 301 \mathrm{~km})$. A sismicidade superficial está associada ao contato das duas placas (oceânica e continental) e deformação dos Andes (concentração de esforços da crosta continental). As mesmas são evidenciadas por falhas geológicas de diversos tipos com sismicidade rasa. As sismicidades intermediária e profunda são devidas à deformação interna e às rupturas em zonas de fraquezas da placa oceânica sob a Cordilheira dos Andes.

O mapa da sismicidade do norte do Peru para magnitudes superiores a 4,0 $\mathrm{Mw}$, mostrado na Figura 1.5a, possuem uma característica importante: os eventos apresentam distribuição geográfica não uniforme. Os epicentros com profundidade superficial encontramse ausentes sob a Cordilheira dos Andes, sugerindo sua pouca deformação possivelmente devido ao efeito de flexura causado pela carga topográfica e os esforços de compressão tanto da placa de Nazca como do cráton do Brasil. Esses esforços causam maior deformação nos flancos onde a crosta é mais fina. Entretanto, nos Andes com crosta mais espessa, as tensões são menores devido à compensação isostática que se mantém em equilíbrio (Assumpção e Sacek, 2013; Rocha et al., 2016). 

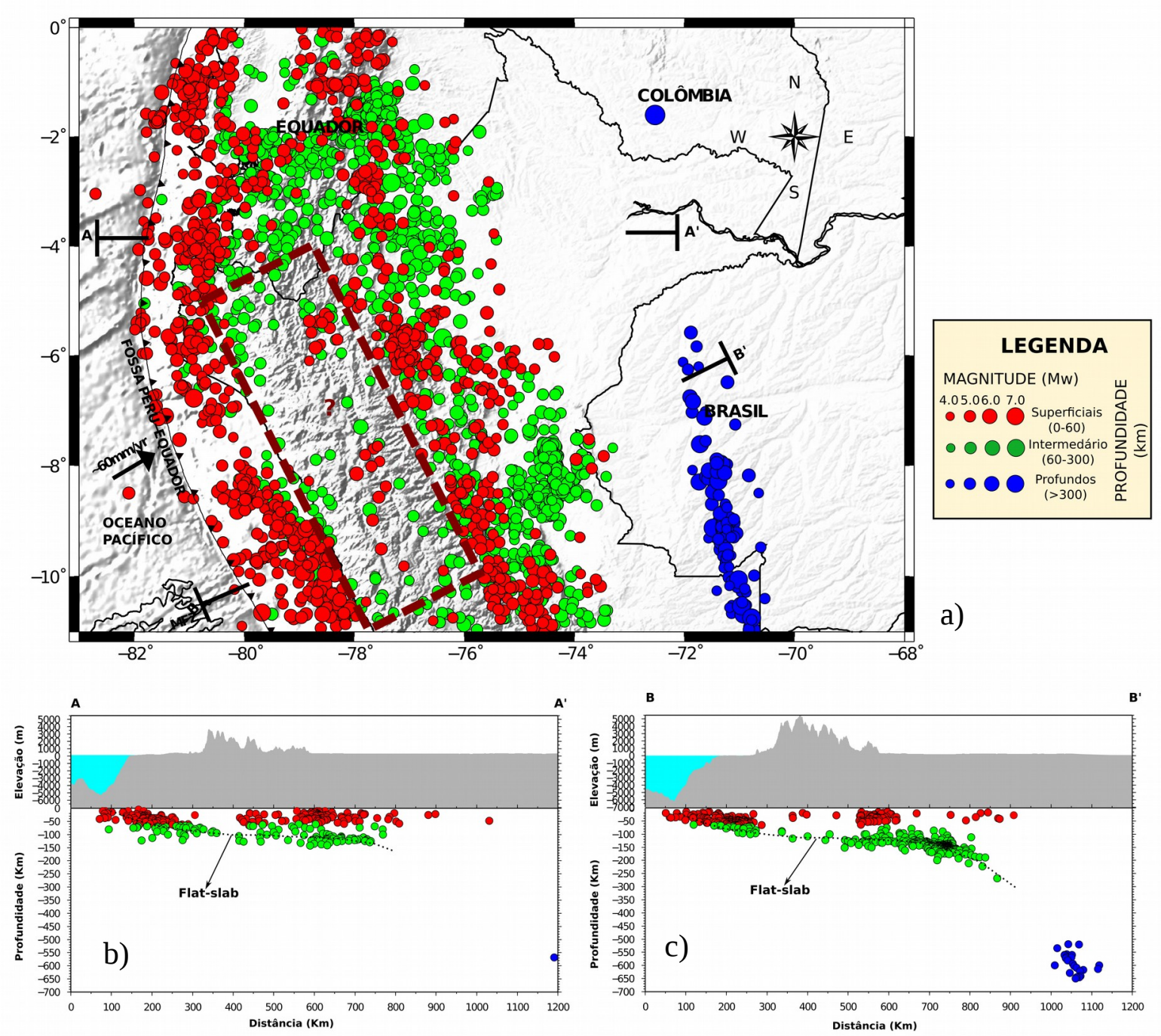

Figura 1.5: Mapa Sísmico do norte do Peru. a) Distribuição espacial da sismicidade com magnitudes iguais ou maiores que 4,0 Mw no período 1960-2016. O polígono com linha tracejada representa a área dos Andes com menor sismicidade. b) Perfil sísmico A-A'. c) Perfil sísmico B-B'.

Na região norte e central do Peru, o mergulho da placa segue a forma sub-horizontal (flat-slab), caracterizada por apresentar a ausência de atividade vulcânica (Gutscher et al., 1999; Skinner e Clayton, 2013; Eakin et al., 2014). Já na região sul, a subducção é do tipo normal com presença da atividade vulcânica. Os perfis verticais A-A' e B-B' (Figuras 1.5b e 1.5c) apresentam a distribuição espacial da sismicidade em profundidade e mostram de maneira geral a geometria da placa oceânica de Nazca. 


\subsection{Considerações sobre os métodos}

A Função do Receptor (FR) é um método geofísico indireto que procura inferir, por meio de registros telessísmicos, a estrutura da Terra abaixo de uma estação sismográfica (Langston, 1979; Owens et al., 1984). Quando uma frente de onda plana P de um telessismo incide sob uma descontinuidade abaixo de uma estação sismográfica, com um ângulo próximo à vertical, parte da sua energia é convertida em ondas S direta e outra parte sofre reflexões S múltiplas.

A FR é a deconvolução da componente radial pela vertical (Langston, 1979; Owens et al., 1984; Ammon et al., 1990; Ammon, 1991). A Figura 1.6 mostra o registro da FR radial, em que as chegadas das fases convertidas e reverberadas são nomeadas de acordo com o percurso. A fase Ps significa onda P convertida em S na Moho, que gera a maior amplitude após a P direta. As reverberações recebem a letra m que representa reflexões na Moho, por exemplo PpPmS, PpSms etc.

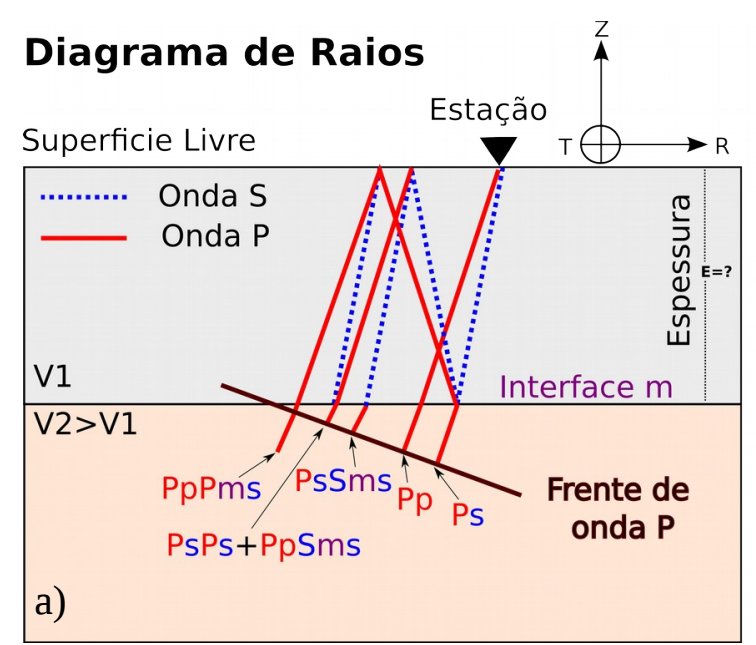

\section{Função do Receptor}

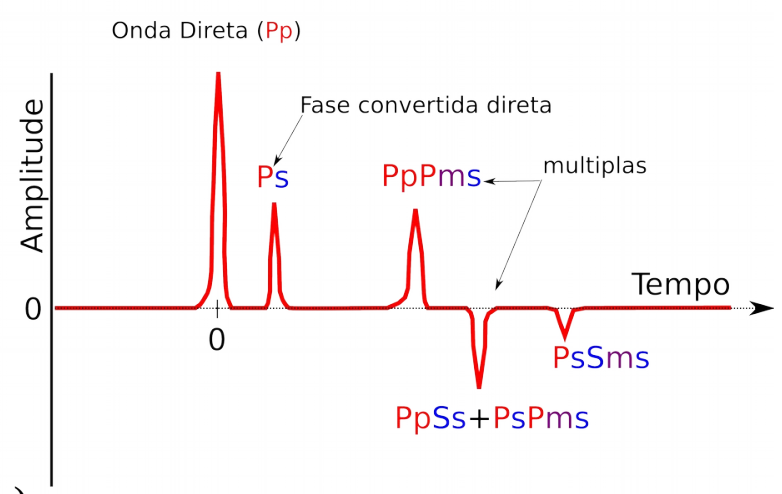

b)

Figura 1.6: Diagrama de raios da Função do Receptor (FR). a) Diagrama de raios simplificados mostrando as principais conversões da onda $P$ em onda $S$, que compreende a FR radial para um semi-espaço. b) Registro da FR radial correspondente às reflexões do diagrama em (a). Com exceção da primeira chegada, as letras maiúsculas denotam o percurso para baixo, as letras minúsculas denotam o percurso para cima, m denota a interface de reflexão, no caso, a Moho. (Modificado de França, 2003). 
Langston (1979) obteve resultados no estudo da crosta usando a FR, o que motivou uma grande quantidade de trabalhos (Owens et al., 1984; Owens e Zandt, 1985; Ammon et al., 1990; Ammon e Zandt, 1993; Zandt e Ammon, 1995) com objetivo de estimar a estrutura da crosta. Atualmente, a FR é uma ferramenta muito importante para determinação da espessura crustal e razão $\mathrm{Vp} / \mathrm{Vs}$.

\subsubsection{Princípios da Função do Receptor}

O registro telessísmico $\left(D(t)_{(V, R, T)}\right)$ é formado pela convolução da assinatura da fonte, com a estrutura da Terra abaixo da estação sismográfica $\left(e(t)_{(V, R, T)}\right), w(t)$ é função temporal da fonte e a resposta do instrumento $(i(t))$. As componentes vertical, radial e tangencial do registro são representadas por Owens et al. (1984) conforme Equações 1, 2 e 3.

$$
\begin{aligned}
& D_{V}(t)=w(t) * e_{V}(t) * i(t) \\
& D_{R}(t)=w(t) * e_{R}(t) * i(t) \\
& D_{T}(t)=w(t) * e_{T}(t) * i(t)
\end{aligned}
$$

Onde os termos $V, R$ e $T$ representam, respectivamente, as componentes vertical, radial, transversal do registro sísmico no tempo $(t)$. O símbolo asterisco $(*)$ representa o operador matemático convolução. Ao aplicar a Transformada de Fourier nas equações 1, 2 e 3, a convolução torna-se uma multiplicação espectral, como mostrado pelas equações abaixo:

$$
\begin{aligned}
& D_{V}(w)=W(w) E_{V}(w) I(w) \\
& D_{R}(w)=W(w) E_{R}(w) I(w) \\
& D_{T}(w)=W(w) E_{T}(w) I(w)
\end{aligned}
$$

Onde $w$ é frequência radial.

Para onda P telessísmica incidido próxima à vertical sob a estação sismográfica, a estrutura da Terra $\left(\mathrm{e}_{V}\right)$ pode ser representada aproximadamente pela função delta de Dirac (elemento neutro da convolução): 


$$
\begin{aligned}
& e_{V} \approx \delta(t) \\
& D_{V}(t) \approx w(t) * s(t)
\end{aligned}
$$

Ao aplicar a deconvolução na componente vertical do registro $\left(\left(D_{V}(t)\right)\right.$ das componentes horizontais $\left(D_{R}(t)\right)$ ou $\left(D_{T}(t)\right)$, isola-se a estrutura abaixo da estação na direção radial $\left(e_{R}(t)\right)$ e tangencial $\left(e_{T}(t)\right)$. No domínio da frequência, a deconvolução é uma divisão espectral apresentada como:

$$
\begin{aligned}
& E_{R}(w)=\frac{D_{R}(w)}{D_{V}(w)} \approx \frac{\delta(t) I(w) S(w)}{I(w) S(w)} \approx \delta(t) \\
& E_{T}(w)=\frac{D_{T}(w)}{I(w) S(w)} \approx \frac{D_{T}(w)}{D_{V}(w)}
\end{aligned}
$$

A deconvolução iterativa no domínio do tempo é uma técnica onde se obtém a deconvolução minimizando, em termos de mínimos quadrados (Ligorría e Ammon, 1999), a diferença entre uma das componentes horizontais (Radial) do sismograma e o sinal estimado que resulta da convolução entre um trem de impulsos reavaliado em cada iteração e a componente vertical do sismograma (Figura 1.7). Os resultados dos processos anteriores fornecem informação do valor e a determinação do primeiro impulso da FR. Esta primeira aproximação é convolvida com a componente vertical para obter um sismograma sintético da componente radial. O sismograma sintético, o qual em realidade é só um pulso obtido anteriormente, é subtraído do sismograma observado para eliminar o impulso estimado.

Com a componente vertical observada e com o novo sismograma sintético da componente radial realiza-se a correlação cruzada para estimar a posição e amplitude do próximo pulso, o procedimento é realizado iterativamente até que a diferença entre o sismograma sintético da componente radial e o sismograma observado cumpra a condição de erro. O sismograma sintético que atende a condição do menor erro é a FR. 
O procedimento utilizado foi adaptado de Kikuchi e Kanamori (1982), que o empregaram para inverter ondas de corpo. Como a FR é tratada como um sismograma, Ligorría e Ammon (1999) utilizaram este procedimento para obter a FR.

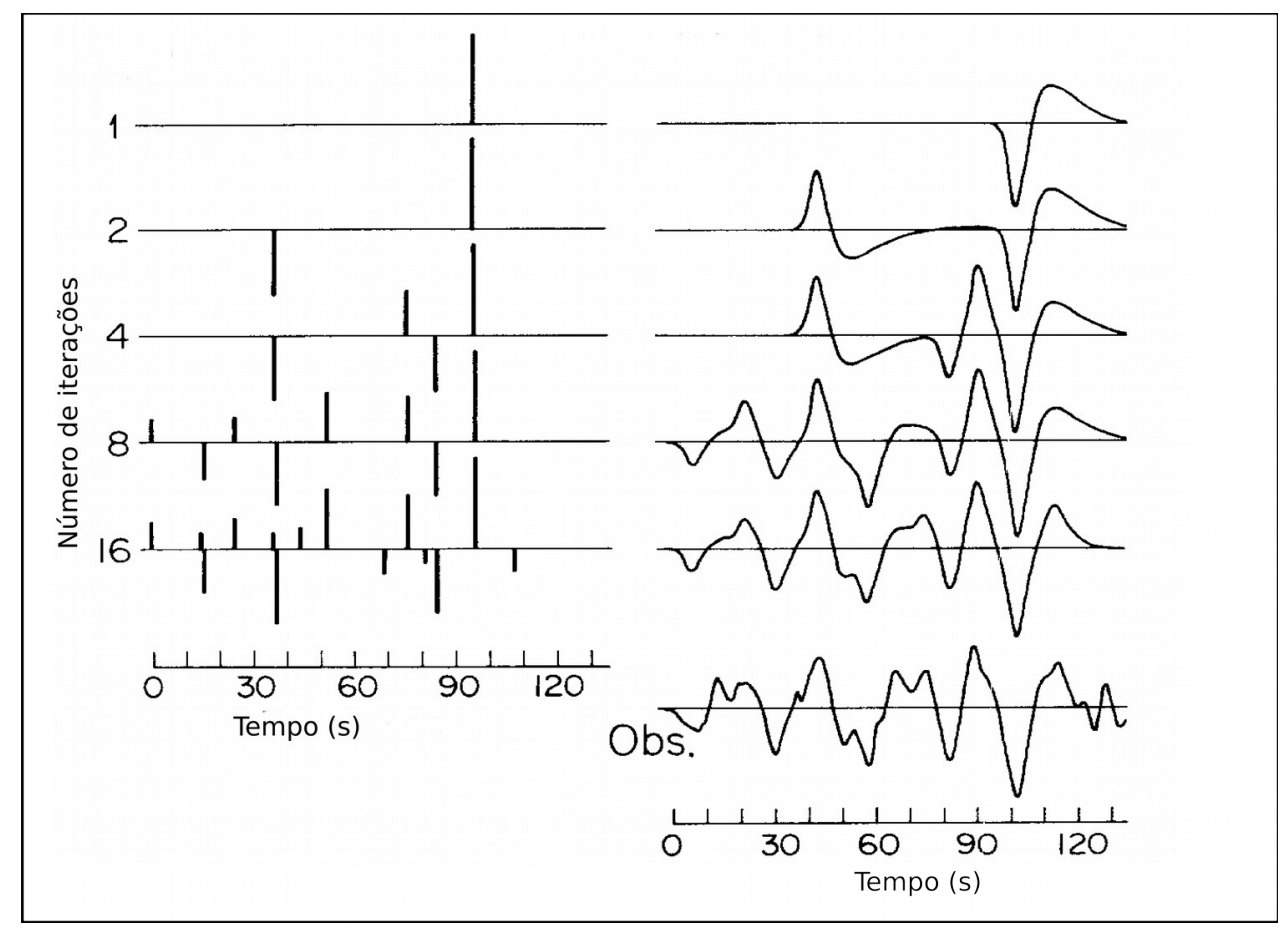

Figura 1.7: Exemplo de deconvolução pela técnica iterativa no domínio de tempo. a) Pulsos agregados em cada iteração. b) Sismograma sintético resultado da convolução entre o trem de impulsos e a componente vertical do sismograma. Para comparação, mostra-se o sismograma observado (Modificado de Kikuchi e Kanamori, 1982).

\subsubsection{Cálculo da espessura e razão $\mathrm{Vp} / \mathrm{Vs}$}

O tempo de percurso das ondas Ps e P na crosta depende da espessura da camada $(h)$, do parâmetro de raio $(\rho)$, da velocidade média da onda $P(V p)$ e da razão $V p / V s$. A relação entre as variáveis foram definidas por Zandt e Ammon (1995) como:

$$
\begin{aligned}
& t_{P s}-t_{p}=h\left[\left(V_{s}^{-2}-p^{2}\right)-\left(V_{p}^{-2}-p^{2}\right)^{1 / 2}\right] \\
& t_{P p P m s}-t_{p}=2 h\left(\frac{1}{V_{p}^{2}}-p^{2}\right)^{1 / 2}
\end{aligned}
$$


Onde o termo $t_{P s}$ é o tempo de chegada da onda $P s$, o $t_{p}$ é o tempo de chegada da onda $P$ e $t_{P p P m s}$ é o tempo de chegada da primeira múltipla.

A razão entre as equações 11 e 12 estabelece a relação entre as velocidades $V p$ e $V s$,

$$
\frac{V_{p}}{V_{s}}=\left\{\left(1-p^{2} V_{p}^{2}\right)\left[2\left(\frac{t_{P s}-t_{P}}{t_{P p P m s}-t_{P s}}\right)+1\right]+p V_{p}^{2}\right\}^{1 / 2}
$$

Para estimar a razão $V_{p} / V_{s}$, não é necessário o valor da espessura crustal. Entretanto, para determinar a espessura crustal, é necessário informar o valor de $V_{p} / V_{s}$ e $V_{p}$, conforme a relação seguinte:

$$
h=\frac{V_{p}\left(t_{P s}-t_{p}\right)}{\left(\sqrt{\frac{V_{p}^{2}}{V_{s}}-p^{2} V_{p}^{2}}-\sqrt{1-p^{2} V_{p}^{2}}\right)}
$$

\subsubsection{Hk-Stacking}

O Hk-Stacking é uma técnica utilizada para obter razões $V p / V s$ e estimativas das espessuras das descontinuidades $h$ (Zhu e Kanamori, 2000) para um modelo que ajusta melhor os traços fornecidos. É baseada nas equações 13 e 14 e a única informação a priori necessária é a velocidade média da onda P. O Hk-Stacking pode ser definido pela seguinte função:

$$
s\left(h, V_{p} / V_{s}\right)=w_{1} \cdot r\left(t_{1}\right)+w_{2} \cdot r\left(t_{2}\right)-w_{3} \cdot r\left(t_{3}\right)
$$

Onde $w_{i}$ são os pesos para as fases Ps, PpPms (1 $1^{\text {a }}$ múltipla) e PpSms+PsPms (2º múltipla), sendo que o somatório dos pesos deve ser igual a $1\left(\sum_{i=1}^{3} w_{1}=1\right)$. A FR é representada por $r(t j), j=1,2,3$ e $t_{1}, t_{2}$ e $t_{3}$ são os tempos de chegada das ondas Ps, PpPms e PpSms+PsPms correspondentes à espessura da crosta $h$ e razão $V p / V s$.

A incerteza associada a cada um dos parâmetros obtidos pelo método Hk-Stacking é estimada pelo método bootstrap (Efron e Tibshirani, 1991). A partir de um conjunto original de FRs, o programa gera subconjuntos contendo traços sorteados aleatoriamente. O método 
repete-se gerando um conjunto de parâmetros $\mathrm{H}$ (profundidade) e k (razão Vp/Vs), a média e o desvio padrão desses valores fornece um valor médio e uma estimativa de erro associada.

A Figura 1.8 apresenta o gráfico da função objetiva da espessura versus Vp/Vs na estação ATH, obtidos pelo programa Hk-stacking considerando 200 subconjuntos. Para uma boa estimativa dos parâmetros de correlação de H-k, atribuem-se pesos para as fases. Zhu e Kanamori (2000) sugerem que os pesos devem ser definidos como Ps=0,7 PpPms=0,2 e PpSms+PsPms=0,1, o que faz com que a fase Ps, que é mais clara, seja mais representativa. Para o valor de Vp, foi utilizado 6,1 km/s, isto é, um valor médio que foi inferido a partir de um modelo de velocidade de crosta para a região norte do Peru proposto por Lindo (1993) e Villegas (2009b). Uma vez que na região de estudo não há informação com estudos de sísmica de refração profunda, as estimativas podem ser afetadas por incertezas.

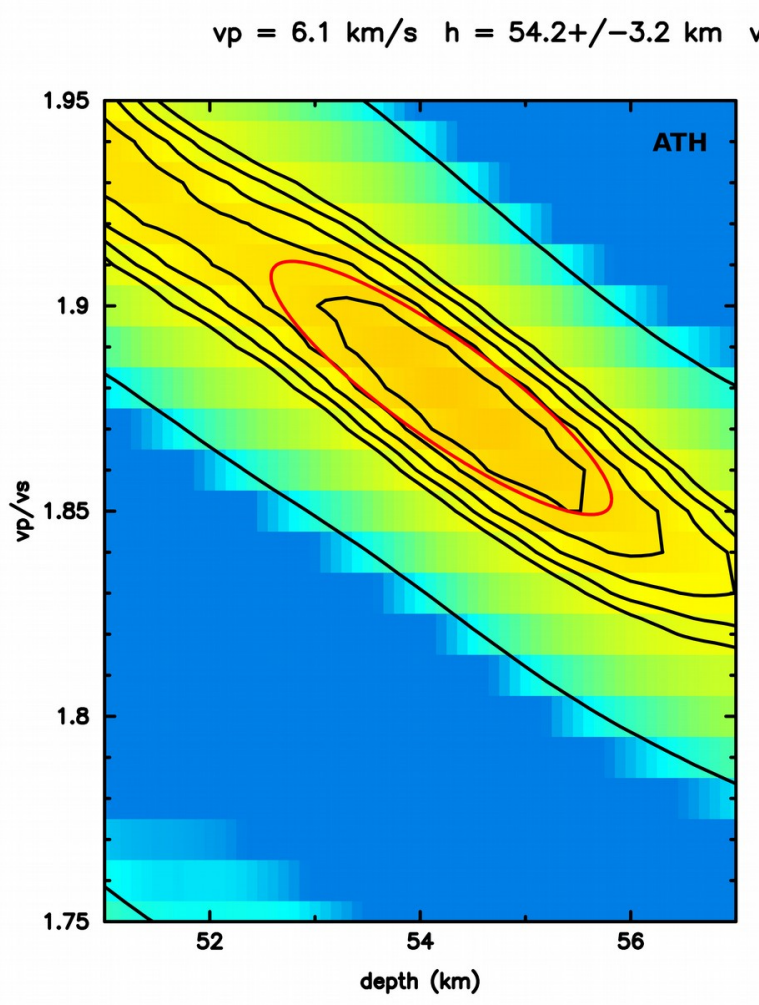

a)
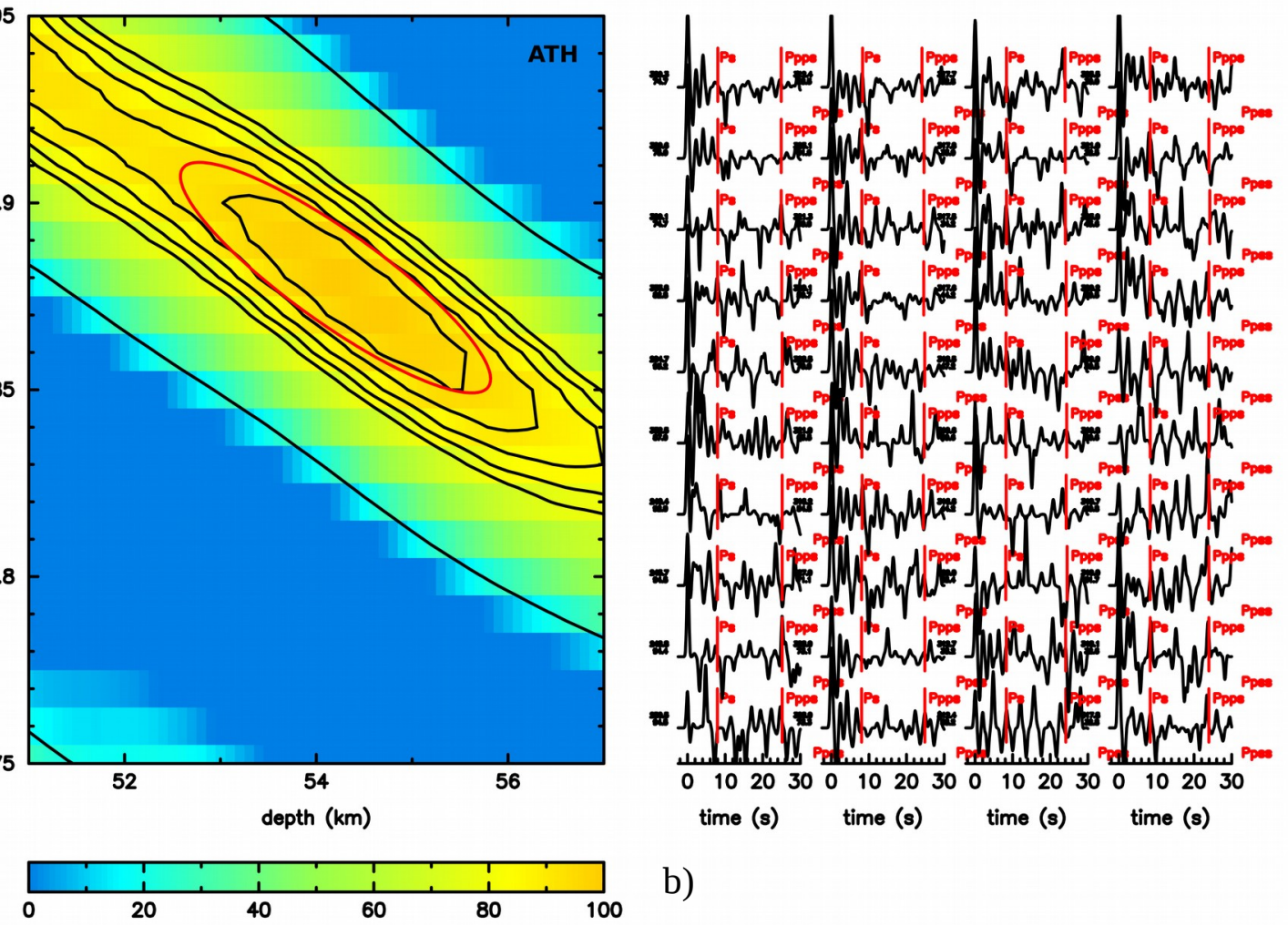

b)

Figura 1.8: Resultado de espessura crustal e razão Vp/Vs para a estação ATH. a) Diagrama Hk-stacking, calculado com os pesos w1=0,7, w2=0,2 e w3=0,1. b) Traços de FRs radiais mostrando os diferentes tempos de chegada das fases convertidas Ps, PpPms e PpSms+PsPms (em vermelho). 


\subsection{Estrutura da Dissertação}

Esta dissertação foi organizada na forma de artigo, com o volume dividido em três capítulos e três anexos que abordam todo o trabalho denominado: Estudo da Estrutura da Crosta no norte do Peru usando a Função do Receptor.

O Capítulo 1 aborda a introdução ao trabalho realizado, os objetivos alcançados, as características tectônicas da área de estudo e descrição do método aplicado.

O capítulo 2 apresenta o artigo com versão em inglês e discute os resultados obtidos neste estudo.

O capítulo 3 sintetiza as principais discussões e conclusões desta pesquisa.

O anexo A mostra o período e lista de estacões sismográficas.

O anexo B apresenta a lista dos dados utilizados neste estudo.

$\mathrm{O}$ anexo $\mathrm{C}$ apresenta as figuras de FR (componente radial) e Vp/Vs estimadas em cada uma das estações sismográficas. 


\subsection{Referências}

Ammon, C., Zandt, G., 1993. The receiver structure beneath the southern Mojave Block. Bull. Seism. Soc. Am. 83, 737-755.

Ammon, C.J., 1991. Isolation of receiver effects from teleseismic P waveforms. Bulletin of the Seismological Society of America 81, 2504-2510.

Ammon, C.J., Randall, G.E., Zandt, G., 1990. On the nonuniqueness of receiver function inversions. Journal of Geophysical Research 95, 15303. doi:10.1029/JB095iB10p15303.

Antonijevic, S.K., Wagner, L.S., Kumar, A., Beck, S.L., Long, M.D., Zandt, G., Tavera, H., Condori, C., 2015. The role of ridges in the formation and longevity of flat slabs. Nature 524, 212-215. doi:10.1038/nature14648.

Aranda, N., Assumpção, M., 2013. Crustal thickness in the northern Andes from teleseismic pP and sS precursors, in: 13th International Congress of the Brazilian Geophysical Society. Society of Exploration Geophysicists and Brazilian Geophysical Society, EXPOGEF, Rio de Janeiro, Brazil, 26-29 August 2013, p. 1781-1785. doi:10.1190/sbgf2013-366.

Assumpção, M., Bianchi, M., Albuquerque, D.F., França, G.S.L.A., Barros, L., 2015. Crustal Thickness Map in South America: an updated version. Extend Abstract 1st Brazilian Symposium on Seismology 1-4.

Assumpção, M., Bianchi, M., Julià, J., Dias, F.L., Sand França, G., Nascimento, R., Drouet, S., Pavão, C.G., Albuquerque, D.F., Lopes, A.E.V., 2013a. Crustal thickness map of Brazil: Data compilation and main features. Journal of South American Earth Sciences 43, 74-85. doi:10.1016/j.jsames.2012.12.009.

Assumpção, M., Feng, M., Tassara, A., Julià, J., 2013b. Models of crustal thickness for South America from seismic refraction, receiver functions and surface wave tomography. Tectonophysics 609, 82-96. doi:10.1016/j.tecto.2012.11.014.

Assumpção, M., Sacek, V., 2013. Intra-plate seismicity and flexural stresses in central Brazil. Geophysical Research Letters 40, 487-491. doi:10.1002/grl.50142.

Audebaud, E., Capdevila, R., Dalmayrac, B., Laubaucher, G., Marocco, R., Mattauer, M., Megard, F., Paredes, J., 1973. Les traits geologiques essentials des Andes Centrales (Perou-Bolivie). Revue Geographie Physique, Geologique et Dinamique. 15(1-2), 73114.

Bernal, I., Tavera, H., 2002. Geodinámica, Sismicidad y Energía sismica en Perú. Monografía-Instituto Geofísico del Perú-Centro Nacional de Datos Geofísicos.

Bishop, B., Beck, S., Zandt, G., Scire, A., Wagner, L., Long, M., Tavera, H., 2014. Trench to andean Thrust Front: Evidence for Coupling of the Peruvian Flat Slab to the Over-riding 
South American Plate. American Geophysical Union, Fall Meeting 2014, abstract \#T23A-4629 2014AGUFM.

Cahill, T., Isacks, B.L., 1992. Seismicity and shape of the subducted Nazca Plate. Journal of Geophysical Research 97, 17503. doi:10.1029/92JB00493.

Chulick, G.S., Detweiler, S., Mooney, W.D., 2013. Seismic structure of the crust and uppermost mantle of South America and surrounding oceanic basins. Journal of South American Earth Sciences 42, 260-276. doi:10.1016/j.jsames.2012.06.002.

Dalmayrac, B., Laubacher, G., R., M., 1980. Geologie des Andes peruviannes, Caracteres generaux de l'evolution geologique des Andes peruviennes. ORDTOM 96-217.

DeMets, C., Gordon, R.G., Argus, D.F., Stein, S., 1990. Current plate motions. Geophysical Journal International 101, 425-478. doi:10.1111/j.1365-246X.1990.tb06579.x

Dewey, J.F., Bird, J.M., 1970. Mountain belts and the new global tectonics. J. geophys. Res. 75, 2625-2647.

Dougherty, S.L., Clayton, R.W., 2014. Seismic structure in southern Peru: evidence for a smooth contortion between flat and normal subduction of the Nazca Plate. Geophysical Journal International 200, 534-555. doi:10.1093/gji/ggu415.

Eakin, C.M., Long, M.D., 2013. Complex anisotropy beneath the Peruvian flat slab from frequency-dependent, multiple-phase shear wave splitting analysis. Journal of Geophysical Research: Solid Earth 118, 4794-4813. doi:10.1002/jgrb.50349.

Eakin, C.M., Long, M.D., Beck, S.L., Wagner, L.S., Tavera, H., Condori, C., 2014. Response of the mantle to flat slab evolution: Insights from local S splitting beneath Peru. Geophysical Research Letters 41, 3438-3446. doi:10.1002/2014GL059943.

Eakin, C.M., Long, M.D., Wagner, L.S., Beck, S.L., Tavera, H., 2015. Upper mantle anisotropy beneath Peru from SKS splitting: Constraints on flat slab dynamics and interaction with the Nazca Ridge. Earth and Planetary Science Letters 412, 152-162. doi:10.1016/j.epsl.2014.12.015.

Efron, B., Tibshirani, R., 1991. Statistical data analysis in the computer age. Science 253, 390-395.

Feng, M., van der Lee, S., Assumpção, M., 2007. Upper mantle structure of South America from joint inversion of waveforms and fundamental mode group velocities of Rayleigh waves. Journal of Geophysical Research 112, B04312. doi:10.1029/2006JB004449.

França, G.S.L.A., 2003. Estrutura da crosta no Sudeste e Centro-Oeste do Brasil, usando função do receptor. Tese de Douturado, 126 pp. Universidade de São Paulo.

Fukao, Y., Yamamoto, A., Kono, M., 1989. Gravity anomaly across the Peruvian Andes. Journal of Geophysical Research 94, 3867. doi:10.1029/JB094iB04p03867. 
Gutscher, M.A., Olivet, J.-L., Aslanian, D., Eissen, J.-P., Maury, R., 1999. The "lost Inca Plateau”: cause of flat subduction beneath Peru? Eart planet. Sci. Lett. 171, 335-341.

Hayes, G.P., Wald, D.J., Johnson, R.L., 2012. Slab1.0: A three-dimensional model of global subduction zone geometries. Journal of Geophysical Research 117, B01302. doi:10.1029/2011JB008524.

James, D.E., 1971. Andean crustal and upper mantle structure. Journal of Geophysical Research 76, 3246-3271. doi:10.1029/JB076i014p03246.

Kikuchi, M., Kanamori, H., 1982. Inversion of complex body waves. Bulletin of the Seismological Society of America 72, 491-506.

Langston, C.A., 1979. Structure under Mount Rainier, Washington, inferred from teleseismic body waves. Journal of Geophysical Research 84, 4749. doi:10.1029/JB084iB09p04749.

Ligorría, J.P., Ammon, C.J., 1999. Iterative Deconvolution and Receiver-Function Estimation. Bull. seism. Soc. Am. 89.

Lindo, R., 1993. Seismotectonique des andes du Perou central: Apport des donnes sismologiques de haute precision. Ph.D. Thesis, Universite Louis-Pasteur, Strasbourg, France. 74.

Lloyd, S., van der Lee, S., França, G.S., Assumpção, M., Feng, M., 2010. Moho map of South America from receiver functions and surface waves. Journal of Geophysical Research 115, B11315. doi:10.1029/2009JB006829.

Ma, Y., Clayton, R.W., Tsai, V.C., Zhan, Z., 2013. Locating a scatterer in the active volcanic area of Southern Peru from ambient noise cross-correlation. Geophysical Journal International 192, 1332-1341. doi:10.1093/gji/ggs103.

Macharé, J., Sébrier, M., Huamán, D., Mercier, J.L., 1986. Tectónica cenozoica de la margen continental peruana. Boletín de la Sociedad Geológica del Perú Geológica del Perú 76, $45-77$.

Mattauer, M., 1976. Las deformaciones de los materiales de la corteza terrestre, Ed. Omega.

Megard, F., 1978. Etude geologique des Andes du Pérou Central. Memoires ORSTOM 86, 310.

Mégard, F., 1987a. Cordilleran Andes and marginal Andes: A review of Andean geology north of the Arica elbow (18º). Geodyn. Ser. 18, 71-95. doi:10.1029/GD018p0071.

Mégard, F., 1987b. Structure and Evolution of the Peruvian Andes, in The Anatomy of Mountain Ranges. eds. Schaer, J.-P. \& Rodgers, J., Princeton University Press. 179-210.

Nocquet, J.-M., Villegas-Lanza, J.C., Chlieh, M., Mothes, P.A., Rolandone, F., Jarrin, P., Cisneros, D., Alvarado, A., Audin, L., Bondoux, F., Martin, X., Font, Y., Régnier, M., 
Vallée, M., Tran, T., Beauval, C., Maguiña Mendoza, J.M., Martinez, W., Tavera, H., Yepes, H., 2014. Motion of continental slivers and creeping subduction in the northern Andes. Nature Geoscience 7, 287-291. doi:10.1038/ngeo2099.

Norabuena, E.O., Dixon, T.H., Stein, S., Harrison, C.G.A., 1999. Decelerating Nazca-South America and Nazca-Pacific Plate motions. Geophysical Research Letters 26, 3405-3408. doi:10.1029/1999GL005394.

Owens, T.J., Zandt, G., 1985. The response of the continental crust-Mantle boundary observed on broadband teleseismic receiver functions. Geophysical Research Letters 12, 705-708. doi:10.1029/GL012i010p00705.

Owens, T.J., Zandt, G., Taylor, S.R., 1984. Seismic evidence for an ancient rift beneath the Cumberland Plateau, Tennessee: A detailed analysis of broadband teleseismic P waveforms. Journal of Geophysical Research 89, 7783. doi:10.1029/JB089iB09p07783.

Pacca, I.G., McReath, I.A., 2000. A Composição e o Calor da Terra. In: Teixeira, W.; Toledo, M.C.M.; Fairchild, T.R.; Taioli, F.. (Org.). Decifrando a Terra. São Paulo: Oficina de Textos 83-96.

Palacios, O., Sánchez, A., Herrera, F., 1995. Geología del Perú, Boletín 55. ed. Lima-Perú.

Pavão, C.G., França, G.S., Bianchi, M., de Almeida, T., Von Huelsen, M.G., 2013. Upperlower crust thickness of the Borborema Province, NE Brazil, using Receiver Function. Journal of South American Earth Sciences 42, 242-249. doi:10.1016/j.jsames.2012.07.003.

Pavão, C.G., França, G.S., Marotta, G.S., Menezes, P.H.B.J., Neto, G.B.S., Roig, H.L., 2012. Spatial interpolation applied to crustal thickness in Brazil. Journal of Geographic Information System 4(2), 142-152.

Phillips, K., Clayton, R.W., 2014. Structure of the subduction transition region from seismic array data in southern Peru. Geophysical Journal International 196, 1889-1905. doi:10.1093/gji/ggt504.

Phillips, K., Clayton, R.W., Davis, P., Tavera, H., Guy, R., Skinner, S., Stubailo, I., Audin, L., Aguilar, V., 2012. Structure of the subduction system in southern Peru from seismic array data. Journal of Geophysical Research 117, B11306. doi:10.1029/2012JB009540.

Rocha, M.P., Azevedo, P.A. de, Marotta, G.S., Schimmel, M., Fuck, R., 2016. Causes of intraplate seismicity in central Brazil from travel time seismic tomography. Tectonophysics 680, 1-7. doi:10.1016/j.tecto.2016.05.005.

Ryan, J., Beck, S., Zandt, G., Wagner, L., Minaya, E., Tavera, H., 2016. Central Andean crustal structure from receiver function analysis. Tectonophysics. doi:10.1016/j.tecto.2016.04.048. 
Ryan, J.C., Ward, K.M., Porter, R.C., Beck, S.L., Zandt, G., Wagner, L.S., Minaya, E., Tavera, H., 2011. Preliminary Results From the CAUGHT Experiment: Investigation of the North Central Andes Subsurface Using Receiver Functions and Ambient Noise Tomography. American Geophysical Union, Fall Meeting 2011, abstract \#T11B-2323.

Skinner, S.M., Clayton, R.W., 2013. The lack of correlation between flat slabs and bathymetric impactors in South America. Earth and Planetary Science Letters 371-372, 1-5. doi:10.1016/j.epsl.2013.04.013.

Soler, P., Sébrier, M., 1990. Nazca slab retreat versus compressional deformation in the central Andes since late Oligocene times. Symposium international géodynamique andine: Résumés des communications 187-190.

Tavera, H., 2014. Evaluación del Peligro asociado a los Sismos y efectos secundarios en Perú. Biblioteca Nacional del Perú. Nº 2014-11704, ISBN: 978-612-4579-9-2.

Tavera, H., Buforn, E., 1998. Sismicidad y sismotectónica de Perú. Fisica de la Tierra 10, 187-219.

Villegas, J.C., 2009a. Proceesing and Analysis of the LISN permanent GPS network: Preliminary Tectonic Results. Nice-France.

Villegas, J.C., 2009b. Modelos de Velocidad Unidimensionales para las Regiones Norte, Centro y Sur del Perú, a partir de la Inversión de los Tiempos de arribo de las ondas P y S de sismos locales. Tesis de Ingeniería U.N.S.A 56-75.

Ward, K.M., Porter, R.C., Zandt, G., Beck, S.L., Wagner, L.S., Minaya, E., Tavera, H., 2014. Erratum: Ambient noise tomography across the Central Andes. Geophysical Journal International 196, 1264-1265. doi:10.1093/gji/ggt429.

Ward, K.M., Porter, R.C., Zandt, G., Beck, S.L., Wagner, L.S., Minaya, E., Tavera, H., 2013. Ambient noise tomography across the Central Andes. Geophysical Journal International 194, 1559-1573. doi:10.1093/gji/ggt166.

Yuan, X., Sobolev, S.., Kind, R., 2002. Moho topography in the central Andes and its geodynamic implications. Earth and Planetary Science Letters 199, 389-402. doi:10.1016/S0012-821X(02)00589-7.

Zandt, G., Ammon, C., 1995. Continental crust composition constrained by mea-surements of crustal Poisson's ratio. Nature 374, 152-154.

Zhu, L., Kanamori, H., 2000. Moho depth variation in southern California from teleseismic receiver functions. J. Geophy. Res. 105, 2969-2980. 


\title{
Capítulo 2
}

\section{Crustal Structure of North Peru from Analysis of Teleseismic Receiver Functions}

Cristobal Condori $^{1,2}$, George S. França ${ }^{1}$, Hernando J. Tavera ${ }^{2}$, Diogo F. Albuquerque ${ }^{1}$, Susan L. Beck ${ }^{3}$, Brandon T. Bishop ${ }^{3}$

${ }^{1}$ Instituto de Geociências, Universidade de Brasília, Campus Universitario Darcy Ribeiro, Asa Norte, Brasília, 70910-900 Brazil

${ }^{2}$ Instituto Geofísico del Perú IGP, Ciencias de la Tierra Sólida CTS, Calle Calatrava Mz. F Lt. 10 Urb. Camino Real Camacho-La Molina Lima-Perú

${ }^{3}$ University of Arizona UA, Department of Geosciences, Gould-Simpson Bldg. 537 USA. email: cristobal.condori@igp.gob.pe; georgesand@unb.br; hernando.tavera@igp.gob.pe; diogofarrapo@gmail.com; slbeck@email.arizona.edu; brandontbishop@email.arizona.edu

Submitted to Journal of South American Earth Sciences on August, 2016

\begin{abstract}
In this study, we present results from teleseismic receiver functions, in order to investigate the crustal thickness and Vp/Vs ratio beneath northern Peru. A total number of 981 receiver functions were analyzed, from data recorded by 28 broadband seismic stations from the Peruvian permanent seismic network, the regional temporary SisNort network and one CTBTO station. The Moho depth and average crustal $\mathrm{Vp} / \mathrm{Vs}$ ratio were determined at each station using the $\mathrm{H}-\mathrm{k}$ stacking technique to identify the arrival times of primary $\mathrm{P}$ to $\mathrm{S}$ conversion and crustal reverberations (PpPms, PpSs+PsPms). The results show that the Moho depth correlates well with the surface topography and increases significantly from West to East, showing a shallow depth of around $25 \mathrm{~km}$ near the coast, a maximum depth of 55-60 km beneath the Andean Cordillera, and a depth of 35-40 km further to the east in the Amazonian Basin. The bulk crustal Vp/Vs ratio ranges between 1.60 and 1.88 with the mean of 1.75 .
\end{abstract}


Higher values between 1.75 and 1.88 are found beneath the Eastern and Western Cordilleras, consistent with a mafic composition in the lower crust. In contrast values vary from 1.60 to 1.75 in the extreme flanks of the Eastern and Western Cordillera indicating a felsic composition. We find a positive relationship between crustal thickness, $\mathrm{Vp} / \mathrm{Vs}$ ratio, the Bouguer anomaly, and topography. These results are consistent with results of previous studies near the study region.

Keywords. Northern Peru, Receiver Function, Crustal Thickness, Vp/Vs ratio

\subsection{Introduction}

The complex structural and tectonic features of northern Peru are due to the rapid convergence ( $\sim 60-70 \mathrm{~mm} / \mathrm{yr}$ ) between the subducting oceanic Nazca plate and the continental South American plate since the Mesozoic (DeMets et al., 1990; Kendrick et al., 2003; Norabuena et al., 1999; Villegas, 2009a). One of the most dramatic consequences of this tectonic process is the presence of the Andes (Dewey and Bird, 1970), which are characterized by the second-largest plateau in the world, and complexities in crustal thickness, major deflections, variations in the angle of subduction (Gutscher et al., 1999), and variations in the width of high topography along-strike (Dalmayrac et al., 1980).

The boundary between the Earth's crust and the mantle, called the Moho, comprises a major change in chemical, rheological, and seismic properties. The Moho has an important relationship to many geological processes of great importance, such as earthquakes, volcanism, and orogeny. Detailed information on the variation of crustal properties and thickness are crucial for understanding the mechanism of crustal thickening, crustal evolution and the degree of isostatic compensation of a region (Yuan et al., 2002; Assumpção et al., 2013).

Crustal thickness in Peru, especially in the southern and central regions, has been the subject of many geophysical studies, using gravity modeling (Fukao et al., 1989, 1999; Tassara and Echaurren, 2012) and seismic data (James, 1971; Ocola et al., 1971; Tavera, 1990; Phillips et al., 2012; Phillips and Clayton, 2014; Bishop et al., 2014; Ryan et al., 2016) to understand tectonic and dynamic processes, as well as the relationship between surface topography (isostasy and mountain building) and the crustal thickness. Additionally crustal structure studies have been carried out along the Peruvian continental margin using wide- 
angle seismic techniques (Hussong et al., 1976; Kulm et al., 1981; Krabbenhöft et al., 2004).

For local crustal structure beneath northern Peru, Hussong et al. (1976) proposed Moho depths between 8 and $12 \mathrm{~km}$ beneath the continental margin, and $30 \mathrm{~km}$ beneath the Pacific coast of northern Peru based on refraction and reflection data. Aranda and Assumpção (2013) estimated a crustal thickness between 35 and $40 \mathrm{~km}$ under the Amazonian Basin at the Brazil-Peru border (Figure 2.1). Additional studies have established regional estimates of crustal thickness beneath northern Peru using a data compilation from seismic refraction experiments, receiver function analysis, and surface-wave dispersion (Chulick et al., 2013, Pavão et al., 2012 and Assumpção et al., 2013, 2015).

Receiver functions are one of the most commonly used techniques for the study of the Earth's crustal structure beneath a broadband seismic station. Seismograms of teleseismic Pwaveforms contain the combined effects of the earthquake source, the propagation medium and the instrument response. To determine Earth structure beneath a broadband seismic station, the effects of local structure, can be isolated from others factors using signal deconvolution (Langston, 1979; Owens et al., 1984; Ammon et al., 1990; Ammon, 1991). The resulting waveform of the isolated site response is known as a receiver function (RF).

To better understand the heterogeneous structure of northern Peru, we have used teleseismic data recorded at broadband seismic stations and analyzed RFs from each station in order to estimate the spatial variations in crustal thickness and the $\mathrm{Vp} / \mathrm{Vs}$ ratio around the stations. We used mainly data collected by the Peruvian National Seismic Network, and also data from a regional seismic network and the recent compilation of information on crustal thickness by Assumpção et al. (2013, 2015). 


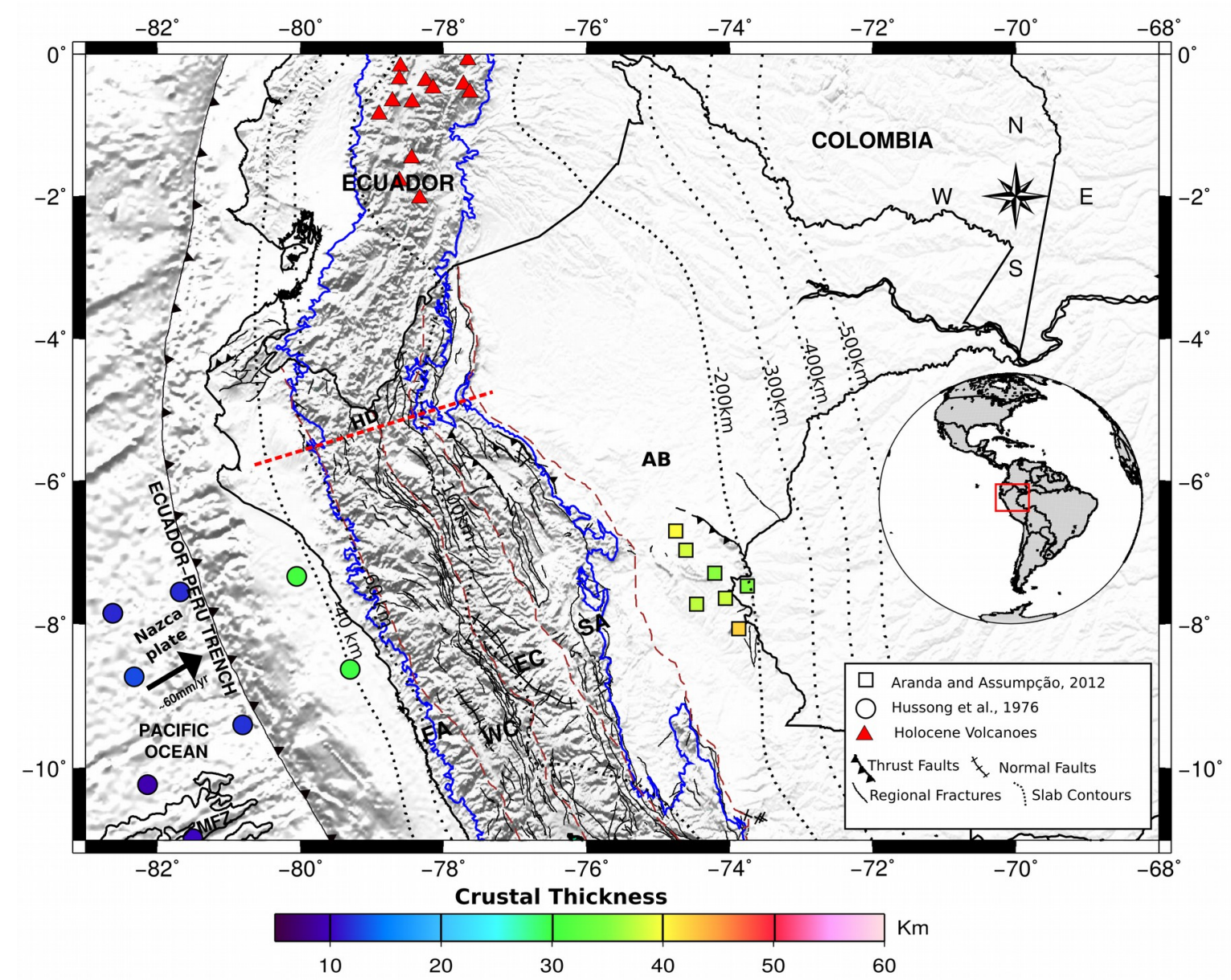

Figure 2.1: Tectonic map of northern Peru, showing the main tectonic features and local crustal thickness result from previous seismic studies (Hussong et al., 1976; Aranda and Assumpção, 2013), black dotted lines represent contours from the Slab1.0 model (Hayes et al., 2012). Blue lines represent the outline of the Andean Cordillera (600 m elevation contour). Brown dashed lines indicate morphostructural units (modified from Audebaud et al., 1973; Dalmayrac et al., 1987; Tavera and Buforn, 1998). Abbreviations: MFZ: Mendaña Fracture Zone; FA: Forearc; WC: Western Cordillera; EC: Eastern Cordillera; SA: SubAndes; AB: Amazonian Basin; and HD: Huancabamba Deflection, represented by the thick red dashed line. 


\subsection{Tectonic Framework}

Northern Peru is located along the portion of the western margin of South America and forms part of the Central Andes (Gansser, 1973) where the tectonics have been driven by subduction processes since the early Mesozoic (Mégard, 1987). As a result of these processes, over geological time scales this region has been the site of the Andean Orogeny. The complex structural evolution of the region has given rise to the formation of different geomorphological structures causing compressive and extensional stresses and resulting in uplift, crustal shortening and thickening, and formation of foreland basins (Soler and Sébrier, 1990).

According to Martinod et al. (2010), the Andean orogenesis has involved three major shortening episodes that correspond to periods of rapid trench-perpendicular plate convergence along the Andean margin: 1) the Late Cretaceous Peruvian Orogeny, 2) the Palaeocene-Eocene Incaic Orogeny, and 3) the Neogene Quechuan Orogeny. The latest episode was apparently associated with ridge impingement and the onset of flat subduction between 15-11 Ma. (Hampel, 2002; Rosenbaum et al., 2005), which increased plate coupling and crustal shortening, reduced arc magmatism and volcanic activity, and enhanced hydrothermal activity (Gutscher et al., 2000; Rosenbaum et al., 2005; Martinod et al., 2010).

Our study focuses on the segment bounded by latitude $0^{\circ} \mathrm{S}$ and $11^{\circ} \mathrm{S}$, where the Andean Cordillera reaches elevations of $\sim 4000 \mathrm{~m}$ and undergoes a major change in trend from NW to NNE at $6^{\circ} \mathrm{S}$ called the Huancabamba Deflection (HD) which changes the topography of the Andes between central Peru and Ecuador, (Cobbing et al., 1981; Mégard, 1984; Mourier et al., 1988; Mitouard et al., 1990). Furthermore, in this region, the subducted Nazca plate presents a “flat-slab” geometry-type (Gutscher et al., 2000; Ramos and Folguera, 2009).

The Peruvian shallow or flat-slab subduction segment $\left(3^{\circ} \mathrm{S}\right.$ to $\left.15^{\circ} \mathrm{S}\right)$ is by far the most extensive region of flat-slab subduction in the world (Gutscher et al., 2000), in which the Nazca Plate subducts at a normal dip $\left(\sim 40^{\circ}\right)$ to a depth of around $100 \mathrm{~km}$ (Figure 2.1), most likely lying directly beneath the overriding continental lithosphere, and then travels horizontally at this depth for several hundred kilometers before steepening again to the east (Cahill and Isacks, 1992; Phillips and Clayton, 2014). The region is characterized by the 
absence of arc volcanism and heat flow ( 40-80 mW/m2) (Henry and Pollack, 1988; Cardoso et al., 2010; Haraldsson, 2011), in contrast to the normally dipping regions to the south.

According to Audebaud et al. (1973), Megard, (1978) and Dalmayrac et al. (1980), our study region can be subdivided into the following main morphostructural units which strike parallel to the Pacific coast from west to east. These are (1) the Forearc, (2) the Western Cordillera, (3) the Eastern Cordillera, (4) Sub-Andes, and (6) the Amazonian Basin.

- The Forearc (FA) is composed mainly of Precambrian and Paleozoic marine sedimentary and metamorphic rocks, and extends from the trench up to the western boundary of the Andean Cordillera following a NW-SE orientation, with maximum elevations between 900 and $1200 \mathrm{~m}$.

- $\quad$ The Western Cordilleras (WC) represents a morphological and structural asymmetry about $150 \mathrm{~km}$ wide and reaches elevations ranging from 3500 to $5000 \mathrm{~m}$. It is dominated by the Coastal Batholith which consist of multiple intrusions. The older units show the effects of compressive deformation that presumably occurred during the late Eocene to Miocene (Megard, 1978; Wipf, 2006).

- $\quad$ The Eastern Cordillera (EC), began to form during the Hercynian (Devonian) period and has a Precambrian basement. It reaches elevations of $\sim 4000 \mathrm{~m}$ and width increases from $\sim 100 \mathrm{~km}$ in the north to $150 \mathrm{~km}$ in the south. It is composed of crystalline and plutonic rocks overlain by Paleozoic shallow marine and continental deposits (Dalmayrac et al., 1980). The main structures in the region include open folds and steep thrust faults.

- $\quad$ The Sub-Andes (SA) belt is a region of eastward converging compressive structures that have decreasing magnitudes of deformation toward the Brazilian Shield (Dumont et al., 1991). It corresponds to a fold and thrust belt which has developed since Miocene times (Tankard et al., 1995) on a heterogeneous substratum inherited from pre-Andean Paleozoic, Triassic and Jurassic basins.

- The Amazonian Basin (AB) is comprised of Paleozoic and Mesozoic marine sediments which are overlain by massive continental deposits of Tertiary age (Megard, 1978; Suárez et al., 1983). The deposits have been faulted and folded most extensively at the 
Andean margin, but deformation decreases toward the east where the sedimentary layer thins onto a foreland basin on the Brazilian Shield.

\subsection{Data}

We have used data from regional and international networks distributed in northern Peru. The first data set was collected from 15 permanent broadband seismic stations and recorded between 01/2012 and 02/2015 by the National Seismological Network (NSN) (Figure 2.2), operated by the Instituto Geofísico del Perú (IGP). The second data set was obtained from the past deployment in NW Peru of a network (SisNort) of 12 temporary local broadband seismic stations operating from 11/2008 to 12/2009. Finally, data from one auxiliary seismic station (AS077-ATH) from the CTBTO (Comprehensive Nuclear-Tes-Ban Treaty Organization) network were also examined for the period from 01/2012 to 02/2015. The seismic stations were equipped with Trillium and Guralp CMG-40T broadband seismometers, with Nanometrics (Trident, Taurus) Digitalizers and Reftek 130s.

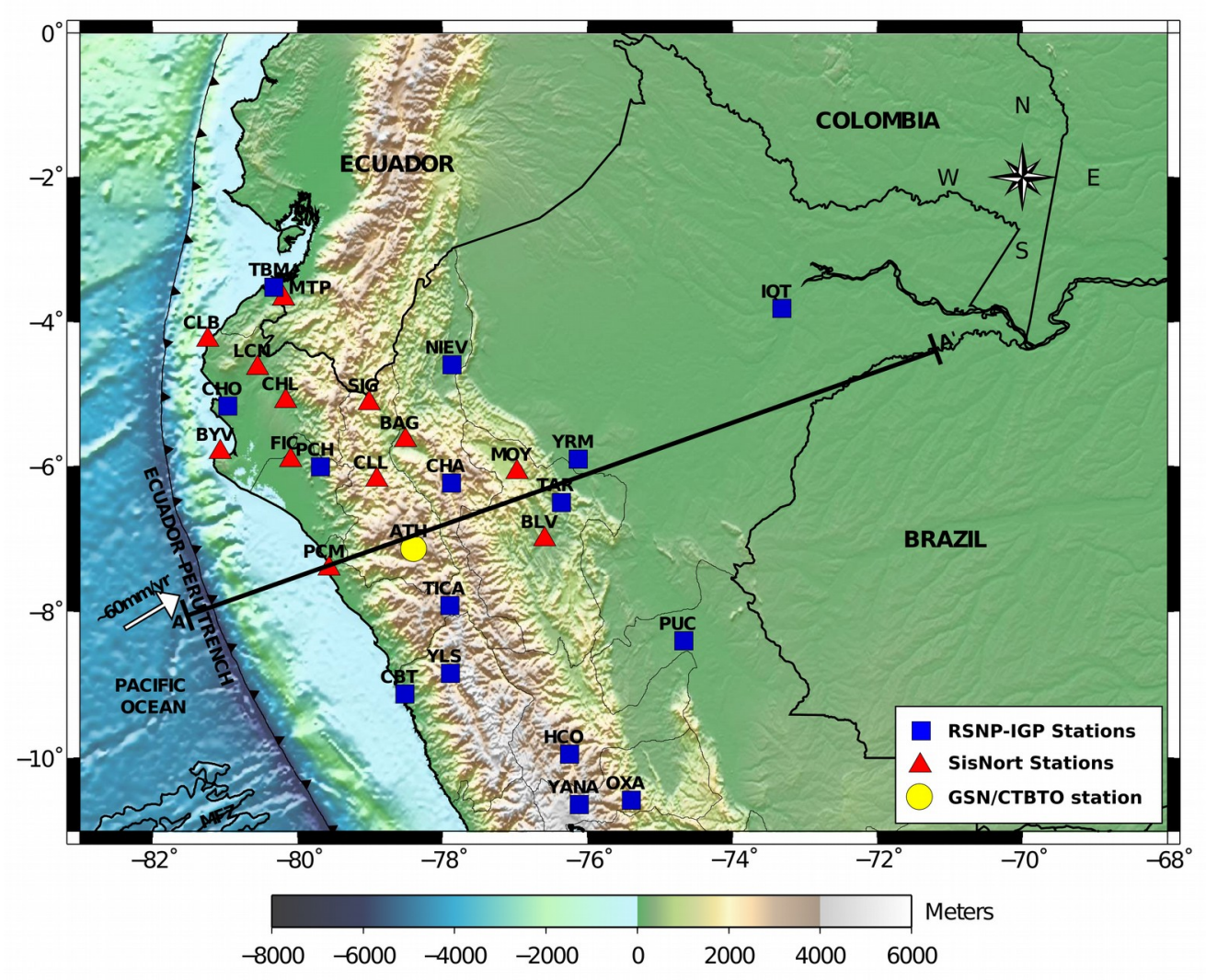

Figure 2.2: Map showing the location of seismic stations in northern Peru used in this study. Lines AA' correspond to schematic cross-section show in the Figure 2.9. 
We obtained records of teleseismic direct P-phase arrivals from each seismometer for the calculation of teleseismic RFs. The information for the teleseismic earthquakes was extracted from the PDE catalogue of US National Earthquake Information Center (NEIC). We selected events with magnitudes greater than $5.5 \mathrm{Mb}$ that occurred at epicentral distances ranging between $30^{\circ}$ and $95^{\circ}$, which in general provided reasonably good coverage in terms of back-azimuth, helping to reduce the influence of lateral crustal structure variations on the analysis of our result (Figure 2.3).

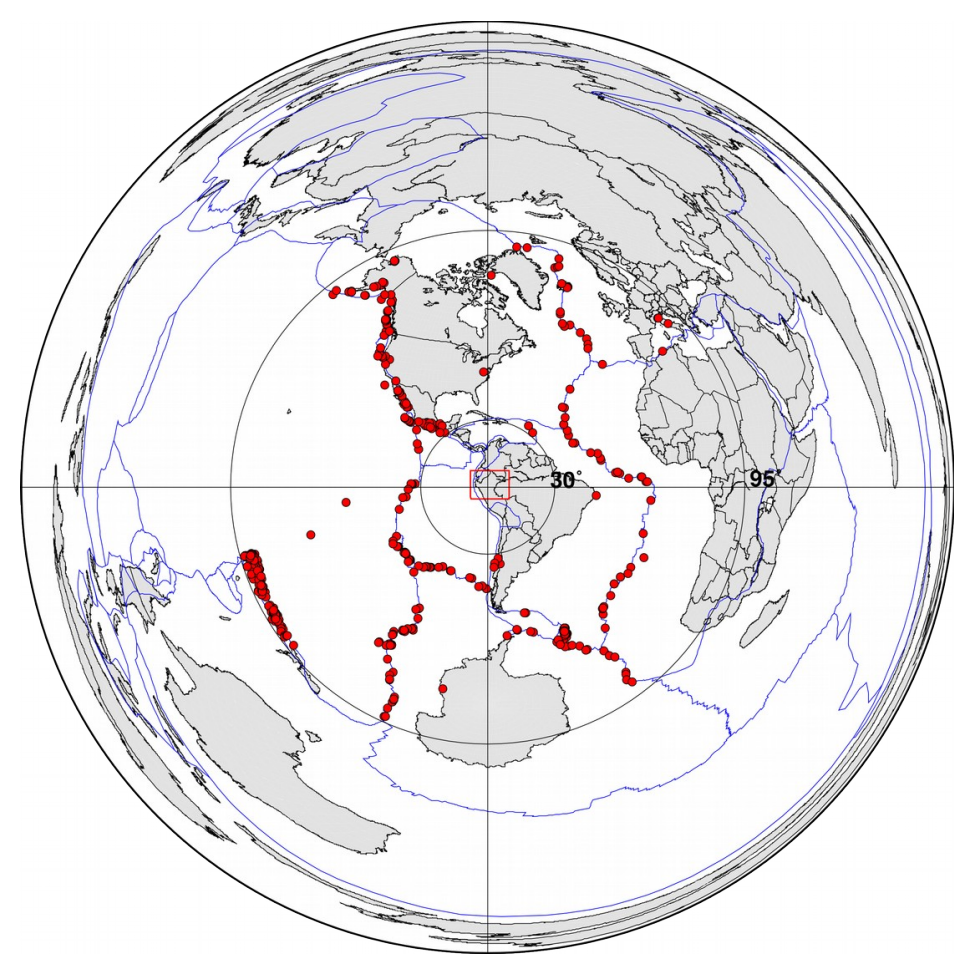

Figure 2.3: The map in azimuthal projection shows the distribution of teleseismic events with magnitude larger than $5.5 \mathrm{Mb}$ used in this study. Red circles represent earthquake epicenter locations used for the computation of receiver functions, large circles represent the distances of $30^{\circ}$ and $95^{\circ}$ from the center of each seismic station distributed inside the red box, blue lines represent tectonic plate boundaries.

\subsection{Methodology}

The RF is a well-established seismological method, and has been extensively used in recent decades to estimate the crustal thickness beneath three-component seismic stations through the identification of major impedance contrasts using the $\mathrm{P}$ to $\mathrm{s}$ converted phase obtained through the deconvolution of the vertical and the radial components of a seismogram in either the frequency domain or the time domain (Langston, 1979; Owens et al., 1984; Zandt 
and Ammon, 1995). The P to s converted phase from the Moho in RF waveforms and their relative arrival times can be used to constrain the crustal thickness and the $\mathrm{Vp} / \mathrm{Vs}$ ratio beneath a seismic station (Zandt and Ammon, 1995; Zhu and Kanamori, 2000), and then the crustal composition can sometimes be inferred from the average $\mathrm{Vp} / \mathrm{Vs}$ (or Poisson’s ratio).

Prior to RF calculation, we automatically identified the P arrival time for each event using the global velocity model included in the TauP software (http://www.seis.sc.edu/taup/) (Crotwell et al., 1999). Then we detrended and tapered the signal. We visually inspected each and manually selected those with high signal-to-noise ratios. We rotated the two horizontal components of the 3-component seismograms to the great circle path for each event to obtain radial and transverse components. Stations with orientation errors in the north component azimuth, were rotated using the analysis of the particle motions of teleseismic $\mathrm{P}$ waves in each station. To eliminate the effects of the ocean or storm waves, surface waves and high frequency noise we applied a band-pass filter to each waveform with corner frequencies of 0.05 and $5 \mathrm{~Hz}$.

In order to remove the source and instrument response, RFs were obtained by deconvolving radial components from vertical components using the time domain iterative deconvolution technique (Ligorría and Ammon, 1999) with a maximum of 500 iterations. We calculated RFs using Gaussian ("a”) factors of 1.0, 1.5, and 2.5. The greater the "a” factor value the more sensitive the resulting RF is to thin features (Frassetto et al., 2011; Poveda et al., 2015), we have used the lowest “a” values for places where a thick crust (>40 km) was expected, and the largest values for locations with thin crust (Poveda et al., 2015).

We used the H-k stacking method of Zhu and Kanamori (2000), to estimate crustal thickness $(\mathrm{H})$ and $\mathrm{Vp} / \mathrm{Vs}(\mathrm{k})$ ratio (Poisson's Ratio) beneath all the stations. We used an a priori assumption of $6.1 \mathrm{~km} / \mathrm{s}$ for the average crustal P-wave velocity, following the local crustal velocity model proposed by Lindo (1993) and Villegas (2009) for this study area.

RFs were stacked using the method of Zhu and Kanamori (2000), which uses the converted phase and multiples to obtain estimates of the depth of an interface and average $\mathrm{Vp} / \mathrm{Vs}$ ratio above the interface by summing along moveouts of the converted phases as a function of ray parameter (Zhu and Kanamori, 2000). A search is done over a range of depths and $\mathrm{Vp} / \mathrm{Vs}$ ratios based on stacks of many events from similar back azimuths. 
The H-k stacking technique sums the amplitudes at the predicted arrival times of Moho Ps and multiples (PpPs and PpSs + PsPs) of the radial RF for different crustal thicknesses $(\mathrm{H})$ and $\mathrm{Vp} / \mathrm{Vs}$ ratios $(\mathrm{k})$. The optimum values are determined by finding the maximum amplitudes of the H-k stack. Given the greater robustness of the P to s conversion at the Moho compared with that of the multiples, we used weighting factors for the Ps, PpPs, and PpSs+PsPs of 0.7, 0.2, and 0.1, respectively, as recommended by Zhu and Kanamori (2000). However, there is a limitation to this technique and cases where it may fail, due to the interference of crustal reverberated phases (Cassidy and Ellis, 1993; Zhu and Kanamori, 2000).

When using the H-k method, the best solution has an associated surrounding region enclosed by an ellipse which represents the area where the stack is within one standard error of the maximum amplitude value (Eaton et al., 2006); we use the ellipse to define the uncertainty in $\mathrm{H}$ and $\mathrm{Vp} / \mathrm{Vs}$. A time window chosen to calculate the RFs from $-5 \mathrm{~s}$ before the P-wave to (30-65) s after the P-wave to retain the Moho conversion phases as well as reverberation phases. Erratic traces or outliers were visually removed, and after this selection we obtained 981 RFs from 28 stations.

Figure 2.4 shows the results of RFs for FIC, ATH and IQT stations that are located in three different geomorphological units, (the FA, WC, and the AB, respectively). The RFs are arranged by back-azimuth, stations FIC and IQT show clear Moho converted Ps phases with positive peaks approximately at 4.5 and $3.5 \mathrm{~s}$, while the station ATH shows the Ps phase at 8 s. The multiples phases (PpPs and PpSs + PsPs) do not show up clearly in the single station RFs and this may be caused by the interference of crustal reverberated phase associated with the complex mid crustal features in the study area. 

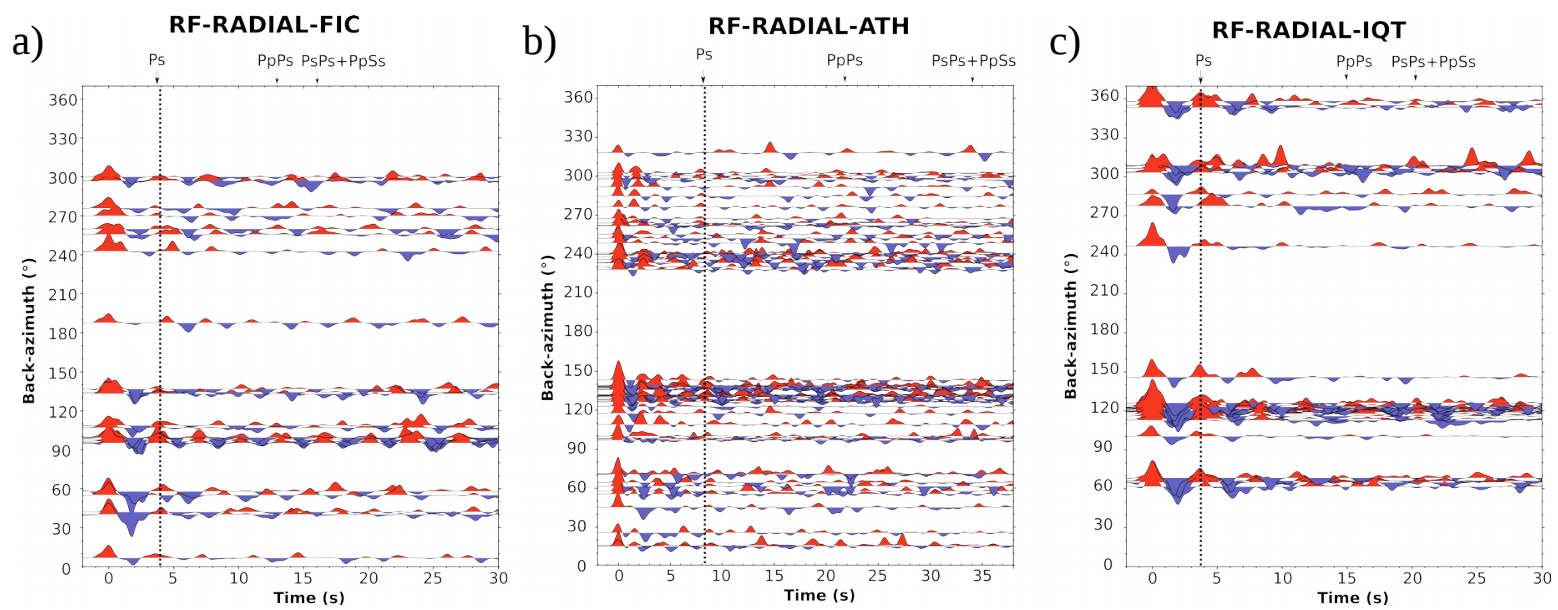

Figure 2.4: Plot of individual radial RFs with different Gaussian filters $(\alpha)$ and time window as a function of back azimuth at three stations located in different tectonic regimes. a) Station FIC of the SisNort Network located close to the coastal Peru-Ecuador border $(\alpha=2.5)$. b) ATH station located in the Andean Cordillera $(\alpha=1.0)$. c) IQT station is located in the Amazonian Basin $(\alpha=2.5)$. Pulses corresponding to the Ps phase from the Moho and multiples (PpPs and PsPs+PpSs) are indicated respectively.

Theoretical travel-time curves of phases Ps and multiples, were calculated using the optimal $\mathrm{H}$ and $\mathrm{k}$ values. For station FIC, the Ps, PpPs and PpSs + PsPs phases can be identified approximately at $\sim 4.5 \mathrm{~s}, \sim 13 \mathrm{~s}$ and $\sim 16 \mathrm{~s}$ after the first $\mathrm{P}$ arrival (Figure 2.4a). For station ATH, we identify the Ps, PpPs and PpSs + PsPs phases at approximately $\sim 8 \mathrm{~s}, \sim 22 \mathrm{~s}$ and $\sim 34$ s (Figure 2.4b). Finally for the station IQT the Ps, PpPs and PpSs + PsPs phases can be identified near $\sim 3.5 \mathrm{~s}, \sim 15 \mathrm{~s}$ and $\sim 20 \mathrm{~s}$ respectively (Figure $2.4 \mathrm{c}$ ). The optimal estimate of $\mathrm{H}$ and $\mathrm{k}$ values (Figure 2.5 ) are $\mathrm{H}=30.6 \pm 2.7 \mathrm{~km}, \mathrm{k}=1.75 \pm 0.07$ for FIC, $\mathrm{H}=54.2 \pm 3.2$ $\mathrm{km}, \mathrm{k}=1.88 \pm 0.06$ for ATH, and $\mathrm{H}=36.0 \pm 2.7 \mathrm{~km}, \mathrm{k}=1.74 \pm 0.06$ for IQT. These values show an obvious change in crustal thickness values consistent with the variations in topography. 

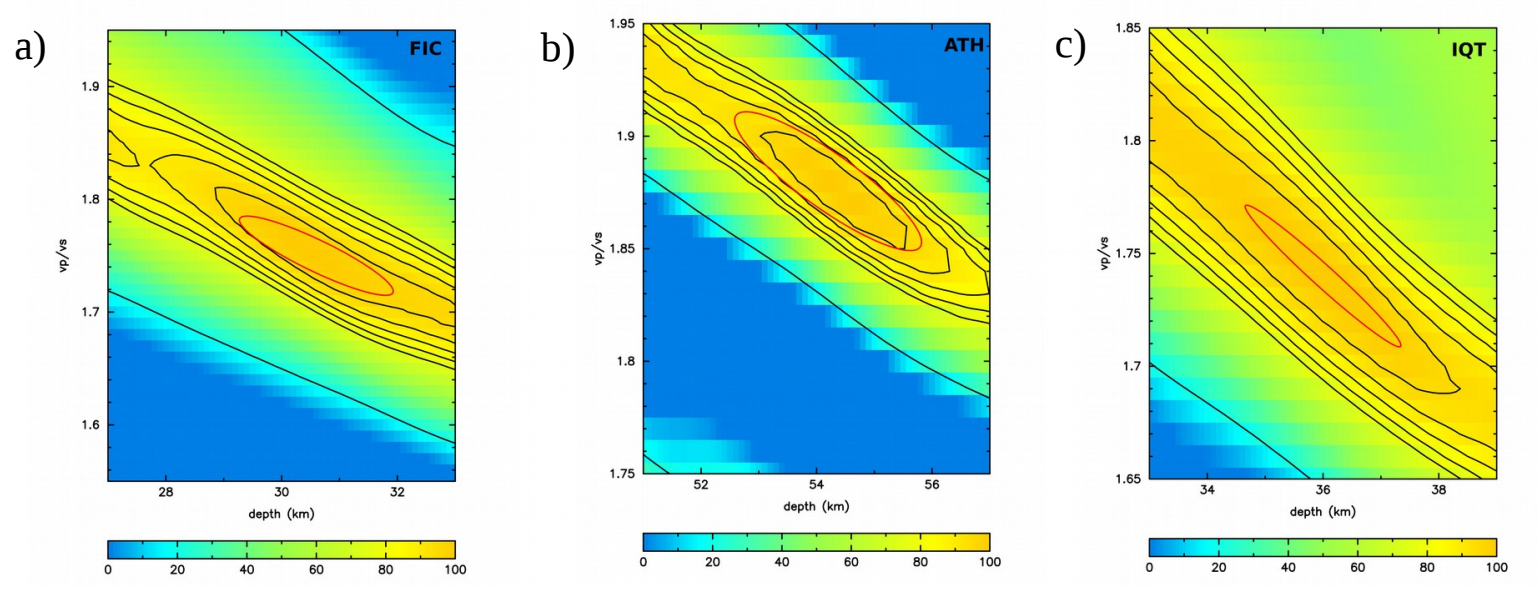

Figure 2.5: Results of $\mathrm{H}-\mathrm{k}$ stacking for three different seismic stations showing the best crustal thickness and Vp/Vs ratios at each station. a) Station FIC of the SisNort Network located close to the coastal Peru-Ecuador border. b) ATH station (CTBTO) located in the Andean Cordillera. c) IQT station (NSN) is located in the Amazonian Basin. The grid search was carried out for an assumed average crustal P-wave velocity of $6.1 \mathrm{~km} / \mathrm{s}$. Colors are stacking surface with contours showing percentage values of the objective function and the red line gives the percent confidence ellipse obtained from bootstrapping the dataset.

\subsection{Results}

Crustal thickness and Vp/Vs ratio are two important factors in characterizing the crustal structure and physical properties of the crust (Zandt and Ammon, 1995). We obtained maps for crustal thickness (Figure 2.6) and Vp/Vs ratio (Figure 2.7) variations measured at 28 seismic stations in the study area. The maps indicate significant lateral variations from west to east in the crustal structure of northern Peru. Detailed results from each station are also listed in Table 2.1.

\subsubsection{Crustal Thickness}

Figure 2.6 shows the distributions of crustal thickness in northern Peru and surrounding the areas based in previous results as well as on values of crustal thickness obtained in this study superimposed onto the map of crustal thickness of South America from Assumpção et al. (2013, 2015). 
We note that measured crustal thickness range from $\sim 22 \mathrm{~km}$ to $\sim 30 \mathrm{~km}$ in the FA zone, which reflect RF results at stations FIC ( 30.6 km), CLB ( 28.2 km), PCM ( 29.5 km), CBT ( 22.5 km), BYV (27.9 km), and CHO ( 27.1 km). Thicker crust appears beneath the coast near to the Peru-Ecuador border, with an average value of $35 \mathrm{~km}$ beneath at stations CHL ( 33.8 km), LCN ( 36.9 km), and MTP ( 35.7 km)

Crustal thickness varies from 50 to $55 \mathrm{~km}$ beneath the WC and EC, showing a clear increase in depth to Moho from north to south, with maximum values appearing in central Peru beneath stations HCO ( 63.3 km), YANA ( 62.7 km), and OXA $(\sim 57.2 \mathrm{~km})$. These values are consistent with previous result for central Peru proposed by Bishop et al. (2014), who estimated a crustal thickness of up to $\sim 62 \mathrm{~km}$ for the area from RFs. In the SA zone, between the EC and the $\mathrm{AB}$ (Figure 2.6), the crustal thickness decreases to an approximate range of $37 \mathrm{~km}$ to $44 \mathrm{~km}$ (stations MOY, TAR, BLV, and NIEV). 
Table 2.1: Summary of Crustal Thickness and Vp/Vs Ratio and their associated uncertainties from $\mathrm{H}-\mathrm{k}$ stacking for each seismic stations, using P-wave velocity of $6.1 \mathrm{~km} / \mathrm{s}$ and weights of $\mathrm{W}_{1}=0.7, \mathrm{~W}_{2}=0.2$, and $\mathrm{W}_{3}=0.1$ respectively.

\begin{tabular}{|c|c|c|c|c|c|c|c|c|c|}
\hline$N$ & Sta & Net. & Longitude & Latitude & Elevation & Moho(km) & $V p / V s$ & $R F s$ & \\
\hline 01 & $P C M$ & $S N N$ & -79.565 & -7.407 & 37 & $29.5 \pm 0.4$ & $1.75 \pm 0.02$ & 11 & 2.5 \\
\hline 02 & $C L B$ & $S N N$ & -81.236 & -4.253 & 4 & $28.2 \pm 1.9$ & $1.72 \pm 0.06$ & 19 & 2.5 \\
\hline 03 & $M T P$ & $S N N$ & -80.194 & -3.683 & 80 & $35.7 \pm 1.1$ & $1.87 \pm 0.06$ & 16 & 2.5 \\
\hline 04 & $L C N$ & $S N N$ & -80.549 & -4.641 & 145 & $36.9 \pm 0.6$ & $1.78 \pm 0.03$ & 19 & 2.5 \\
\hline 05 & CHL & $S N N$ & -80.158 & -5.095 & 165 & $33.8 \pm 2.3$ & $1.71 \pm 0.05$ & 29 & 2.5 \\
\hline 06 & $F I C$ & $S N N$ & -80.097 & -5.918 & 78 & $30.6 \pm 2.7$ & $1.75 \pm 0.07$ & 25 & 2.5 \\
\hline 07 & $C L L$ & $S N N$ & -78.910 & -6.184 & 1578 & $53.8 \pm 1.9$ & $1.77 \pm 0.04$ & 25 & 1.5 \\
\hline 08 & $S I G$ & $S N N$ & -79.012 & -5.125 & 18 & $52.6 \pm 1.5$ & $1.76 \pm 0.04$ & 32 & 1.5 \\
\hline 04 & $B A G$ & $S N N$ & -78 & -5.6 & & $54.5 \pm 2.5$ & $1.88 \pm 0.06$ & 27 & 1.5 \\
\hline 10 & $M O Y$ & $S N N$ & -76.970 & -6.075 & 959 & $39.8 \pm 0.6$ & $1.74 \pm 0.05$ & 13 & 2.5 \\
\hline 11 & $B L V$ & $S N N$ & -76.592 & -7.0 & 30 & $39.4 \pm 1.9$ & $1.81 \pm 0.06$ & 25 & 2.5 \\
\hline 12 & $B Y V$ & $S N N$ & -81.065 & -5.7989 & 70 & $27.9 \pm 1.1$ & $1.63 \pm 0.06$ & 15 & 2.5 \\
\hline 13 & $A T H$ & СТВТO & -78.395 & -7.135 & 3151 & $54.2 \pm 3.2$ & $1.88 \pm 0.06$ & 107 & 1.0 \\
\hline 14 & $T B M$ & $N S N$ & -80.322 & -3.52 & 24 & $31.9 \pm 2.2$ & $1.72 \pm 0.06$ & 15 & 2.5 \\
\hline 15 & $Y R M$ & $N S N$ & -76.129 & -5.897 & 149 & $37.9 \pm 0.5$ & $1.76 \pm 0.03$ & 58 & 2.5 \\
\hline 16 & $\mathrm{CHO}$ & $N S N$ & -80.962 & -5.1 & & $27.1 \pm 0.5$ & $1.70 \pm 0.02$ & 43 & 2.5 \\
\hline 17 & NIEV & $N S N$ & -77.866 & -4.597 & 230 & $44.3 \pm 0.4$ & $1.68 \pm 0.02$ & 18 & 1.5 \\
\hline 18 & $\mathrm{PCH}$ & $N S N$ & -79.682 & -6.005 & 62 & $31.8 \pm 1.1$ & $1.74 \pm 0.04$ & 80 & 2.5 \\
\hline 19 & CHA & $N S N$ & -77.877 & -6.227 & 2370 & $47.2 \pm 1.6$ & $1.77 \pm 0.07$ & 53 & 1.5 \\
\hline 20 & $T A R$ & $N S N$ & -76.357 & -6.496 & 358 & $37.1 \pm 2.8$ & $1.62 \pm 0.05$ & 61 & 2.5 \\
\hline 21 & TICA & $N S N$ & -77.901 & -7.917 & 2819 & $52.8 \pm 1.8$ & $1.78 \pm 0.03$ & 35 & 1.5 \\
\hline 22 & $C B T$ & $N S N$ & -78.521 & -9.128 & 53 & $22.5 \pm 0.8$ & $1.68 \pm 0.06$ & 34 & 2.5 \\
\hline 23 & $Y A N A$ & $N S N$ & -76.112 & -10.638 & 835 & $62.7 \pm 1.0$ & $1.80 \pm 0.02$ & 27 & 1.0 \\
\hline 24 & $O X A$ & $N S N$ & -75.398 & -10.578 & 1840 & $57.2 \pm 2.4$ & $1.83 \pm 0.04$ & 34 & 1.0 \\
\hline 25 & $P U C$ & $N S N$ & -74.668 & -8.397 & 142 & $37.6 \pm 1.1$ & $1.78 \pm 0.04$ & 32 & 2.5 \\
\hline 26 & $I Q T$ & $N S N$ & -73.320 & -3.816 & 105 & $36.0 \pm 2.7$ & $1.74 \pm 0.06$ & 33 & 2.5 \\
\hline 27 & $\mathrm{HCO}$ & $N S N$ & -76.249 & -9.952 & 1966 & $63.3 \pm 3.8$ & $1.85 \pm 0.04$ & 20 & 1.0 \\
\hline 28 & $Y L S$ & $N S N$ & -77.889 & -8.847 & 3208 & $45.7 \pm 1.0$ & $1.79 \pm 0.03$ & 75 & 2.5 \\
\hline
\end{tabular}

SNN-SisNort Network, CTBTO Network, NSN National Seismological Network, RFs-Number of seismic traces in each station, Gaussian filter width $(\alpha)$

Overall, thinner crust is observed in the $\mathrm{AB}$ with values between $35 \mathrm{~km}$ and $40 \mathrm{~km}$ (station PUC, YRM, and IQT). This is consistent with results from Aranda and Assumpção (2013) who estimated a crustal thickness of 37-40 km in this region. 
The similar pattern in crustal thickness have also been found in previous studies derived from different techniques such as CCP stacks, gravity and surface waves (Fukao et al., 1989; Aranda and Assumpção, 2013; Assumpção et al., 2013, 2015; Chulick et al., 2013; Bishop et al., 2014).

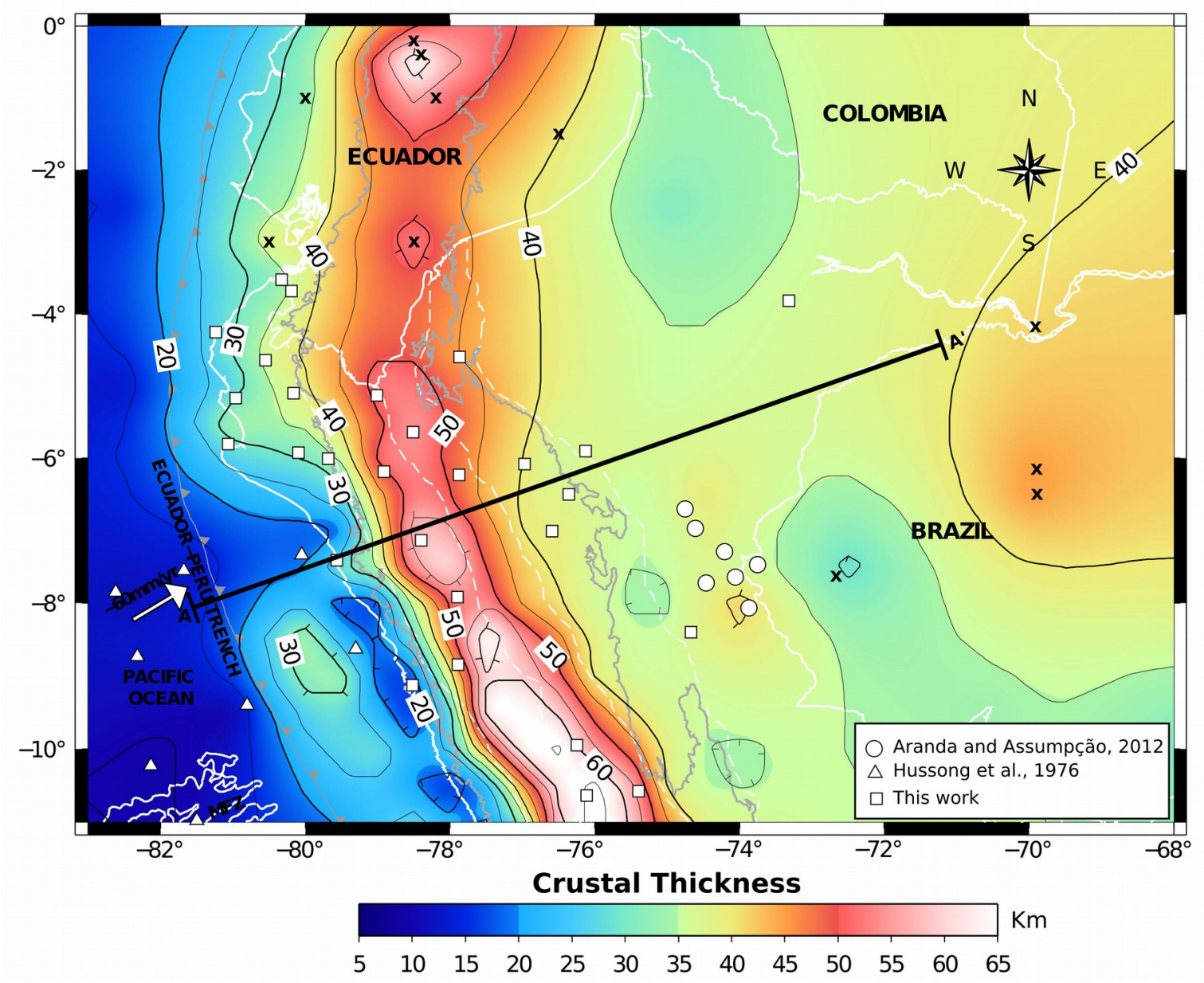

Figure 2.6: Crustal thickness map in kilometers beneath northern Peru and adjacent areas. In addition to our results, we have also included data from previous studies compiled by Assumpção et al. (2013, 2015). Lines AA' correspond to schematic cross-section showing in Figure 2.9. Contour interval is $5 \mathrm{~km}$. 


\subsubsection{Vp/Vs Ratio}

In order to obtain the crustal thickness from the P to s conversion, we also calculated the $\mathrm{Vp} / \mathrm{Vs}$ value of the crust under each station using the Zhu and Kanamori, (2000) method. Given the great uncertainty in the lateral variation of the $\mathrm{Vp} / \mathrm{Vs}$ ratios, we do not present an interpolated map of this variable but only show site estimates (Figure 2.7). Resulting Vp/Vs ratios show the bulk or average value for the crust under each station and range between 1.62 and 1.88 with an average of 1.75 for the entire area (Figure 2.8).

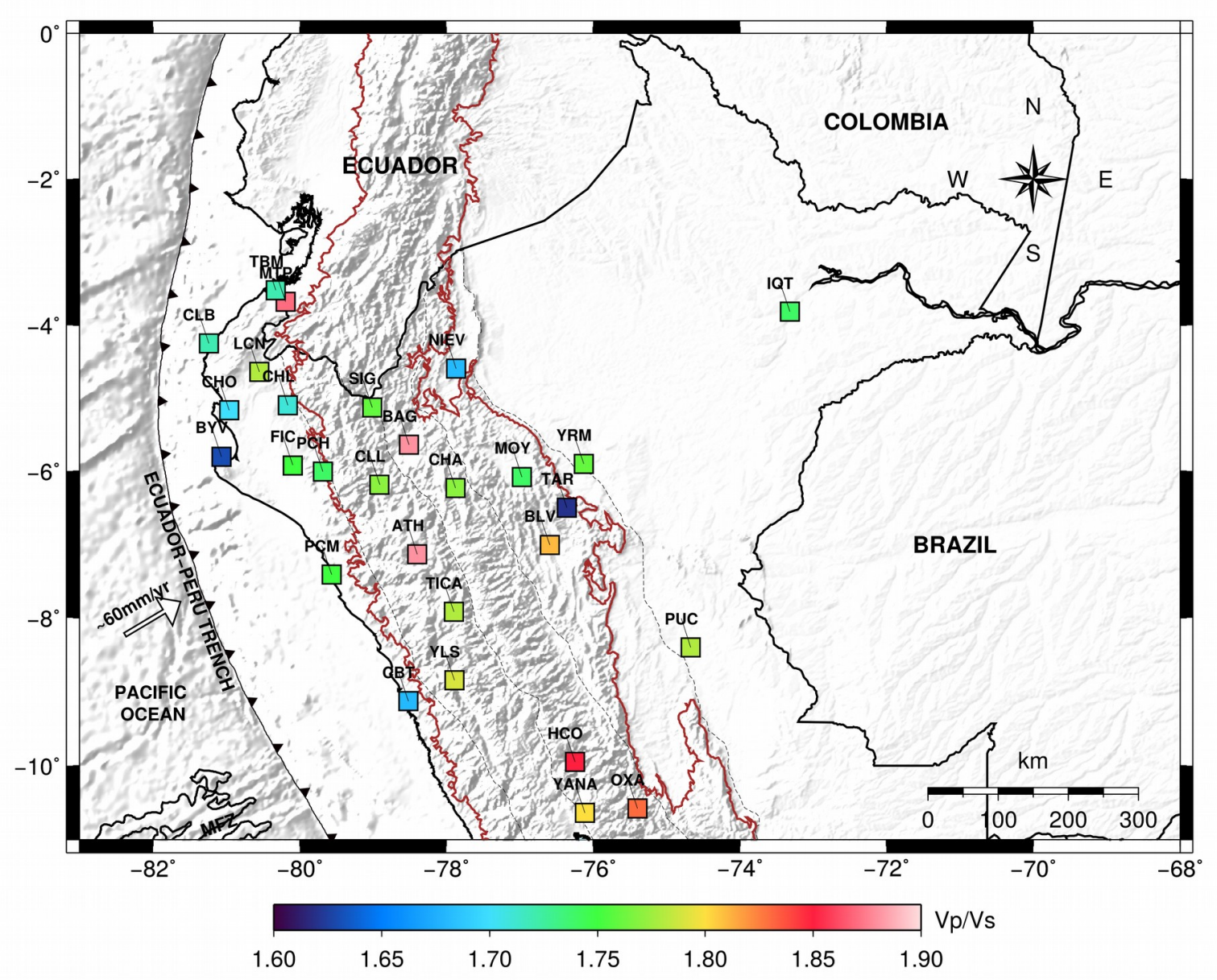

Figure 2.7: Vp/Vs ratios for the station analyzed in this study.

Several areas with high Vp/Vs ratios appear in our results. Vp/Vs values between 1.77 and 1.88 are observed at stations $\operatorname{CHA}(\sim 1.77)$, $\operatorname{LLS}(\sim 1.79), \operatorname{BAG}(\sim 1.88)$, $\operatorname{ATH}(\sim 1.88)$, YANA( 1.80), OXA ( 1.83), $\mathrm{HCO}(\sim 1.85)$ beneath the WC and EC and are associated with regions of high crustal thickness. This may indicate the presence of relatively weak materials with mafic compositions (Musacchio et al., 1997), small amounts of partial melt or anisotropy 
resulting from subduction processes. The comparatively low $\mathrm{Vp} / \mathrm{Vs}$ values $(<1.75)$ are mostly located in the FA, SA and $\mathrm{AB}$ at stations $\mathrm{CHO}(\sim 1.70), \mathrm{BYV}(\sim 1.63) \mathrm{NIEV}(\sim 1.70)$, and IQT( 1.74) (Figure 2.7).

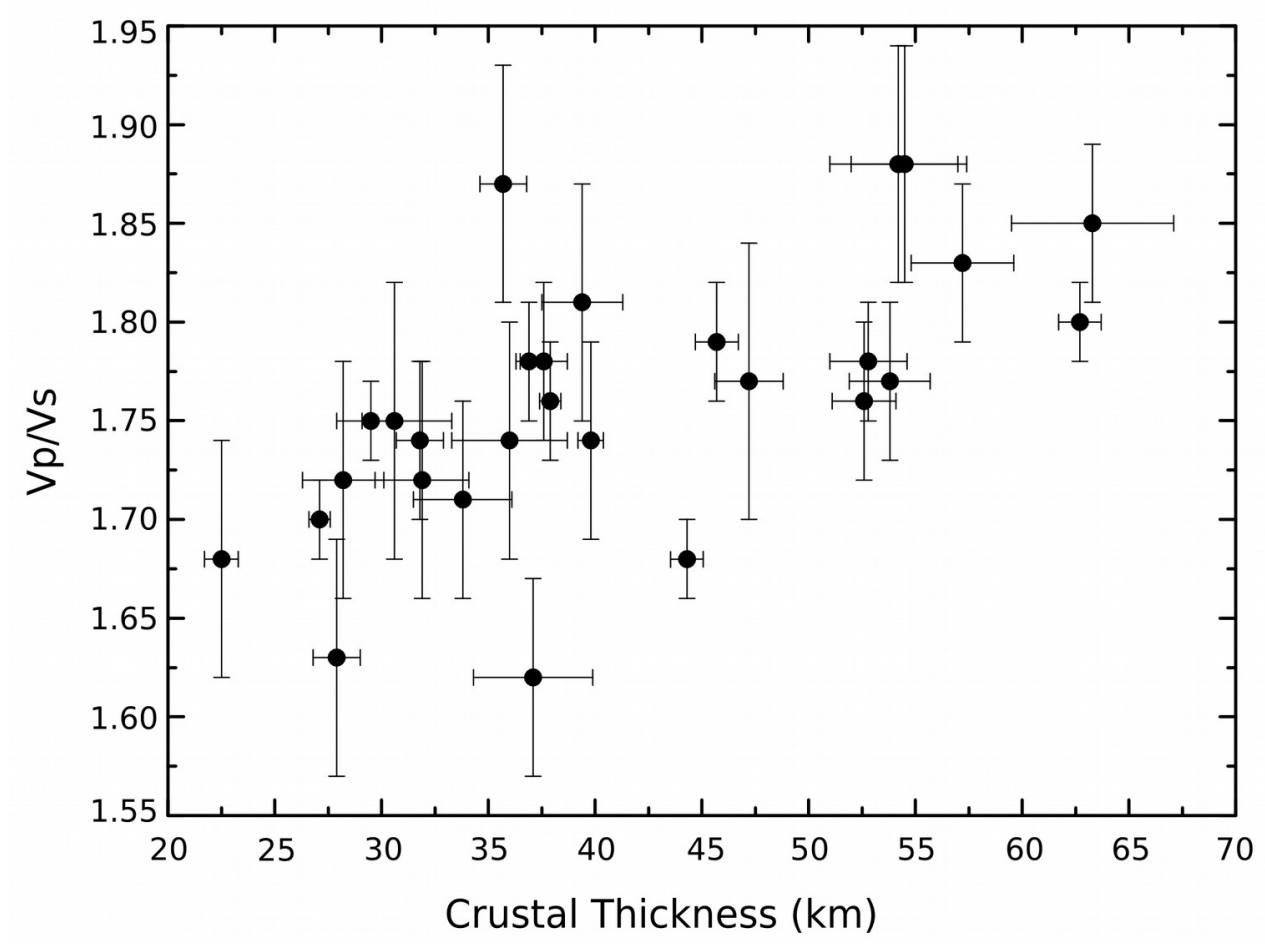

Figure 2.8: $\mathrm{Vp} / \mathrm{Vs}$ ratio versus crustal thickness for the stations analyzed in this study. Bars associated with each circles represent the estimated uncertainty. See Table 2.1 for numerical values.

Figure 2.8 summarizes the crustal thickness and $\mathrm{Vp} / \mathrm{Vs}$ results for each station and shows an approximate dependence between these two variables. Uncertainties in crustal thickness estimates are less than $3.8 \mathrm{~km}$ while the crustal thickness varies between 22 and 65 $\mathrm{km}$. Vp/Vs values can have uncertainties as high as 0.07 . Given this uncertainty $\mathrm{Vp} / \mathrm{Vs}$ ratios are limited to values between 1.55 and 1.95 for the crust. 


\subsection{Discussions}

The distribution of the crustal thicknesses and $\mathrm{Vp} / \mathrm{Vs}$ ratios in our study area reflect the characteristics of different geomorphological units in northern Peru. Although, the previous models have been used little information for their studies, our observed values are consistent with those obtained by Fukao et al. (1989), Lloyd et al. (2010), Aranda and Assumpção (2013), Chulick et al. (2013), Bishop et al. (2014), and Assumpção et al. (2013, 2015) In general, all previous crustal models for northern Peru suggest that the greatest crustal thickness occurs in the EC and WC. The RFs that we present in this study confirm these observations and inferences.

\subsubsection{Crustal Thickness}

The crustal thickness varies between 25 and $55 \mathrm{~km}$ in northern Peru and the surrounding area (Figure 2.6). We have found a sharp increase in crustal thickness from north to south along the Andean Cordillera that matches variations in the elevation. We find average crustal thicknesses of $\sim 50 \mathrm{~km}$ near the Peru-Ecuador border in the Huancabamba Deflection region $\left(6^{\circ} \mathrm{S}\right)$ where elevations reach at most $\sim 1800 \mathrm{~m}$ while values to the south vary from 55 to $60 \mathrm{~km}$ near central Peru (consistent with the results of Bishop et al. (2014)) where elevation reach maximum values of $\sim 4300 \mathrm{~m}$.

For the purposes of comparison, topography has been labeled on the top of each profile in Figure 2.9. The section A-A' extends from the FA, crossing the Andean Cordillera and into the AB. Along this profile, the Moho depth decrease from $\sim 60 \mathrm{~km}$ beneath the WC to $\sim 45$ beneath the $\mathrm{AB}$, which is similar to the change in topography.

Lateral variations of the elevation (ETOPO1), the Bouguer gravity anomaly (Fukao et al., 1999; Förste et al., 2014) and crustal thickness (this study) along a W-E profile (Figure 2.9), shows that quite asymmetric gravity anomalies are associated with the WC and the EC, in marked contrast with the symmetric pattern in the topographic profile. According to Fukao et al. (1989) gravity and crustal models indicate the WC is approximately in isostatic equilibrium, while the EC is not, and this contrast in mechanical state and the difference in recent tectonics suggest that the WC and the EC have not been uplifted entirely through the same tectonic process. Our model of crustal thickness shows small differences that likely indicate that hypothesis. 


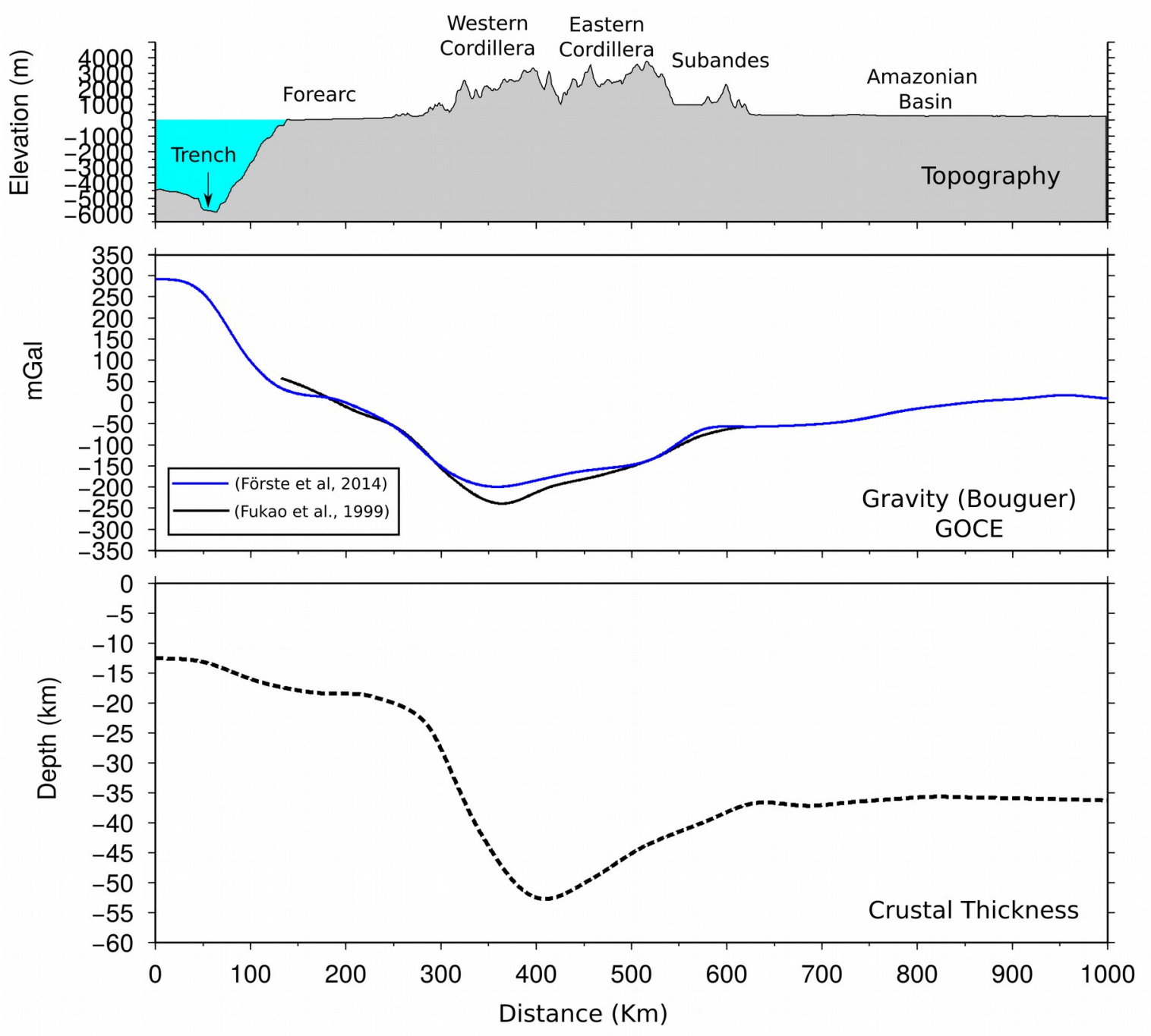

Figure 2.9: Cross section showing profiles: (top) topography, (middle) Bouguer anomaly interpolate and (bottom) crustal thickness interpolate along the sections A-A' from Figures 2.2 and 2.6.

\subsubsection{Vp/Vs Ratio}

The Vp/Vs ratio (or Poisson's ratio) offers critical constraints on determining crustal thickness and is sensitive to rock composition, generally increasing with higher mafic content (Zandt and Ammon, 1995). Laboratory experiments have shown that many physical and chemical factors can induce variations of the average crustal Vp/Vs ratio (Christensen, 1996). $\mathrm{Vp} / \mathrm{Vs}$ ratio shows little variation with changes in pressure and temperature. However, the mineral content of rocks plays a significant role in $\mathrm{Vp} / \mathrm{Vs}$ ratio variation. The amount of 
quartz and plagioclase feldspar present in common igneous rocks has the dominant effect on the $\mathrm{Vp} / \mathrm{Vs}$ ratio (Chevrot and van der Hilst, 2000). In general, mafic rocks have a high Vp/Vs ratio while felsic rocks have a low $\mathrm{Vp} / \mathrm{Vs}$ ratio, due to their different mineral contents.

The $\mathrm{Vp} / \mathrm{Vs}$ ratio values are not distributed in a uniform pattern, but in general the $\mathrm{Vp} /$ Vs ratios correlate overall with geomorphological units. We see that high average values (Figure 2.10) can be associated with regions of greater crustal thickness and low values are mostly located in the coastal FA, the SA, and the AB where the crustal thickness is thinnest.

Figure 2.10, shows the variation in $\mathrm{Vp} / \mathrm{Vs}$ ratios and indicate significant lateral heterogeneity beneath northern Peru. The FA, SA, and AB have the lowest Vp/Vs ratios (1.621.76), which imply that the crust may be more felsic in composition. In contrast, high $\mathrm{Vp} / \mathrm{Vs}$ ratios (1.78-1.88) are observed around the WC and EC. These higher Vp/Vs ratios indicate that the crust beneath these areas is probably more mafic in composition particularly associated to an existence of old arc volcanic, and presence of anisotropy caused by the migration of the Nazca Ridge (Antonijevic et al., 2015). In addition, the region presents values of heat flow that range between 40 and $80 \mathrm{~mW} / \mathrm{m} 2$ (Cardoso et al., 2010; Haraldsson, 2011) which corresponds to the variation of $\mathrm{Vp} / \mathrm{Vs}$ ratio and crustal thickness (Figure 2.10). This could be reflecting zones of partial melt in the crust which cause hydrothermal activity and elevated temperatures seen in numerous surface manifestations including hot springs in this region that have been linked to the geothermal gradient (Vargas and Cruz, 2010).

Our Hk-stacking analysis shows that the average $\mathrm{Vp} / \mathrm{Vs}$ ratio of the crust for the entire area is 1.75 . This value is consistent with the $\mathrm{Vp} / \mathrm{Vs}$ ratio of 1.75 used in previous RF studies in central Peru. Bishop et al. (2014) used Wadati diagrams (Wadati, 1933) in central Peru for the PULSE array and determined a Vp/Vs ratio of $1.75 \pm 0.01$ and this value is consistent with values determined by Hk-stacking immediately south of our study area (Phillips et al., 2012) and more generally in the central Andes (Cunningham et al., 1986; Dorbath and Granet, 1996). Expressed in terms of Poisson's ratio, our average value is comparable to the global crustal average value (0.26-0.27) reported by Christensen (1996) and Zandt and Ammon (1995). 


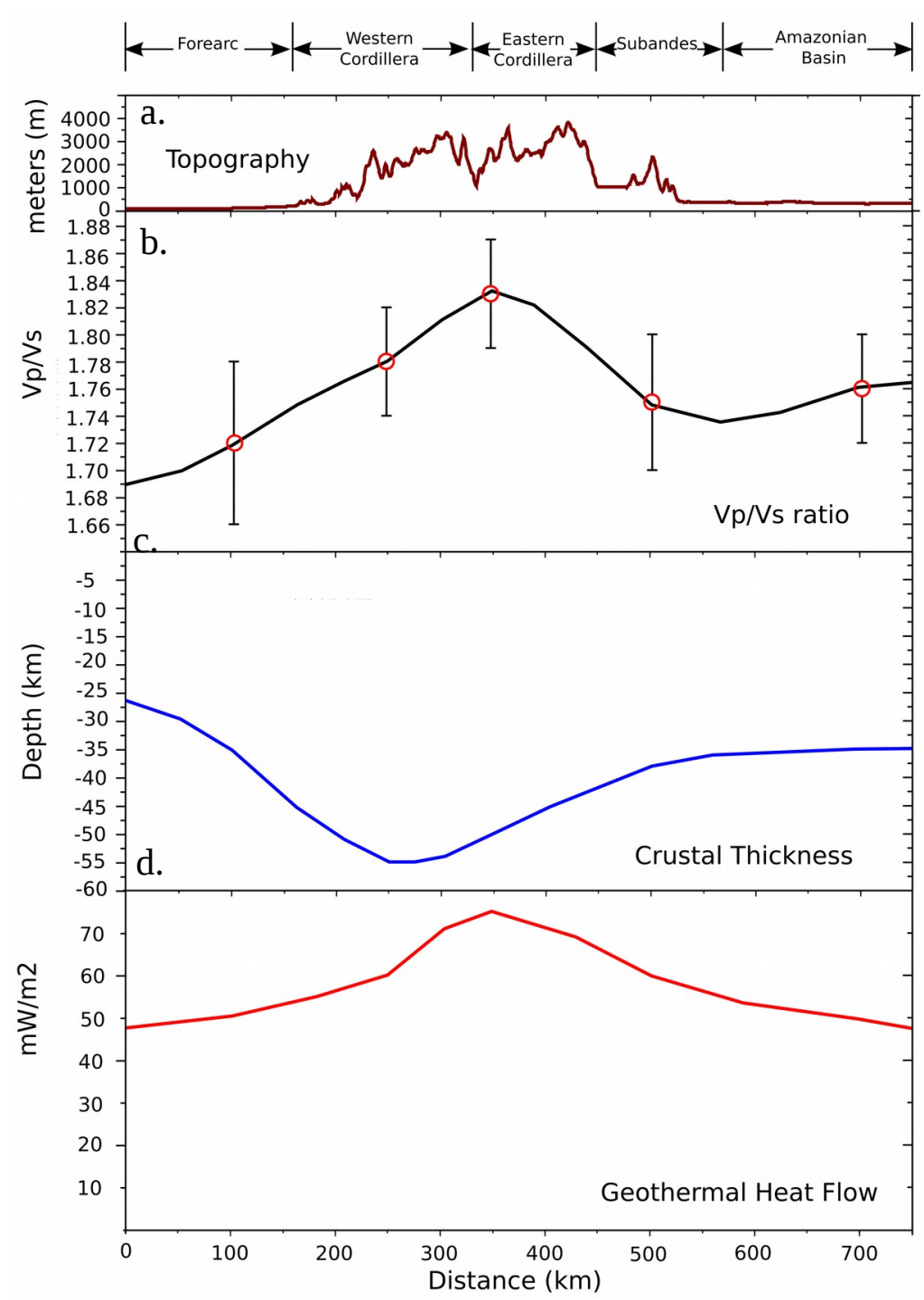

Figure 2.10: a) Topography showing change in elevation associated with the different geomorphological units in northern Peru. b) Average $\mathrm{Vp} / \mathrm{Vs}$ ratio. c) Average Crustal Thickness and d) Average Geothermal Heat Flow (Cardoso et al., 2010).

The study region is characterized by crustal complexities and intense tectonic activity (orogenesis active extensional and compressional processes), and these complexities are reflected in the RFs. However, the spatial density of seismometers and the good azimuthal coverage of data have helped us in the reconstruction of the crustal structure and Moho geometry beneath northern Peru. These results should be useful for future studies of crustal structure and evolution in northern Peru, however further investigation is required for a better understanding of the seismological features we have observed. 


\subsection{Conclusions}

We have investigated the crustal structure beneath northern Peru, a region that has not been studied in detail previously, by applying the RF method to estimate the crustal thickness and $\mathrm{Vp} / \mathrm{Vs}$ ratio at 28 broadband seismic stations. The distributions of the crustal thickness and $\mathrm{Vp} / \mathrm{Vs}$ ratio show a good correlation with the region's known geological and tectonic features, and in general agree with compilations made by Assumpção et al. (2013, 2015). Imaging of the P-to-s conversion from the Moho suggest that the crustal thickness is around $25 \mathrm{~km}$ near the coast, have a maximum thickness of 55-60 km beneath the Andean Cordillera, and $35-40 \mathrm{~km}$ further to the east in the Amazonian basin. The heterogeneous and complex crustal composition is revealed by $\mathrm{Vp} / \mathrm{Vs}$ ratios that have high values $(1.78-1.88)$ in the WC and EC and low values (1.62-1.77) in the FA, SA, and AB.

- The maximum crustal thickness is beneath the WC than the EC and thins to the west beneath the FA and to the east beneath the SA and AB.

- The average crustal thickness is consistent with those reported in previous studies.

- The $\mathrm{Vp} / \mathrm{Vs}$ ratios correlate with the variations in heat flow, crustal thickness, and topography with the high elevations of the WC and EC having high Vp/Vs ratios and the low elevations of the FA, SA and AB having lower Vp/Vs ratios. This suggests a dominantly felsic composition in the middle crust and an intermediate to more mafic composition at the base of the crust under high elevations.

- There is a discontinuous change in crustal thickness across the Sub-Andes.

- The Moho dips steeply eastward beneath the western slope of the WC.

- Our results provide some constraints on understanding the mechanism of uplift and crustal thickening in the region and help to increase the database of crustal thicknesses for better understanding the geodynamic of Northern Peru. 


\subsection{Acknowledgements}

The data used in this study were provided by the Peruvian National Seismic Network and by the Instituto Geofísico del Perú. This research was supported by CAPES. We would like to thank the Observatorio Sismológico-OBSIS and Universidade de Brasília-UnB. We also thank Marcelo Assumpção (IAG-USP) for providing compiled data of crustal thickness for adjacent regions to our study area and for valuable contributions to the manuscript. We also thank to Marcelo Peres for their contributions. GSF thanks CNPq for his PQ grants (307255/2013-1).

\subsection{References}

Ammon, C.J., 1991. Isolation of receiver effects from teleseismic P waveforms. Bulletin of the Seismological Society of America 81, 2504-2510.

Ammon, C.J., Randall, G.E., Zandt, G., 1990. On the nonuniqueness of receiver function inversions. Journal of Geophysical Research 95, 15303. doi:10.1029/JB095iB10p15303.

Antonijevic, S.K., Wagner, L.S., Kumar, A., Beck, S.L., Long, M.D., Zandt, G., Tavera, H., Condori, C., 2015. The role of ridges in the formation and longevity of flat slabs.Nature 524, 212-215. doi:10.1038/nature14648.

Aranda, N., Assumpção, M., 2013. Crustal thickness in the northern Andes from teleseismic pP and sS precursors, in: 13th International Congress of the Brazilian Geophysical Society. Society of Exploration Geophysicists and Brazilian Geophysical Society, EXPOGEF, Rio de Janeiro, Brazil, 26-29 August 2013, pp. 1781-1785. doi:10.1190/sbgf2013-366.

Assumpção, M., Bianchi, M., Albuquerque, D.F., França, G.S.L.A., Barros, L., 2015. Crustal Thickness Map in South America: an updated version. Extend Abstract 1st Brazilian Symposium on Seismology 1-4.

Assumpção, M., Feng, M., Tassara, A., Julià, J., 2013. Models of crustal thickness for South America from seismic refraction, receiver functions and surface wave tomography. Tectonophysics 609, 82-96. doi:10.1016/j.tecto.2012.11.014.

Audebaud, E., Capdevila, R., Dalmayrac, B., Laubaucher, G., Marocco, R., Mattauer, M., Megard, F., Paredes, J., 1973. Les traits geologiques essentials des Andes Centrales (Perou-Bolivie). Revue Geographie Physique, Geologique et Dinamique. 15(1-2), 73114.

Bishop, B., Beck, S., Zandt, G., Scire, A., Wagner, L., Long, M., Tavera, H., 2014. Trench to andean Thrust Front: Evidence for Coupling of the Peruvian Flat Slab to the Over-riding South American Plate. American Geophysical Union, Fall Meeting 2014, abstract 
\#T23A-4629 2014AGUFM.

Cahill, T., Isacks, B.L., 1992. Seismicity and shape of the subducted Nazca Plate. Journal of Geophysical Research 97, 17503. doi:10.1029/92JB00493.

Cardoso, R.R., Hamza, V.M., Alfaro, C., 2010. Geothermal resource base for South America: A continental perspective. Proceedings World Geothermal Congress 2010, Bali, Indonesia, 25-29 April 2010, 6 pp.

Cassidy, J.F., Ellis, R.M., 1993. S wave velocity structure of the northern Cascadia subduction zone. J. Geophys. Res 4407-4421.

Chevrot, S., van der Hilst, R.D., 2000. The Poisson ratio of the Australian crust: geological and geophysical implications. Earth and Planetary Science Letters 183, 121-132. doi:10.1016/S0012-821X(00)00264-8.

Christensen, N.I., 1996. Poisson's ratio and crustal seismology. Journal of Geophysical Research 101, 3139. doi:10.1029/95JB03446.

Chulick, G.S., Detweiler, S., Mooney, W.D., 2013. Seismic structure of the crust and uppermost mantle of South America and surrounding oceanic basins. Journal of South American Earth Sciences 42, 260-276. doi:10.1016/j.jsames.2012.06.002.

Crotwell, H.P., Owens, T.J., Ritsema, J., 1999. The TauP Toolkit: Flexible Seismic Travel-time and Ray-path Utilities. Seismological Research Letters 70, 154-160. doi:10.1785/gssrl.70.2.154.

Cunningham, P.S., Roecker, S.W., Hatzfeld, D., 1986. Three-dimensional P and S wave velocity structures of southern Peru and their tectonic implications. J. geophys. Res. 91, 9517-9532.

Dalmayrac, B., Laubacher, G., R., M., 1987. Caracteres generaux de l’evolution geologique des Andes peruviannes. ORDTOM 122-501.

Dalmayrac, B., Laubacher, G., R., M., 1980. Geologie des Andes peruviannes, Caracteres generaux de l'evolution geologique des Andes peruviennes. ORDTOM 96-217.

DeMets, C., Gordon, R.G., Argus, D.F., Stein, S., 1990. Current plate motions. Geophysical Journal International 101, 425-478. doi:10.1111/j.1365-246X.1990.tb06579.x.

Dewey, J.F., Bird, J.M., 1970. Mountain belts and the new global tectonics. J. geophys. Res. 75, 2625-2647.

Dorbath, C., Granet, M., 1996. Local earthquake tomography of the Altiplano and the Eastern Cordillera of northern Bolivia. Tectonophysics 259, 117-136.

Dumont, J.F., Deza, E., Garcia, F., 1991. Morphostructural provinces and neotectonics in the Amazonian lowlands of Peru. Journal of South American Earth Sciences 4, 373-381. 
doi:10.1016/0895-9811(91)90008-9.

Eaton, D.W., Dineva, S., Mereu, R., 2006. Crustal thickness and Vp/Vs variations in the Grenville orogen (Ontario, Canada) from analysis of teleseismic receiver functions. Tectonophysics 420, 223-238.

Förste, C., Bruinsma, S., Marty, J.-C., Flechtner, F., Abrykosov, O., Dahle, C., Lemoine, J.M., Neumayer, K.-H., Biancale, R., Barthelmes, F., König, R., 2014. EIGEN-6C4 The latest combined global gravity field model including GOCE data up to degree and order 2190 of GFZ Potsdam and GRGS Toulouse. GFZ Data Services.

Frassetto, A.M., Zandt, G., Gilbert, H., Owens, T.J., Jones, C.H., 2011. Structure of the Sierra Nevada from receiver functions and implications for lithospheric foundering. Geosphere 7(4), 898-921. doi:10.1130/GES00570.1.

Fukao, Y., Kono, M., Yamamoto, A., Saito, M., Nawa, K., Giesecke, A., Perales, P., 1999. Gravity Measurements and Data Reduction for Bouguer Anomaly Map of Peru. Bull. Earthq. Res. Inst. Univ.Tokyo 74, 161-266.

Fukao, Y., Yamamoto, A., Kono, M., 1989. Gravity anomaly across the Peruvian Andes. Journal of Geophysical Research 94, 3867. doi:10.1029/JB094iB04p03867.

Gansser, A., 1973. Facts and theories on the Andes. Journal of the Geological Society 129, 93-131.

Gutscher, M.A., Olivet, J.-L., Aslanian, D., Eissen, J.-P., Maury, R., 1999. The "lost Inca Plateau”: cause of flat subduction beneath Peru? Eart planet. Sci. Lett. 171, 335-341.

Gutscher, M.A., Spakman, W., Bijwaard, H., Engdahl, E.R., 2000. Geodyanmics of flat subduction: seismicity and tomographic constraints from the Andean margin. Tectonics 19, 814-833.

Hampel, A., 2002. The migration history of the Nazca Ridge along the Peruvian active margin: a re-evaluation. Earth and Planetary Science Letters 203, 665-679. doi:10.1016/S0012-821X(02)00859-2.

Haraldsson, I.G., 2011. Geothermal activity and development in South America: Short overview of the status in Bolivia, Chile, Ecuador and Peru. Presented at "Short Course on Geothermal Drilling, Resource Development and Power Plants”, Santa Tecla, El Salvador, January 16-22 18.

Hayes, G.P., Wald, D.J., Johnson, R.L., 2012. Slab1.0: A three-dimensional model of global subduction zone geometries. Journal of Geophysical Research 117, B01302. doi:10.1029/2011JB008524.

Henry, S.G., Pollack, H.N., 1988. Terrestrial heat flow above the Andean Subduction Zone in Bolivia and Peru. Journal of Geophysical Research 93, 15153. 
doi:10.1029/JB093iB12p15153.

Hussong, D.M., Edwards, P.B., Johnson, S.H., Campbell, J.F., Sutton, G.H., 1976. Crustal structure of the Peru-Chile trench: $8^{\circ}-12^{\circ} \mathrm{S}$ latitude. The geophysics of the Pacific Ocean Basin and its margins., in: AGU Geophysical Monograph 19. pp. 71-81.

James, D.E., 1971. Andean crustal and upper mantle structure. Journal of Geophysical Research 76, 3246-3271. doi:10.1029/JB076i014p03246.

Kendrick, E., Bevis, M., Smalley, R., Brooks, B., Vargas, R.B., Lauría, E., Fortes, L.P.S., 2003. The Nazca-South America Euler vector and its rate of change. Journal of South American Earth Sciences 16, 125-131. doi:10.1016/S0895-9811(03)00028-2.

Krabbenhöft, A., Bialas, J., Kopp, H., Kukowski, N., Hübscher, C., 2004. Crustal structure of the Peruvian continental margin from wide-angle seismic studies. Geophysical Journal International 159, 749-764. doi:10.1111/j.1365-246X.2004.02425.x.

Kulm, L.D., Prince, R.A., French, W., Johnson, S., Masias, A., 1981. Crustal structure and tectonics of the central Peru continental margin and trench. Geol Soc. Am. Mem. 154, 445-468.

Langston, C.A., 1979. Structure under Mount Rainier, Washington, inferred from teleseismic body waves. Journal of Geophysical Research 84, 4749. doi:10.1029/JB084iB09p04749.

Ligorría, J.P., Ammon, C.J., 1999. Iterative Deconvolution and Receiver-Function Estimation. Bull. seism. Soc. Am. 89.

Lindo, R., 1993. Seismotectonique des andes du Perou central: Apport des donnes sismologiques de haute precision. Ph.D. Thesis, Universite Louis-Pasteur, Strasbourg, France. 74.

Lloyd, S., van der Lee, S., França, G.S., Assumpção, M., Feng, M., 2010. Moho map of South America from receiver functions and surface waves. Journal of Geophysical Research 115, B11315. doi:10.1029/2009JB006829.

Martinod, J., Husson, L., Roperch, P., Guillaume, B., Espurt, N., 2010. Horizontal subduction zones, convergence velocity and the building of the Andes. Earth and Planetary Science Letters 299, 299-309. doi:10.1016/j.epsl.2010.09.010.

Megard, F., 1978. Etude geologique des Andes du Pérou Central. Memoires ORSTOM 86, 310.

Mégard, F., 1987. Cordilleran Andes and marginal Andes: A review of Andean geology north of the Arica elbow (18ºs). Geodyn. Ser. 18, 71-95. doi:10.1029/GD018p0071.

Mitouard, P., Kissel, C., Laj, C., 1990. Post-Oligocene rotations in southern Ecuador and northern Peru and the formation of the Huancabamba deflection in the Andean Cordillera. Earth and Planetary Science Letters 98, 329-339. doi:10.1016/0012- 
821X(90)90035-V.

Mourier, T., Mégard, F., Rivera, L., Arguedas, A.P., 1988. L’évolution mésozoique des Andes de Huancabamba (nord Pérou-sud Ecuateur) et l'hypothèse de l'accrétion du bloc Amotape-Tahuin. Bull. Soc. Géol.France 4, 69-79.

Musacchio, G., Mooney, W.D., Luetgert, J.H., Christensen, N.I., 1997. Composition of the crust in the Grenville and Appalachian Provinces of North America inferred from V P /V S ratios. Journal of Geophysical Research 102, 15225. doi:10.1029/96JB03737.

Norabuena, E.O., Dixon, T.H., Stein, S., Harrison, C.G.A., 1999. Decelerating Nazca-South America and Nazca-Pacific Plate motions. Geophysical Research Letters 26, 3405-3408. doi:10.1029/1999GL005394.

Ocola, L., Meyer, R.L., Aldrich, L.T., 1971. Cross crustal structure under Peru-Bolivia altiplano. Earthquakes notes, Seismological Society of America 42, 3-4.

Owens, T.J., Zandt, G., Taylor, S.R., 1984. Seismic evidence for an ancient rift beneath the Cumberland Plateau, Tennessee: A detailed analysis of broadband teleseismic P waveforms. Journal of Geophysical Research 89, 7783. doi:10.1029/JB089iB09p07783.

Pavão, C.G., França, G.S., Marotta, G.S., Menezes, P.H.B.J., Neto, G.B.S., Roig, H.L., 2012. Spatial interpolation applied to crustal thickness in Brazil. Journal of Geographic Information System 4(2), 142-152.

Phillips, K., Clayton, R.W., 2014. Structure of the subduction transition region from seismic array data in southern Peru. Geophysical Journal International 196, 1889-1905. doi:10.1093/gji/ggt504.

Phillips, K., Clayton, R.W., Davis, P., Tavera, H., Guy, R., Skinner, S., Stubailo, I., Audin, L., Aguilar, V., 2012. Structure of the subduction system in southern Peru from seismic array data. Journal of Geophysical Research 117, B11306. doi:10.1029/2012JB009540.

Poveda, E., Monsalve, G., Vargas, C.A., 2015. Receiver functions and crustal structure of the northwestern Andean region, Colombia. Journal of Geophysical Research: Solid Earth 120, 2408-2425. doi:10.1002/2014JB011304.

Ramos, V.A., Folguera, A., 2009. Andean flat-slab subduction through time. Geol. Soc., Lond., Spec. Publ. 327, 31-54.

Rosenbaum, G., Giles, D., Saxon, M., Betts, P.G., Weinberg, R.F., Duboz, C., 2005. Subduction of the Nazca Ridge and the Inca Plateau: Insights into the formation of ore deposits in Peru. Earth and Planetary Science Letters 239, 18-32. doi:10.1016/j.epsl.2005.08.003.

Ryan, J., Beck, S., Zandt, G., Wagner, L., Minaya, E., Tavera, H., 2016. Central Andean crustal structure from receiver function analysis. Tectonophysics. 
doi:10.1016/j.tecto.2016.04.048.

Soler, P., Sébrier, M., 1990. Nazca slab retreat versus compressional deformation in the central Andes since late Oligocene times. Symposium international géodynamique andine: Résumés des communications 187-190.

Suárez, G., Molnar, P., Burchfiel, B.C., 1983. Seismicity, fault plane solutions, depth of faulting, and active tectonics of the Andes of Peru, Ecuador, and southern Colombia. Journal of Geophysical Research 88, 10403. doi:10.1029/JB088iB12p10403.

Tankard, A.J., Suárez, S.R., Welsink, H.J., 1995. Petroleum geology of the sub-Andean basins of Peru. Petroleum basins of South America, AAPG Menoir 62, 423-444.

Tassara, A., Echaurren, A., 2012. Anatomy of the Andean subduction zone: three dimensional density model upgraded and compared against global-scale models. Geophysical Journal International 189, 161-168.

Tavera, H., 1990. Interpretación de las Anomalías de Estación a partir de fases P y PKIKP para la región del Perú Central. Boletín Sociedad Geológica del Perú 81, 47-54.

Tavera, H., Buforn, E., 1998. Sismicidad y sismotectónica de Perú. Fisica de la Tierra 10, 187-219.

Vargas, V., Cruz, V., 2010. Geothermal Map of Perú, in: Proceedings World Geothermal Congress 2010. Bali, Indonesia, p. 7.

Villegas, J.C., 2009a. Proceesing and Analysis of the LISN permanent GPS network: Preliminary Tectonic Results. Nice-France.

Villegas, J.C., 2009b. Modelos de Velocidad Unidimensionales para las Regiones Norte, Centro y Sur del Perú, a partir de la Inversión de los Tiempos de arribo de las ondas P y $\mathrm{S}$ de sismos locales. Tesis de Ingeniería U.N.S.A 56-75.

Wadati, K., 1933. On the travel time of earthquake waves, Part II. Geophys. Mag. 7, 101-111.

Wipf, M.A., 2006. Evolution of the Western Cordillera and Coastal Margin of Peru : Evidence from low-temperature Thermochronology and Geomorphology. Swiss Federal Institute of Technology Zürich 163.

Yuan, X., Sobolev, S.., Kind, R., 2002. Moho topography in the central Andes and its geodynamic implications. Earth and Planetary Science Letters 199, 389-402. doi:10.1016/S0012-821X(02)00589-7.

Zandt, G., Ammon, C., 1995. Continental crust composition constrained by measurements of crustal Poisson's ratio. Nature 374, 152-154.

Zhu, L., Kanamori, H., 2000. Moho depth variation in southern California from teleseismic receiver functions. J. Geophy. Res. 105, 2969-2980. 


\section{Capítulo 3}

\section{Discussão e Conclusões}

\subsection{Discussão}

O estudo da FR realizado neste trabalho permite estimar a espessura crustal e a razão Vp/Vs para os diferentes domínios tectônicos da região norte do Peru. Os resultados mostram coerência com a variação da topografia da litosfera superior e os modelos estabelecidos em estudos prévios (James, 1971; Tavera, 1990; Bishop et al., 2014; Assumpção et al., 2013, 2015). Como esperado, os modelos da crosta sugerem que a maior espessura ocorre na Cordilheira dos Andes (CA).

As primeiras estimativas da espessura crustal em nossa área de estudo foram realizados por Fukao et al. (1989), usando dados de gravidade e estudos sismológicos obtidos na CA desde a costa até a BA e as espessuras máximas estimadas foram de 45 km no norte e $55 \mathrm{~km}$ no centro do território peruano. No entanto, os valores máximos estimados neste estudo foram de $50 \mathrm{~km}$ para o norte e $60 \mathrm{~km}$ para o centro, sugerindo $5 \mathrm{~km}$ a mais do que o estimado com métodos gravimétricos por Fukao et al. (1989) e consistentes com as estimativas propostas por Tavera (1990), Bishop et al. (2014), e Assumpção et al. (2013, 2015).

Para uma análise mais detalhada, apresentam-se os valores das espessuras crustais e de razão Vp/Vs para cada estação sismográfica sobre o mapa topográfico (Figuras 3.1a e 3.1b). Além de caracterizar a Moho e a razão Vp/Vs quanto aos valores numéricos, os mapas permitiram diferenciar domínios tectônicos de acordo com as variações de espessura e composição.

Na ZC, localizada ao longo da margem da costa até a COC, estimam-se valores de espessura de entre 22 e $35 \mathrm{~km}$, enquanto que na CA, especificamente na COC e COR, os valores variam localmente de 47 até $63 \mathrm{~km}$, apresentando valores mais altos na região central. Para a ZS, os valores apresentam uma diminuição de 37 a 44 km para finalmente apresentar uma espessura constante de, aproximadamente, $37 \mathrm{~km}$ na BA. 

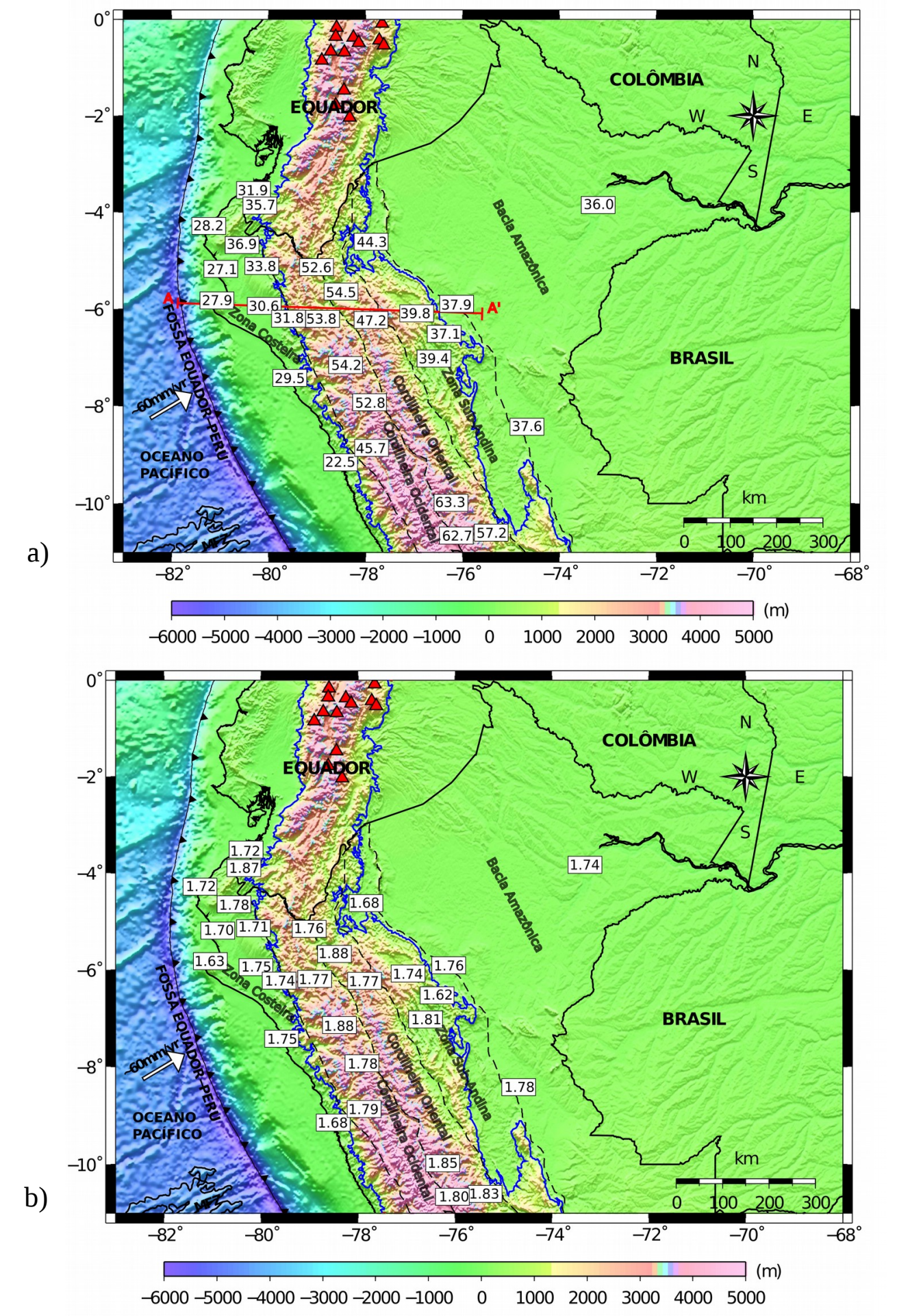

Figura 3.1: Mapa topográfico da área de estudo. As cores indicam a elevação em metros, a linha azul indica a geometria da Cordilheira dos Andes (elevação 600 m) e as linhas pretas representam as diferentes unidades geomorfológicas. a) Valores de espessura crustal estimados a partir da FR. A linha vermelha representa o perfil A-A' que será mostrado na Figura 3.11. b) Valores de razão de Vp/Vs para cada estação sismográfica. 
O norte e centro do Peru são caracterizados atualmente como zonas não vulcânicas, devido ao tipo de subduç̧ão (flat-slab) entre as latitudes $2^{\circ} \mathrm{S}$ e $15^{\circ} \mathrm{S}$, que se estende de maneira sub-horizontal alongo da profundidade de $100 \mathrm{~km}$ embaixo da placa Sul-Americana (Hasegawa e Sacks, 1981; Cahill e Isacks, 1992; Gutscher et al., 1999; Gutscher, 2003) e que, provavelmente, atua como uma barreira no manto restringindo a circulação do fluxo da astenosfera e formação do magma (Barazangi e Isacks, 1976). Por outro lado, diversos autores sugerem que o flat-slab é afetado pela Dorsal de Nazca que começou na latitude 9-11으 aproximadamente há 11-15 milhões de anos e que, subsequentemente, migra a uma velocidade relativa de $43 \mathrm{~mm} / \mathrm{ano}$ (Hampel, 2002; Rosenbaum et al., 2005), o que muda a geometria da placa de Nazca de normal a sub-horizontal, sendo a posição atual na latitude 14$17^{\circ}$ S, entre a região centro e sul do Peru onde começa o arco vulcânico ativo.

As evidências geológicas indicam a provável existência de atividade vulcânica passada na área de estudo, corroborada pela presença de rochas vulcânicas pertencentes ao grupo Calipuy, constituída por lavas predominantemente andesíticas e piroclásticas (Wilson, 1984; Reyes e Caldas, 1987). Por outro lado, na região, há diversas fontes de águas termais ( 70) que estariam associadas à circulação de águas naturais nas falhas regionais com temperaturas elevadas, como resultado do alto gradiente geotérmico presente a profundidades rasas devido a estruturas geológicas (Vargas e Cruz, 2010).

\subsubsection{Razão Vp/Vs e Fluxo de Calor Geotérmico}

Estudos confirmam que os valores altos de razão $\mathrm{Vp} / \mathrm{Vs}$ estão associados às zonas de alto gradiente térmico, especialmente naquelas com atividade vulcânica (Nakajima et al., 2001; Poveda et al., 2015). Entretanto, outros estudos revelam que a própria temperatura não parece ser um fator crucial no incremento de Vp/Vs (Chatterjee et al., 1985; Christensen, 1996; Wagner et al., 2008).

O mapa de razão Vp/Vs (Figura 3.2a) apresenta as variações composicionais da crosta dentro dos domínios tectônicos, com valores entre 1,63 e 1,86, com aumento dentro da CA de 1,82 a 1,85. Esse aumento da razão Vp/Vs sugere uma crosta inferior mais máfica que na crosta superior sob os Andes. 

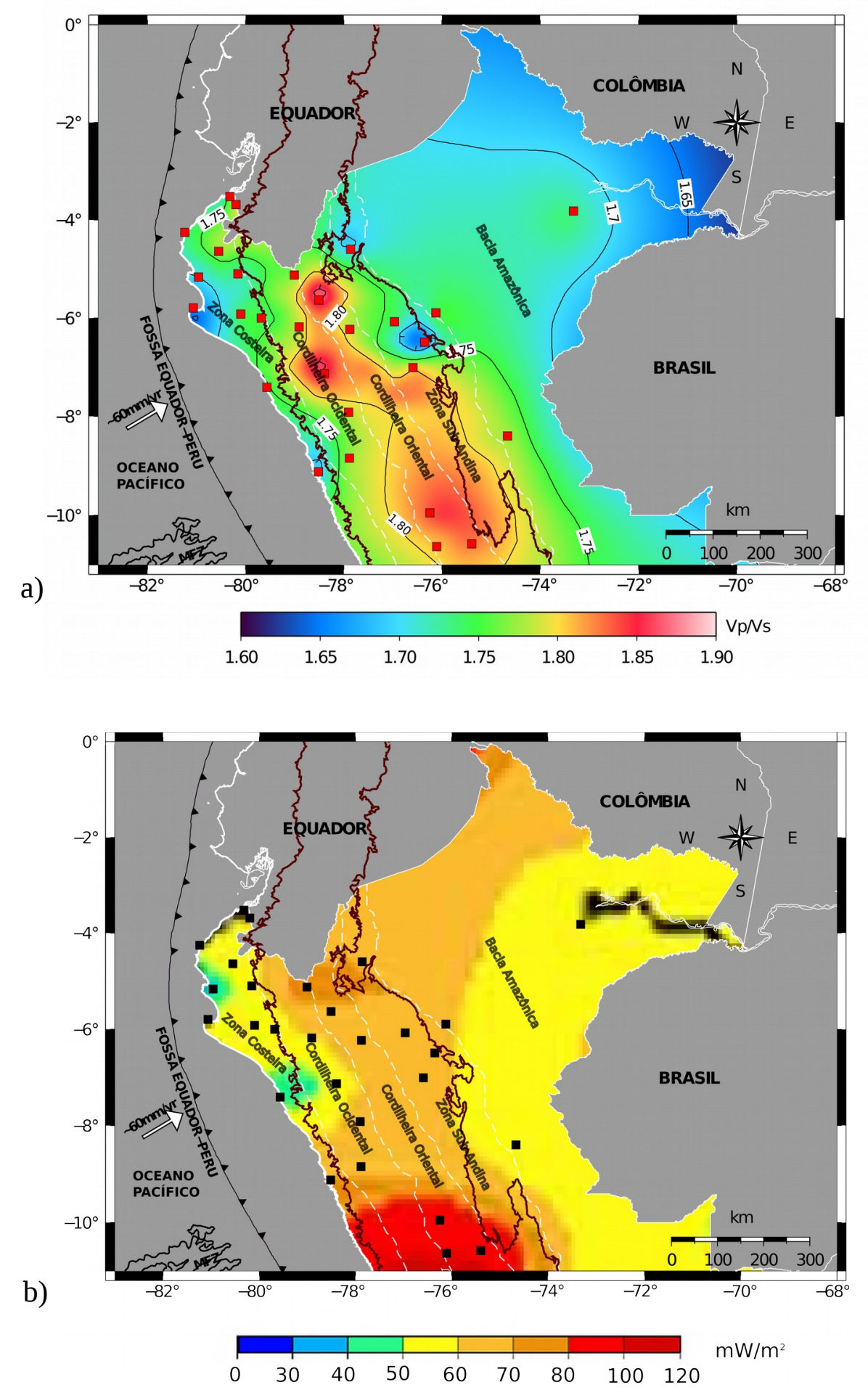

Figura 3.2: a) Mapa de razão Vp/Vs. b) Mapa do Fluxo de Calor Geotérmico (Modificado de Cardoso et al. 2010). Os quadrados vermelhos e pretos indicam as estações sismográficas e as linhas tracejadas em branco, os limites das unidades geomorfológicas e a linha marrom indica a geometria da Cordilheira dos Andes (elevação 600 m). 
Assume-se que a razão Vp/Vs, provavelmente, deva sua variação e origem nas zonas com fraturamento e ao processo de fusão parcial na crosta inferior, o que pode gerar materiais mais máficos. Por outro lado, esses altos valores podem estar associados também com a anisotropia na crosta média (Wang et al., 2012).

O mapa dos valores de Fluxo de Calor Geotérmico (FCG) para a região de estudo variam entre 40 e $80 \mathrm{~mW} / \mathrm{m}^{2}$ (Figura 3.2b), indicando valores altos na região central, com valores de até $80 \mathrm{~mW} / \mathrm{m}^{2}$, consistentes com os de $\mathrm{Vp} / \mathrm{Vs}$ (1.80-1.88), principalmente na COC e COR. Já nas ZC e BA, os valores de FCG variam entre 40 e $65 \mathrm{~mW} / \mathrm{m}^{2}$, coerentes com os valores baixos de Vp/Vs (1.60-1.75). A correlação positiva entre o valor de Vp/Vs e o FCG indica que a CA apresenta composição máfica e, em termos de deformação, é menos rígida. No entanto, nos flancos da CA, a composição é mas félsica e o valor de FCG indica materiais mais rígidos, provavelmente pode ser a explicação da maior sismicidade nessa área.

\subsubsection{Correlação com dados gravimétricos}

Os valores de anomalias gravimétricas são devidos, principalmente, à variação das propriedades e espessura da crosta e indicam uma correlação com a topografia e densidade. Assim, baixos valores gravimétrico (anomalia Bouguer) correspondem a uma crosta mais espessa e altos valores, a uma crosta mais fina (França, 2003).

O mapa dos valores de anomalia Bouguer (Figura 3.3a) foi gerado a partir dos dados de medições locais compilados por Fukao et al. (1999), que mostra concordância e correlação com a elevação da topografia. Os valores variam de entre -350 até $100 \mathrm{mGals,} \mathrm{sendo}$ apresentado com valores negativos nas regiões mais elevadas e de maior espessura crustal, principalmente na região central do Peru, mais precisamente na COC. Isso indica que a crosta é mais espessa na COC do que na COR, como mostra o mapa da Figura 3.3b.

Por outro lado, na ZS, no limite entre a COR e a BA, os valores de anomalia Bouguer que mostram que essa região é mais densa que certamente deve ser influência do afinamento crustal, já que a Vp/Vs para essa região varia entre 1,67 a 1,70 que é indicativo de uma crosta mais félsica. 

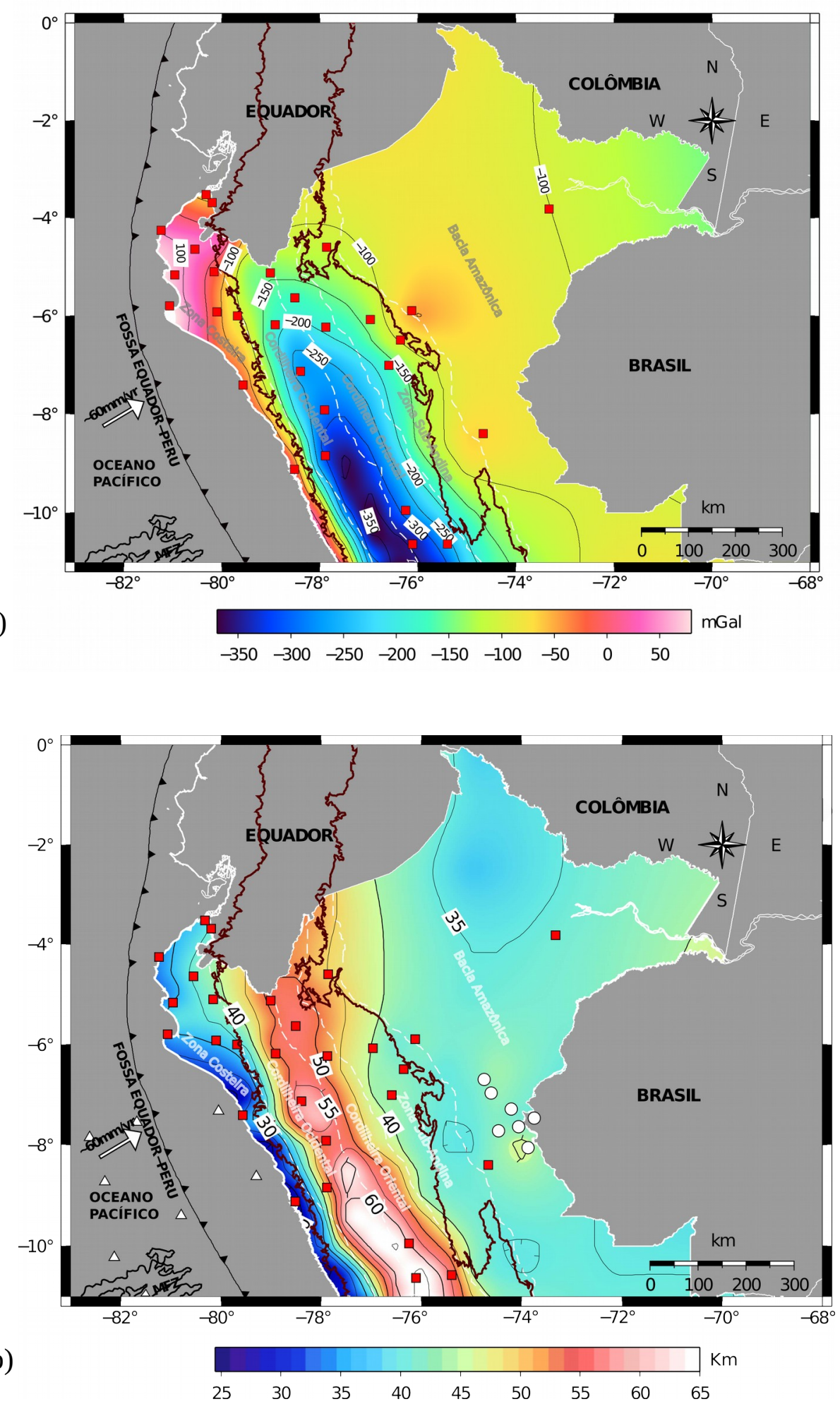

Figura 3.3: a) Mapa de anomalia Bouguer. b) Mapa de espessura crustal. As linhas tracejadas em branco são os limites das diferentes unidades geomorfológicas e a linha marrom indica a geometria da Cordilheira dos Andes (elevação 600 m). 
A Figura 3.4 apresenta a correlação entre os valores médios de anomalia Bouguer e espessura crustal em cada estação sismográfica na região do estudo. A correlação mostra um comportamento esperado para uma crosta compensada isostaticamente, como já descrito por Assumpção et al. 2013, em que era aplicado para a América do Sul como todo.

a)

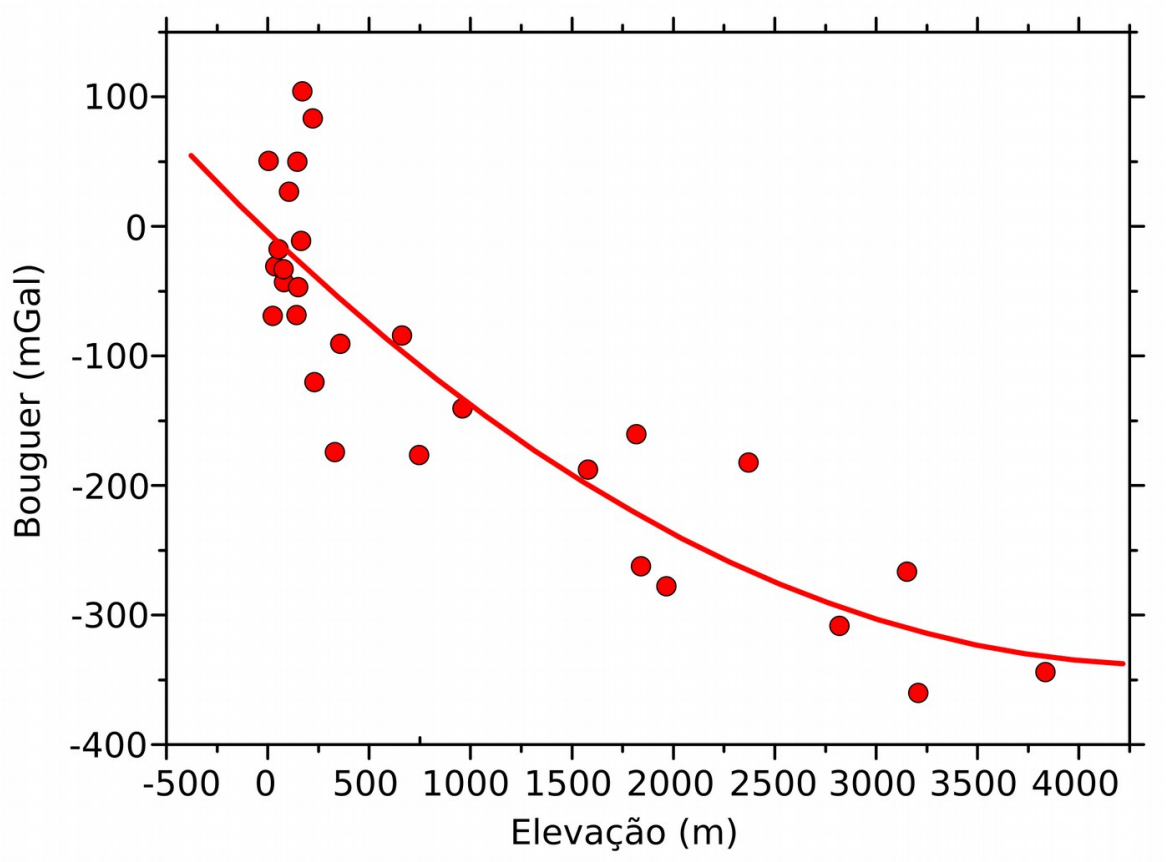

b)

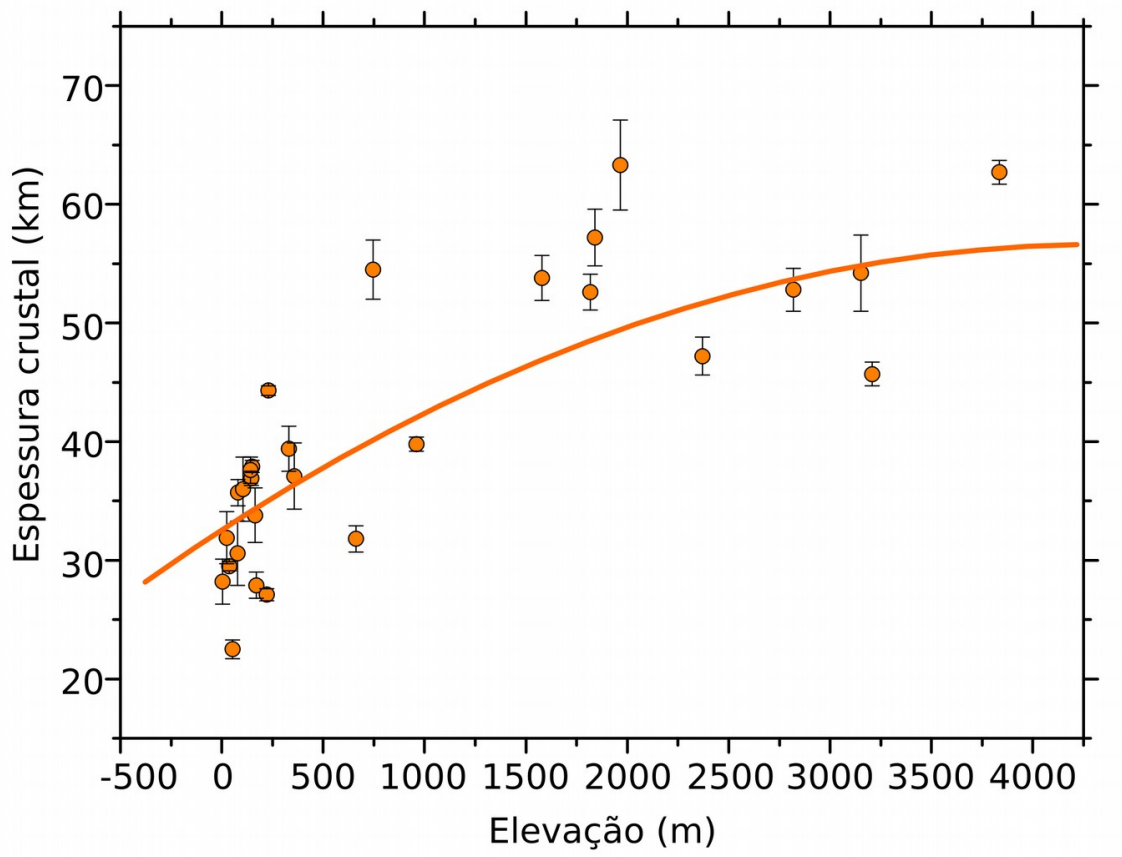

Figura 3.4: a) Variação da anomalia Bouguer com a elevação da estação. b) Variação da espessura crustal com a elevação da estação. 


\subsubsection{Comparação dos resultados}

Diversos modelos de estrutura da crosta foram propostos usando dados e metodologias diferentes (sísmicos ou gravimétricos) que, de maneira geral, abrangem a área de estudo com estimativas próximas às escalas continental (Chulick et al., 2013; Assumpção et al., 2013, 2015) e global (Soller et al., 1982; Reguzzoni et al., 2013; Reguzzoni e Sampietro, 2015). Há diversos modelos crustais disponíveis como: CRUST1.0 (Laske et al., 2013), CRUST2.0 (Bassin et al., 2000) e CRUST5.1 (Mooney et al., 1998).

Geralmente, esses modelos apresentam valores muito diferentes e não homogêneos de estimativas de espessura crustal, devido às variações laterais locais ou ao uso de diferentes hipóteses geológicas e geofísicas, bem como diferentes tipos de dados. Em termos de qualidade, distribuição espacial e resolução, em particular, os modelos da crosta globais com base unicamente em dados sísmicos (por exemplo o modelo CRUST5.1), pode nos ajudar a ter uma ideia do valor de espessura da crosta, mas localmente não reflete a informação por possuir grandes incertezas na estimativa.

Para a comparação dos mapas de espessura crustal (modelos prévios) com os propostos neste estudo, consideram-se dois modelos com informação atualizada, como o proposto por Assumpção et al. (2013, 2015) e o modelo global CRUST1.0 (Laske et al., 2013). 


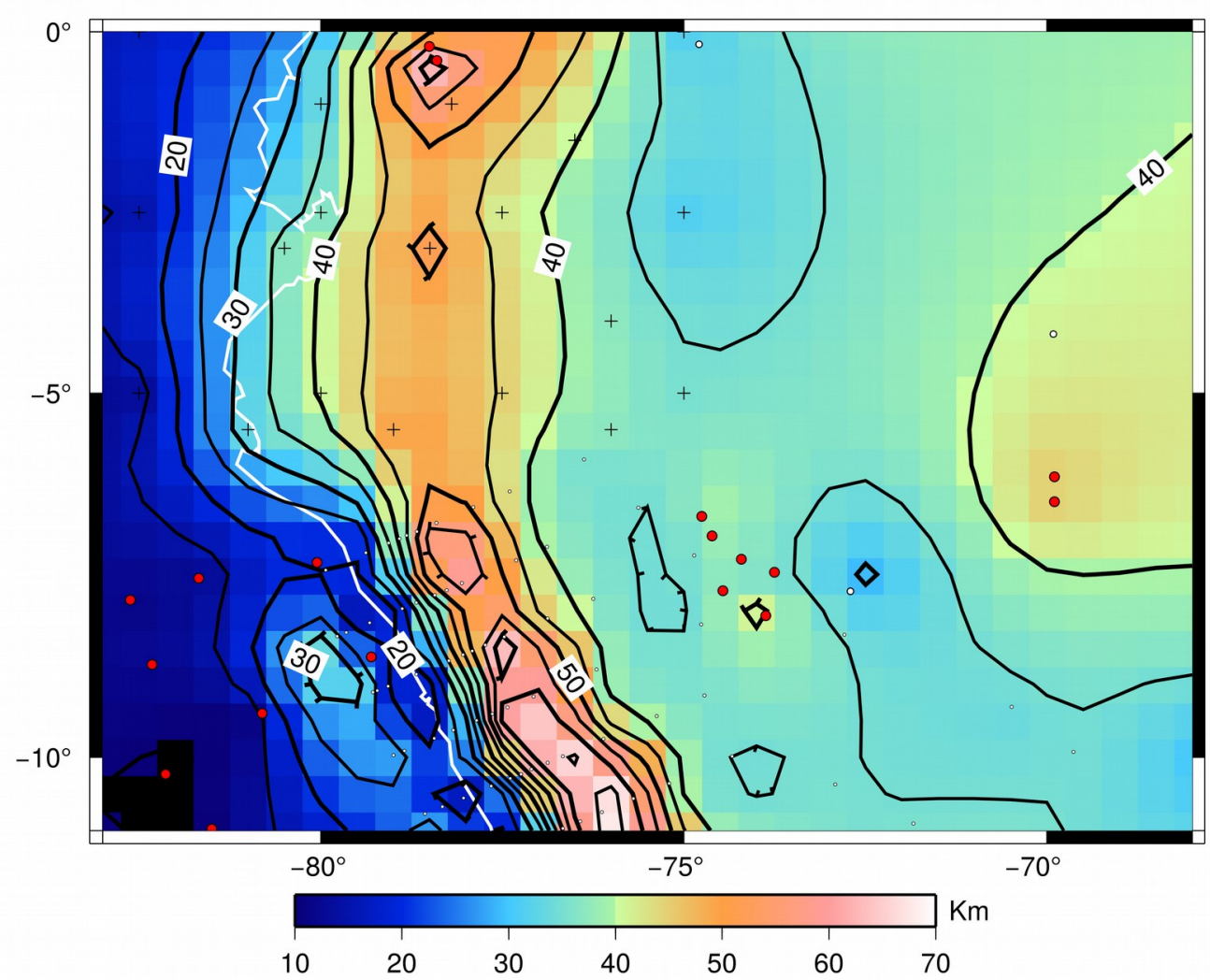

Figura 3.5: Mapa de contorno de espessura crustal para a região norte do Peru proposto por Assumpção et al. (2013, 2015), gerados a partir de dados compilados anteriormente.

O modelo proposto por Assumpção et al. (2013, 2015) indica que os valores altos de espessura crustal embaixo da CA variam entre 40 e $45 \mathrm{~km}$ para a região norte da área de estudo (Figura 3.5), com um aumento progressivo em direção à região central, com valores de 55 a $60 \mathrm{~km}$. No entanto, na BA, o valor médio é de $35 \mathrm{~km}$, um valor atribuído ao escudo brasileiro. Valores semelhantes foram obtidos neste estudo com a FR, mostrando uma diferença de 5 km a mais do que o estimado por Assumpção et al. $(2013,2015)$ para a região norte e similares para a região central (Figura 3.6a).

Para uma análise detalhada, gerou-se um novo modelo, com os dados obtidos neste estudo e com os propostos por Assumpção et al. (2013, 2015). Este modelo (Figura 3.6b), por apresentar maior quantidade de dados/estações, maior cobertura azimutal e menores incertezas nas estimativas da espessura da crosta, permite caracterizar melhor as feições da crosta, as quais são coerentes com as características tectônicas da área de estudo. 


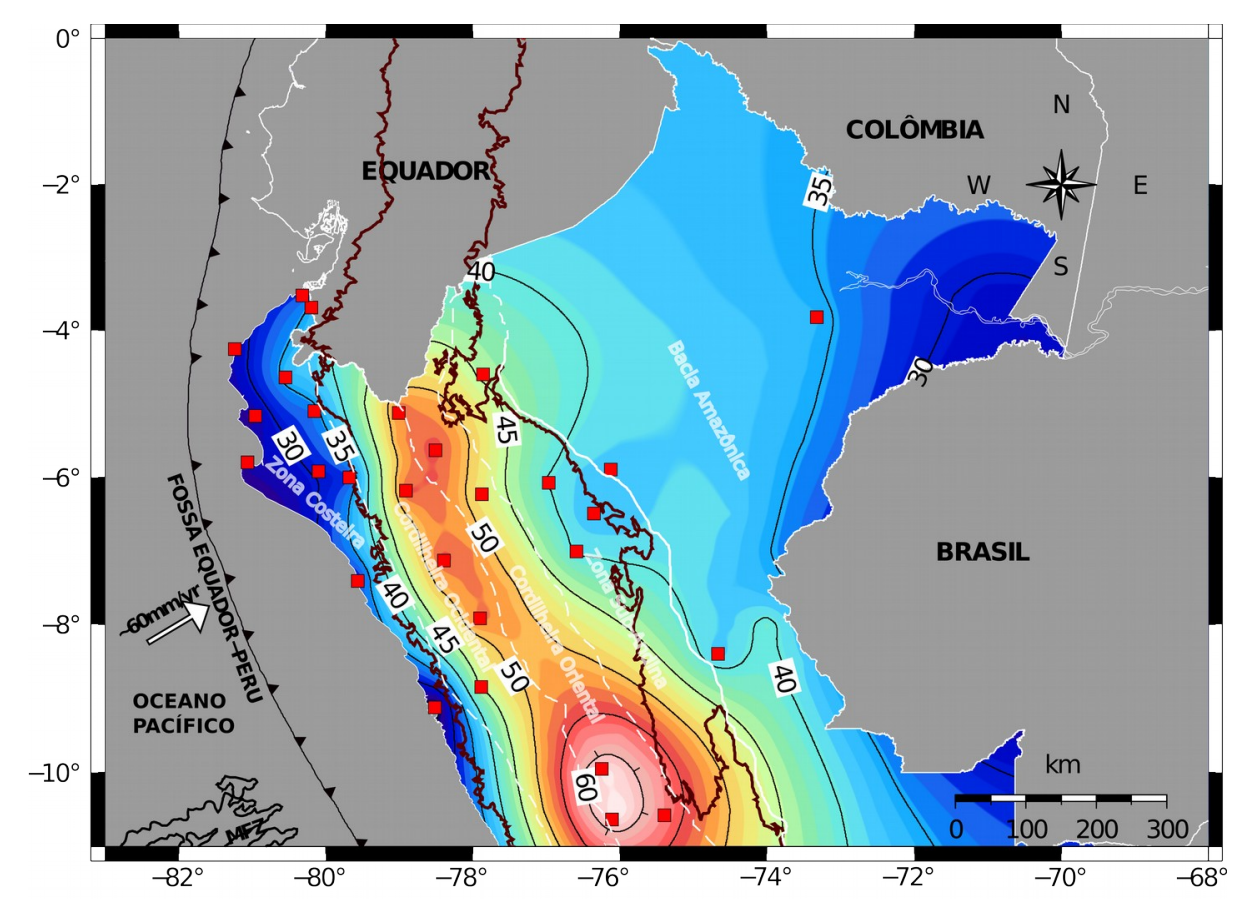

a)
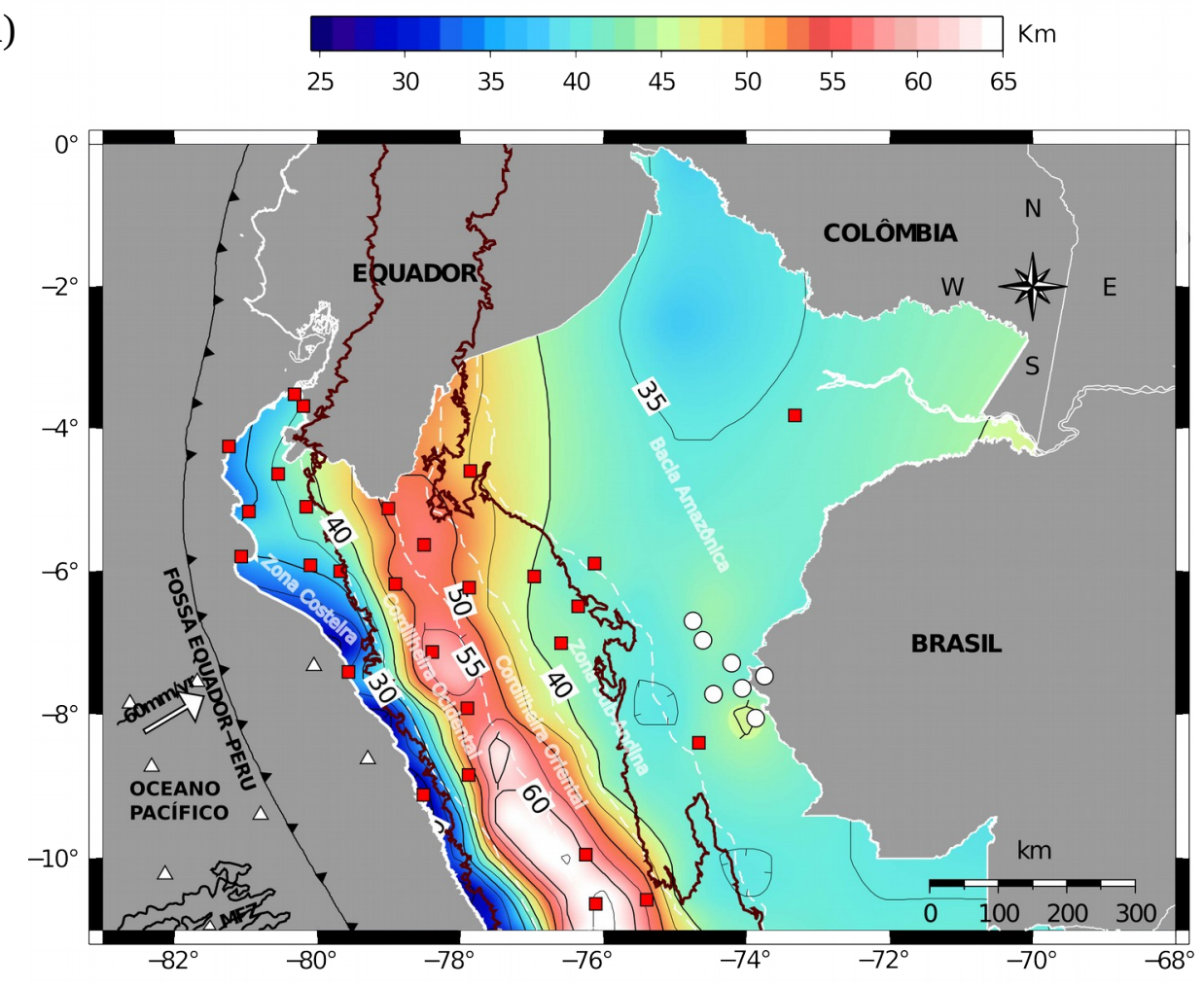

b)

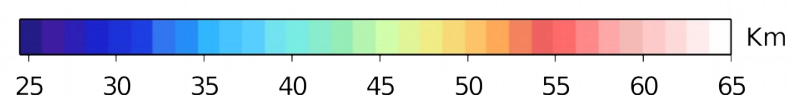

Figura 3.6: Modelos de espessura crustal. a) Modelo A interpolado com dados de RF calculados neste estudo. b) Modelo B interpolado com dados do Modelo A e com dados compilados por Assumpção et al. (2013, 2015). 
O modelo global de espessura crustal CRUST 1.0 (Laske et al., 2013) mostra valores altos que variam de 40 a $45 \mathrm{~km}$ para a região norte e de 45 a $50 \mathrm{~km}$ para região central (Figura 3.7). Na zona da BA, o valor varia de 40 a $45 \mathrm{~km}$.

As estimativas de espessura crustal calculadas a partir do método de RF, neste estudo (Modelo A, Figura 3.6a), indicam que os valores são dez vezes maiores, tanto para a região norte quanto para o centro do Peru em relação ao modelo CRUST 1.0 e 5 km de diferença com o Modelo A (Figura 3.6b) e o modelo de Assumpção et al. (2013, 2015) (Figura 3.5).

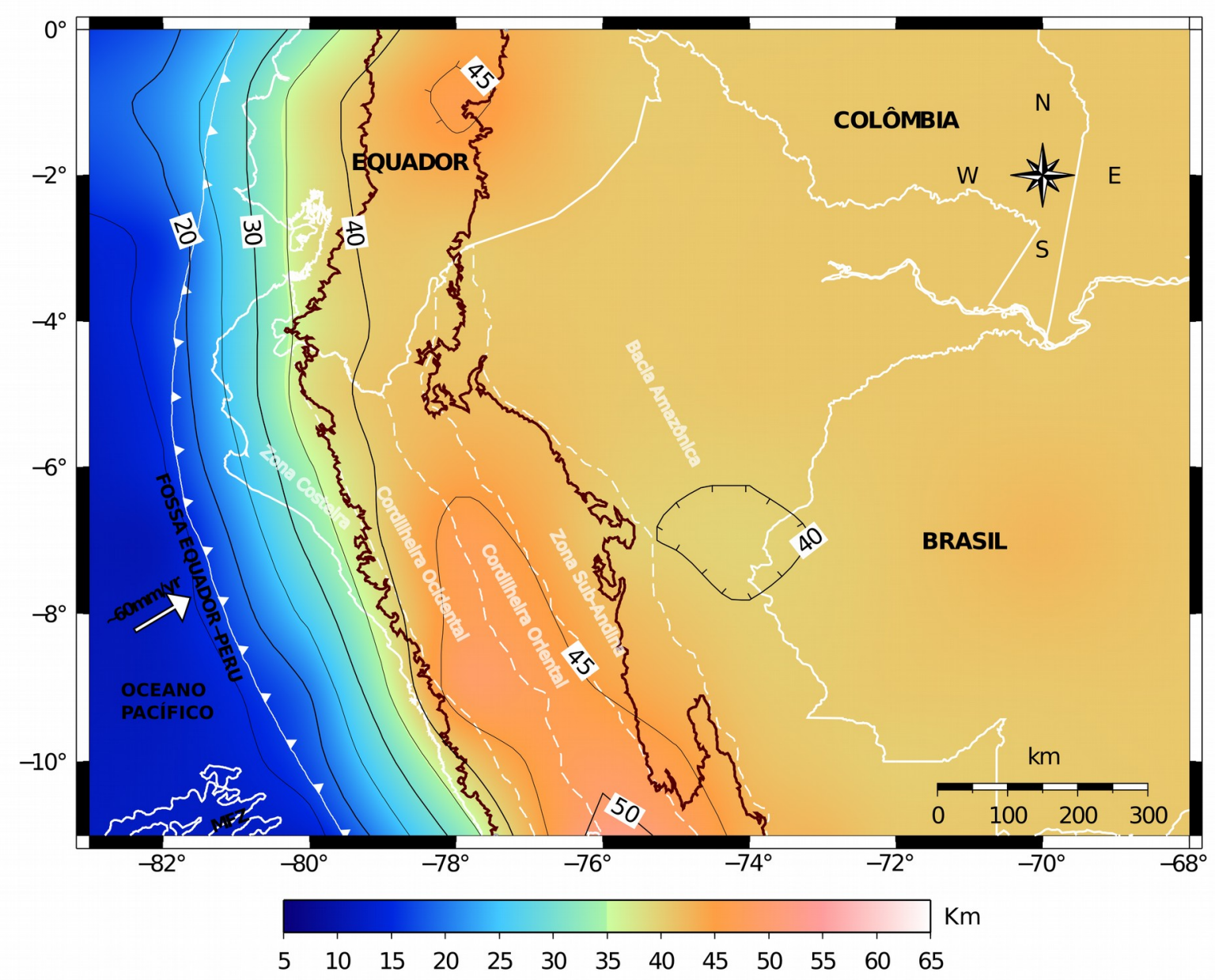

Figura 3.7: Mapa de espessura crustal do modelo CRUST 1.0 (Laske et al., 2013) para a região norte do Peru. 
Recentes estudos de estimativas de espessura crustal com dados de FR (Projeto PULSE) e dados de gravimetria (Tassara e Echaurren, 2012) foram propostos por Bishop et al. (2014) para as regiões centro e sul do Peru (Figura 3.8). Os resultados indicam que os valores altos de espessura crustal sob a CA variam de entre 50 e 60 km para a região central, os quais são coerentes com as estimativas de nosso estudo (Figura 3.6a), e entre 60 e $70 \mathrm{~km}$ para a região sul, observando-se valores máximos sob o Altiplano. A zona de transição onde a placa de Nazca muda a geometria de sub-horizontal para normal é evidenciada por uma diminuição dos valores da espessura crustal que variam de 40 a 50 km (Figura 3.8).

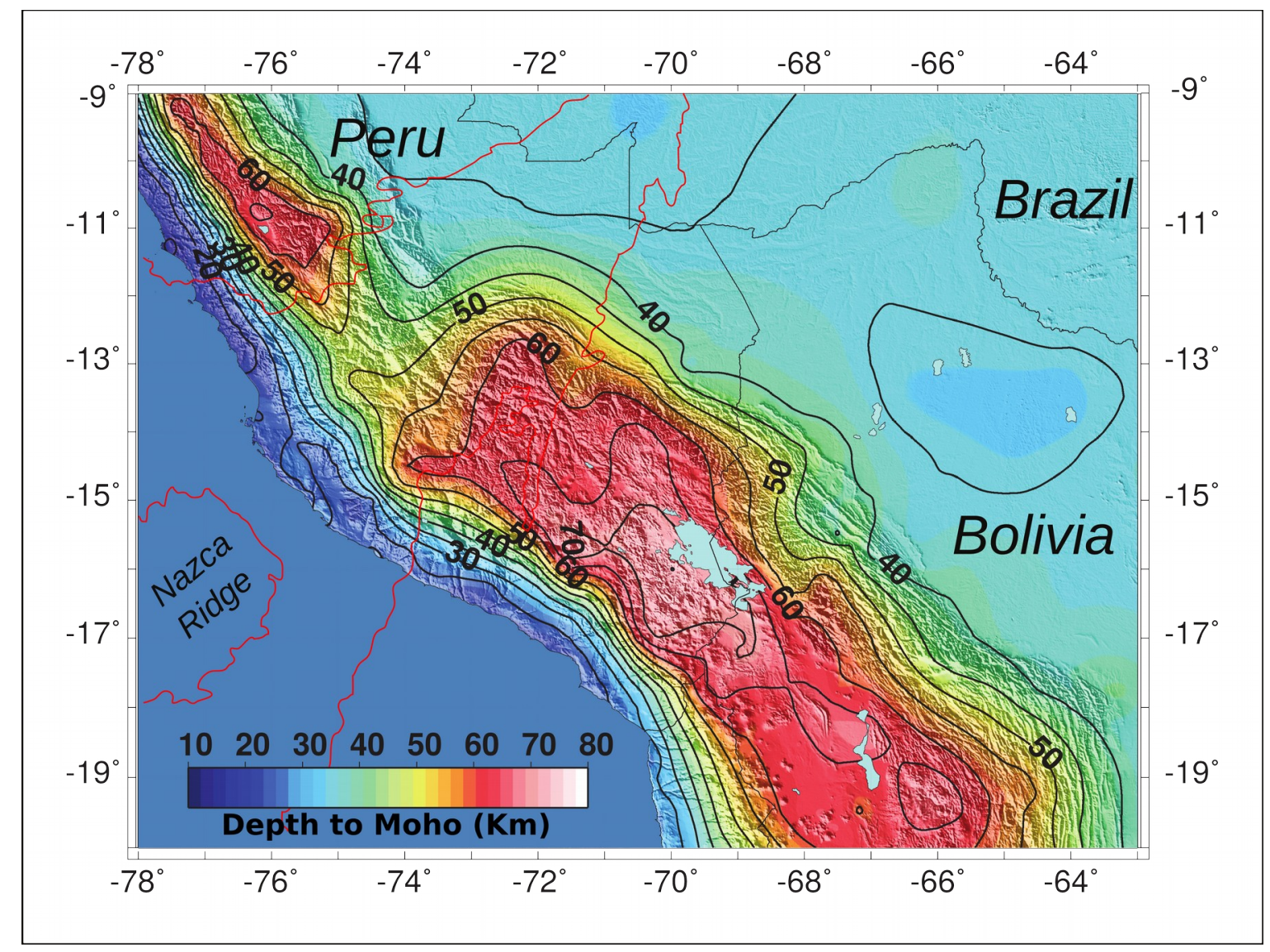

Figura 3.8: Mapa de contorno de espessura crustal para as regiões centro e sul do Peru proposto por Bishop et al. (2014) a partir de estudos de RF e gravimetria.

Em geral, a espessura crustal no território peruano tem variação entre 65 e 70 km na região sul (James, 1971; Phillips et al., 2012; Phillips e Clayton, 2014; Bishop et al., 2014), entre 60 e 65 km na região central (James, 1971; Tavera, 1990; Bishop et al., 2014) e entre 50 e $55 \mathrm{~km}$ no norte do Peru de acordo com os esultados obtidos neste estudo. 


\subsubsection{Geometria da Moho}

Os Andes são um claro exemplo da orogênese continental, que é o resultado do processo de subducção presente na borda Oeste do continente Sul-Americano (Dalmayrac et al. 1987). Atualmente, a dinâmica dos Andes continua ativa pela constante movimentação das placas tectônicas, de maneira que o soerguimento dos Andes se dá a uma razão de velocidade de $\sim 1 \mathrm{~mm} /$ ano de acordo a medição de dados de GPS (Global Position System). Esses processos influenciam diretamente nas características e geometria da espessura da crosta (Figura 3.9).

A descontinuidade de Moho, na região norte do Peru, é uma interface irregular com profundidade que varia localmente entre 20 e $55 \mathrm{~km}$, em contraste com as características tectônicas locais e regionais da topografia da CA (Figura 3.9). A crosta mais espessa na região de estudo distribui-se ao longo da CA, onde as elevações variam de 2.000 a 3.500 metros.

As razões sobre as variações rasas da Moho com referência às regiões Centro e Sul do Peru, provavelmente podem ser devido à influência da deflexão de Huancabamba, onde começa a mudança da orientação da CA com baixa elevação topográfica. Por outro lado, recentes modelos de deformação da margem Norte do Peru propostos por Nocquet et al. (2014) e Villegas (2016) com base em estudos de medições de GPS, sugerem que o acoplamento das placas nesta região é fraco e superficial, o que é evidenciado pela ausência de grandes terremotos e alta elevação topográfica.

Fukao et al. (1989), usando informações de dados de gravimetria, espessura crustal e sismicidade, conclui que a COC encontra-se, aproximadamente, em equilíbrio isostático, mas a COR não. O que indicaria que a formação da COC e a COR atribui-se a processos tectônicos diferentes, associados a idades do Mesozóico Terciário ao COC e COR, do Paleozóico (Cobbing e Pitcher, 1972). 


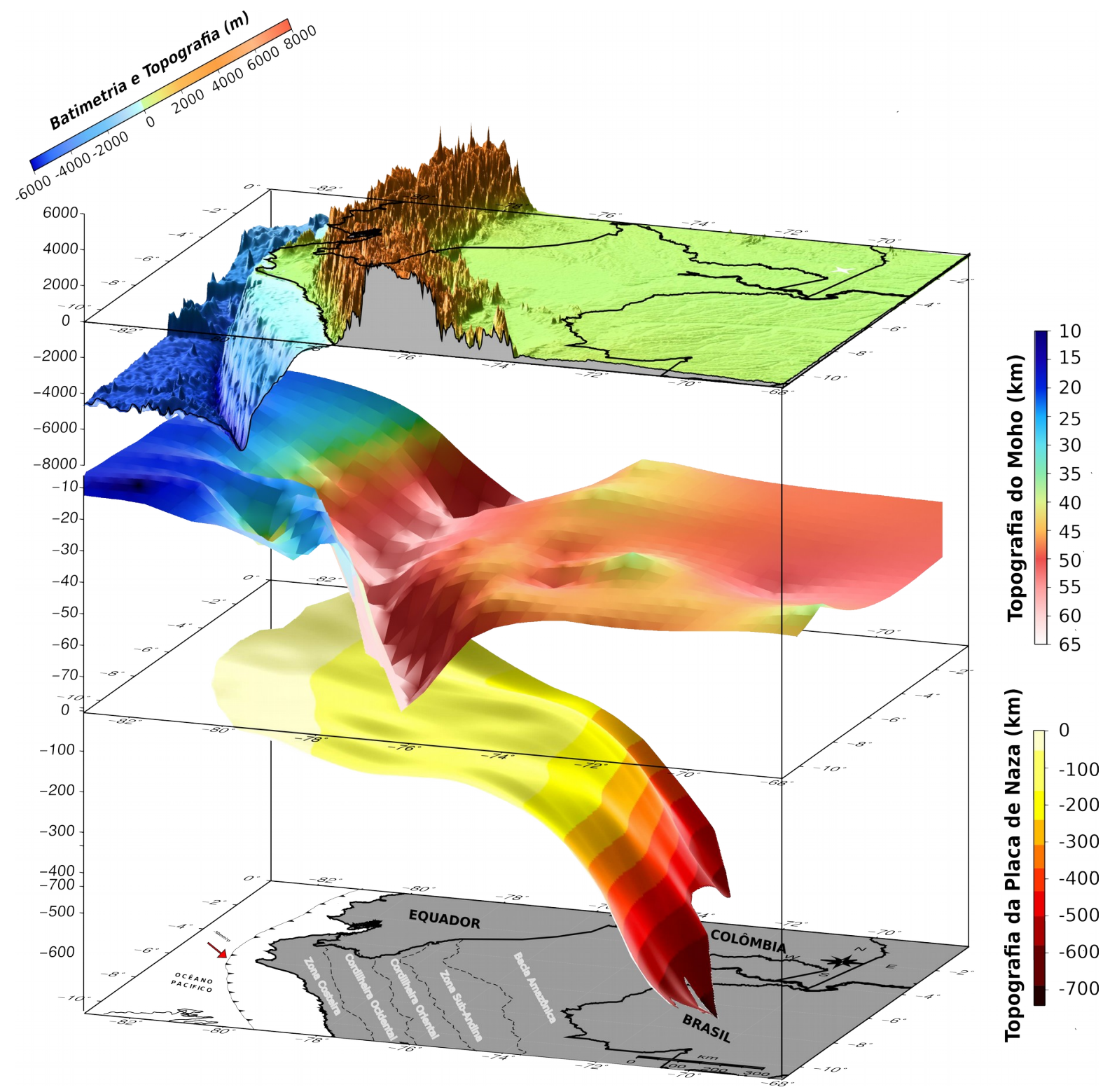

Figura 3.9: Diagrama em 3D mostrando a topografia, espessura crustal e a geometria da placa de Nazca (modelo Slab1.0 Hayes et al. 2012) para a região norte do Peru.

\subsubsection{Função do Receptor na Cordilheira dos Andes}

O maior encurtamento e formação de uma alta topografia na CA iniciou no Mesozóico Terciário como resposta ao processo de subducção das placas litosféricas de Nazca e a SulAmericana (Cobbing e Pitcher, 1972; Dalmayrac et al., 1980, 1987; Cobbing et al., 1981) e o maior espessamento da crosta iniciou-se entre aproximadamente 30 e 40 milhões de anos e 
continua até o presente (Mamani et al., 2010). Em geral, a complexidade tectônica compreende principalmente a presença de variação lateral, mudança na elevação e orientação da CA e interferência da placa oceânica de Nazca.

O estudo da crosta com o método de FR detalhada (arranjo linear de estações), usando diferentes fases de ondas de corpo no Peru, foi aplicado principalmente nas regiões centrais por Bishop et al. (2014) e sul, por Phillips et al. (2012) e Phillips e Clayton (2014). Esses resultados permitiram caracterizar as variações locais de espessura crustal, a descontinuidade intermediária (Conrad), geometria da placa de Nazca e propriedades relacionadas com as zonas de baixa velocidade e anisotropia sísmica na crosta-manto.

Neste estudo, estimamos a espessura crustal utilizando uma rede de estações bem espalhadas e com informação somente de onda P. As respostas da FR para as estações na CA mostram, principalmente, caraterísticas particulares refletindo a complexidade da tectônica da área. Para a análise, utilizamos a resposta da FR na componente radial, que pode mostrar conversões na Moho, em estruturas de baixa velocidade, em descontinuidades intermediárias e até em anisotropias sísmicas.

As FRs obtidas embaixo da COC nas estações sismográficas HYL, ATH e PCH (Figura 3.10), na região norte do Peru, sugerem a presença de heterogeneidades na crosta intermediária e superior, associadas com bacias sedimentares em superfície e com zonas de baixa velocidade entre 20 e $30 \mathrm{~km}$ aproximadamente, que apresentam fortes conversões negativas entre 1 e 5 s nas FRs, como também na superfície da Moho, observadas geralmente nas estações localizadas na CA. 

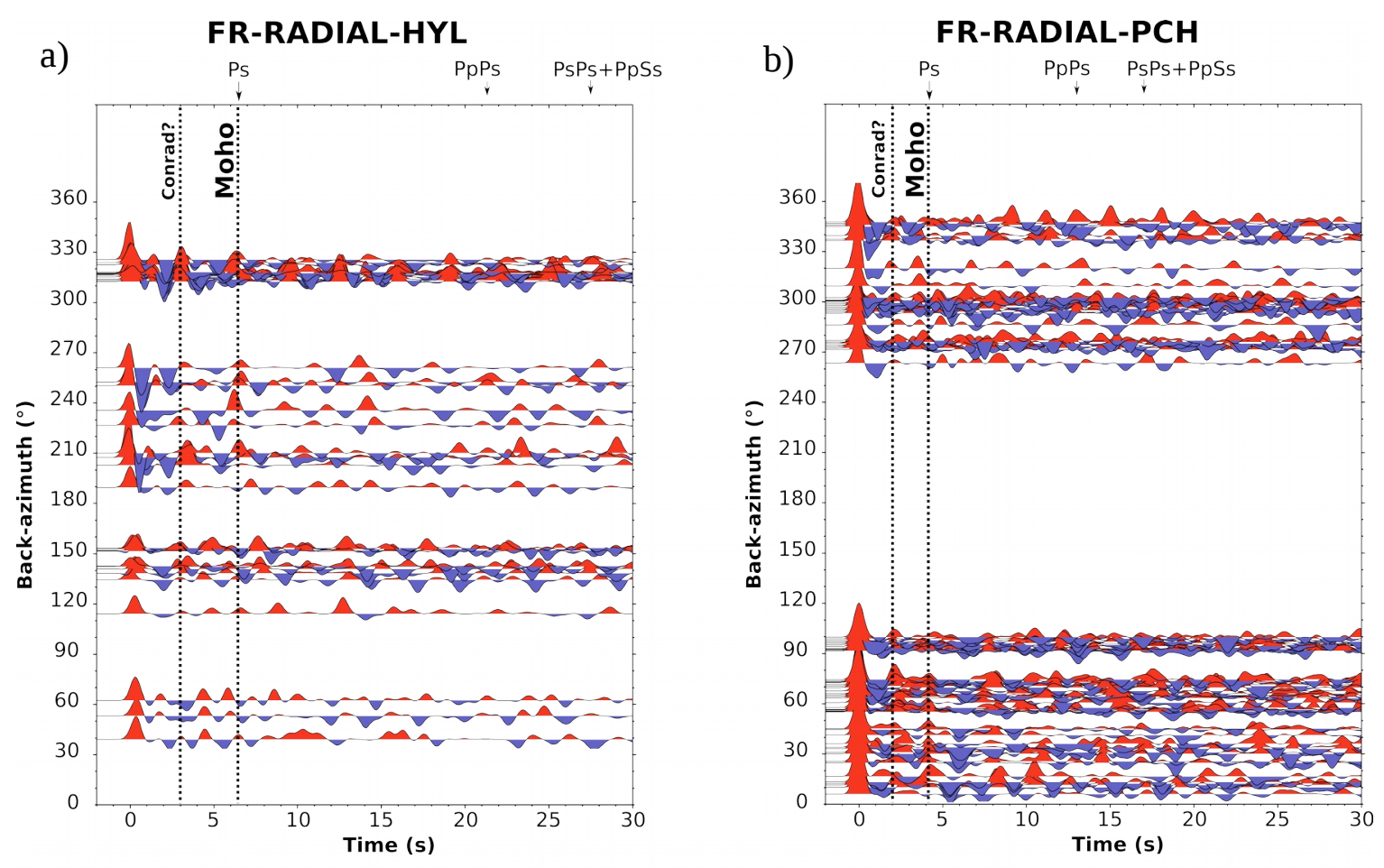

FR-RADIAL-ATH

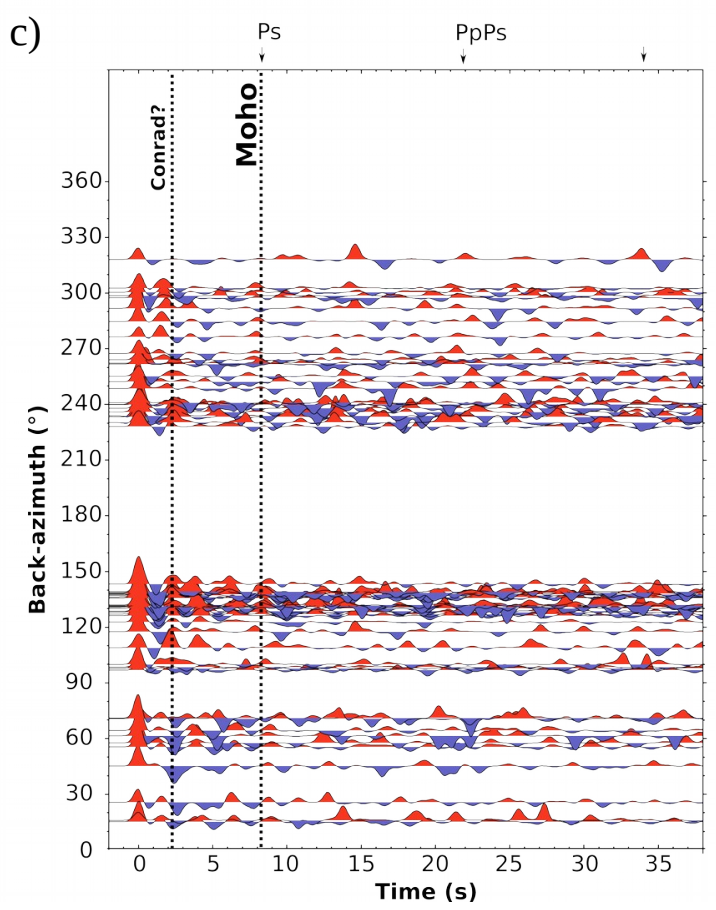

Figura 3.10: Traços de Função do Receptor gerados pela técnica de deconvolução iterativa no domínio do tempo com dados das estações: a) YLS (Huaylas), b) PCH (Portachuelo) e c) ATH (Atahuallpa). Todas estão localizadas na Cordilheira dos Andes. 
A Figura 3.10 mostra que a fase Ps possui um tempo de chegada variável, entre 4 e $8 \mathrm{~s}$ após a fase P. A chegada das fases apresenta uma variação em relação ao azimute e caraterísticas similares são observados nas estações TICA, CHA e SIG (Anexo C), especialmente na COR e COC. As FRs mostram, também, uma fase negativa e uma positiva depois da onda P direta, que provavelmente representam a camada de baixa velocidade na crosta, associadas a estruturas sedimentares. Por outro lado, observam-se conversões entre 2 e 3 s em todas as direções azimutais, indicando uma estrutura na crosta intermediária (Descontinuidade de Conrad), aproximadamente entre 20 a $25 \mathrm{~km}$ de profundidade.

As estações PCH e ATH mostram mudanças abruptas nas polaridades dos refratores com relação aos back-azimuths entre $300^{\circ}$ e $348^{\circ}$, o que, provavelmente, podem indicar a presença de anisotropia sísmica na crosta intermediária (Ozacar e Zandt, 2004; SchultePelkum et al., 2005). Para uma melhor análise da anisotropia crustal, sugere-se analisar a FR na componente tangencial ou aplicar outros métodos usando ondas S (Shear wave splitting) (Crampin e Lovell, 1991; Musumeci et al., 2005; Vecsey et al., 2007).

\subsubsection{Modelo de subducção e espessura crustal}

A aplicação da técnica de Common Conversion Point Stacking (CCPS -Dueker e Sheehan, 1997), a qual é utilizada para imagear a crosta e o manto superior a partir de perfis de FR, pode permitir caracterizar, detalhadamente, as descontinuidades rasas e a geometria da Placa de Nazca e zonas de baixa velocidade (ZBV) na interface crosta-manto. Por exemplo, a ZBV foi evidenciada em diversas zonas de subducção, tais como na borda ocidental do continente sul-americano (Yuan et al., 2000; Sodoudi et al., 2011; Poveda et al., 2015) e em outras regiões de subducção (Bostock, 2013).

Infelizmente não foi possível aplicar o método CCPS neste estudo, devido ao nível de ruido dos dados, configuração linear de estações. No entanto, a Figura 3.11 mostra uma secção de FR com parâmetro de raio de referência $p=0.07 \mathrm{~s} / \mathrm{km}$ para cada estação localizada ao longo do perfil topográfico A-A' da Figura 3.1a. Os tempos das fases Ps indicam a geometria da Moho (linha verde). A tendência da subducção da placa de Nazca (linha tracejada azul) é aproximada usando a distribuição espacial da sismicidade em profundidade. 
Além disso, as estruturas tectônicas mostram uma boa correlação com a sismicidade da região.

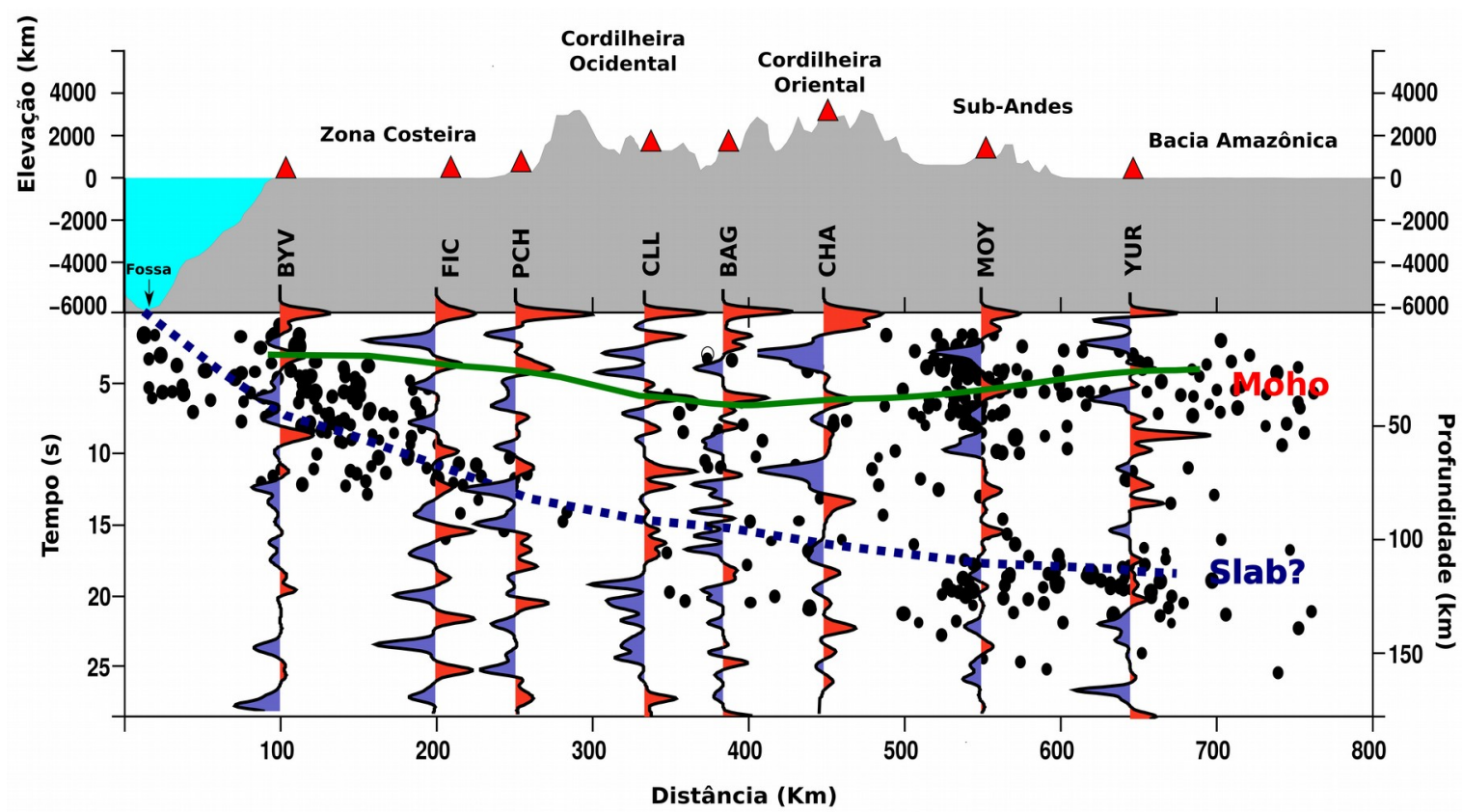

Figura 3.11: Secção de FR para cada estação ao longo do perfil A-A' (Figura 3.1a) em que os pontos pretos apresentam os epicentros da sismicidade do catálogo sísmico do IGP (19602016). As fases Ps estão marcadas com linha verde e a linha tracejada azul apresenta os traços aproximados da placa de Nazca de acordo com a distribuição da sismicidade em profundidade.

A Figura 3.12a, mostra um modelo de subducção para a região norte do Peru, a partir das estimativas de espessura da crosta obtidas neste estudo e o modelo Slab1.0 (Hayes et al., 2012). Em geral, a crosta apresenta uma espessura média de $50 \mathrm{~km}$ sob os Andes, com valores de razão de $\mathrm{Vp} / \mathrm{Vs}$ altos sob esta região e baixos nos flancos extremos. A dinâmica ativa do processo de subducção é evidenciada pela constante ocorrência de sismicidade com diferentes focos associados a fontes sismogênicas: (1) fricção das placas, (2) deformação interna da placa de Nazca e (3) deformação da Cordilheira dos Andes (Figura 3.12b). 

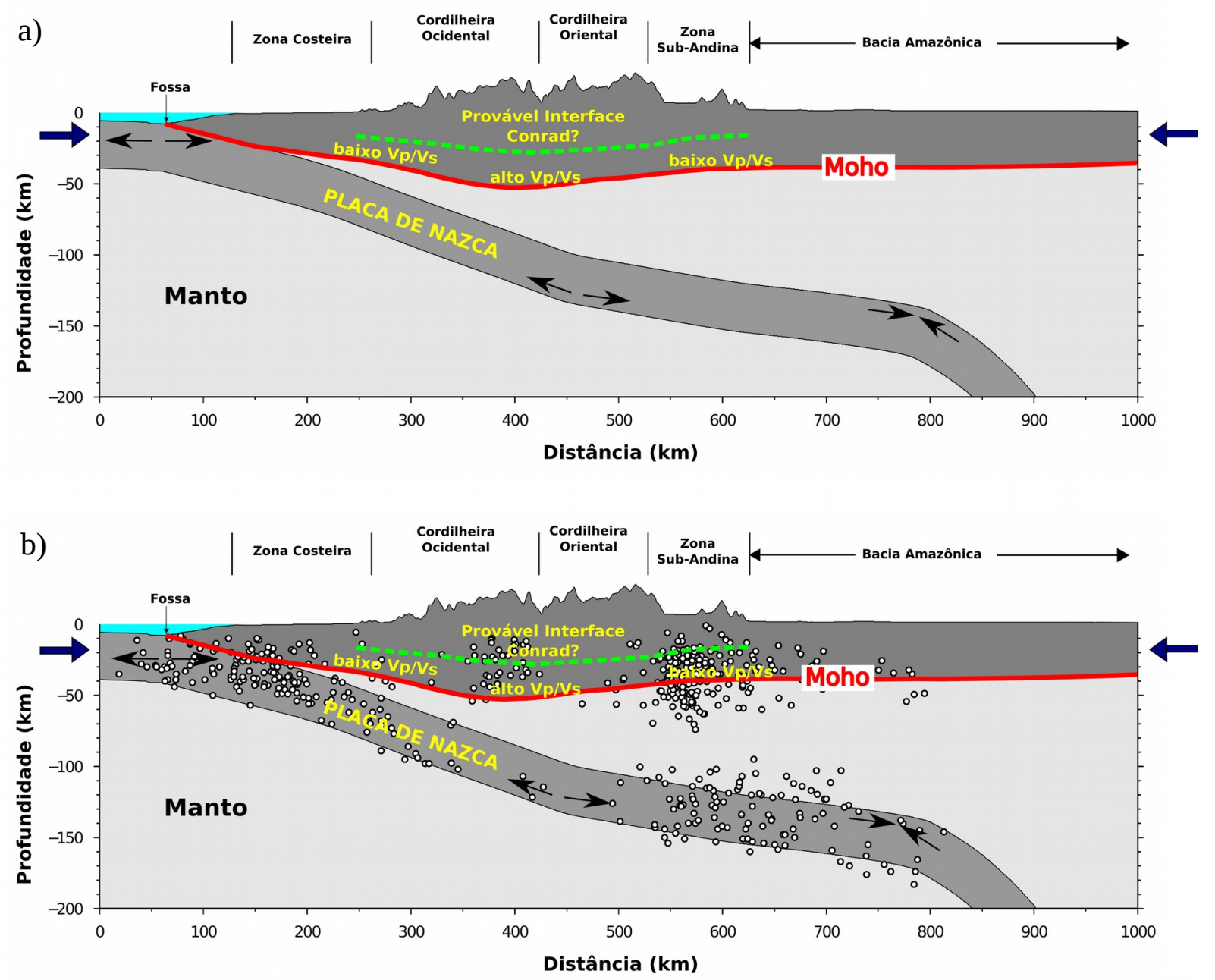

Figura 3.12: a) Modelo de subduç̧ão proposto a partir dos resultados das estimativas de espessura crustal e o modelo Slab1.0 (Hayes et al., 2012). b) Correlação com a sismicidade local e regional. Os pontos brancos representam os epicentros da sismicidade com magnitudes 5,0 Mw do catálogo sísmico do IGP (1960-2016).

Constata-se uma concentração de sismos crustais logo abaixo da SA, com focos distribuídos entre 20 e $35 \mathrm{~km}$. Esse fato pode estar correlacionado com fatores como diferenças composicionais entre a CA e a BA (contraste entre valores de $\mathrm{Vp} / \mathrm{Vs}$ ), a mudança abrupta nas espessuras crustais e pela concentração dos esforços causados pela maior deformação da CA na Deflexão de Huancabamba. 


\subsection{Conclusões}

As estimativas de espessura crustal na região norte do Peru, obtidas por meio da Função do Receptor de registros que procedem de 28 estações sismográficas, indicam uma relação com as estruturas tectônicas. No entanto, essas estimativas podem ser afetadas por incertezas das informações inicias (velocidade média da onda P na crosta). Com base no comportamento da crosta, é possível concluir que:

- A Zona Costeira possui espessura crustal variando de 25 a $35 \mathrm{~km}$ e Vp/Vs média de 1,72, o que indica uma composição félsica.

- Na Cordilheira Ocidental, a crosta tem espessura entre 45 e 55 km e Vp/Vs média de 1,78. Devido a sua reduzida dimensão ao longo da costa e mudança abrupta na elevação topográfica, a Moho mergulha para E-W, chegando a profundidades de até 60 km perto da região central do Peru.

- Na Cordilheira Oriental, a espessura crustal é de aproximadamente $50 \mathrm{~km}$ e apresenta uma diminuição no limite Sub-Andes. A razão Vp/Vs média é de 1,83, indicando rochas com composição máfica.

- A Zona Sub-Andina tem espessura variando entre 35 e $45 \mathrm{~km}$ e Vp/Vs média de 1,75, o que indica rochas com composição félsica.

- A Bacia Amazônica apresenta valores de espessura crustal aproximadamente constantes, de $\sim 35 \mathrm{~km}$ e Vp/Vs média de 1,76.

- Na região norte, as espessuras encontradas para os Andes são maiores do que no modelo de Assumpção et al. (2013, 2015), esse deve ao fato que nossos resultados são inéditos e não usada até então para a estimativa crustais. Assim o trabalho contribui de forma efetiva para a região ausente de informação.

- As espessuras crustais e a resposta gravimétrica mostram correlação nos Andes e nos flancos, indicando provável equilíbrio isostático, como o descrito por Assumpção et al. (2013). 
- Fortes conversões são observadas entre 2 e 3 s nas estações localizadas na CA, as quais podem estar relacionadas à descontinuidade intermediária (Conrad), entre 20 e $30 \mathrm{~km}$.

- Foram observados valores negativos depois da fase P direta entre 1 e 1,5 s nas estações localizadas na ZC, ZS e BA, que provavelmente seja influença da camada sedimentar.

- O valor médio de Vp/Vs foi 1,75 \pm 0,02 para o norte do Peru, coerente com o obtido por Bishop et al. (2014) para a região central do Peru (Vp/Vs 1,75 $\pm 0,01)$, indicando um comportamento crustal similar.

- Os valores de razão $\mathrm{Vp} / \mathrm{Vs}$ indicam correlação com a espessura crustal e valores de Fluxo de Calor Geotérmico, indicando provavelmente maior conteúdo félsico nos flancos na Cordilheira dos Andes e maior conteúdo máfico sob a CA. Esses valores, em termos da razão de Poisson (0,25 e 0,26), mostram relação com a crosta de idades de Cenozóicas a Mesozóicas (Zandt e Ammon, 1995).

- Os valores altos de Vp/Vs na Cordilheira dos Andes podem estar associados a regiões com anisotropia sísmica ou zonas com fraturamento na crosta inferior.

- A mudança de orientação da Cordilheira dos Andes, baixa elevação topográfica e subducção de tipo sub-horizontal são, provavelmente, as causas dos valores baixos de espessura da crosta na área de estudo em comparação às regiões centro e sul do Peru.

A partir dos resultados obtidos e pela relevância desses resultados, esta dissertação apresenta importante contribuição ao estudo da estrutura da crosta na região norte do Peru. Dessa forma, espera-se que os novos dados de espessura crustal, apresentados neste trabalho, melhorem os modelos na região norte do Peru e o banco de dados da região.

É importante a aplicação de novas técnicas, como a tomografia sísmica, a inversão conjunta das curvas de dispersão de ondas de superfície e Função do Receptor, que são utilizadas para gerar modelos com a variação de velocidade das ondas sísmicas de acordo com a profundidade. Essas técnicas, quando utilizadas em conjunto, podem ajudar interpretar melhor os resultados deste estudo. 


\subsection{Referências}

Assumpção, M., Bianchi, M., Albuquerque, D.F., França, G.S.L.A., Barros, L., 2015. Crustal Thickness Map in South America: an updated version. Extend Abstract 1st Brazilian Symposium on Seismology 1-4.

Assumpção, M., Feng, M., Tassara, A., Julià, J., 2013. Models of crustal thickness for South America from seismic refraction, receiver functions and surface wave tomography. Tectonophysics 609, 82-96. doi:10.1016/j.tecto.2012.11.014.

Barazangi, M., Isacks, B.L., 1976. Spatial distribution of earthquakes and subduction of the Nazca plate beneath South America. Geology 4, 686. doi:10.1130/00917613(1976)4<686:SDOEAS>2.0.CO;2.

Bassin, C., Laske, G., Masters, G., 2000. The Current Limits of Resolution for Surface Wave Tomography in North America. EOS Trans AGU 81, 897.

Bishop, B., Beck, S., Zandt, G., Scire, A., Wagner, L., Long, M., Tavera, H., 2014. Trench to andean Thrust Front: Evidence for Coupling of the Peruvian Flat Slab to the Over-riding South American Plate. American Geophysical Union, Fall Meeting 2014, abstract \#T23A-4629 2014AGUFM.

Bostock, M.G., 2013. The Moho in subduction zones. Tectonophysics 609, 547-557. doi:10.1016/j.tecto.2012.07.007.

Cahill, T., Isacks, B.L., 1992. Seismicity and shape of the subducted Nazca Plate. Journal of Geophysical Research 97, 17503. doi:10.1029/92JB00493.

Cardoso, R.R., Hamza, V.M., Alfaro, C., 2010. Geothermal resource base for South America: A continental perspective. Proceedings World Geothermal Congress 2010, Bali, Indonesia, 25-29 April 2010, 6 pp.

Chatterjee, S.N., Pitt, A.M., Iyer, H.M., 1985. Vp/Vs ratios in the Yellowstone National Park region, Wyoming. Journal of Volcanology and Geothermal Research 26, 213-230. doi:10.1016/0377-0273(85)90057-5.

Christensen, N.I., 1996. Poisson's ratio and crustal seismology. Journal of Geophysical Research 101, 3139. doi:10.1029/95JB03446.

Chulick, G.S., Detweiler, S., Mooney, W.D., 2013. Seismic structure of the crust and uppermost mantle of South America and surrounding oceanic basins. Journal of South American Earth Sciences 42, 260-276. doi:10.1016/j.jsames.2012.06.002.

Cobbing, E.J., Pitcher, W.S., 1972. Plate Tectonics and the Peruvian Andes. Nature Physical Science 240, 51-53. doi:10.1038/physci240051a0.

Cobbing, E.J., Pitcher, W.S., Wilson, J.J., Baldock, J.W., Taylor, W.P., McCourt, W.J., and Snelling, N.J., 1981. The geology of the western Cordillera of Northern Peru. Overseas 
Memoir of the Institute of Geological Sciences London 5, 143.

Crampin, S., Lovell, J.H., 1991. A decade of shear-wave splitting in the Earth's crust: what does it mean? what use can we make of it? and what should we do next? Geophysical Journal International 107, 387-407. doi:10.1111/j.1365-246X.1991.tb01401.x.

Dalmayrac, B., Laubacher, G., R., M., 1987. Caracteres generaux de l'evolution geologique des Andes peruviannes. ORDTOM 122-501.

Dalmayrac, B., Laubacher, G., R., M., 1980. Geologie des Andes peruviannes, Caracteres generaux de l'evolution geologique des Andes peruviennes. ORDTOM 96-217.

Dueker, K.G., Sheehan, A.F., 1997. Mantle discontinuity structure from midpoint stacks of converted P to S waves across the Yellowstone hotspot track. Journal of Geophysical Research: Solid Earth 102, 8313-8327. doi:10.1029/96JB03857.

França, G.S.L.A., 2003. Estrutura da crosta no Sudeste e Centro-Oeste do Brasil, usando função do receptor. Tese de Douturado, 126 pp. Universidade de São Paulo.

Fukao, Y., Kono, M., Yamamoto, A., Saito, M., Nawa, K., Giesecke, A., Perales, P., 1999. Gravity Measurements and Data Reduction for Bouguer Anomaly Map of Peru. Bull. Earthq. Res. Inst. Univ.Tokyo 74, 161-266.

Fukao, Y., Yamamoto, A., Kono, M., 1989. Gravity anomaly across the Peruvian Andes. Journal of Geophysical Research 94, 3867. doi:10.1029/JB094iB04p03867.

Gutscher, M.-A., 2003. Thermal models of flat subduction and the rupture zone of great subduction earthquakes. Journal of Geophysical Research 108, 2009. doi:10.1029/2001JB000787.

Gutscher, M.A., Olivet, J.-L., Aslanian, D., Eissen, J.-P., Maury, R., 1999. The "lost Inca Plateau”: cause of flat subduction beneath Peru? Eart planet. Sci. Lett. 171, 335-341.

Hampel, A., 2002. The migration history of the Nazca Ridge along the Peruvian active margin: a re-evaluation. Earth and Planetary Science Letters 203, 665-679. doi:10.1016/S0012-821X(02)00859-2.

Hasegawa, A., Sacks, I.S., 1981. Subduction of the Nazca Plate beneath Peru as determined from seismic observations. Journal of Geophysical Research: Solid Earth 86, 4971-4980. doi:10.1029/JB086iB06p04971.

Hayes, G.P., Wald, D.J., Johnson, R.L., 2012. Slab1.0: A three-dimensional model of global subduction zone geometries. Journal of Geophysical Research 117, B01302. doi:10.1029/2011JB008524.

James, D.E., 1971. Andean crustal and upper mantle structure. Journal of Geophysical Research 76, 3246-3271. doi:10.1029/JB076i014p03246. 
Laske, G., Masters, G., Ma, Z., Pasyanos, M., 2013. Update on CRUST1.0 - A 1-degree Global Model of Earth’s Crust. Geophys. Res. Abstracts, 15, Abstract EGU2013-2658.

Mamani, M., Worner, G., Sempere, T., 2010. Geochemical variations in igneous rocks of the Central Andean orocline (13 S to $18 \mathrm{~S}$ ): Tracing crustal thickening and magma generation through time and space. Geological Society of America Bulletin 122, 162182. doi:10.1130/B26538.1.

Mooney, W.D., Laske, G., Masters, T.G., 1998. CRUST 5.1: A global crustal model at $5^{\circ} \times 5^{\circ}$. Journal of Geophysical Research: Solid Earth 103, 727-747. doi:10.1029/97JB02122.

Musumeci, C., Patane, D., Scarfi, L., Gresta, S., 2005. Stress Directions and Shear-Wave Anisotropy: Observations from Local Earthquakes in Southeastern Sicily, Italy. Bulletin of the Seismological Society of America 95, 1359-1374. doi:10.1785/0120040108.

Nakajima, J., Matsuzawa, T., Hasegawa, A., Zhao, D., 2001. Three-dimensional structure of V $\mathrm{p}, \mathrm{V} \mathrm{s}$, and V p / V s beneath northeastern Japan: Implications for arc magmatism and fluids. Journal of Geophysical Research: Solid Earth 106, 21843-21857. doi:10.1029/2000JB000008.

Nocquet, J.-M., Villegas-Lanza, J.C., Chlieh, M., Mothes, P.A., Rolandone, F., Jarrin, P., Cisneros, D., Alvarado, A., Audin, L., Bondoux, F., Martin, X., Font, Y., Régnier, M., Vallée, M., Tran, T., Beauval, C., Maguiña Mendoza, J.M., Martinez, W., Tavera, H., Yepes, H., 2014. Motion of continental slivers and creeping subduction in the northern Andes. Nature Geoscience 7, 287-291. doi:10.1038/ngeo2099.

Ozacar, A.A., Zandt, G., 2004. Crustal seismic anisotropy in central Tibet: Implications for deformational style and flow in the crust. Geophysical Research Letters 31, n/a-n/a. doi:10.1029/2004GL021096.

Phillips, K., Clayton, R.W., 2014. Structure of the subduction transition region from seismic array data in southern Peru. Geophysical Journal International 196, 1889-1905. doi:10.1093/gji/ggt504.

Phillips, K., Clayton, R.W., Davis, P., Tavera, H., Guy, R., Skinner, S., Stubailo, I., Audin, L., Aguilar, V., 2012. Structure of the subduction system in southern Peru from seismic array data. Journal of Geophysical Research 117, B11306. doi:10.1029/2012JB009540.

Poveda, E., Monsalve, G., Vargas, C.A., 2015. Receiver functions and crustal structure of the northwestern Andean region, Colombia. Journal of Geophysical Research: Solid Earth 120, 2408-2425. doi:10.1002/2014JB011304.

Reguzzoni, M., Sampietro, D., 2015. GEMMA: An Earth crustal model based on GOCE satellite data. International Journal of Applied Earth Observation and Geoinformation 35, 31-43. doi:10.1016/j.jag.2014.04.002.

Reguzzoni, M., Sampietro, D., Sanso, F., 2013. Global Moho from the combination of the 
CRUST2.0 model and GOCE data. Geophysical Journal International 195, 222-237. doi:10.1093/gji/ggt247.

Reyes, L., Caldas, J., 1987. Geología de los Cuadrángulos de Las Playas, La Tina, Las lomas y otros. INGEMMET, Bol. N 39 Serie “A”, Lima.

Rosenbaum, G., Giles, D., Saxon, M., Betts, P.G., Weinberg, R.F., Duboz, C., 2005. Subduction of the Nazca Ridge and the Inca Plateau: Insights into the formation of ore deposits in Peru. Earth and Planetary Science Letters 239, 18-32. doi:10.1016/j.epsl.2005.08.003.

Schulte-Pelkum, V., Monsalve, G., Sheehan, A., Pandey, M.R., Sapkota, S., Bilham, R., Wu, F., 2005. Imaging the Indian subcontinent beneath the Himalaya. Nature 435, 12221225. doi:10.1038/nature03678.

Sodoudi, F., Yuan, X., Asch, G., Kind, R., 2011. High-resolution image of the geometry and thickness of the subducting Nazca lithosphere beneath northern Chile. Journal of Geophysical Research 116, B04302. doi:10.1029/2010JB007829.

Soller, D.R., Ray, R.D., Brown, R.D., 1982. A new global crustal thickness map. Tectonics 1, 125-149. doi:10.1029/TC001i002p00125.

Tassara, A., Echaurren, A., 2012. Anatomy of the Andean subduction zone: three dimensional density model upgraded and compared against global-scale models. Geophysical Journal International 189, 161-168.

Tavera, H., 1990. Interpretación de las Anomalías de Estación a partir de fases P y PKIKP para la región del Perú Central. Boletín Sociedad Geológica del Perú 81, 47-54.

Vargas, V., Cruz, V., 2010. Geothermal Map of Perú, in: Proceedings World Geothermal Congress 2010. Bali, Indonesia, p. 7.

Vecsey, L., Plomerova, J., Kozlovkaya, E., Babuska, V., 2007. Shear wave splitting as a diagnostic of variable anisotropic structure of the upper mantle beneath central 36Fennoscandia. Tectonophysics 438 (1-4), 21 pp.

Villegas, J.C., 2016. The, Earthquake cycle and continental deformation along Zone, Peruvian subduction. These de Docteur en Sciences. Unv. Nice-Sophia Antipolis. 48-95.

Wagner, L.S., Anderson, M.L., Jackson, J.M., Beck, S.L., Zandt, G., 2008. Seismic evidence for orthopyroxene enrichment in the continental lithosphere. Geology 36, 935. doi:10.1130/G25108A.1.

Wang, X.-Q., Schubnel, A., Fortin, J., David, E.C., Guéguen, Y., Ge, H.-K., 2012. High Vp/Vs ratio: Saturated cracks or anisotropy effects? Geophysical Research Letters 39, n/a-n/a. doi:10.1029/2012GL051742.

Wilson, J., 1984. Geología de los Cuandrángulos de Jayanca, Incahuasi, Cutervo, Chiclayo, 
Chongoyape, Chota, Celendin, Pacasmayo y Chepén. Bol. Nº 38 Serie A Carta Geol. Nac. INGEMMET.

Yuan, X., Sobolev, S. V., Kind, R., Oncken, O., Bock, G., Asch, G., Schurr, B., Graeber, F., Rudloff, A., Hanka, W., Wylegalla, K., Tibi, R., Haberland, C., Rietbrock, A., Giese, P., Wigger, P., Röwer, P., Zandt, G., Beck, S., Wallace, T., Pardo, M., Comte, D., 2000. Subduction and collision processes in the Central Andes constrained by converted seismic phases. Nature 408, 958-961. doi:10.1038/35050073.

Zandt, G., Ammon, C., 1995. Continental crust composition constrained by mea-surements of crustal Poisson’s ratio. Nature 374, 152-154. 


\section{Anexo A}

Coordenadas e período de operatividade das estações sismográficas utilizadas neste estudo.

Tabela A.1: Coordenadas das estações sismográficas. SN refere-se as estações pertencentes ao projeto SisNort. CTBTO corresponde a rede mundial (Comprehensive Nuclear-Test-Ban Treaty Organization). RSN refere-se as estações pertencentes ao Rede Sismográfica Nacional do Instituto Geofísico do Peru.

\begin{tabular}{|c|c|c|c|c|c|c|c|}
\hline$N$ & Sta & Net. & Longitude & Latitude & Altitud & Sensor & Nome \\
\hline$\overline{01}$ & $P C M$ & $S N$ & -79.565 & -7.407 & 37 & $G 40 T$ & Pacasmayo \\
\hline 02 & $C L B$ & $S N$ & -81.236 & -4.253 & 4 & G40T & Cabo Blanco \\
\hline 03 & $M T P$ & $S N$ & -80.194 & -3.683 & 80 & G40T & Mata Palo \\
\hline 04 & $L C N$ & $S N$ & -80.549 & -4.641 & 145 & $G 40 T$ & Lancones \\
\hline 05 & CHL & $S N$ & -80.158 & -5.095 & 165 & G40T & Chulucanas \\
\hline 06 & $F I C$ & $S N$ & -80.097 & -5.918 & 78 & G40T & Ficuar \\
\hline 07 & $C L L$ & $S N$ & -78.910 & -6.184 & 1578 & $G 40 T$ & Callyuc \\
\hline 08 & $S I G$ & $S N$ & -79.012 & -5.125 & 1818 & G40T & San Ignacio \\
\hline 09 & $B A G$ & $S N$ & -78.508 & -5.636 & 747 & $G 40 T$ & Bagua \\
\hline 10 & $M O Y$ & $S N$ & -76.970 & -6.075 & 959 & G40T & Moyobamba \\
\hline 11 & $B L V$ & $S N$ & -76.592 & -7.006 & 330 & $G 40 T$ & Bellavista \\
\hline 12 & $B Y V$ & $S N$ & -81.065 & -5.7989 & 170 & $G 40 T$ & Bayovar \\
\hline 13 & $A T H$ & СТВТО & -78.395 & -7.135 & 3151 & $G S$ & Atahuallpa \\
\hline 14 & $T B M$ & $R S N$ & -80.322 & -3.523 & 24 & $T 40$ & Tumbes \\
\hline 15 & $Y R M$ & $R S N$ & -76.129 & -5.897 & 149 & $T 40$ & Yurimaguas \\
\hline 16 & $\mathrm{CHO}$ & $R S N$ & -80.962 & -5.167 & 221 & $T 40$ & Chocan \\
\hline 17 & $N I E V$ & $R S N$ & -77.866 & -4.597 & 230 & $T 40$ & Nieva \\
\hline 18 & $\mathrm{PCH}$ & $R S N$ & -79.682 & -6.005 & 662 & $T 40$ & Portachuelo \\
\hline 19 & $\mathrm{CHA}$ & $R S N$ & -77.877 & -6.227 & 2370 & $G 40 T$ & Chachapoyas \\
\hline 20 & $T A R$ & $R S N$ & -76.357 & -6.496 & 358 & $G 40 T$ & Tarapoto \\
\hline 21 & TICA & $R S N$ & -77.901 & -7.917 & 2819 & $T C$ & Ticapampa \\
\hline 22 & $C B T$ & $R S N$ & -78.521 & -9.128 & 53 & $G 40 T$ & Chimbote \\
\hline 23 & $Y A N A$ & $R S N$ & -76.112 & -10.638 & 3835 & $T C$ & Yanaquihua \\
\hline 24 & $O X A$ & $R S N$ & -75.398 & -10.578 & 1840 & G40T & Oxapampa \\
\hline 25 & $P U C$ & $R S N$ & -74.668 & -8.397 & 142 & $T 40$ & Pucallpa \\
\hline 26 & $I Q T$ & $R S N$ & -73.320 & -3.816 & 105 & $T 40$ & Iquitos \\
\hline 27 & $\mathrm{HCO}$ & $R S N$ & -76.249 & -9.952 & 1966 & $G 40 T$ & Huánuco \\
\hline 28 & $Y L S$ & $R S N$ & -77.889 & -8.847 & 3208 & T40 & Huaylas \\
\hline
\end{tabular}
$3 \mathrm{~T}$

Guralp-G40T, Trillium T40T, Trillium Compact TC, Guralp System CMG- 


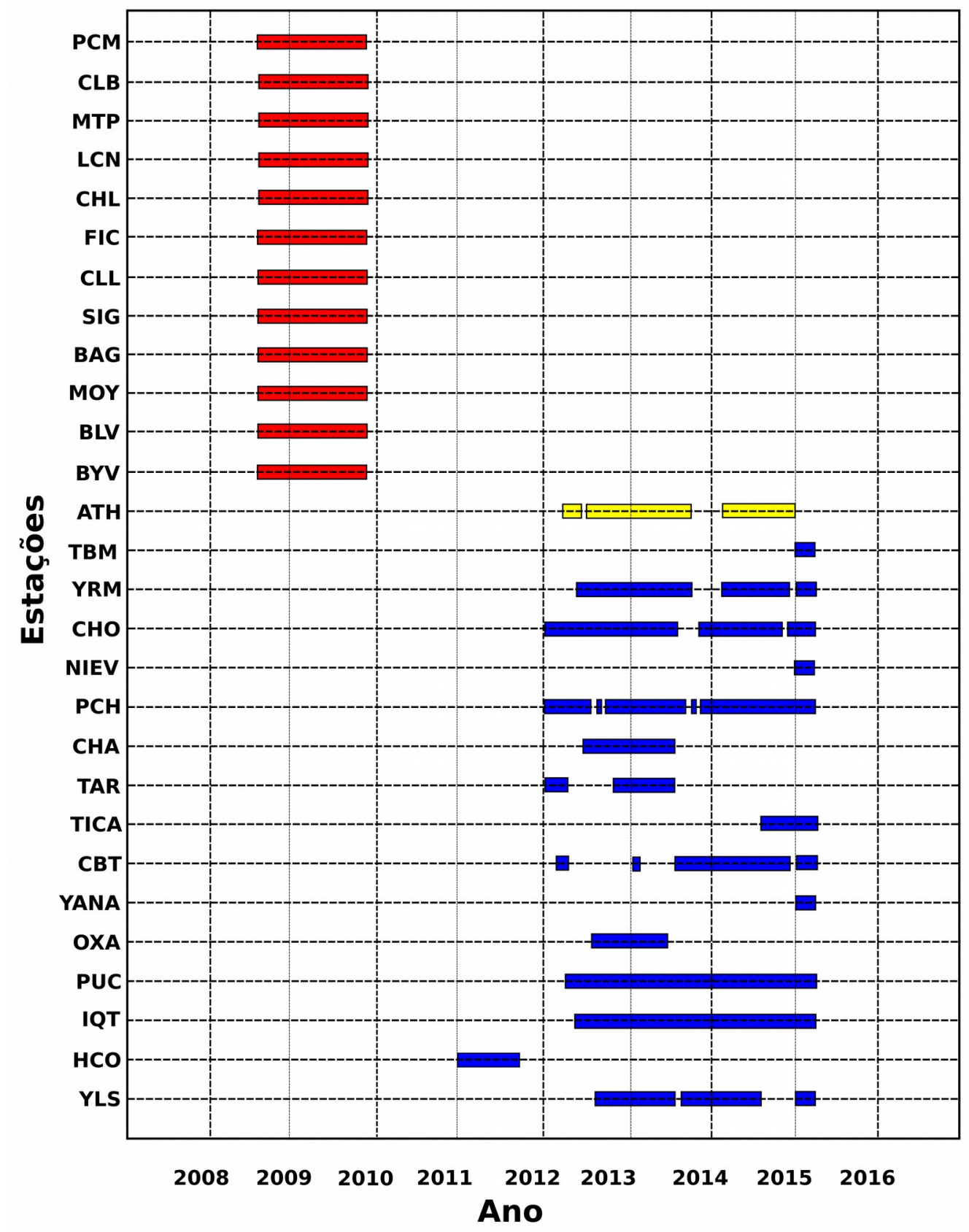

Figura A.1: Gráfico mostrando os períodos em que os dados foram obtidos nas estações, barras em vermelho para a Rede SisNort em amarelo a rede CTBTO e em azul para a Rede Sismográfica Nacional do IGP. 


\section{Anexo B}

Eventos usados na Função do Receptor em cada estação (Rede SisNort, CTBTO e IGP) para o estudo da espessura crustal.

\section{Rede Sismográfica Temporal}

Projeto SisNort

Tabela B.1: Lista de eventos detectados pelas estações da Rede SisNort

\begin{tabular}{|c|c|c|c|c|c|c|c|c|c|c|}
\hline Ano & Dia & Hora & Min. & Seg. & Lat. & Long. & $\mathrm{M}$ & $\operatorname{Dist}\left({ }^{\circ}\right)$ & Azimute $\left(^{\circ}\right)$ & Estações \\
\hline 2008 & 333 & 13 & 42 & 33 & 40.464 & -126.957 & 5.8 & 64.07 & 124.7 & CLL \\
\hline 2008 & 336 & 20 & 21 & 36 & -22.92 & -175.127 & 5.5 & 93.38 & 98.1 & CLL, BAG, SIG, MTP, CHL, FIC, BYV, CLB \\
\hline 2008 & 344 & 06 & 24 & 44 & -31.2660 & -176.853 & 6.6 & 92.42 & 100.1 & PCM, BYV, CLB, FIC, LCN, CHL, SIG, BAG \\
\hline 2008 & 354 & 08 & 31 & 54 & 47.013 & -27.301 & 5.8 & 68.59 & 238.8 & MTP, SIG, BAG, BLV, BYV, CLB \\
\hline 2008 & 355 & 21 & 05 & 55 & -31.184 & -13.393 & 5.6 & 65.89 & 278.3 & BAG, SIG, FIC, CHL, MTP, CLB \\
\hline 2008 & 359 & 09 & 11 & 59 & -17.267 & -171.867 & 6.0 & 89.43 & 94.2 & BYV, CLB, FIC, CHL, BAG \\
\hline 2008 & 360 & 08 & 11 & 60 & 49.139 & -128.606 & 5.8 & 67.88 & 126.8 & LCN, SIG \\
\hline 2009 & 001 & 06 & 27 & 01 & -34.849 & -107.733 & 5.7 & 39.77 & 48.5 & SIG, MOY \\
\hline 2009 & 002 & 19 & 42 & 02 & 0.635 & -26.84 & 5.6 & 52.02 & 262.4 & $\mathrm{BAG}, \mathrm{MTP}$ \\
\hline 2009 & 002 & 20 & 14 & 02 & 0.705 & -27.077 & 5.5 & 53.39 & 263.2 & CHL \\
\hline 2009 & 005 & 10 & 59 & 05 & 23.902 & -108.823 & 5.5 & 38.84 & 132.5 & CLB, FIC, SIG, BAG \\
\hline 2009 & 018 & 14 & 11 & 18 & -30.227 & -177.857 & 6.3 & 93.64 & 97.0 & CLB, FIC, LCN, CHL \\
\hline 2009 & 024 & 01 & 28 & 24 & -28.159 & -176.619 & 5.8 & 94.34 & 98.1 & $\mathrm{SIG}, \mathrm{CHL}$ \\
\hline 2009 & 028 & 12 & 39 & 28 & -16.964 & -171.977 & 5.6 & 89.56 & 94.3 & CLB \\
\hline 2009 & 043 & 18 & 54 & 43 & -31.206 & -177.836 & 5.8 & 93.88 & 97.7 & $\mathrm{LCN}$ \\
\hline 2009 & 048 & 03 & 30 & 48 & -30.75 & -178.615 & 6.0 & 94.33 & 99.4 & FIC \\
\hline 2009 & 049 & 03 & 07 & 49 & -53.003 & 20.816 & 5.9 & 88.88 & 259.9 & $\mathrm{BLV}, \mathrm{BAG}$ \\
\hline 2009 & 049 & 21 & 53 & 49 & -27.3910 & -176.236 & 6.9 & 92.56 & 99.6 & PCM, BYV, CLB, FIC, LCN, CHL, CLL, SIG, BAG \\
\hline 2009 & 059 & 14 & 33 & 59 & -60.568 & -24.919 & 6.3 & 67.55 & 299.5 & CLL, BAG, FIC, CHL, LCN, BYV, CLB, MTP \\
\hline 2009 & 065 & 10 & 50 & 65 & 80.314 & -1.964 & 6.5 & 91.59 & 257.8 & MTP, LCN, SIG, CHL, BAG, MOY, FIC, CLL, BLV \\
\hline 2009 & 071 & 05 & 18 & 71 & -60.812 & -23.92 & 5.5 & 66.37 & 300.5 & $\mathrm{BLV}, \mathrm{SIG}$ \\
\hline
\end{tabular}


Tabela B.2: Lista de eventos detectados pelas estações da Rede SisNort

\begin{tabular}{|c|c|c|c|c|c|c|c|c|c|c|}
\hline Ano & Dia & Hora & Min. & Seg. & Lat. & Long. & $\mathrm{M}$ & $\operatorname{Dist}\left({ }^{\circ}\right)$ & Azimute $\left(^{\circ}\right)$ & Estações \\
\hline 2009 & 078 & 18 & 17 & 78 & -23.1550 & -174.590 & 7.6 & 91.77 & 98.7 & PCM, BYV, CLB, FIC, LCN, CHL, CLL, BAG, BLV, MOY \\
\hline 2009 & 089 & 07 & 13 & 89 & 56.4020 & -152.769 & 6.0 & 86.98 & 108.1 & PCM, BYV, CLB, MTP, CHL, SIG, FIC, CLL, BLV \\
\hline 2009 & 094 & 11 & 07 & 94 & -22.539 & -174.658 & 5.5 & 93.01 & 97.9 & CLL \\
\hline 2009 & 094 & 18 & 39 & 94 & -56.003 & -27.947 & 5.5 & 63.88 & 300.7 & CLL, BAG, FIC, SIG, CHL \\
\hline 2009 & 096 & 01 & 32 & 96 & 42.37 & 13.319 & 6.3 & 94.30 & 265.7 & MOY, BLV \\
\hline 2009 & 098 & 06 & 26 & 98 & -58.007 & -7.266 & 5.5 & 76.03 & 282.9 & SIG \\
\hline 2009 & 106 & 14 & 57 & 06 & -60.288 & -27.029 & 6.7 & 64.79 & 303.4 & BLV, CLL, BAG, FIC, CHL, LCN, BYV, CLB, MTP \\
\hline 2009 & 108 & 02 & 03 & 08 & -28.865 & -177.301 & 5.7 & 93.50 & 98.6 & FIC \\
\hline 2009 & 117 & 16 & 46 & 17 & 16.9560 & -99.572 & 5.8 & 31.30 & 139.2 & PCM, BAG, CLL, MOY \\
\hline 2009 & 136 & 18 & 22 & 36 & 56.435 & -152.546 & 5.9 & 83.33 & 108.0 & BYV, CLB, LCN, CHL, FIC, BAG \\
\hline 2009 & 137 & 19 & 24 & 37 & 82.519 & -8.791 & 5.5 & 92.91 & 249.2 & $\mathrm{BAG}, \mathrm{BLV}$ \\
\hline 2009 & 142 & 19 & 24 & 42 & 18.151 & -98.394 & 5.6 & 30.04 & 138.6 & SIG \\
\hline 2009 & 149 & 01 & 04 & 49 & 18.38 & -106.594 & 5.5 & 35.88 & 128.0 & SIG \\
\hline 2009 & 154 & 21 & 37 & 54 & 19.682 & -109.182 & 5.6 & 37.74 & 127.8 & CHL \\
\hline 2009 & 156 & 13 & 39 & 56 & -35.456 & -104.258 & 5.7 & 36.88 & 42.7 & FIC, CLL, BAG, SIG \\
\hline 2009 & 157 & 20 & 33 & 57 & 23.8300 & -46.216 & 6.0 & 45.03 & 230.5 & PCM, MOY, BLV, MTP, BAG, SIG, CLL, LCN, CHL, BYV, CLB \\
\hline 2009 & 160 & 22 & 42 & 60 & -55.102 & -126.543 & 5.6 & 61.47 & 55.1 & FIC, CLL, MTP \\
\hline 2009 & 161 & 23 & 13 & 61 & -41.592 & -84.094 & 5.6 & 35.10 & 13.0 & BLV, CLL, FIC, MOY, BAG, CHL, SIG, LCN, BYV, CLB, MTP \\
\hline 2009 & 167 & 20 & 05 & 67 & -54.404 & 5.869 & 6.1 & 79.94 & 272.0 & BLV, MOY, CLL, BAG, FIC, SIG, CHL, MTP, CLB \\
\hline 2009 & 173 & 19 & 28 & 73 & 61.969 & -150.801 & 5.5 & 86.73 & 108.3 & BAG, MOY \\
\hline 2009 & 178 & 15 & 45 & 78 & -33.004 & -15.924 & 5.5 & 61.72 & 280.6 & BLV, BAG, CLL, SIG, CHL, MTP \\
\hline 2009 & 184 & 11 & 00 & 84 & 25.2200 & -109.618 & 5.9 & 43.71 & 134.0 & PCM, CLB, LCN, CHL, FIC, BAG, CLL, MOY \\
\hline 2009 & 188 & 19 & 11 & 88 & 75.343 & -72.691 & 6.0 & 79.98 & 188.0 & LCN, CHL, FIC, MOY, CLL, BLV \\
\hline 2009 & 189 & 19 & 23 & 89 & -35.927 & -102.687 & 6.0 & 36.39 & 40.1 & FIC, CLL, CHL, BAG, SIG, MOY \\
\hline 2009 & 198 & 03 & 20 & 98 & -21.931 & -174.998 & 5.6 & 93.98 & 97.6 & BAG \\
\hline 2009 & 211 & 20 & 05 & 11 & -20.834 & -174.151 & 5.7 & 91.80 & 95.6 & $\mathrm{LCN}$ \\
\hline 2009 & 213 & 13 & 33 & 13 & -56.336 & -124.118 & 6.0 & 62.04 & 51.1 & $\mathrm{LCN}$ \\
\hline 2009 & 215 & 17 & 55 & 15 & 28.982 & -113.025 & 5.5 & 45.29 & 130.4 & MTP, CHL, BLV \\
\hline 2009 & 215 & 17 & 59 & 15 & 29.0700 & -112.914 & 6.9 & 48.49 & 133.2 & PCM, CLB, LCN, FIC, SIG, CLL, BLV, CLL \\
\hline
\end{tabular}


Tabela B.3: Lista de eventos detectados pelas estações da Rede SisNort

\begin{tabular}{|c|c|c|c|c|c|c|c|c|c|l|}
\hline Ano & Dia & Hora & Min. & Seg. & Lat. & Long. & M & Dist $\left(^{\circ}\right)$ & Azimute $\left(^{\circ}\right)$ & Estações \\
\hline 2009 & 224 & 14 & 50 & 24 & -57.671 & -25.429 & 5.5 & 65.91 & 298.9 & CLL \\
2009 & 225 & 11 & 17 & 25 & -21.756 & -174.381 & 5.6 & 92.86 & 97.7 & CLL \\
2009 & 227 & 13 & 22 & 27 & 18.1 & -100.616 & 5.5 & 32.16 & 135.2 & BAG, CLL \\
2009 & 232 & 06 & 35 & 32 & 72.209 & 0.951 & 6.0 & 90.74 & 260.5 & MTP, SIG, CLL, FIC \\
2009 & 242 & 14 & 51 & 42 & -15.2220 & -172.491 & 6.6 & 90.96 & 97.9 & PCM, BYV, CLB, FIC, CHL, CLL, SIG, BAG, BLV \\
2009 & 253 & 19 & 46 & 53 & -29.957 & -111.786 & 5.5 & 38.26 & 57.6 & FIC, LCN, BAG \\
2009 & 260 & 23 & 21 & 60 & -29.1740 & -112.314 & 6.2 & 37.69 & 61.4 & PCM, BYV, CLB, CLL, SIG, BAG, BLV \\
2009 & 261 & 18 & 46 & 61 & 19.392 & -108.438 & 5.6 & 38.66 & 128.3 & CLL, BLV \\
2009 & 264 & 08 & 30 & 64 & 71.01 & -7.85 & 5.6 & 89.79 & 247.7 & BLV \\
2009 & 267 & 07 & 16 & 67 & 18.8110 & -107.209 & 6.4 & 37.74 & 131.2 & PCM, CLB, MTP, LCN, CHL, SIG, BAG, CLL, MOY, BLV \\
2009 & 272 & 17 & 48 & 72 & -15.5120 & -171.937 & 8.1 & 90.39 & 97.7 & PCM, CLB, LCN, CHL, CLL, SIG, BAG, BLV, MOY \\
2009 & 275 & 01 & 07 & 75 & -16.371 & -173.39 & 6.1 & 90.69 & 96.2 & BYV, CHL, CLL, SIG \\
\hline
\end{tabular}


Rede Sismográfica Mundial Comprehensive Nuclear Test Ban Treaty-CTBTO

Tabela B.4: Lista de eventos detectados pela estação da Rede CTBTO

\begin{tabular}{|c|c|c|c|c|c|c|c|c|c|c|}
\hline Ano & Dia & Hora & Min. & Seg. & Lat. & Long. & $\mathrm{M}$ & $\operatorname{Dist}\left({ }^{\circ}\right)$ & Azimute $\left(^{\circ}\right)$ & Estações \\
\hline 2012 & 149 & 22 & 00 & 49 & -19.962 & -175.976 & 5.9 & 94.73 & 99.3 & ATH \\
\hline 2012 & 150 & 07 & 13 & 50 & 44.851 & 11.086 & 5.8 & 94.64 & 264.6 & ATH \\
\hline 2012 & 153 & 05 & 18 & 53 & -77.08 & -148.864 & 5.5 & 78.72 & 72.5 & ATH \\
\hline 2012 & 222 & 02 & 42 & 22 & 19.946 & -109.332 & 5.6 & 40.67 & 128.4 & ATH \\
\hline 2012 & 237 & 07 & 16 & 37 & -63.581 & 171.324 & 5.5 & 92.44 & 111.3 & ATH \\
\hline 2012 & 243 & 13 & 56 & 43 & 71.441 & -10.605 & 6.7 & 89.80 & 246.7 & ATH \\
\hline 2012 & 258 & 07 & 29 & 58 & -39.676 & -16.01 & 5.5 & 64.34 & 282.6 & ATH \\
\hline 2012 & 266 & 07 & 11 & 66 & -20.896 & -174.194 & 5.5 & 92.93 & 98.7 & ATH \\
\hline 2012 & 269 & 03 & 19 & 69 & -15.517 & -173.901 & 5.6 & 93.46 & 98.3 & ATH \\
\hline 2012 & 269 & 23 & 53 & 69 & 24.666 & -110.173 & 6.3 & 44.29 & 131.5 & ATH \\
\hline 2012 & 275 & 17 & 39 & 75 & 18.607 & -107.164 & 5.5 & 38.24 & 129.4 & $\mathrm{ATH}$ \\
\hline 2012 & 279 & 00 & 27 & 79 & 17.479 & -46.457 & 5.5 & 39.96 & 234.9 & ATH \\
\hline 2012 & 282 & 06 & 34 & 82 & 25.127 & -109.574 & 6.0 & 44.19 & 132.5 & ATH \\
\hline 2012 & 302 & 03 & 15 & 02 & 52.788 & -132.101 & 7.8 & 75.03 & 124.1 & ATH \\
\hline 2012 & 304 & 03 & 00 & 04 & 52.365 & -131.902 & 6.2 & 74.69 & 124.2 & ATH \\
\hline 2012 & 308 & 13 & 06 & 08 & 7.048 & -34.073 & 5.6 & 46.45 & 253.2 & ATH \\
\hline 2012 & 313 & 02 & 12 & 13 & 49.231 & -128.477 & 6.1 & 71.11 & 126.4 & ATH \\
\hline 2012 & 335 & 11 & 33 & 35 & -18.824 & -175.595 & 5.7 & 94.56 & 99.0 & ATH \\
\hline 2012 & 339 & 01 & 55 & 39 & 61.237 & -150.76 & 5.8 & 87.86 & 108.8 & ATH \\
\hline 2012 & 349 & 10 & 45 & 49 & 31.095 & -119.66 & 6.4 & 54.84 & 126.8 & ATH \\
\hline 2013 & 009 & 21 & 56 & 09 & -57.05 & -141.465 & 5.6 & 69.57 & 70.8 & ATH \\
\hline 2013 & 055 & 21 & 07 & 55 & -32.176 & -178.058 & 5.7 & 94.39 & 101.2 & ATH \\
\hline 2013 & 095 & 22 & 41 & 95 & -55.8 & -124.27 & 5.5 & 60.53 & 54.9 & ATH \\
\hline 2013 & 112 & 01 & 23 & 12 & 18.127 & -101.908 & 6.0 & 34.22 & 135.2 & ATH \\
\hline 2013 & 124 & 23 & 49 & 24 & -54.663 & -135.966 & 5.5 & 65.82 & 66.7 & ATH \\
\hline 2013 & 130 & 20 & 06 & 30 & -28.983 & -13.229 & 5.7 & 64.91 & 275.9 & ATH \\
\hline 2013 & 131 & 21 & 00 & 31 & -17.954 & -175.099 & 6.4 & 94.23 & 98.8 & ATH \\
\hline 2013 & 140 & 09 & 56 & 40 & -44.866 & -80.746 & 6.4 & 37.66 & 3.8 & ATH \\
\hline 2013 & 143 & 21 & 20 & 43 & -20.561 & -175.765 & 6.3 & 94.44 & 99.2 & ATH \\
\hline 2013 & 158 & 20 & 23 & 58 & -43.742 & -16.156 & 5.7 & 65.18 & 284.6 & ATH \\
\hline 2013 & 167 & 03 & 01 & 67 & -56.243 & -27.533 & 5.5 & 63.12 & 300.4 & ATH \\
\hline 2013 & 167 & 05 & 25 & 67 & 18.149 & -99.204 & 5.8 & 32.48 & 138.9 & ATH \\
\hline 2013 & 175 & 22 & 11 & 75 & 10.701 & -42.594 & 6.6 & 39.84 & 245.1 & ATH \\
\hline 2013 & 183 & 18 & 46 & 83 & -35.91 & -102.919 & 5.7 & 36.41 & 44.0 & ATH \\
\hline 2013 & 233 & 12 & 44 & 33 & 16.878 & -99.498 & 6.2 & 31.73 & 137.2 & ATH \\
\hline 2013 & 246 & 20 & 30 & 46 & 51.244 & -130.397 & 6.1 & 73.29 & 125.3 & ATH \\
\hline 2013 & 247 & 00 & 34 & 47 & 51.183 & -130.225 & 6.0 & 73.16 & 125.4 & ATH \\
\hline 2013 & 248 & 04 & 08 & 48 & 15.184 & -45.232 & 6.0 & 39.69 & 238.3 & ATH \\
\hline 2014 & 088 & 07 & 56 & 88 & -0.848 & -21.92 & 5.9 & 56.70 & 262.1 & ATH \\
\hline 2014 & 105 & 04 & 09 & 05 & -53.497 & 8.722 & 6.8 & 82.59 & 268.1 & ATH \\
\hline 2014 & 108 & 14 & 33 & 08 & 17.397 & -100.972 & 7.2 & 33.08 & 135.7 & ATH \\
\hline 2014 & 114 & 03 & 21 & 14 & 49.639 & -127.732 & 6.5 & 70.96 & 127.2 & ATH \\
\hline 2014 & 123 & 09 & 10 & 23 & 67.63 & -162.207 & 5.5 & 94.17 & 98.4 & ATH \\
\hline 2014 & 128 & 17 & 06 & 28 & 17.235 & -100.746 & 6.4 & 32.81 & 135.8 & ATH \\
\hline 2014 & 130 & 07 & 42 & 30 & 17.219 & -100.812 & 6.0 & 32.84 & 135.7 & ATH \\
\hline 2014 & 136 & 11 & 07 & 36 & 17.086 & -60.365 & 5.9 & 29.98 & 218.0 & ATH \\
\hline 2014 & 150 & 11 & 43 & 50 & -55.306 & -128.581 & 5.5 & 62.32 & 59.4 & ATH \\
\hline 2014 & 151 & 12 & 00 & 51 & 18.788 & -107.469 & 6.2 & 38.58 & 129.3 & $\mathrm{ATH}$ \\
\hline 2014 & 156 & 17 & 29 & 56 & -29.15 & -112.483 & 5.9 & 38.89 & 62.4 & ATH \\
\hline 2014 & 158 & 04 & 56 & 58 & 67.725 & -162.375 & 5.5 & 94.25 & 98.3 & $\mathrm{ATH}$ \\
\hline 2014 & 167 & 12 & 14 & 67 & 67.697 & -162.612 & 5.7 & 94.33 & 98.0 & ATH \\
\hline
\end{tabular}


Tabela B.5: Lista de eventos detectados pela estação da Rede CTBTO

\begin{tabular}{|c|c|c|c|c|c|c|c|c|c|c|}
\hline Ano & Dia & Hora & Min. & Seg. & Lat. & Long. & $\mathrm{M}$ & $\operatorname{Dist}\left({ }^{\circ}\right)$ & Azimute $\left(^{\circ}\right)$ & Estações \\
\hline 2014 & 174 & 21 & 21 & 74 & -30.17 & -177.188 & 5.6 & 94.04 & 100.6 & ATH \\
\hline 2014 & 174 & 19 & 32 & 74 & -29.977 & -177.725 & 6.9 & 94.53 & 100.8 & ATH \\
\hline 2014 & 180 & 08 & 03 & 80 & -55.47 & -28.367 & 6.9 & 62.33 & 300.8 & ATH \\
\hline 2014 & 181 & 01 & 56 & 81 & 0.054 & -17.343 & 5.6 & 61.37 & 261.9 & ATH \\
\hline 2014 & 182 & 05 & 53 & 82 & -56.62 & -141.784 & 5.6 & 69.60 & 71.2 & ATH \\
\hline 2014 & 198 & 12 & 01 & 98 & 60.349 & -140.333 & 6.0 & 82.82 & 118.0 & ATH \\
\hline 2014 & 210 & 10 & 52 & 10 & 17.682 & -95.653 & 6.3 & 30.01 & 143.9 & ATH \\
\hline 2014 & 222 & 18 & 54 & 22 & 27.681 & -111.632 & 5.5 & 47.27 & 132.2 & ATH \\
\hline 2014 & 223 & 10 & 20 & 23 & -29.974 & -176.096 & 5.5 & 93.14 & 100.0 & ATH \\
\hline 2014 & 236 & 10 & 30 & 36 & 38.215 & -122.312 & 6.0 & 60.89 & 128.0 & ATH \\
\hline 2014 & 246 & 08 & 26 & 46 & -15.025 & -173.521 & 5.5 & 93.17 & 98.2 & ATH \\
\hline 2014 & 246 & 20 & 41 & 46 & -26.642 & -114.739 & 5.9 & 39.64 & 67.3 & ATH \\
\hline 2014 & 248 & 19 & 43 & 48 & -26.708 & -114.25 & 5.8 & 39.26 & 66.8 & ATH \\
\hline 2014 & 249 & 07 & 55 & 49 & -26.765 & -114.472 & 5.9 & 39.46 & 66.9 & ATH \\
\hline 2014 & 249 & 07 & 00 & 49 & -26.648 & -114.5 & 6.1 & 39.44 & 67.1 & ATH \\
\hline 2014 & 249 & 19 & 30 & 49 & 18.753 & -107.049 & 6.2 & 38.25 & 129.7 & ATH \\
\hline 2014 & 250 & 07 & 20 & 50 & 64.544 & -17.395 & 5.5 & 84.45 & 240.7 & ATH \\
\hline 2014 & 258 & 08 & 17 & 58 & 64.573 & -17.397 & 5.5 & 84.47 & 240.7 & ATH \\
\hline 2014 & 265 & 16 & 11 & 65 & -56.023 & -27.779 & 5.7 & 62.89 & 300.5 & ATH \\
\hline 2014 & 281 & 02 & 48 & 81 & 23.844 & -108.331 & 6.1 & 42.49 & 132.8 & ATH \\
\hline 2014 & 282 & 02 & 21 & 82 & -32.108 & -110.811 & 7.0 & 39.11 & 57.5 & ATH \\
\hline 2014 & 283 & 04 & 15 & 83 & -32.165 & -110.836 & 5.6 & 39.16 & 57.5 & ATH \\
\hline 2014 & 288 & 11 & 28 & 88 & 64.481 & -18.004 & 5.5 & 84.19 & 240.1 & ATH \\
\hline 2014 & 305 & 10 & 12 & 05 & -31.92 & -111.107 & 5.8 & 39.22 & 58.1 & ATH \\
\hline 2014 & 305 & 11 & 07 & 05 & -31.852 & -111.244 & 6.0 & 39.29 & 58.3 & ATH \\
\hline 2014 & 356 & 07 & 30 & 56 & -54.105 & -146.094 & 5.8 & 71.25 & 75.8 & ATH \\
\hline 2015 & 026 & 17 & 55 & 26 & -54.675 & -136.77 & 5.6 & 66.25 & 67.4 & ATH \\
\hline 2015 & 028 & 21 & 19 & 28 & 40.318 & -124.607 & 5.7 & 63.58 & 126.9 & ATH \\
\hline 2015 & 044 & 19 & 10 & 44 & 52.649 & -31.902 & 7.1 & 71.46 & 229.4 & ATH \\
\hline 2015 & 047 & 22 & 11 & 47 & -55.52 & -28.259 & 6.2 & 62.40 & 300.7 & ATH \\
\hline
\end{tabular}


Rede Sismográfica Nacional do Instituto Geofísico do Peru (IGP)

Tabela B.6: Lista de eventos detectados pelas estações da Rede do IGP

\begin{tabular}{|l|c|c|c|c|c|c|c|c|c|l|}
\hline Ano & Dia & Hora & Min. & Seg. & Lat. & Long. & M & Dist $\left(^{\circ}\right)$ & Azimute $\left(^{\circ}\right)$ & Estações \\
\hline 2011 & 170 & 11 & 15 & 70 & -55.02 & -128.89 & 5.5 & 61.01 & 63.5 & HCO \\
2011 & 181 & 04 & 43 & 81 & -23.53 & -175.66 & 5.7 & 94.63 & 102.8 & HCO \\
2011 & 187 & 19 & 16 & 87 & -29.31 & -176.26 & 7.6 & 93.82 & 103.5 & HCO \\
2011 & 187 & 20 & 48 & 87 & -29.57 & -176.11 & 5.6 & 93.63 & 103.5 & HCO \\
2011 & 188 & 09 & 43 & 88 & -29.21 & -176.79 & 5.8 & 94.29 & 103.8 & HCO \\
2011 & 190 & 07 & 21 & 90 & -21.13 & -174.42 & 5.6 & 94.03 & 102.2 & HCO \\
2011 & 190 & 19 & 48 & 90 & -29.35 & -176.93 & 5.9 & 94.38 & 103.9 & HCO \\
2011 & 192 & 07 & 28 & 92 & -29.49 & -176.63 & 5.9 & 94.10 & 103.7 & HCO \\
2011 & 192 & 11 & 01 & 92 & -22.82 & -174.64 & 5.6 & 93.87 & 102.4 & HCO \\
2011 & 192 & 16 & 00 & 92 & -49.76 & -114.07 & 5.7 & 50.56 & 51.5 & HCO \\
2011 & 196 & 13 & 36 & 96 & -60.99 & -23.66 & 6.1 & 63.77 & 299.3 & HCO \\
2011 & 197 & 07 & 16 & 97 & -22.48 & -174.88 & 5.7 & 94.15 & 102.4 & HCO \\
2011 & 202 & 23 & 14 & 02 & -62.52 & 164.78 & 5.9 & 93.90 & 120.2 & HCO \\
2011 & 207 & 17 & 52 & 07 & 25.09 & -109.54 & 6.0 & 47.64 & 132.9 & HCO \\
2011 & 208 & 23 & 07 & 08 & 10.77 & -43.46 & 5.9 & 38.60 & 238.9 & HCO \\
2011 & 217 & 16 & 21 & 17 & -30.00 & -176.60 & 5.7 & 93.95 & 103.7 & HCO \\
2011 & 222 & 23 & 55 & 22 & -7.10 & -12.81 & 6.0 & 62.79 & 262.5 & HCO \\
2011 & 235 & 17 & 59 & 35 & 37.92 & -78.04 & 5.7 & 47.68 & 177.6 & HCO \\
2011 & 240 & 10 & 17 & 40 & -24.54 & -115.99 & 5.6 & 40.50 & 76.0 & HCO \\
2011 & 243 & 12 & 28 & 43 & 43.60 & -28.86 & 5.6 & 68.53 & 231.2 & HCO \\
2011 & 248 & 10 & 13 & 48 & -15.25 & -173.55 & 6.2 & 94.43 & 101.5 & HCO \\
2011 & 252 & 19 & 52 & 52 & 49.39 & -127.07 & 6.5 & 73.97 & 127.4 & HCO \\
2011 & 266 & 19 & 09 & 66 & -9.16 & -109.55 & 5.9 & 32.88 & 94.2 & HCO \\
2011 & 282 & 18 & 10 & 82 & -49.86 & -116.29 & 5.5 & 51.76 & 53.8 & HCO \\
\hline
\end{tabular}


Tabela B.7: Lista de eventos detectados pelas estações da Rede do IGP

\begin{tabular}{|c|c|c|c|c|c|c|c|c|c|c|}
\hline Ano & Dia & Hora & Min. & Seg. & Lat. & Long. & $\mathrm{M}$ & $\operatorname{Dist}\left({ }^{\circ}\right)$ & Azimute $\left({ }^{\circ}\right)$ & Estações \\
\hline 2011 & 283 & 05 & 25 & 83 & -25.38 & -116.32 & 5.5 & 40.99 & 75.3 & $\mathrm{HCO}$ \\
\hline 2011 & 286 & 04 & 25 & 86 & 43.42 & -127.26 & 5.6 & 70.52 & 125.7 & $\mathrm{HCO}$ \\
\hline 2011 & 294 & 18 & 10 & 94 & -28.88 & -176.03 & 7.4 & 93.73 & 103.4 & $\mathrm{HCO}$ \\
\hline 2012 & 005 & 01 & 26 & 05 & -17.99 & -173.22 & 5.5 & 94.58 & 98.3 & TAR \\
\hline 2012 & 006 & 19 & 00 & 06 & -6.28 & -107.31 & 5.5 & 30.79 & 92.1 & TAR \\
\hline 2012 & 012 & 14 & 24 & 12 & -52.09 & 28.24 & 5.5 & 93.77 & 254.5 & TAR \\
\hline 2012 & 013 & 16 & 12 & 13 & -60.68 & -27.06 & 5.5 & 65.36 & 304.0 & TAR \\
\hline 2012 & 015 & 13 & 49 & 15 & -60.89 & -56.12 & 5.9 & 56.36 & 335.6 & TAR \\
\hline 2012 & 015 & 14 & 31 & 15 & -60.87 & -56.03 & 6.0 & 56.36 & 335.5 & TAR \\
\hline 2012 & 016 & 04 & 09 & 16 & -60.62 & -56.39 & 5.7 & 56.06 & 335.9 & TAR \\
\hline 2012 & 022 & 06 & 04 & 22 & -56.93 & -25.23 & 6.0 & 64.16 & 300.7 & TAR \\
\hline 2012 & 022 & 06 & 10 & 22 & -56.65 & -24.95 & 5.5 & 64.14 & 300.3 & TAR \\
\hline 2012 & 023 & 16 & 10 & 23 & -36.46 & -73.18 & 6.1 & 29.98 & 353.7 & TAR \\
\hline 2012 & 024 & 16 & 41 & 24 & -56.43 & -27.89 & 5.5 & 62.65 & 303.1 & TAR \\
\hline 2012 & 028 & 04 & 51 & 28 & -36.63 & -110.66 & 5.6 & 43.38 & 54.7 & TAR \\
\hline 2012 & 035 & 20 & 16 & 35 & 48.71 & -128.10 & 5.7 & 71.16 & 124.5 & TAR \\
\hline 2012 & 040 & 08 & 59 & 40 & -56.41 & -25.99 & 5.5 & 63.53 & 301.3 & TAR \\
\hline 2012 & 042 & 03 & 04 & 42 & -37.36 & -73.33 & 5.6 & 30.86 & 354.1 & TAR \\
\hline 2012 & 054 & 05 & 18 & 54 & -17.77 & -13.20 & 5.5 & 62.56 & 271.9 & TAR \\
\hline 2012 & 149 & 22 & 00 & 49 & -19.96 & -175.98 & 5.9 & 94.59 & 101.0 & HYS \\
\hline 2012 & 153 & 05 & 18 & 53 & -77.08 & -148.86 & 5.5 & 77.16 & 73.3 & HYS, CHO, YRM \\
\hline 2012 & 159 & 04 & 05 & 59 & -36.07 & -70.57 & 6.0 & 32.22 & 354.8 & IQT \\
\hline 2012 & 159 & 04 & 11 & 59 & -36.07 & -70.57 & 6.0 & 30.48 & 349.0 & YRM \\
\hline 2012 & 181 & 15 & 31 & 81 & -24.75 & -9.66 & 5.8 & 64.58 & 277.9 & IQT \\
\hline 2012 & 181 & 15 & 42 & 81 & -24.75 & -9.66 & 5.8 & 63.91 & 272.7 & PUC, PCH \\
\hline 2012 & 200 & 04 & 35 & 00 & -55.66 & -128.89 & 5.9 & 61.20 & 64.4 & OXA, HYS \\
\hline 2012 & 203 & 05 & 07 & 03 & -37.71 & -179.97 & 5.7 & 94.08 & 104.3 & HYS, OXA \\
\hline 2012 & 208 & 10 & 33 & 08 & -21.02 & -174.49 & 5.6 & 94.00 & 98.2 & CHA, OXA \\
\hline 2012 & 222 & 02 & 42 & 22 & 19.95 & -109.33 & 5.6 & 40.46 & 126.9 & CHA, PUC \\
\hline 2012 & 223 & 18 & 50 & 23 & 52.63 & -167.42 & 6.2 & 94.64 & 94.1 & CHA \\
\hline 2012 & 225 & 18 & 43 & 25 & -63.00 & -157.72 & 5.5 & 77.13 & 88.0 & OXA, CHA \\
\hline
\end{tabular}


Tabela B.8: Lista de eventos detectados pelas estações da Rede do IGP

\begin{tabular}{|l|l|l|l|l|l|c|c|c|c|l|}
\hline Ano & Dia & Hora & Min. & Seg. & Lat. & Long. & M & Dist $\left(^{\circ}\right)$ & Azimute $\left.{ }^{\circ}\right)$ & Estações \\
\hline 2012 & 229 & 13 & 31 & 29 & -36.43 & -98.91 & 5.8 & 33.47 & 40.0 & HYS, CHA \\
2012 & 230 & 21 & 33 & 30 & 8.35 & -103.00 & 5.5 & 30.33 & 123.8 & HYS \\
2012 & 230 & 21 & 34 & 30 & 8.35 & -103.00 & 5.5 & 32.81 & 119.8 & PUC \\
2012 & 231 & 17 & 58 & 31 & -15.60 & -173.04 & 5.7 & 93.37 & 97.4 & CHA \\
2012 & 237 & 07 & 18 & 32 & 47.79 & -128.62 & 5.6 & 69.87 & 124.9 & CHA, HYS, OXA \\
2012 & 237 & 07 & 15 & 37 & -63.58 & 171.32 & 5.5 & 90.55 & 115.4 & OXA \\
2012 & 237 & 10 & 15 & 37 & -63.58 & 171.32 & 5.5 & 93.48 & 111.4 & CHA \\
2012 & 239 & 11 & 34 & 39 & -65.44 & -179.53 & 5.6 & 94.79 & 103.8 & HYS \\
2012 & 239 & 21 & 07 & 39 & 33.02 & -179.78 & 5.6 & 86.28 & 107.4 & OXA \\
2012 & 243 & 13 & 56 & 43 & 71.44 & -10.61 & 6.7 & 88.69 & 249.8 & CHO, CHA, PUC \\
2012 & 250 & 23 & 39 & 50 & -4.60 & -105.89 & 5.8 & 31.28 & 98.6 & PUC \\
2012 & 258 & 07 & 28 & 58 & -39.68 & -16.01 & 5.5 & 60.72 & 284.3 & PUC, HYS \\
2012 & 258 & 07 & 29 & 58 & -39.68 & -16.01 & 5.5 & 64.54 & 283.8 & CHA \\
2012 & 266 & 07 & 11 & 66 & -20.90 & -174.19 & 5.5 & 93.74 & 98.0 & CHA \\
2012 & 268 & 10 & 44 & 68 & -21.21 & -174.29 & 5.5 & 92.20 & 97.2 & PCH, CHA \\
2012 & 269 & 23 & 45 & 69 & 24.67 & -110.17 & 6.3 & 45.70 & 123.2 & IQT, CHA, YRM, OXA \\
2012 & 275 & 17 & 39 & 75 & 18.61 & -107.16 & 5.5 & 38.02 & 127.8 & CHA \\
2012 & 276 & 19 & 54 & 76 & -64.97 & 177.83 & 5.6 & 90.35 & 105.5 & CHA \\
2012 & 282 & 06 & 26 & 82 & 25.13 & -109.57 & 6.0 & 45.50 & 124.1 & IQT \\
2012 & 282 & 06 & 34 & 82 & 25.13 & -109.57 & 6.0 & 43.88 & 131.1 & CHA, YRM \\
2012 & 295 & 01 & 37 & 95 & 66.31 & -18.67 & 5.6 & 83.85 & 239.2 & CHA, PUC \\
2012 & 302 & 03 & 04 & 02 & 52.79 & -132.10 & 7.8 & 74.85 & 117.9 & IQT \\
2012 & 302 & 03 & 15 & 02 & 52.79 & -132.10 & 7.8 & 79.49 & 123.3 & OXA \\
2012 & 302 & 03 & 25 & 02 & 52.72 & -132.12 & 5.8 & 75.10 & 121.4 & YRM, OXA \\
2012 & 302 & 19 & 05 & 02 & 52.67 & -132.60 & 6.3 & 75.33 & 121.0 & YRM \\
2012 & 302 & 19 & 21 & 02 & 52.29 & -132.08 & 5.8 & 74.23 & 123.1 & CHA, OXA \\
2012 & 304 & 02 & 49 & 04 & 52.37 & -131.90 & 6.2 & 74.55 & 117.9 & IQT \\
\hline
\end{tabular}


Tabela B.9: Lista de eventos detectados pelas estações da Rede do IGP

\begin{tabular}{|c|c|c|c|c|c|c|c|c|c|c|}
\hline Ano & Dia & Hora & Min. & Seg. & Lat. & Long. & $\mathrm{M}$ & $\operatorname{Dist}\left({ }^{\circ}\right)$ & Azimute $\left(^{\circ}\right)$ & Estações \\
\hline 2012 & 304 & 03 & 00 & 04 & 52.37 & -131.90 & 6.2 & 74.18 & 123.2 & CHA, YRM, OXA \\
\hline 2012 & 308 & 13 & 06 & 08 & 7.05 & -34.07 & 5.6 & 43.33 & 249.9 & PUC, OXA \\
\hline 2012 & 311 & 11 & 16 & 11 & -35.47 & -104.80 & 5.6 & 36.16 & 49.3 & HYS \\
\hline 2012 & 313 & 02 & 01 & 13 & 49.23 & -128.48 & 6.1 & 71.13 & 120.1 & IQT \\
\hline 2012 & 313 & 02 & 12 & 13 & 49.23 & -128.48 & 6.1 & 70.62 & 125.5 & CHA, YRM \\
\hline 2012 & 313 & 02 & 13 & 13 & 49.23 & -128.48 & 6.1 & 72.82 & 126.9 & HYS, OXA \\
\hline 2012 & 317 & 20 & 54 & 17 & 57.79 & -142.86 & 6.3 & 82.30 & 114.6 & CHA, OXA \\
\hline 2012 & 318 & 04 & 38 & 18 & -45.76 & -77.05 & 6.1 & 39.40 & 358.7 & $\mathrm{CHA}$ \\
\hline 2012 & 320 & 09 & 26 & 20 & 18.35 & -100.38 & 6.1 & 33.03 & 135.7 & $\mathrm{CHA}$ \\
\hline 2012 & 321 & 06 & 34 & 21 & -53.96 & -134.76 & 5.6 & 63.68 & 70.7 & OXA \\
\hline 2012 & 321 & 06 & 35 & 21 & -53.96 & -134.76 & 5.6 & 63.74 & 67.3 & HYS, PCH, CHA \\
\hline 2012 & 322 & 05 & 25 & 22 & -18.38 & -172.32 & 5.9 & 90.70 & 96.5 & PCH, HYS, CHA \\
\hline 2012 & 322 & 05 & 26 & 22 & -18.38 & -172.32 & 5.9 & 94.08 & 97.5 & YRM, PUC \\
\hline 2012 & 331 & 00 & 23 & 31 & -9.10 & -108.33 & 5.5 & 30.09 & 91.9 & HYS, CHA, PUC \\
\hline 2012 & 335 & 11 & 33 & 35 & -18.82 & -175.60 & 5.7 & 94.46 & 100.8 & HYS \\
\hline 2012 & 338 & 09 & 38 & 38 & -54.67 & -136.24 & 5.6 & 64.81 & 68.4 & HYS, TAR, YRM \\
\hline 2012 & 339 & 01 & 55 & 39 & 61.24 & -150.76 & 5.8 & 84.95 & 110.2 & CHO, CHA, TAR, HYS \\
\hline 2012 & 347 & 01 & 57 & 47 & -19.56 & -176.28 & 5.5 & 94.95 & 101.1 & HYS \\
\hline 2012 & 349 & 10 & 44 & 49 & 31.10 & -119.66 & 6.4 & 51.66 & 127.4 & $\mathrm{CHO}$ \\
\hline 2012 & 349 & 10 & 45 & 49 & 31.10 & -119.66 & 6.4 & 53.15 & 127.0 & PCH, CHA, YRM, TAR, HYS, OXA \\
\hline 2012 & 361 & 23 & 12 & 61 & -56.19 & -144.48 & 5.5 & 69.74 & 75.2 & HYS \\
\hline 2012 & 361 & 23 & 13 & 61 & -56.19 & -144.48 & 5.5 & 71.16 & 72.0 & PCH, CHO, CHA, TAR \\
\hline 2012 & 362 & 00 & 43 & 62 & -35.78 & -73.26 & 5.9 & 30.24 & 347.2 & $\mathrm{PCH}, \mathrm{CHO}$ \\
\hline 2012 & 365 & 12 & 27 & 65 & 14.45 & -92.99 & 5.5 & 30.40 & 144.0 & OXA \\
\hline 2013 & 005 & 09 & 09 & 05 & 55.39 & -134.65 & 7.5 & 74.77 & 123.7 & $\mathrm{CHO}, \mathrm{PCH}$ \\
\hline 2013 & 005 & 09 & 10 & 05 & 55.39 & -134.65 & 7.5 & 77.17 & 121.5 & CHA, YRM, TAR, HYL, OXA \\
\hline 2013 & 009 & 21 & 57 & 09 & -57.05 & -141.47 & 5.6 & 71.17 & 72.2 & TAR \\
\hline 2013 & 013 & 16 & 36 & 13 & 25.89 & -110.10 & 5.7 & 41.90 & 133.4 & CHO, PCH, CHA, TAR, HYS \\
\hline
\end{tabular}


Tabela B.10: Lista de eventos detectados pelas estações da Rede do IGP

\begin{tabular}{|c|c|c|c|c|c|c|c|c|c|c|}
\hline Ano & Dia & Hora & Min. & Seg. & Lat. & Long. & $\mathrm{M}$ & $\operatorname{Dist}\left({ }^{\circ}\right)$ & Azimute $\left(^{\circ}\right)$ & Estações \\
\hline 2013 & 014 & 15 & 07 & 14 & 55.16 & -134.55 & 5.5 & 74.59 & 123.7 & $\mathrm{CHO}, \mathrm{PCH}, \mathrm{CHA}, \mathrm{TAR}, \mathrm{HYS}$ \\
\hline 2013 & 020 & 23 & 43 & 20 & 53.87 & -35.13 & 5.5 & 69.41 & 224.4 & TAR, PCH, OXA \\
\hline 2013 & 021 & 22 & 43 & 21 & -7.65 & -33.98 & 5.8 & 45.44 & 269.1 & $\mathrm{PCH}, \mathrm{CHO}$ \\
\hline 2013 & 023 & 07 & 49 & 23 & -44.62 & -79.08 & 5.5 & 35.66 & 2.0 & HYS, TAR, CHA, PCH \\
\hline 2013 & 027 & 10 & 12 & 27 & -16.12 & -173.24 & 5.7 & 92.73 & 99.9 & HYS, OXA, TAR \\
\hline 2013 & 049 & 03 & 48 & 49 & 5.54 & -32.96 & 5.5 & 43.88 & 251.9 & PUC, YRM, TAR, OXA \\
\hline 2013 & 049 & 03 & 49 & 49 & 5.54 & -32.96 & 5.5 & 46.39 & 256.0 & CHA \\
\hline 2013 & 049 & 12 & 32 & 49 & -30.77 & -178.12 & 5.9 & 93.56 & 98.1 & CHO, HYS \\
\hline 2013 & 049 & 16 & 45 & 49 & -30.73 & -178.14 & 5.5 & 94.24 & 99.5 & $\mathrm{PCH}$ \\
\hline 2013 & 050 & 22 & 42 & 50 & -17.44 & -173.47 & 5.7 & 92.73 & 100.1 & HYS, CHA, TAR \\
\hline 2013 & 051 & 21 & 29 & 51 & 18.55 & -103.71 & 5.8 & 34.05 & 133.6 & PCH, CHA \\
\hline 2013 & 078 & 03 & 38 & 78 & -58.92 & -24.41 & 5.9 & 61.50 & 299.6 & OXA, HYS, TAR, YRM, CHA, PCH, CHO \\
\hline 2013 & 081 & 22 & 53 & 81 & -28.04 & -176.57 & 5.5 & 92.59 & 97.2 & $\mathrm{CHO}, \mathrm{HYS}$ \\
\hline 2013 & 081 & 22 & 54 & 81 & -28.04 & -176.57 & 5.5 & 94.78 & 99.6 & CHA \\
\hline 2013 & 085 & 13 & 10 & 85 & 16.19 & -98.15 & 5.5 & 30.00 & 136.4 & CHA, TAR \\
\hline 2013 & 087 & 03 & 47 & 87 & -23.60 & -175.51 & 5.5 & 93.00 & 97.8 & $\mathrm{PCH}, \mathrm{OXA}$ \\
\hline 2013 & 087 & 04 & 38 & 87 & -28.46 & -175.47 & 5.6 & 93.75 & 99.1 & CHA, TAR \\
\hline 2013 & 090 & 17 & 20 & 90 & -65.60 & -177.85 & 5.6 & 85.48 & 105.6 & OXA, PCH, CHO, CHA, TAR \\
\hline 2013 & 095 & 22 & 41 & 95 & -55.80 & -124.27 & 5.5 & 58.95 & 59.8 & OXA, TAR \\
\hline 2013 & 096 & 10 & 38 & 96 & -55.71 & -123.23 & 5.5 & 58.40 & 58.8 & OXA, CHA, TAR \\
\hline
\end{tabular}


Tabela B.11: Lista de eventos detectados pelas estações da Rede do IGP

\begin{tabular}{|c|c|c|c|c|c|c|c|c|c|c|}
\hline Ano & Dia & Hora & Min. & Seg. & Lat. & Long. & $\mathrm{M}$ & $\operatorname{Dist}\left({ }^{\circ}\right)$ & Azimute $\left(^{\circ}\right)$ & Estações \\
\hline 2013 & 110 & 05 & 23 & 10 & -54.78 & 1.15 & 5.8 & 77.51 & 276.5 & TAR, CHO \\
\hline 2013 & 112 & 01 & 16 & 12 & 18.13 & -101.91 & 6.0 & 35.67 & 125.0 & IQT \\
\hline 2013 & 112 & 01 & 22 & 12 & 18.13 & -101.91 & 6.0 & 31.06 & 136.3 & $\mathrm{CHO}, \mathrm{PCH}$ \\
\hline 2013 & 112 & 01 & 23 & 12 & 18.13 & -101.91 & 6.0 & 33.92 & 133.4 & CHA, YRM, TAR, HYS \\
\hline 2013 & 120 & 06 & 35 & 20 & 37.66 & -25.01 & 5.8 & 64.94 & 239.0 & TAR, CHO, OXA \\
\hline 2013 & 120 & 14 & 51 & 20 & -65.39 & 179.45 & 5.5 & 86.62 & 108.1 & OXA, HYS, PCH \\
\hline 2013 & 124 & 23 & 49 & 24 & -54.66 & -135.97 & 5.5 & 64.66 & 68.1 & HYS, CHA, TAR, YRM \\
\hline 2013 & 130 & 20 & 05 & 30 & -28.98 & -13.23 & 5.7 & 60.69 & 274.0 & OXA \\
\hline 2013 & 130 & 20 & 06 & 30 & -28.98 & -13.23 & 5.7 & 61.07 & 276.6 & PUC, TAR, HYS, CHA, CHO \\
\hline 2013 & 131 & 20 & 59 & 31 & -17.95 & -175.10 & 6.4 & 92.43 & 96.2 & $\mathrm{CHO}$ \\
\hline 2013 & 136 & 06 & 08 & 36 & -57.58 & -6.93 & 5.7 & 73.56 & 284.1 & TAR, CHA, PCH \\
\hline 2013 & 138 & 04 & 18 & 38 & -53.09 & 22.08 & 5.6 & 88.90 & 256.8 & HYS, TAR, YRM \\
\hline 2013 & 140 & 09 & 55 & 40 & -44.87 & -80.75 & 6.4 & 35.98 & 4.8 & HYS, TAR, CHA, PCH \\
\hline 2013 & 143 & 17 & 32 & 43 & -23.03 & -177.11 & 7.4 & 95.02 & 101.7 & HYS, OXA \\
\hline 2013 & 144 & 03 & 57 & 44 & 40.19 & -121.06 & 5.7 & 60.96 & 128.9 & CHA, YRM, TAR \\
\hline 2013 & 144 & 11 & 23 & 44 & -24.34 & -174.92 & 5.9 & 92.37 & 97.6 & PCH, HYS \\
\hline 2013 & 153 & 04 & 16 & 53 & -57.19 & -141.63 & 5.5 & 71.30 & 72.3 & TAR \\
\hline 2013 & 158 & 20 & 23 & 58 & -43.74 & -16.16 & 5.7 & 61.69 & 286.6 & PUC, HYS, PCH \\
\hline 2013 & 167 & 03 & 01 & 67 & -56.24 & -27.53 & 5.5 & 61.39 & 299.9 & HYS \\
\hline 2013 & 167 & 03 & 02 & 67 & -56.24 & -27.53 & 5.5 & 66.08 & 298.9 & $\mathrm{CHO}$ \\
\hline 2013 & 167 & 05 & 18 & 67 & 18.15 & -99.20 & 5.8 & 33.61 & 128.0 & IQT \\
\hline 2013 & 167 & 05 & 25 & 67 & 18.15 & -99.20 & 5.8 & 30.81 & 139.5 & $\mathrm{PCH}$ \\
\hline 2013 & 175 & 22 & 04 & 75 & 10.70 & -42.59 & 6.6 & 33.85 & 246.4 & $\mathrm{IQT}$ \\
\hline 2013 & 175 & 22 & 11 & 75 & 10.70 & -42.59 & 6.6 & 40.17 & 242.4 & HYS, PCH, CHO \\
\hline 2013 & 183 & 09 & 51 & 83 & -15.80 & -173.80 & 5.5 & 93.32 & 100.1 & HYS \\
\hline 2013 & 183 & 18 & 46 & 83 & -35.91 & -102.92 & 5.7 & 35.32 & 46.4 & HYS, PCH, CHO \\
\hline 2013 & 184 & 03 & 53 & 84 & 51.53 & -166.94 & 5.8 & 92.96 & 95.9 & $\mathrm{PCH}$ \\
\hline 2013 & 196 & 14 & 03 & 96 & -60.87 & -25.14 & 7.3 & 67.46 & 306.4 & IQT \\
\hline
\end{tabular}


Tabela B.12: Lista de eventos detectados pelas estações da Rede do IGP

\begin{tabular}{|l|c|c|c|c|c|c|c|c|c|l|}
\hline Ano & Dia & Hora & Min. & Seg. & Lat. & Long. & M & Dist $\left(^{\circ}\right)$ & Azimute $\left(^{\circ}\right)$ & Estações \\
\hline 2013 & 196 & 14 & 14 & 96 & -60.87 & -25.14 & 7.3 & 66.70 & 302.7 & YRM \\
2013 & 197 & 19 & 51 & 97 & -63.30 & -62.48 & 5.7 & 55.47 & 341.4 & HYS, PCH \\
2013 & 200 & 11 & 53 & 00 & -30.39 & -176.24 & 5.7 & 92.68 & 98.5 & PCH, HYS \\
2013 & 205 & 03 & 45 & 05 & -23.13 & -177.22 & 5.9 & 94.63 & 98.5 & PCH \\
2013 & 207 & 21 & 43 & 07 & -57.91 & -23.84 & 6.2 & 67.29 & 296.9 & PCH \\
2013 & 213 & 20 & 14 & 13 & -15.24 & -173.50 & 6.0 & 92.19 & 96.8 & PCH \\
2013 & 224 & 18 & 14 & 24 & -56.52 & -142.32 & 5.7 & 70.13 & 69.9 & PCH \\
2013 & 233 & 12 & 44 & 33 & 16.88 & -99.50 & 6.2 & 30.04 & 137.6 & PCH, YRM, CBT \\
2013 & 236 & 08 & 53 & 36 & -22.52 & -175.24 & 5.8 & 92.91 & 97.6 & PCH \\
2013 & 248 & 04 & 08 & 48 & 15.18 & -45.23 & 6.0 & 37.13 & 237.9 & YRM \\
2013 & 259 & 07 & 37 & 59 & -29.96 & -178.83 & 5.5 & 95.02 & 103.1 & HYS \\
2013 & 264 & 17 & 02 & 64 & -33.51 & -178.02 & 5.8 & 93.55 & 102.9 & HYS \\
2013 & 273 & 08 & 27 & 73 & 49.50 & -28.53 & 5.5 & 72.91 & 232.3 & CBT \\
2013 & 284 & 21 & 38 & 84 & -30.66 & -178.48 & 6.2 & 93.89 & 102.9 & CBT \\
2013 & 297 & 19 & 36 & 97 & -58.15 & -12.80 & 6.7 & 69.57 & 286.1 & CBT \\
2013 & 298 & 18 & 07 & 98 & -19.36 & -173.73 & 5.7 & 91.94 & 100.3 & CBT \\
2013 & 306 & 19 & 18 & 06 & -19.21 & -172.40 & 5.7 & 90.73 & 99.8 & CBT \\
2013 & 313 & 15 & 06 & 13 & -28.32 & -176.77 & 5.5 & 93.63 & 102.0 & HYS \\
2013 & 323 & 23 & 29 & 23 & -63.29 & -164.94 & 5.7 & 80.26 & 90.9 & CBT \\
2013 & 327 & 08 & 01 & 27 & -17.12 & -176.55 & 6.5 & 94.99 & 101.1 & CBT \\
2013 & 329 & 07 & 29 & 29 & -53.87 & -53.91 & 6.0 & 48.81 & 326.9 & CBT \\
2013 & 335 & 03 & 29 & 35 & 41.68 & -126.88 & 5.5 & 62.66 & 126.3 & CHO, PCH \\
2013 & 335 & 03 & 30 & 35 & 41.68 & -126.88 & 5.5 & 67.27 & 126.8 & CBT \\
2013 & 336 & 12 & 31 & 36 & -53.32 & 25.50 & 5.5 & 90.83 & 254.1 & HYS \\
2013 & 362 & 06 & 54 & 62 & -56.43 & -142.54 & 5.6 & 68.76 & 73.4 & HYS, CHO \\
2013 & 362 & 19 & 09 & 62 & -1.37 & -15.17 & 5.8 & 65.84 & 265.0 & CHO \\
2013 & 362 & 19 & 19 & 62 & -18.20 & -174.32 & 5.9 & 93.38 & 100.4 & HYS \\
2014 & 032 & 04 & 08 & 32 & -56.83 & -27.34 & 6.1 & 61.78 & 300.0 & HYS \\
\hline
\end{tabular}


Tabela B.13: Lista de eventos detectados pelas estações da Rede do IGP

\begin{tabular}{|c|c|c|c|c|c|c|c|c|c|c|}
\hline Ano & Dia & Hora & Min. & Seg. & Lat. & Long. & $\mathrm{M}$ & $\operatorname{Dist}\left({ }^{\circ}\right)$ & Azimute $\left({ }^{\circ}\right)$ & Estações \\
\hline 2014 & 032 & 04 & 09 & 32 & -56.83 & -27.34 & 6.1 & 65.11 & 299.8 & $\mathrm{PCH}, \mathrm{CHO}$ \\
\hline 2014 & 033 & 09 & 39 & 33 & -32.91 & -177.88 & 6.5 & 93.56 & 102.8 & HYS, PCH \\
\hline 2014 & 039 & 20 & 00 & 39 & -60.43 & -45.19 & 5.7 & 60.20 & 319.5 & $\mathrm{PCH}, \mathrm{CHO}$ \\
\hline 2014 & 045 & 07 & 51 & 45 & -22.96 & -114.33 & 5.6 & 36.77 & 66.3 & CHO, CBT, PCH, HYS, PUC \\
\hline 2014 & 049 & 09 & 33 & 49 & 14.67 & -58.93 & 6.5 & 30.02 & 220.0 & HYS \\
\hline 2014 & 053 & 22 & 49 & 53 & -60.24 & -47.28 & 5.5 & 59.40 & 321.7 & $\mathrm{PCH}$ \\
\hline 2014 & 069 & 05 & 28 & 69 & 40.83 & -125.13 & 6.8 & 65.70 & 128.0 & $\mathrm{CBT}$ \\
\hline 2014 & 070 & 02 & 54 & 70 & -60.86 & -19.98 & 6.4 & 67.05 & 293.8 & IQT \\
\hline 2014 & 071 & 19 & 38 & 71 & -23.59 & -175.09 & 5.6 & 92.40 & 100.9 & IQT \\
\hline 2014 & 072 & 19 & 22 & 72 & 41.90 & -126.90 & 5.5 & 67.41 & 126.9 & IQT \\
\hline 2014 & 088 & 07 & 55 & 88 & -0.85 & -21.92 & 5.9 & 53.12 & 260.2 & $\mathrm{PUC}, \mathrm{CHO}$ \\
\hline 2014 & 099 & 08 & 37 & 99 & -49.85 & -114.28 & 5.6 & 52.48 & 45.4 & $\mathrm{PCH}$ \\
\hline 2014 & 105 & 04 & 08 & 05 & -53.50 & 8.72 & 6.8 & 79.36 & 270.3 & PUC, HYS, YRM, PCH \\
\hline 2014 & 107 & 13 & 20 & 07 & -55.04 & -129.53 & 5.7 & 61.45 & 61.9 & HYS \\
\hline 2014 & 108 & 14 & 27 & 08 & 17.40 & -100.97 & 7.2 & 34.52 & 125.1 & IQT \\
\hline 2014 & 108 & 14 & 33 & 08 & 17.40 & -100.97 & 7.2 & 31.39 & 136.1 & PCH, YRM \\
\hline 2014 & 108 & 14 & 34 & 08 & 17.40 & -100.97 & 7.2 & 34.68 & 137.0 & HYS \\
\hline 2014 & 108 & 18 & 57 & 08 & 67.72 & -162.67 & 5.5 & 92.83 & 98.7 & $\mathrm{PCH}$ \\
\hline 2014 & 110 & 01 & 54 & 10 & -26.56 & -115.02 & 5.9 & 45.88 & 67.7 & IQT \\
\hline 2014 & 110 & 02 & 01 & 10 & -26.56 & -115.02 & 5.9 & 39.35 & 70.3 & HYS, PCH, PUC \\
\hline 2014 & 114 & 03 & 10 & 14 & 49.64 & -127.73 & 6.5 & 70.92 & 120.8 & IQT \\
\hline 2014 & 114 & 03 & 21 & 14 & 49.64 & -127.73 & 6.5 & 69.34 & 127.8 & $\mathrm{PCH}$ \\
\hline 2014 & 114 & 20 & 05 & 14 & -24.01 & -176.67 & 5.9 & 94.00 & 98.3 & $\mathrm{PCH}$ \\
\hline 2014 & 116 & 06 & 15 & 16 & -20.75 & -174.71 & 6.1 & 92.65 & 97.4 & $\mathrm{PCH}$ \\
\hline 2014 & 123 & 09 & 10 & 23 & 67.63 & -162.21 & 5.5 & 92.65 & 99.2 & $\mathrm{PCH}$ \\
\hline 2014 & 126 & 20 & 58 & 26 & -36.17 & -97.05 & 6.3 & 34.01 & 32.1 & $\mathrm{PCH}$ \\
\hline 2014 & 128 & 17 & 06 & 28 & 17.24 & -100.75 & 6.4 & 31.12 & 136.2 & PCH, YRM, CBT \\
\hline 2014 & 130 & 07 & 42 & 30 & 17.22 & -100.81 & 6.0 & 33.54 & 131.2 & YRM, HYS \\
\hline
\end{tabular}


Tabela B.14: Lista de eventos detectados pelas estações da Rede do IGP

\begin{tabular}{|c|c|c|c|c|c|c|c|c|c|c|}
\hline Ano & Dia & Hora & Min. & Seg. & Lat. & Long. & $\mathrm{M}$ & $\operatorname{Dist}\left({ }^{\circ}\right)$ & Azimute $\left(^{\circ}\right)$ & Estações \\
\hline 2014 & 130 & 14 & 28 & 30 & 60.00 & -152.13 & 5.6 & 89.79 & 108.7 & CBT \\
\hline 2014 & 132 & 18 & 47 & 32 & -49.94 & -114.80 & 6.5 & 50.61 & 49.1 & CBT, HYS, PCH, CHO, YRM \\
\hline 2014 & 136 & 11 & 07 & 36 & 17.09 & -60.37 & 5.9 & 30.08 & 224.4 & $\mathrm{CHO}, \mathrm{CBT}$ \\
\hline 2014 & 137 & 12 & 24 & 37 & -54.25 & -146.69 & 5.7 & 69.92 & 77.4 & CBT, HYS, CHO, PCH, YRM \\
\hline 2014 & 138 & 01 & 11 & 38 & -14.67 & -175.53 & 5.7 & 94.49 & 100.6 & CBT \\
\hline 2014 & 138 & 06 & 51 & 38 & -14.81 & -175.90 & 5.6 & 94.82 & 100.7 & CBT \\
\hline 2014 & 138 & 23 & 53 & 38 & -4.42 & -105.94 & 5.8 & 31.35 & 98.8 & PUC \\
\hline 2014 & 139 & 01 & 59 & 39 & -4.77 & -105.55 & 5.5 & 30.91 & 98.3 & PUC \\
\hline 2014 & 139 & 22 & 57 & 39 & -57.03 & -25.15 & 5.7 & 62.93 & 298.0 & HYS, CHO \\
\hline 2014 & 141 & 10 & 12 & 41 & 17.12 & -95.07 & 5.8 & 30.82 & 146.7 & CBT, HYS \\
\hline 2014 & 142 & 08 & 47 & 42 & -55.40 & -28.28 & 5.5 & 60.68 & 299.5 & CBT \\
\hline 2014 & 142 & 08 & 48 & 42 & -55.40 & -28.28 & 5.5 & 62.32 & 303.6 & YRM, CHO \\
\hline 2014 & 143 & 23 & 52 & 43 & 45.01 & -27.84 & 5.5 & 66.61 & 234.0 & YRM \\
\hline 2014 & 144 & 08 & 30 & 44 & 16.53 & -98.14 & 5.7 & 31.18 & 133.9 & YRM \\
\hline 2014 & 144 & 08 & 31 & 44 & 16.53 & -98.14 & 5.7 & 32.07 & 141.3 & CBT \\
\hline 2014 & 150 & 11 & 43 & 50 & -55.31 & -128.58 & 5.5 & 60.54 & 60.4 & CBT, HYS \\
\hline 2014 & 151 & 12 & 00 & 51 & 18.79 & -107.47 & 6.2 & 36.88 & 129.3 & $\mathrm{PCH}$ \\
\hline 2014 & 151 & 12 & 01 & 51 & 18.79 & -107.47 & 6.2 & 39.48 & 125.5 & YRM, CBT, HYS \\
\hline 2014 & 154 & 04 & 49 & 54 & -54.97 & -129.62 & 5.6 & 60.90 & 61.6 & $\mathrm{CBT}$ \\
\hline 2014 & 154 & 04 & 50 & 54 & -54.97 & -129.62 & 5.6 & 61.46 & 62.0 & HYS, PCH \\
\hline 2014 & 155 & 12 & 10 & 55 & 59.03 & -136.75 & 5.7 & 79.02 & 121.7 & $\mathrm{PCH}$ \\
\hline 2014 & 155 & 12 & 11 & 55 & 59.03 & -136.75 & 5.7 & 82.31 & 122.1 & CBT, HYS \\
\hline 2014 & 156 & 17 & 22 & 56 & -29.15 & -112.48 & 5.9 & 44.90 & 63.3 & IQT, PCH, YANA, TICA, TBM, PUC \\
\hline 2014 & 158 & 04 & 56 & 58 & 67.73 & -162.38 & 5.5 & 92.72 & 99.0 & $\mathrm{PCH}$ \\
\hline 2014 & 167 & 12 & 14 & 67 & 67.70 & -162.61 & 5.7 & 92.81 & 98.8 & $\mathrm{PCH}$ \\
\hline 2014 & 174 & 19 & 32 & 74 & -29.98 & -177.73 & 6.9 & 93.40 & 102.5 & CBT \\
\hline 2014 & 174 & 22 & 33 & 74 & -29.97 & -177.25 & 5.9 & 92.93 & 97.6 & $\mathrm{CHO}$ \\
\hline 2014 & 180 & 07 & 52 & 80 & -55.47 & -28.37 & 6.9 & 62.85 & 307.6 & IQT \\
\hline
\end{tabular}


Tabela B.15: Lista de eventos detectados pelas estações da Rede do IGP

\begin{tabular}{|c|c|c|c|c|c|c|c|c|c|c|}
\hline Ano & Dia & Hora & Min. & Seg. & Lat. & Long. & $\mathrm{M}$ & $\operatorname{Dist}\left({ }^{\circ}\right)$ & Azimute $\left(^{\circ}\right)$ & Estações \\
\hline 2014 & 180 & 08 & 03 & 80 & -55.47 & -28.37 & 6.9 & 62.31 & 303.7 & YRM \\
\hline 2014 & 180 & 14 & 30 & 80 & -55.41 & -28.11 & 5.6 & 62.40 & 303.4 & YRM \\
\hline 2014 & 180 & 14 & 42 & 80 & -55.36 & -28.11 & 5.7 & 58.25 & 300.8 & YANA, HYS, TICA, YRM \\
\hline 2014 & 180 & 14 & 43 & 80 & -55.36 & -28.11 & 5.7 & 64.01 & 299.9 & PCH, TBM \\
\hline 2014 & 180 & 17 & 28 & 80 & -14.98 & -175.51 & 6.7 & 93.14 & 96.1 & $\mathrm{CHO}$ \\
\hline 2014 & 181 & 01 & 55 & 81 & 0.05 & -17.34 & 5.6 & 57.78 & 260.1 & $\mathrm{PUC}, \mathrm{PCH}$ \\
\hline 2014 & 182 & 05 & 53 & 82 & -56.62 & -141.78 & 5.6 & 68.42 & 72.6 & HYS \\
\hline 2014 & 184 & 20 & 03 & 84 & -30.46 & -176.45 & 6.3 & 92.90 & 101.9 & HYS \\
\hline 2014 & 193 & 17 & 59 & 93 & -55.42 & -27.97 & 5.6 & 61.57 & 300.5 & TICA, NIEV, TBM \\
\hline 2014 & 198 & 11 & 49 & 98 & 60.35 & -140.33 & 6.0 & 82.16 & 112.0 & IQT \\
\hline 2014 & 198 & 12 & 01 & 98 & 60.35 & -140.33 & 6.0 & 81.25 & 118.7 & $\mathrm{PCH}$ \\
\hline 2014 & 199 & 18 & 36 & 99 & -34.63 & -179.58 & 5.6 & 94.75 & 100.5 & $\mathrm{PCH}$ \\
\hline 2014 & 206 & 11 & 06 & 06 & 58.31 & -136.96 & 6.1 & 78.31 & 119.1 & NIEV, TICA \\
\hline 2014 & 206 & 11 & 07 & 06 & 58.31 & -136.96 & 6.1 & 84.45 & 120.4 & YANA \\
\hline 2014 & 207 & 11 & 24 & 07 & -60.04 & -18.68 & 5.8 & 68.10 & 293.5 & TICA, PCH \\
\hline 2014 & 207 & 11 & 25 & 07 & -60.04 & -18.68 & 5.8 & 73.09 & 293.4 & TBM \\
\hline 2014 & 208 & 01 & 36 & 08 & 23.72 & -45.58 & 6.0 & 42.27 & 232.4 & NIEV, PCH, TICA, YANA \\
\hline 2014 & 210 & 10 & 52 & 10 & 17.68 & -95.65 & 6.3 & 30.37 & 138.8 & YRM, TICA, YANA \\
\hline 2014 & 213 & 04 & 23 & 13 & 36.86 & 3.18 & 5.5 & 85.64 & 261.0 & NIEV, TICA \\
\hline 2014 & 214 & 14 & 12 & 14 & -55.43 & -28.31 & 5.6 & 61.41 & 300.8 & TICA, YRM, PCH, NIEV \\
\hline 2014 & 222 & 18 & 54 & 22 & 27.68 & -111.63 & 5.5 & 43.31 & 130.8 & TBM, YRM, YANA \\
\hline 2014 & 223 & 13 & 38 & 23 & -41.33 & -84.96 & 5.5 & 31.56 & 16.8 & YANA, TICA \\
\hline 2014 & 236 & 10 & 30 & 36 & 38.22 & -122.31 & 6.0 & 61.38 & 125.1 & YRM \\
\hline 2014 & 236 & 20 & 31 & 36 & -55.32 & -28.52 & 5.5 & 61.26 & 301.0 & TICA \\
\hline 2014 & 244 & 11 & 53 & 44 & 64.68 & -17.48 & 5.5 & 85.02 & 239.9 & TICA, YANA \\
\hline 2014 & 246 & 20 & 41 & 46 & -26.64 & -114.74 & 5.9 & 39.75 & 73.8 & YANA \\
\hline 2014 & 246 & 20 & 41 & 46 & -26.64 & -114.74 & 5.9 & 42.10 & 71.9 & PUC, YRM \\
\hline 2014 & 247 & 05 & 46 & 47 & -21.39 & -173.32 & 6.0 & 91.28 & 96.9 & PCH, PUC \\
\hline
\end{tabular}


Tabela B.16: Lista de eventos detectados pelas estações da Rede do IGP

\begin{tabular}{|l|c|c|c|c|c|c|c|c|c|l|}
\hline Ano & Dia & Hora & Min. & Seg. & Lat. & Long. & M & Dist $\left(^{\circ}\right)$ & Azimute $\left(^{\circ}\right)$ & Estações \\
\hline 2014 & 248 & 19 & 43 & 48 & -26.71 & -114.25 & 5.8 & 39.24 & 68.2 & TICA, TBM \\
2014 & 248 & 19 & 44 & 48 & -26.71 & -114.25 & 5.8 & 41.70 & 71.5 & PUC \\
2014 & 249 & 06 & 53 & 49 & -26.65 & -114.50 & 6.1 & 45.48 & 67.2 & IQT \\
2014 & 249 & 07 & 00 & 49 & -26.65 & -114.50 & 6.1 & 39.55 & 73.6 & YANA, TBM, PUC, YRM \\
2014 & 249 & 07 & 55 & 49 & -26.77 & -114.47 & 5.9 & 38.28 & 69.5 & CBT \\
2014 & 249 & 07 & 56 & 49 & -26.77 & -114.47 & 5.9 & 41.35 & 64.2 & NIEV, PUC, YRM \\
2014 & 249 & 19 & 30 & 49 & 18.75 & -107.05 & 6.2 & 39.14 & 125.9 & YRM, TICA, YANA \\
2014 & 258 & 07 & 20 & 50 & 64.54 & -17.40 & 5.5 & 84.99 & 239.9 & TICA \\
2014 & 265 & 16 & 11 & 65 & -56.02 & -27.78 & 5.7 & 61.23 & 299.3 & CBT, TICA, YRM \\
2014 & 268 & 17 & 51 & 68 & 61.95 & -151.82 & 6.2 & 87.94 & 101.9 & IQT \\
2014 & 268 & 18 & 04 & 68 & 61.95 & -151.82 & 6.2 & 89.47 & 107.9 & TICA, CBT, YANA \\
2014 & 271 & 06 & 36 & 71 & -19.13 & -176.34 & 5.7 & 94.41 & 101.1 & CBT \\
2014 & 272 & 13 & 55 & 72 & 64.51 & -17.32 & 5.6 & 85.00 & 240.0 & TICA, CBT \\
2014 & 277 & 19 & 22 & 77 & 17.42 & -94.82 & 5.6 & 30.25 & 145.1 & TICA \\
2014 & 277 & 19 & 23 & 77 & 17.42 & -94.82 & 5.6 & 33.48 & 145.1 & YANA \\
2014 & 280 & 10 & 34 & 80 & 64.53 & -17.20 & 5.5 & 85.05 & 240.1 & TICA \\
2014 & 281 & 02 & 40 & 81 & 23.84 & -108.33 & 6.1 & 43.84 & 124.2 & IQT \\
2014 & 281 & 02 & 48 & 81 & 23.84 & -108.33 & 6.1 & 43.18 & 129.2 & YRM \\
2014 & 281 & 02 & 49 & 81 & 23.84 & -108.33 & 6.1 & 46.59 & 133.8 & YANA \\
2014 & 282 & 02 & 21 & 82 & -32.11 & -110.81 & 7.0 & 38.93 & 59.0 & TICA \\
2014 & 282 & 02 & 22 & 82 & -32.11 & -110.81 & 7.0 & 41.59 & 58.6 & YRM \\
2014 & 282 & 02 & 39 & 82 & -32.10 & -110.87 & 6.6 & 40.40 & 51.6 & TBM, YRM \\
2014 & 282 & 08 & 14 & 82 & -32.61 & -111.66 & 5.7 & 45.92 & 59.5 & IQT \\
2014 & 282 & 08 & 21 & 82 & -32.61 & -111.66 & 5.7 & 41.88 & 63.1 & PUC \\
2014 & 282 & 08 & 22 & 82 & -32.61 & -111.66 & 5.7 & 42.46 & 58.9 & YRM \\
2014 & 283 & 04 & 15 & 83 & -32.17 & -110.84 & 5.6 & 38.98 & 58.9 & TICA, PCH, YRM \\
\hline
\end{tabular}


Tabela B.17: Lista de eventos detectados pelas estações da Rede do IGP

\begin{tabular}{|c|c|c|c|c|c|c|c|c|c|c|}
\hline Ano & Dia & Hora & Min. & Seg. & Lat. & Long. & $\mathrm{M}$ & $\operatorname{Dist}\left({ }^{\circ}\right)$ & Azimute $\left(^{\circ}\right)$ & Estações \\
\hline 2014 & 285 & 05 & 51 & 85 & 57.28 & -33.27 & 5.6 & 71.43 & 227.6 & NIEV, TBM \\
\hline 2014 & 285 & 05 & 52 & 85 & 57.28 & -33.27 & 5.6 & 73.45 & 228.7 & PCH, TICA \\
\hline 2014 & 287 & 18 & 54 & 87 & -16.37 & -148.11 & 5.7 & 69.83 & 88.9 & NIEV, YANA, PUC \\
\hline 2014 & 288 & 11 & 28 & 88 & 64.48 & -18.00 & 5.5 & 82.21 & 238.5 & YRM, PUC \\
\hline 2014 & 288 & 11 & 29 & 88 & 64.48 & -18.00 & 5.5 & 86.58 & 236.7 & YANA \\
\hline 2014 & 305 & 10 & 12 & 05 & -31.92 & -111.11 & 5.8 & 38.64 & 64.6 & IQT, YANA \\
\hline 2014 & 305 & 10 & 13 & 05 & -31.92 & -111.11 & 5.8 & 41.36 & 55.8 & NIEV, YRM \\
\hline 2014 & 305 & 11 & 07 & 05 & -31.85 & -111.24 & 6.0 & 38.72 & 64.8 & IQT, YANA, CHO, TICA, NIEV \\
\hline 2014 & 307 & 08 & 31 & 07 & 4.67 & -32.68 & 5.5 & 43.89 & 252.9 & PUC \\
\hline 2014 & 307 & 08 & 32 & 07 & 4.67 & -32.68 & 5.5 & 45.88 & 250.4 & IQT, YANA, NIEV, TICA, TBM \\
\hline 2014 & 321 & 11 & 33 & 21 & -36.00 & -102.20 & 5.5 & 35.71 & 44.3 & TICA \\
\hline 2014 & 321 & 11 & 34 & 21 & -36.00 & -102.20 & 5.5 & 38.14 & 37.1 & TBM, NIEV \\
\hline 2014 & 345 & 14 & 03 & 45 & -56.75 & -25.43 & 5.6 & 60.25 & 298.8 & IQT, YANA, TICA \\
\hline 2014 & 347 & 12 & 53 & 47 & -28.97 & -112.20 & 5.5 & 38.35 & 69.0 & IQT, YANA \\
\hline 2014 & 352 & 20 & 21 & 52 & -56.63 & -25.37 & 5.5 & 63.44 & 298.5 & TICA \\
\hline 2014 & 356 & 07 & 30 & 56 & -54.11 & -146.09 & 5.8 & 69.72 & 79.9 & IQT, YANA, TICA, PCH \\
\hline 2014 & 362 & 20 & 41 & 62 & -59.77 & -27.15 & 5.5 & 66.68 & 300.7 & $\mathrm{PCH}, \mathrm{NIEV}, \mathrm{CHO}, \mathrm{TBM}$ \\
\hline 2014 & 363 & 17 & 52 & 63 & -56.66 & -24.85 & 5.6 & 63.71 & 298.0 & TICA, PCH, NIEV, CHO, TBM \\
\hline 2015 & 018 & 23 & 20 & 18 & -35.46 & -105.76 & 5.7 & 36.75 & 50.6 & HYS, TICA, PCH, TBM, NIEV \\
\hline 2015 & 026 & 17 & 55 & 26 & -54.68 & -136.77 & 5.6 & 64.58 & 71.6 & IQT, YANA, TBM, NIEV \\
\hline 2015 & 028 & 21 & 18 & 28 & 40.32 & -124.61 & 5.7 & 59.57 & 126.0 & TBM \\
\hline 2015 & 028 & 21 & 19 & 28 & 40.32 & -124.61 & 5.7 & 64.50 & 127.0 & TICA \\
\hline 2015 & 032 & 20 & 13 & 32 & -49.32 & -8.12 & 5.6 & 67.68 & 279.9 & IQT, YANA, HYL, TICA, YRM \\
\hline 2015 & 044 & 19 & 10 & 44 & 52.65 & -31.90 & 7.1 & 68.98 & 230.2 & NIEV, CHO, PCH, TICA, IQT, YANA \\
\hline 2015 & 047 & 22 & 10 & 47 & -55.52 & -28.26 & 6.2 & 61.49 & 300.8 & TICA, YRM, PCH, NIEV, CHO, TBM \\
\hline 2015 & 049 & 01 & 22 & 49 & 8.29 & -103.05 & 5.5 & 30.33 & 123.6 & HYS, YANA \\
\hline
\end{tabular}




\section{Anexo C}

RF (componente radial) e Hk-stacking para cada estação (Rede SisNort, CTBTO e IGP) ordenadas de acordo com o Back-azimute e Distância.

\section{Rede Sismográfica Temporal}

Projeto SisNort 

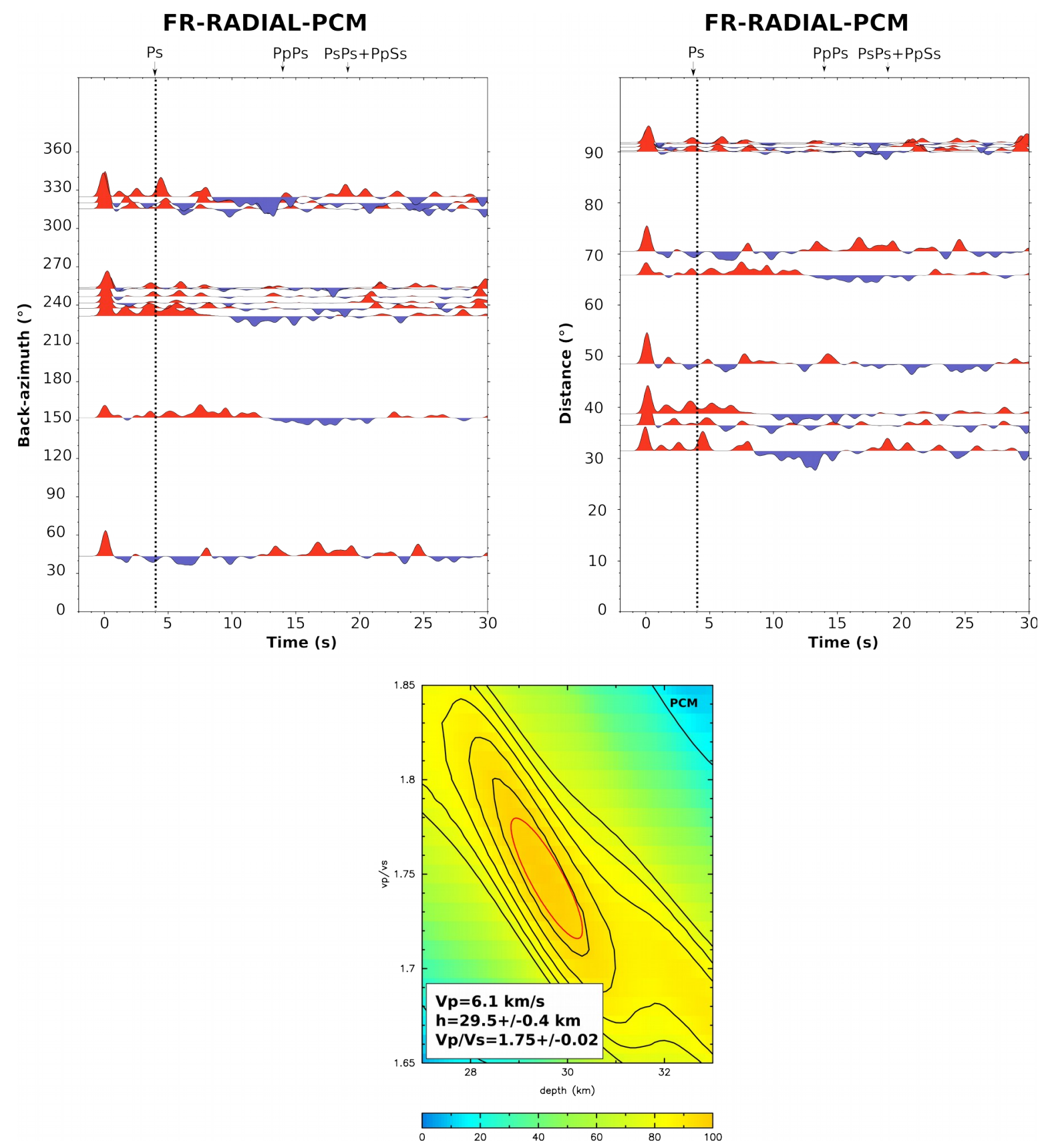

Figura C.1: RF (Radial) e Hk-stacking para a estação PCM. 

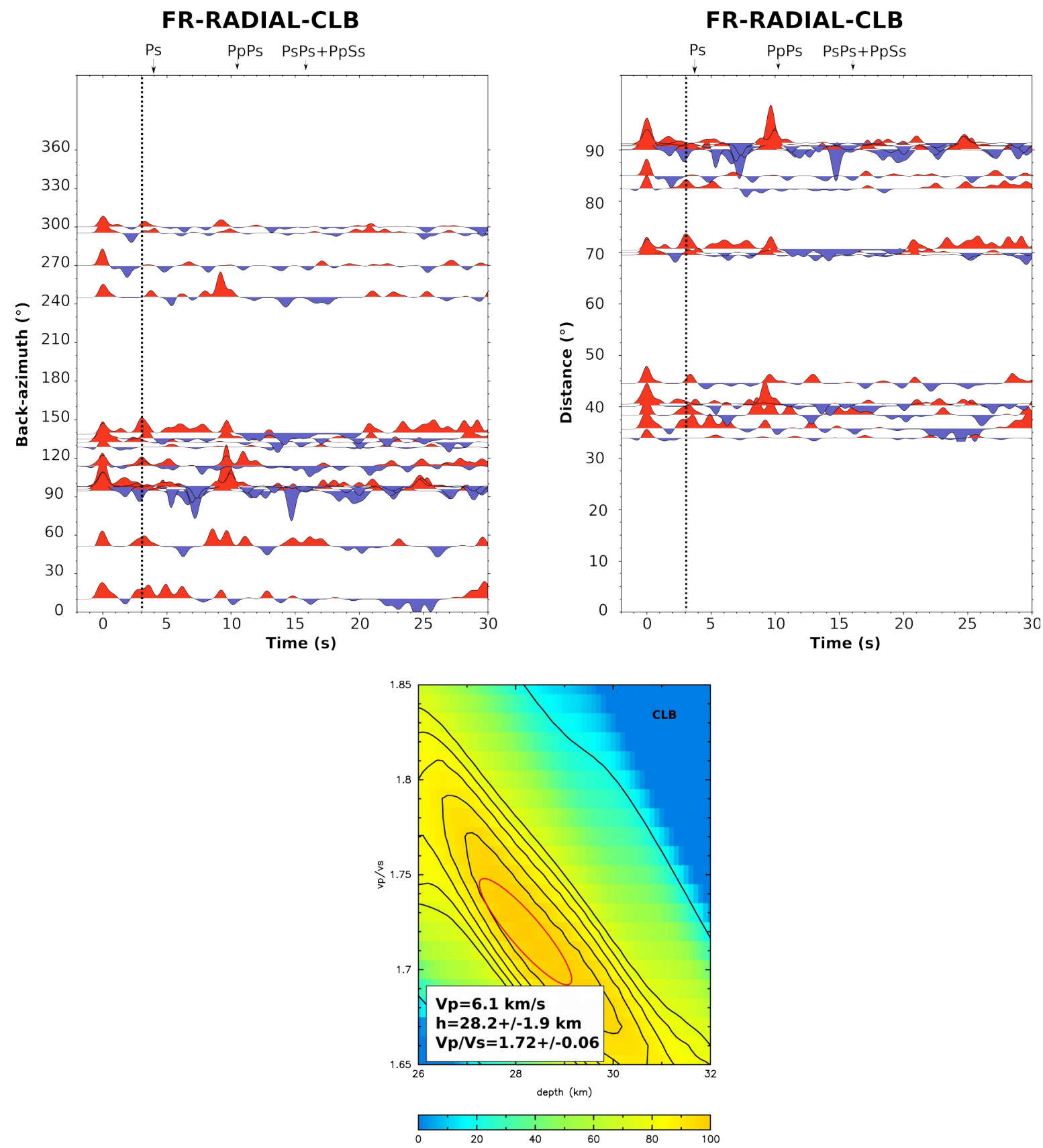

Figura C.2: RF (Radial) e Hk-stacking para a estação CLB. 

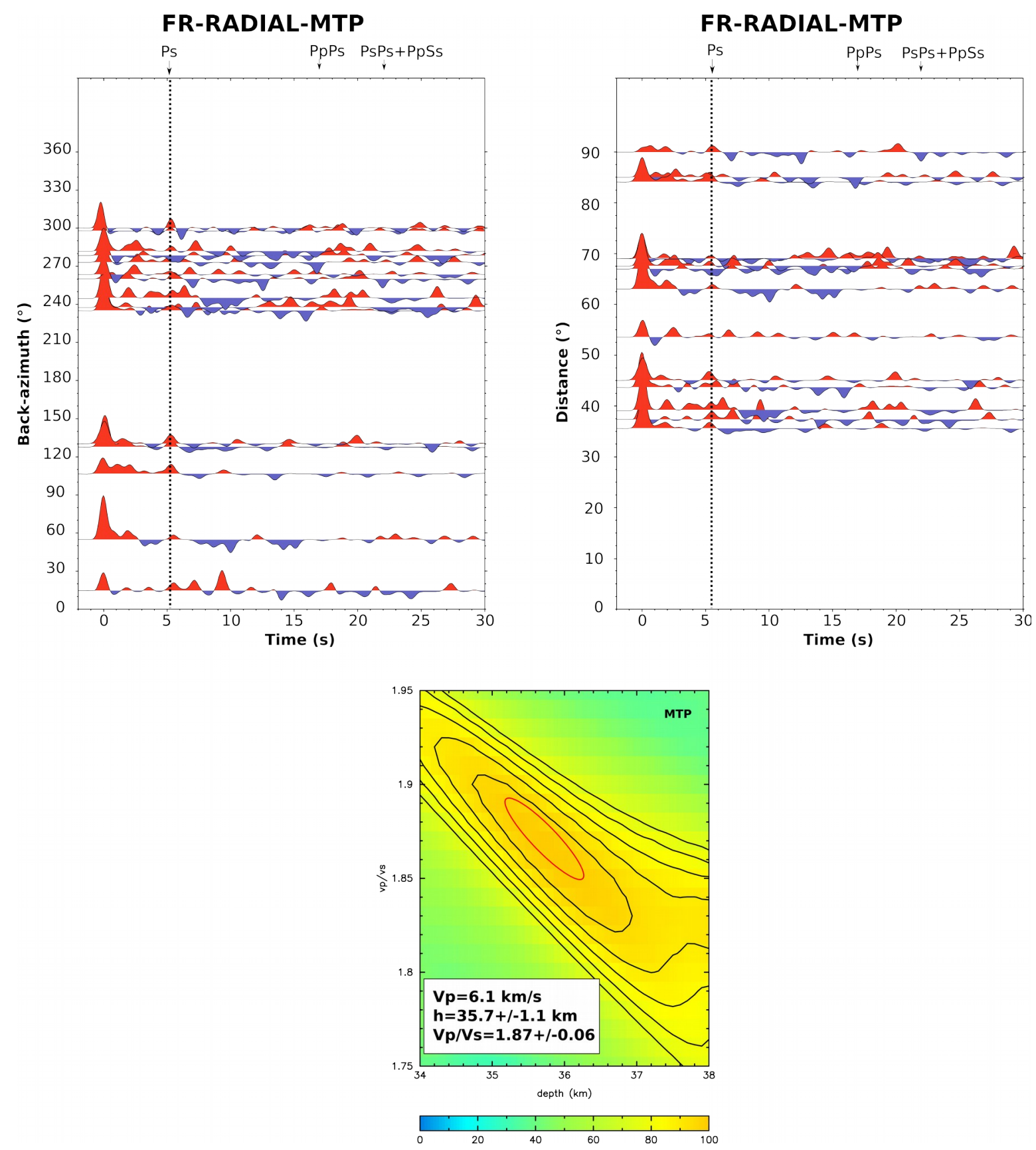

Figura C3: RF (Radial) e Hk-stacking para a estação MTP. 

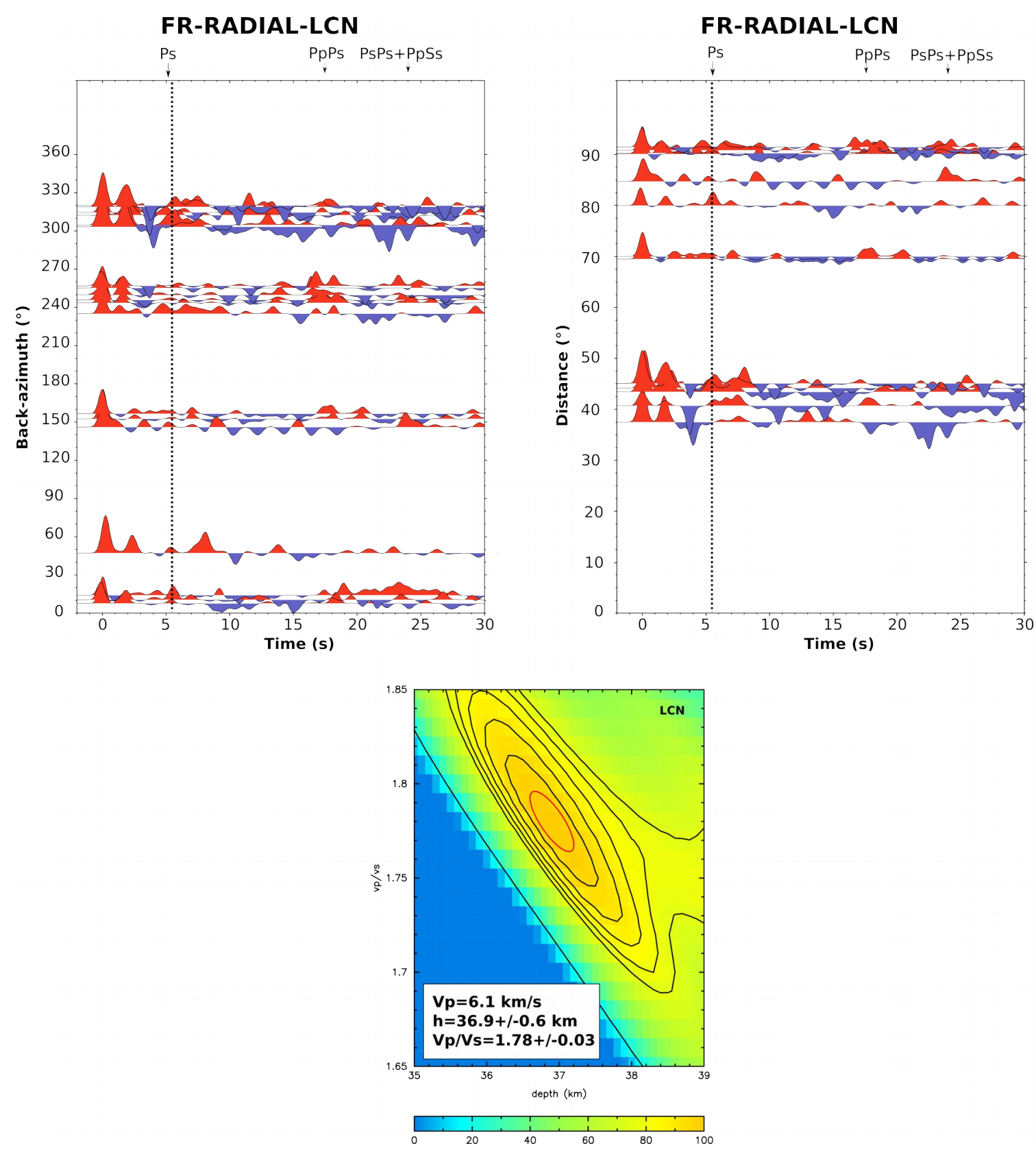

Figura C.4: RF (Radial) e Hk-stacking para a estação LCN. 

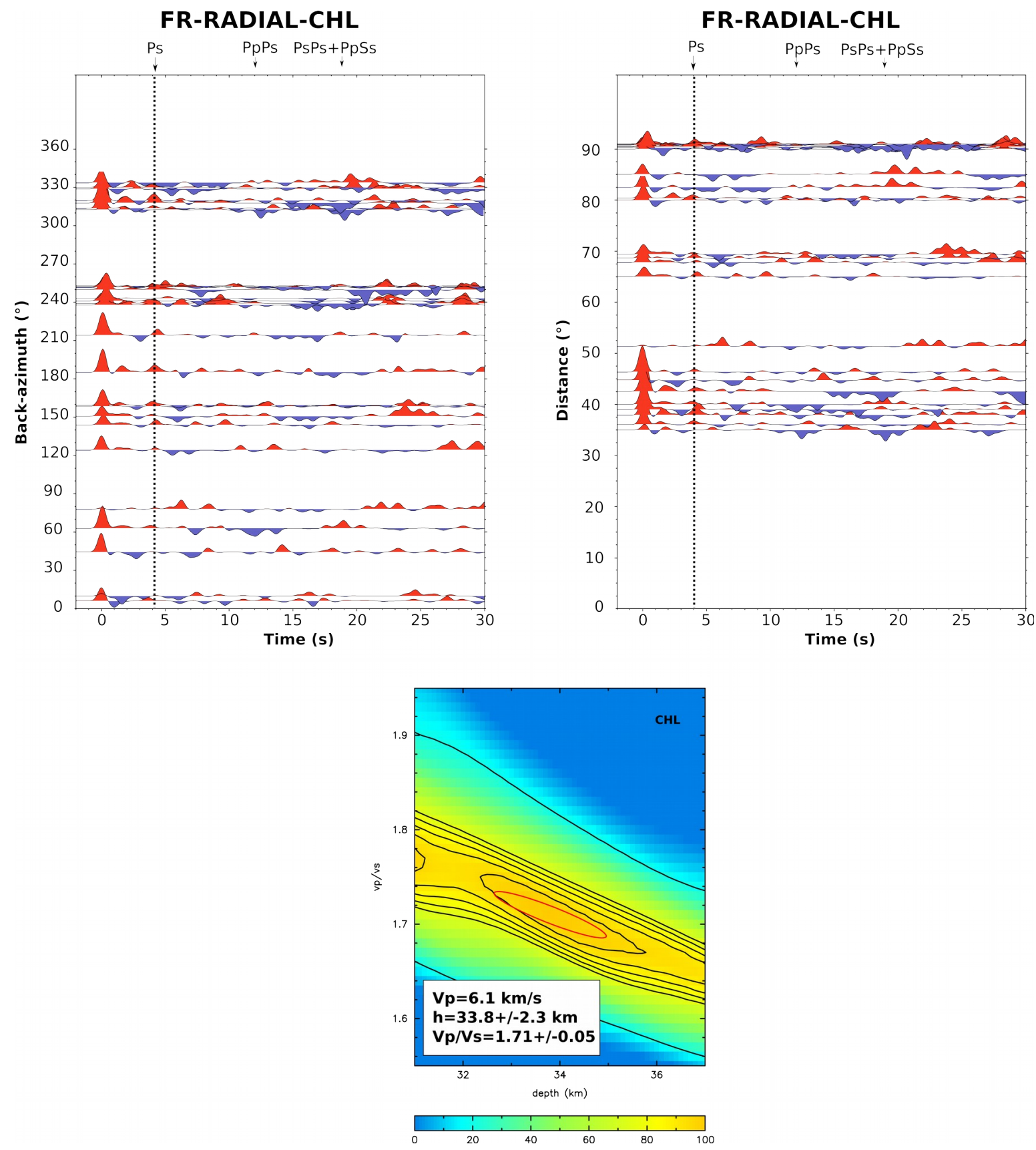

Figura C.5: RF (Radial) e Hk-stacking para a estação CHL. 

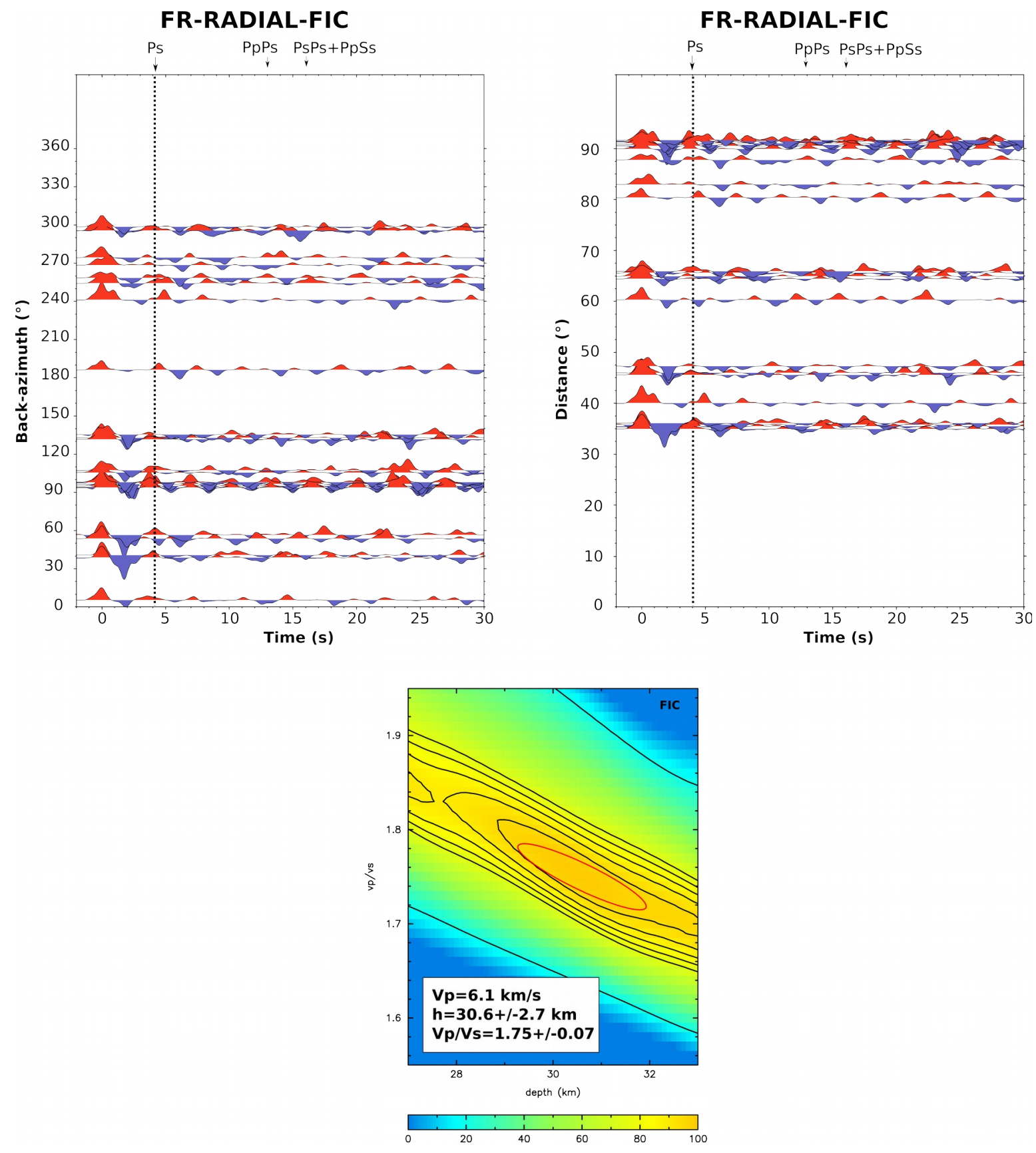

Figura C.6: RF (Radial) e Hk-stacking para a estação FIC. 
FR-RADIAL-CLL

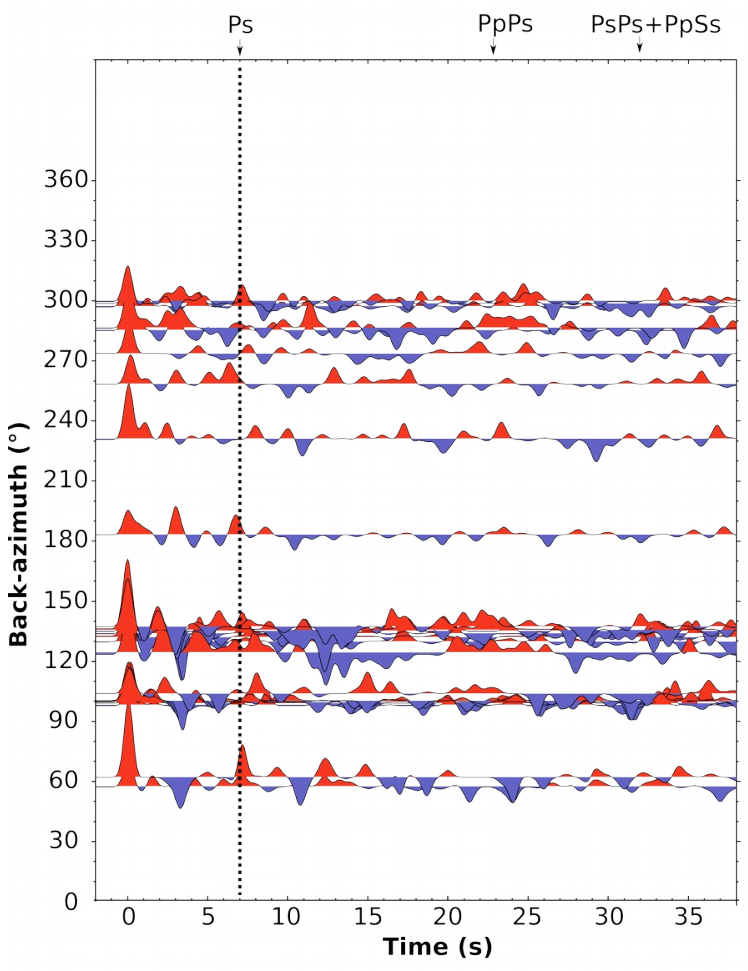

FR-RADIAL-CLL

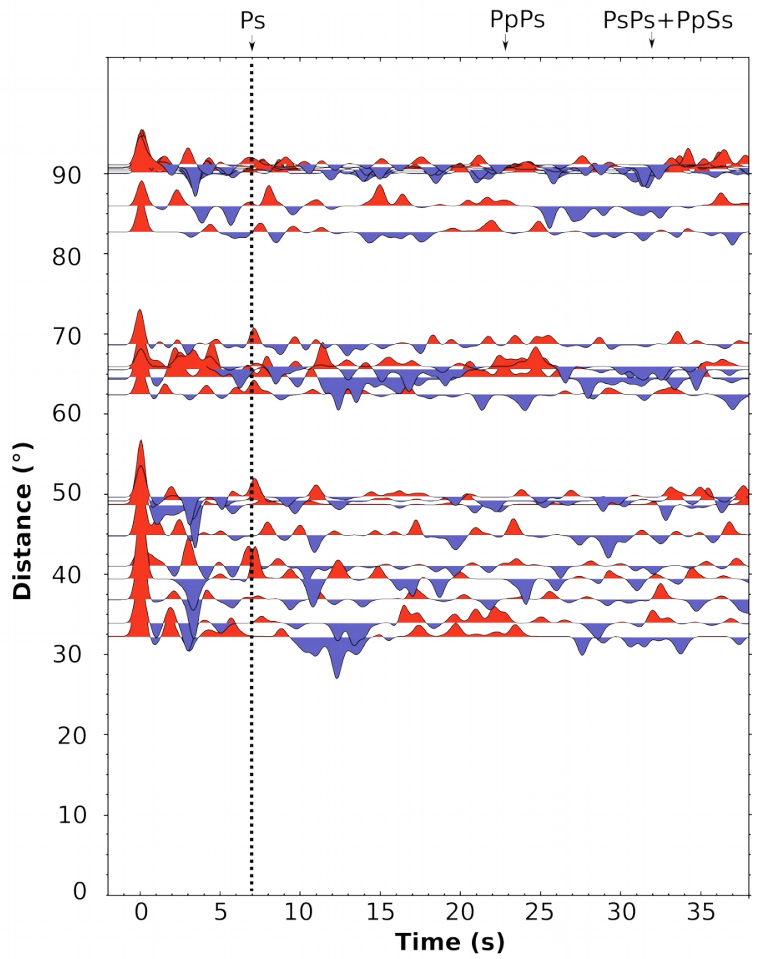

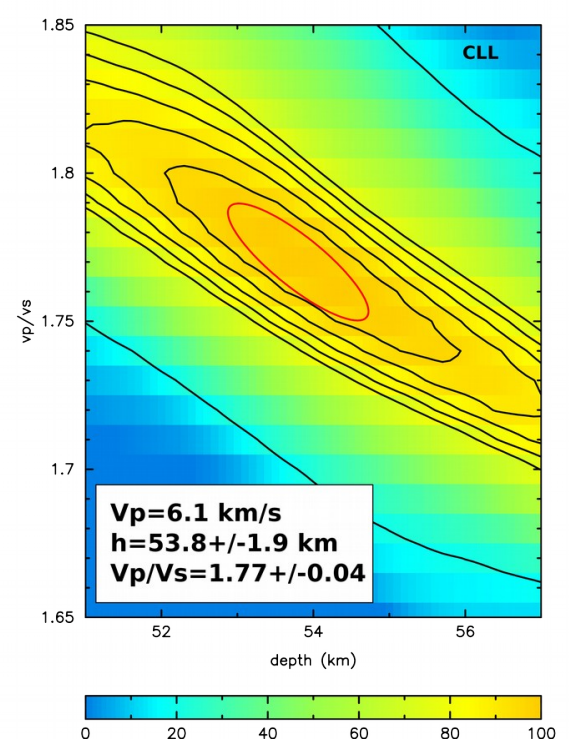

Figura C.7: RF (Radial) e Hk-stacking para a estação CLL. 
FR-RADIAL-SIG

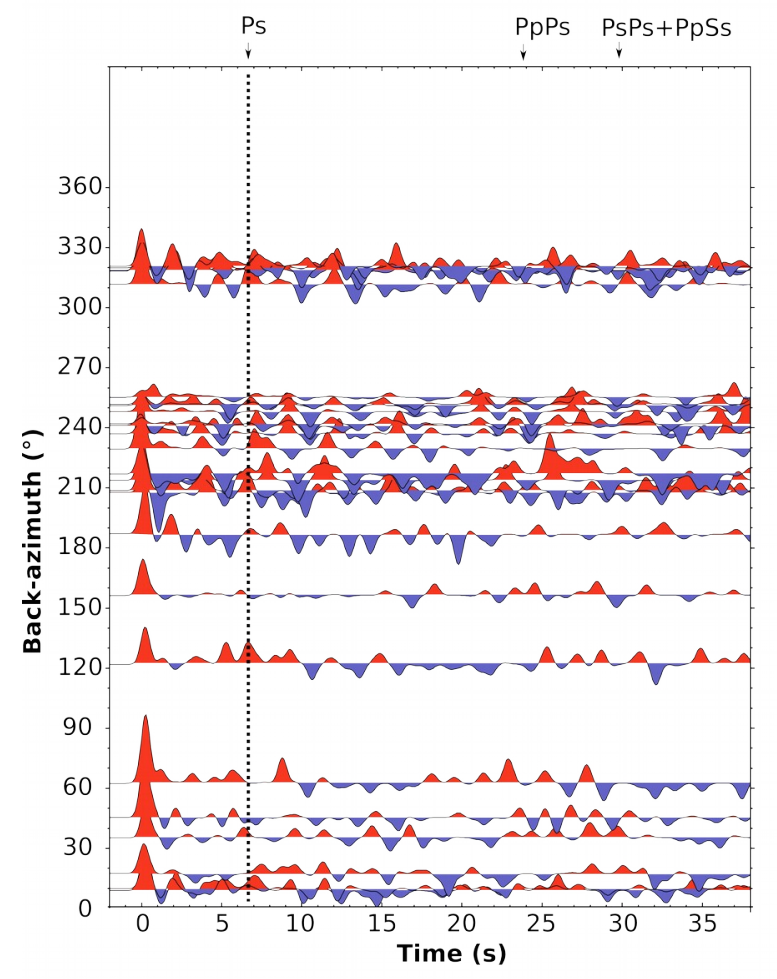

FR-RADIAL-SIG

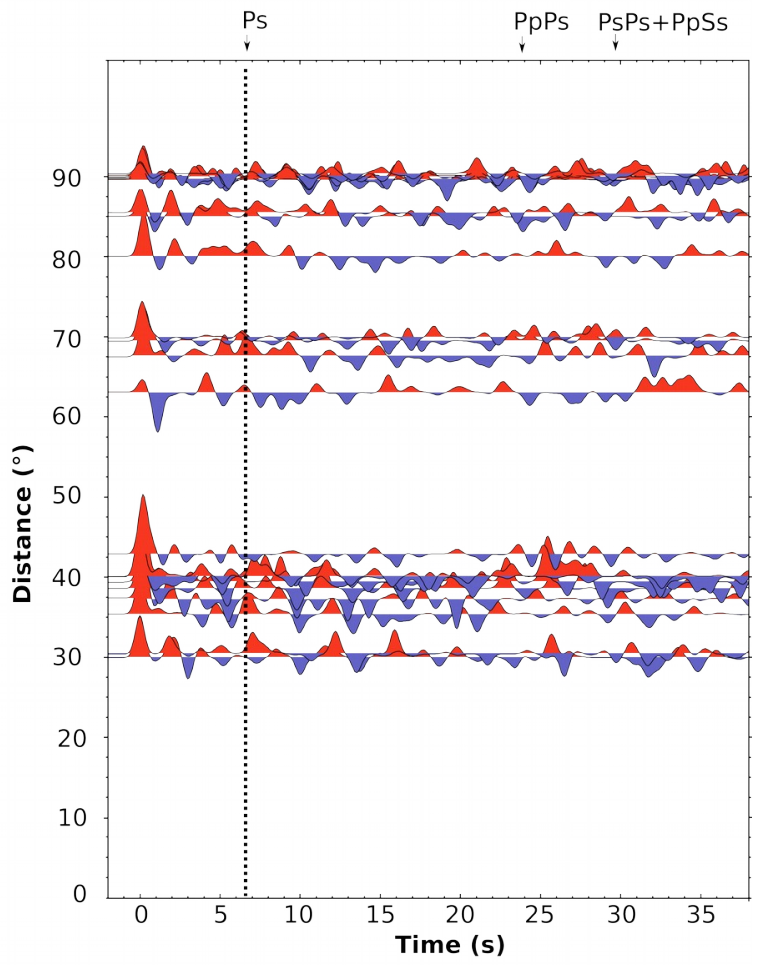

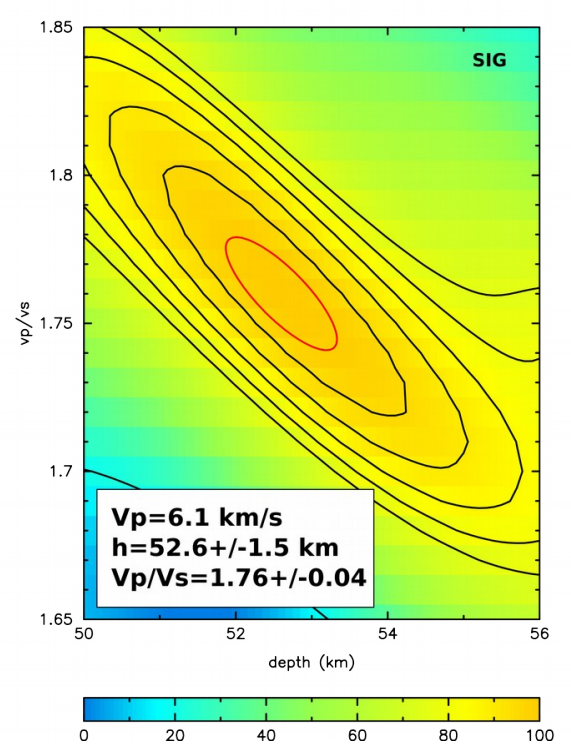

Figura C.8: RF (Radial) e Hk-stacking para a estação SIG. 
FR-RADIAL-BAG

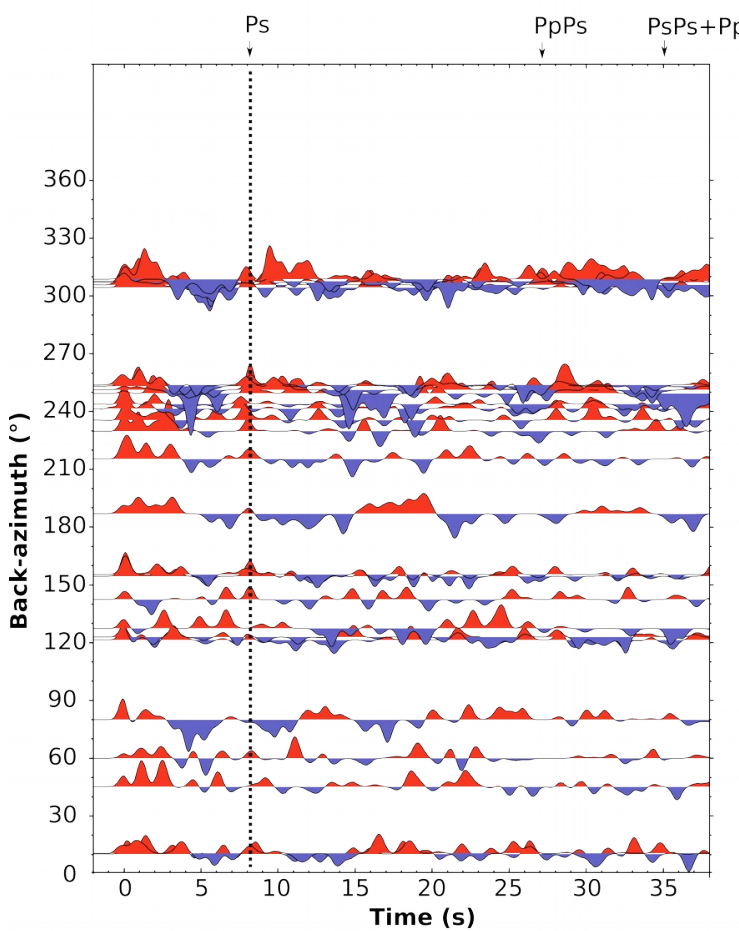

FR-RADIAL-BAG

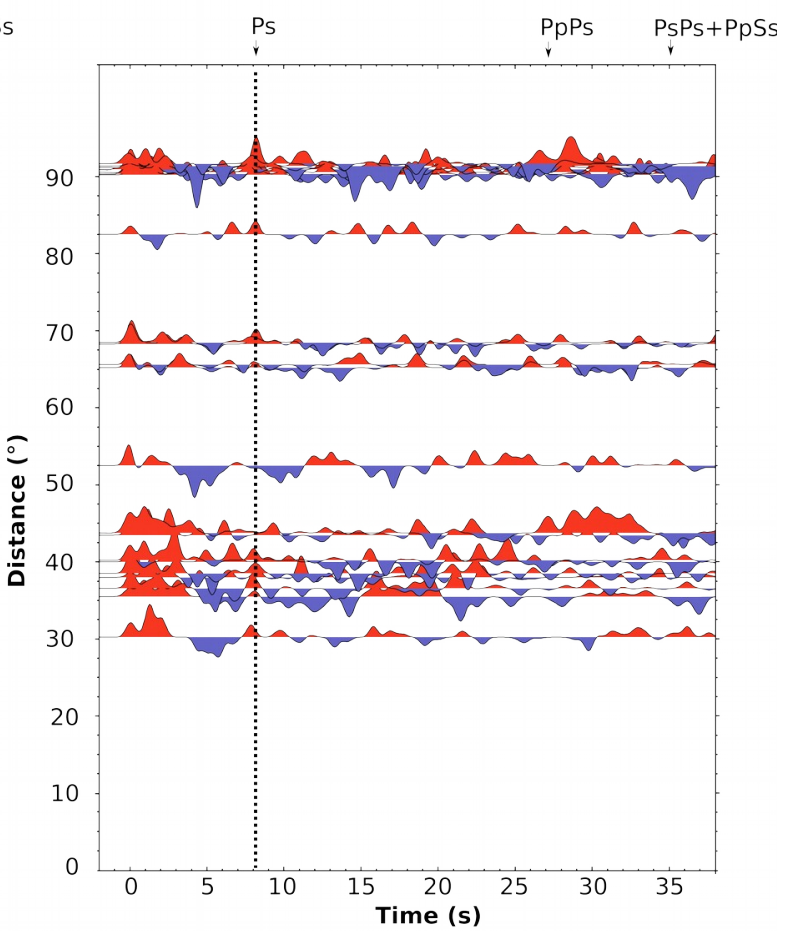

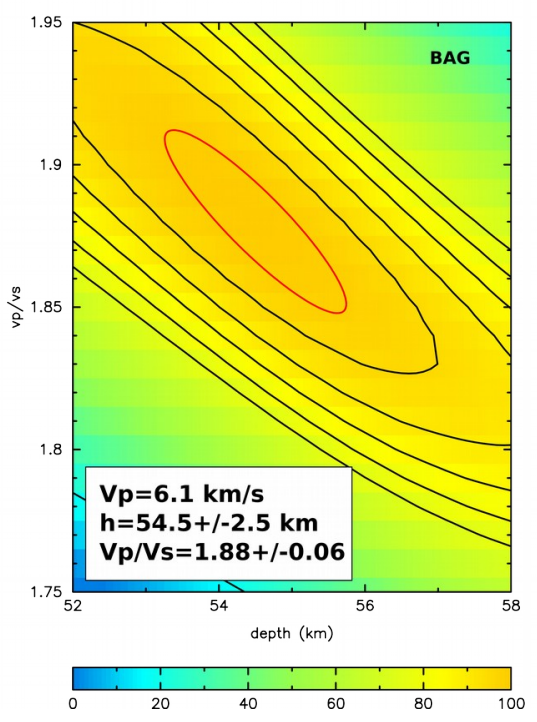

Figura C.9: RF (Radial) e Hk-stacking para a estação BAG. 

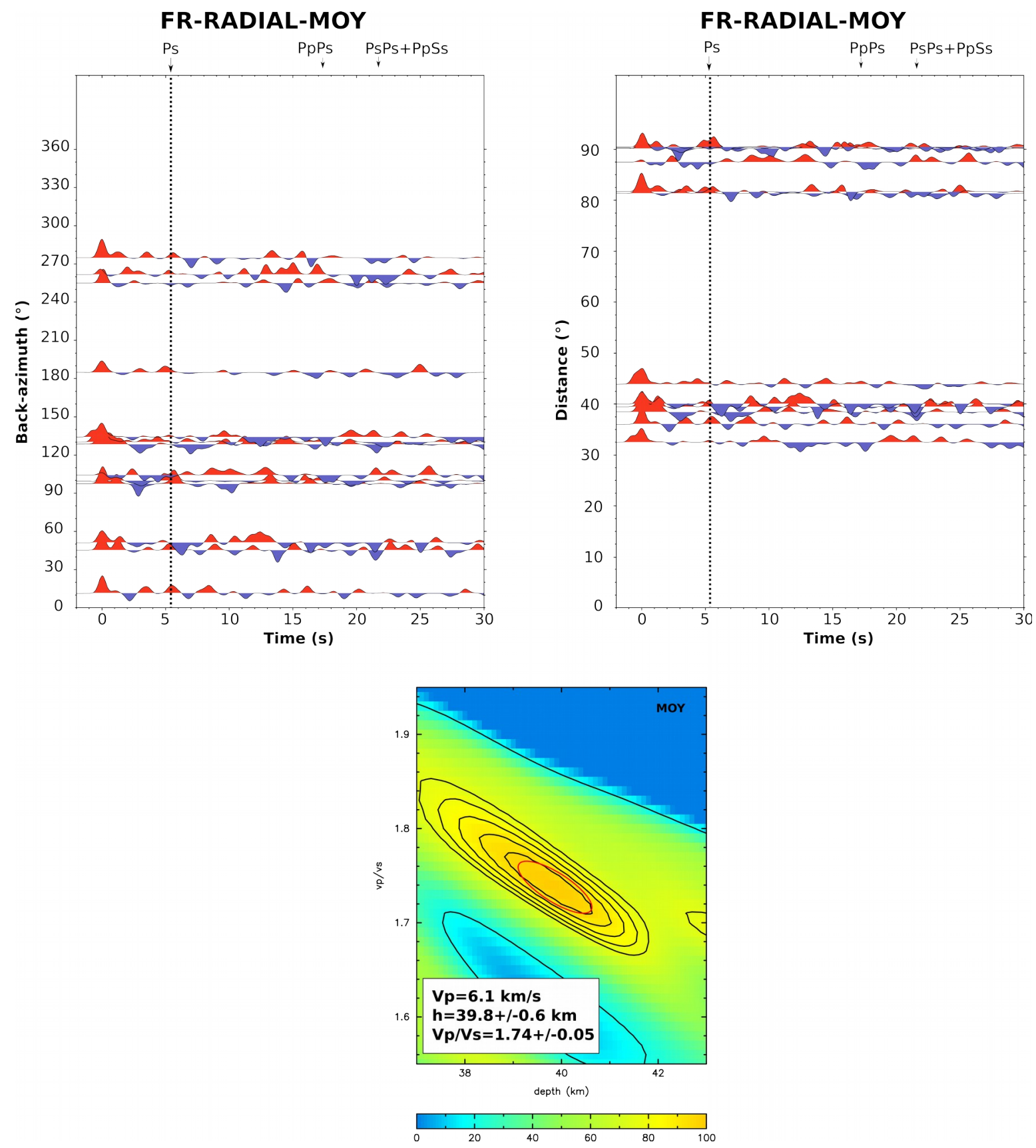

Figura C.10: RF (Radial) e Hk-stacking para a estação MOY. 

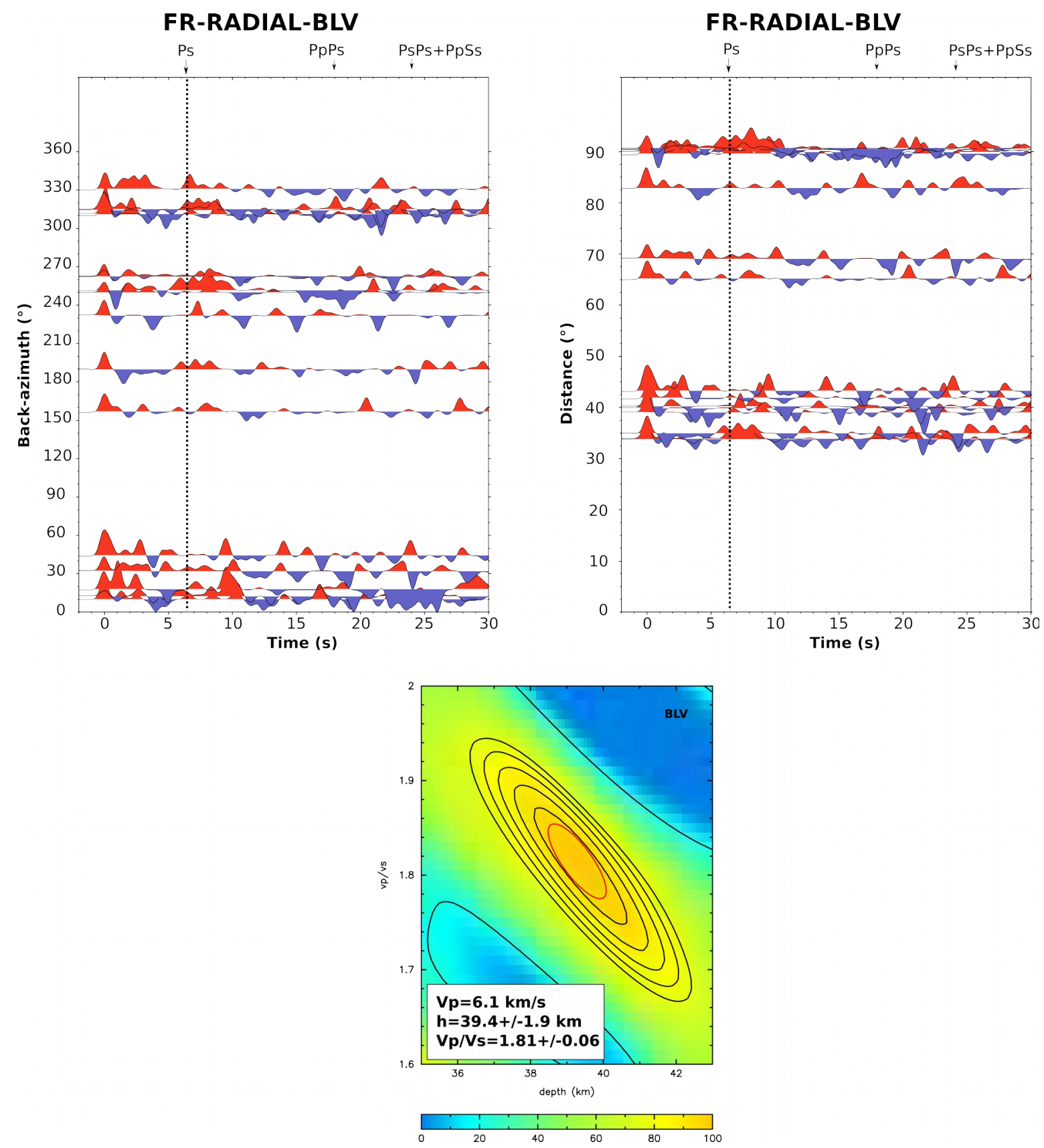

Figura C.11: RF (Radial) e Hk-stacking para a estação BLV. 

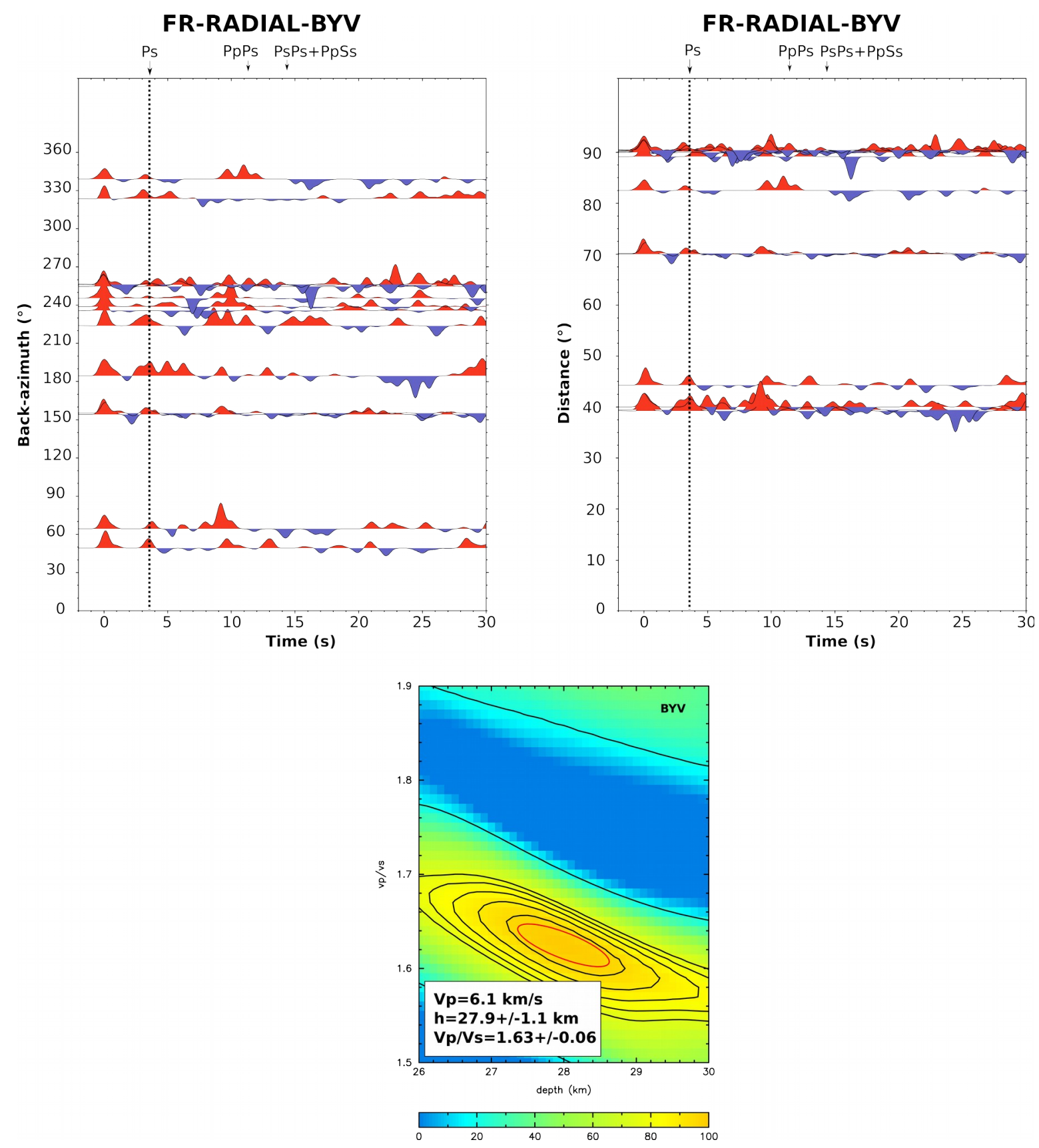

Figura C.12: RF (Radial) e Hk-stacking para a estação BYV. 
Rede Sismográfica Mundial

Comprehensive Nuclear Test Ban Treaty-CTBTO 
FR-RADIAL-ATH

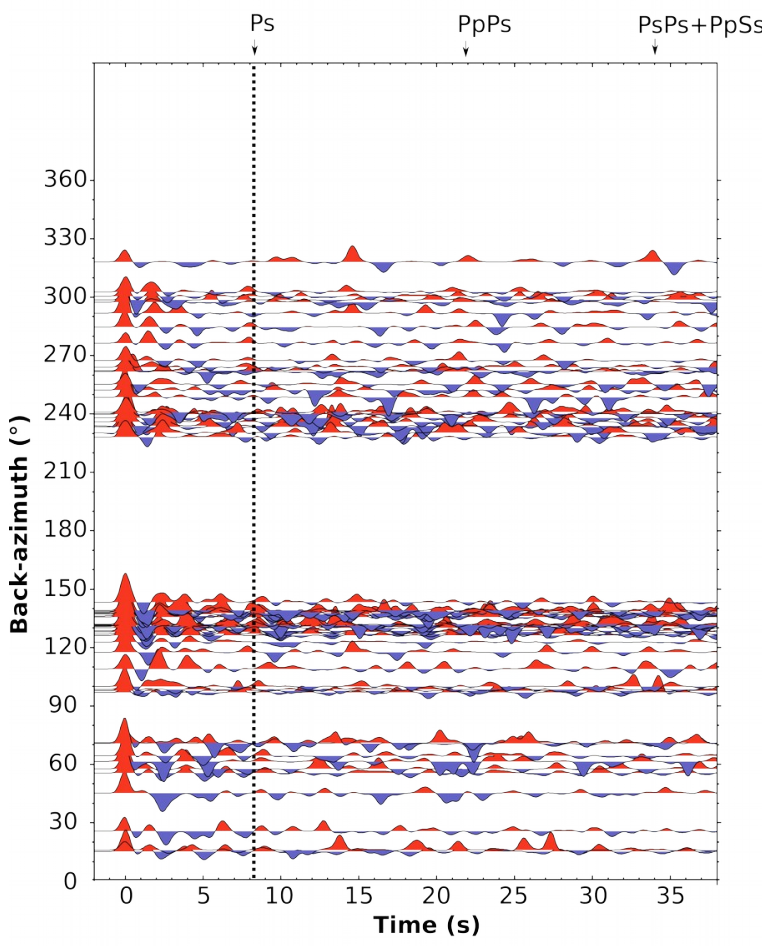

FR-RADIAL-ATH

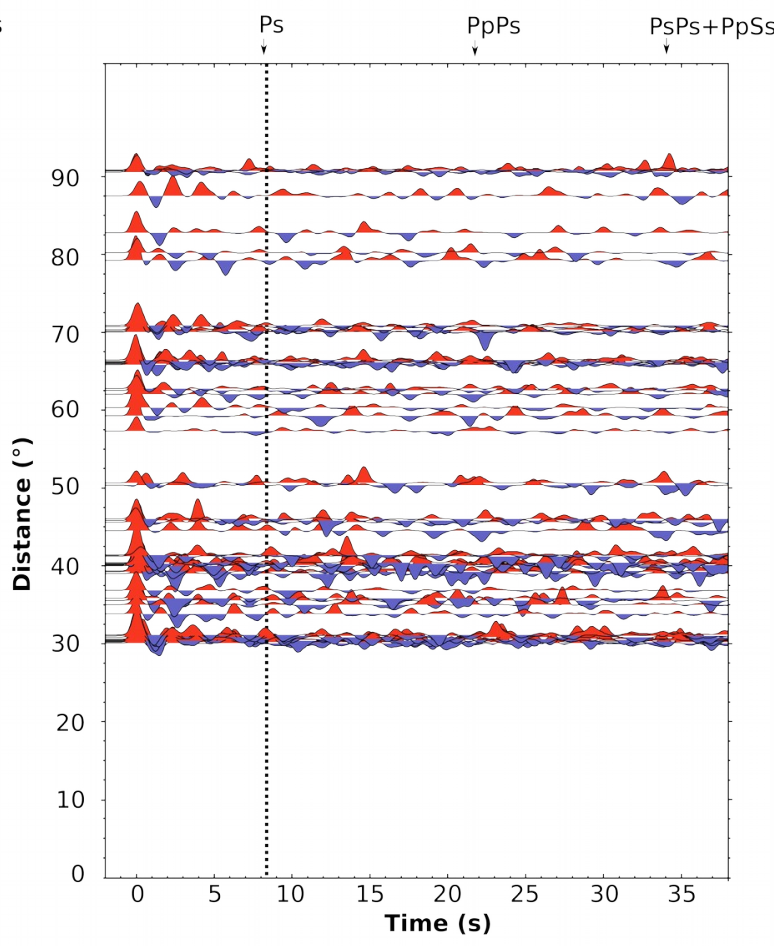

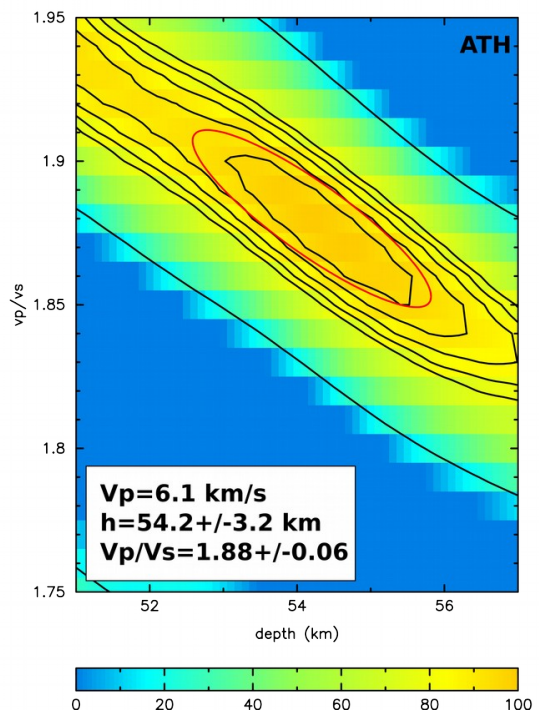

Figura C.13: RF (Radial) e Hk-stacking para a estação ATH. 
Rede Sismográfica Nacional

Instituto Geofísico do Peru (IGP) 

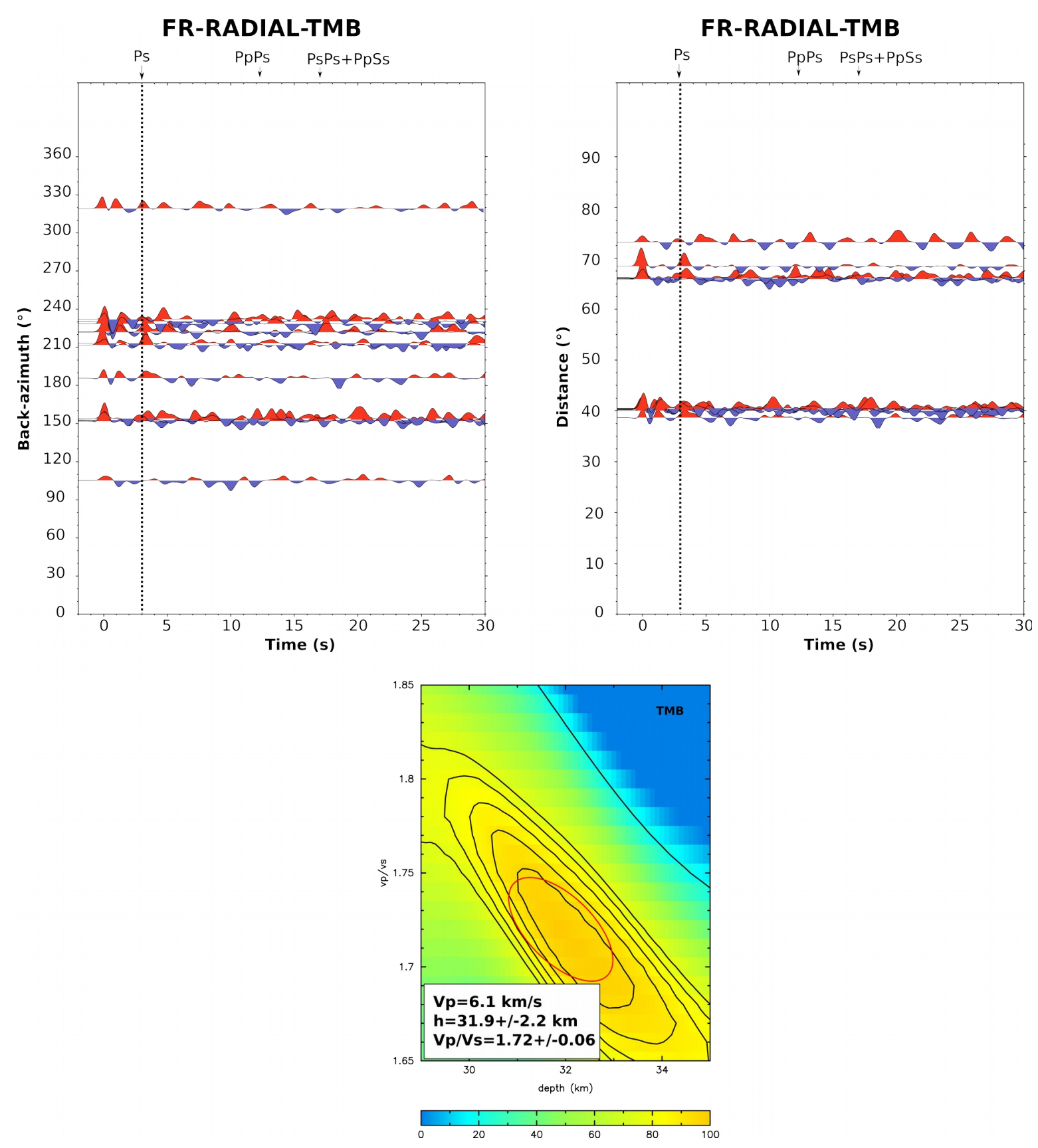

Figura C.14: RF (Radial) e Hk-stacking para a estação TBM. 


\section{FR-RADIAL-YRM}

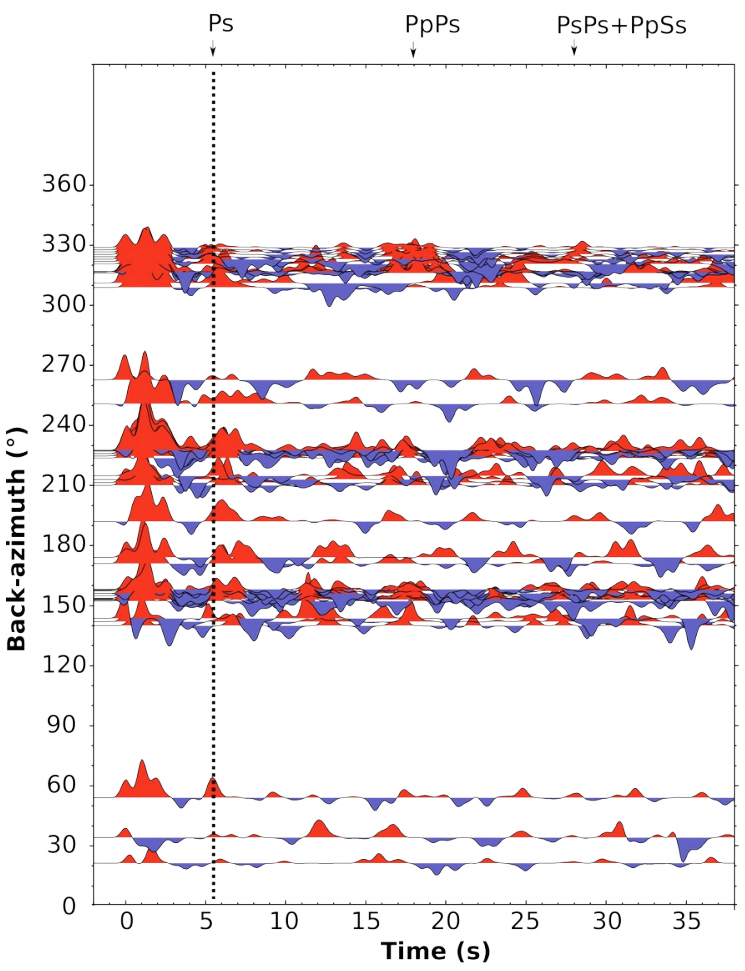

FR-RADIAL-YRM

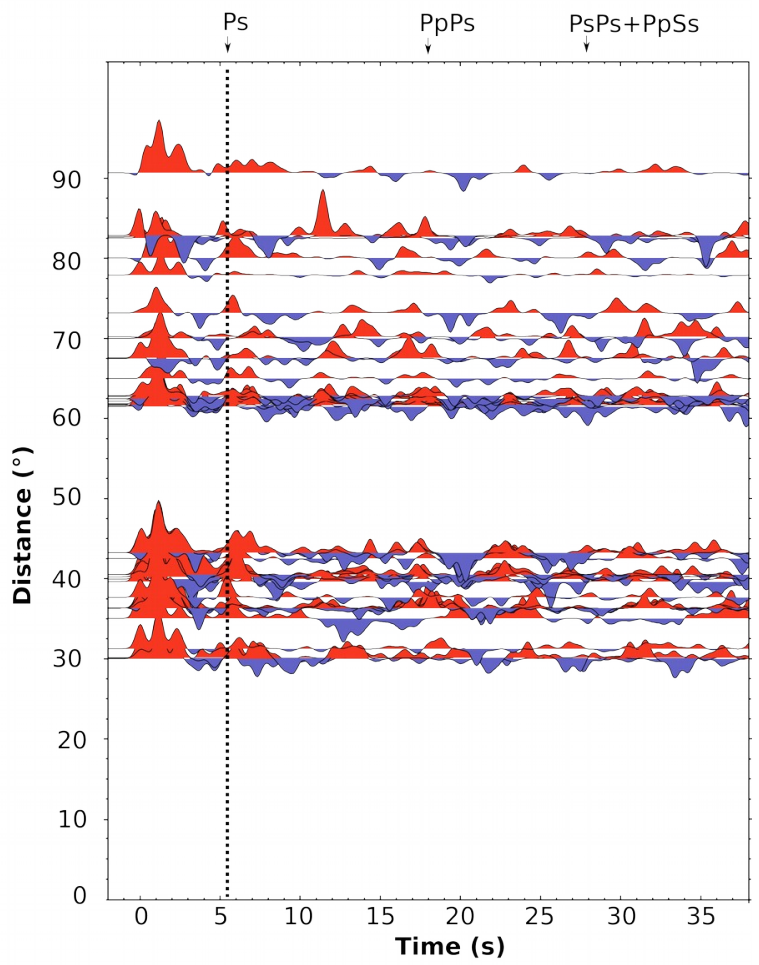

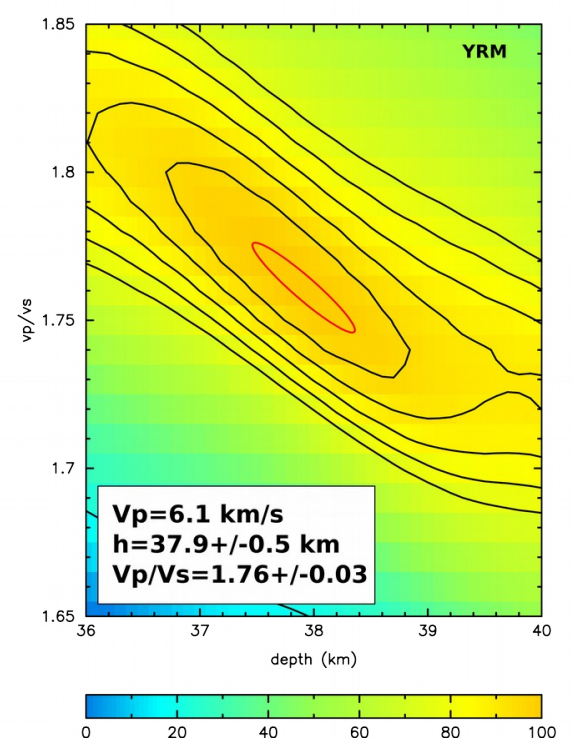

Figura C.15: RF (Radial) e Hk-stacking para a estação YRM. 

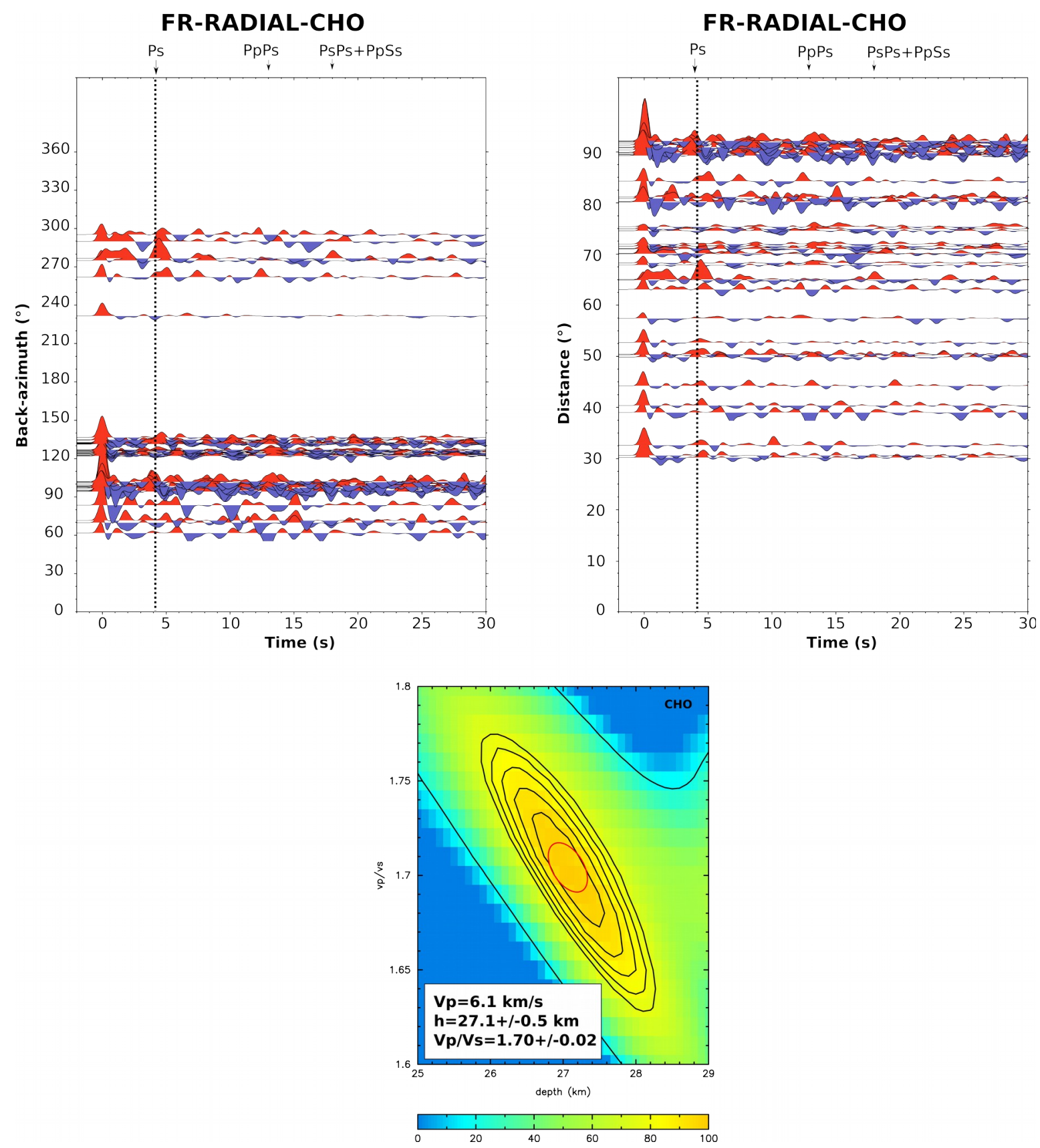

Figura C.16: RF (Radial) e Hk-stacking para a estação CHO. 

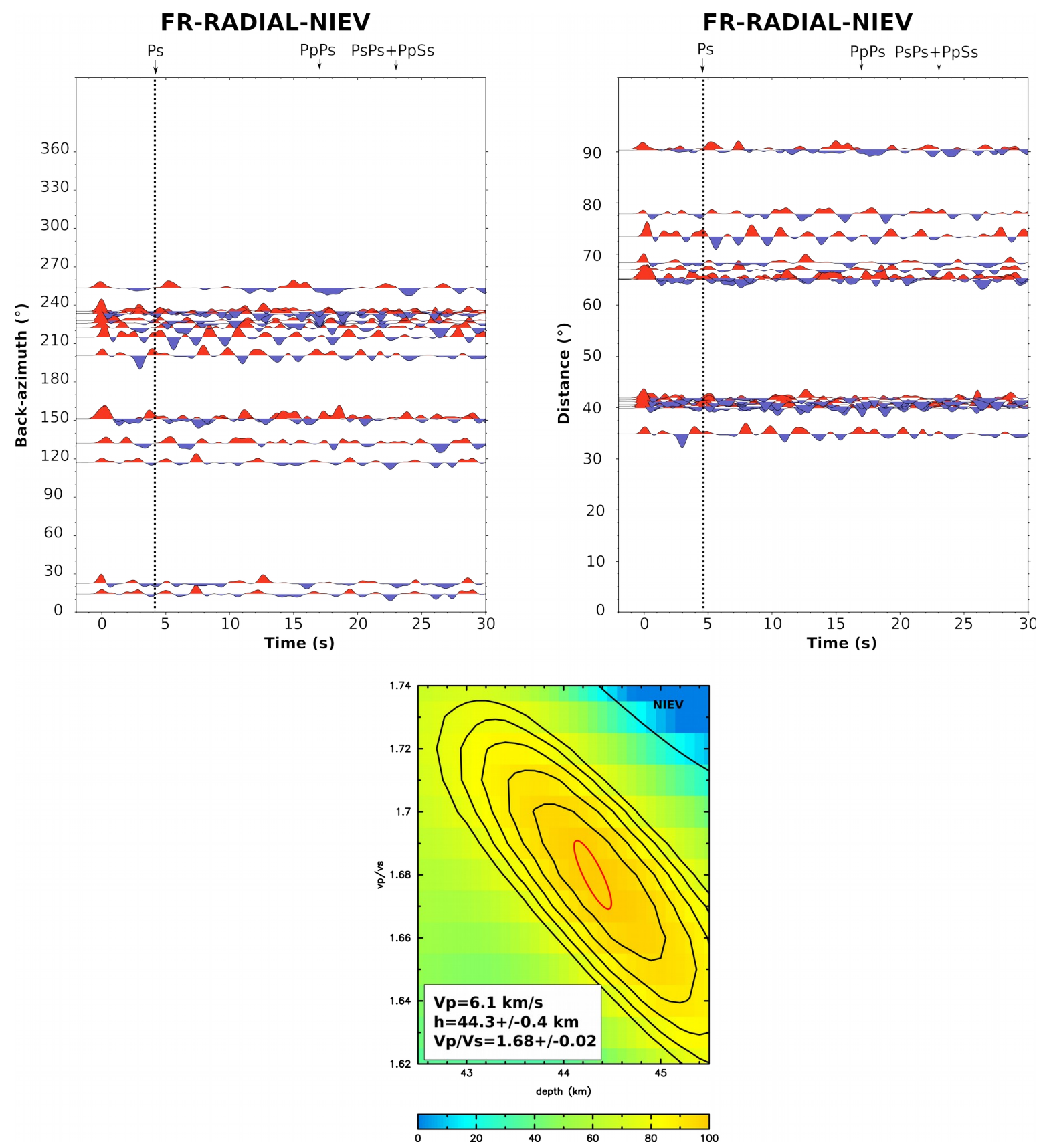

Figura C.17: RF (Radial) e Hk-stacking para a estação NIEV. 

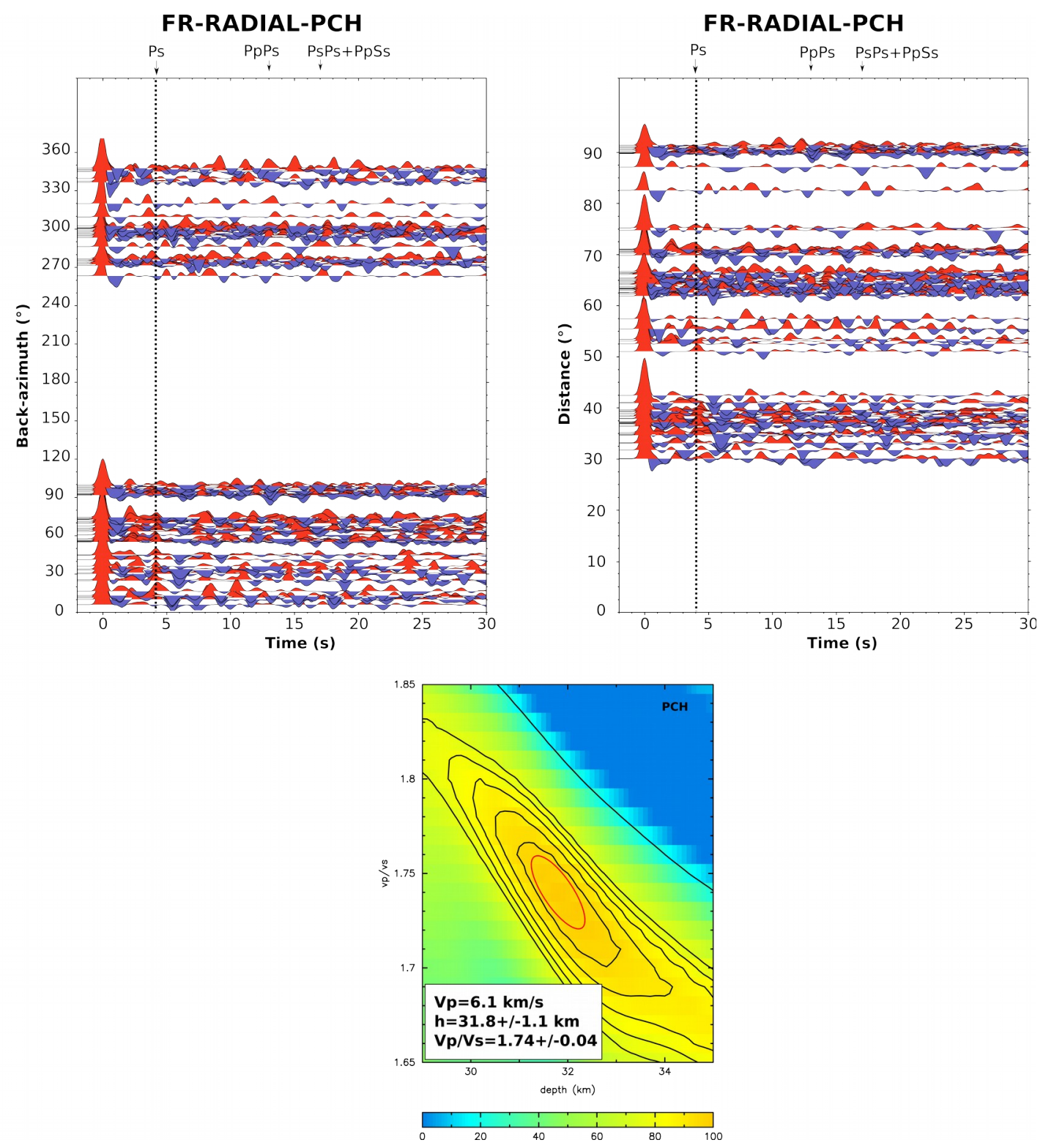

Figura C.18: RF (Radial) e Hk-stacking para a estação PCH. 

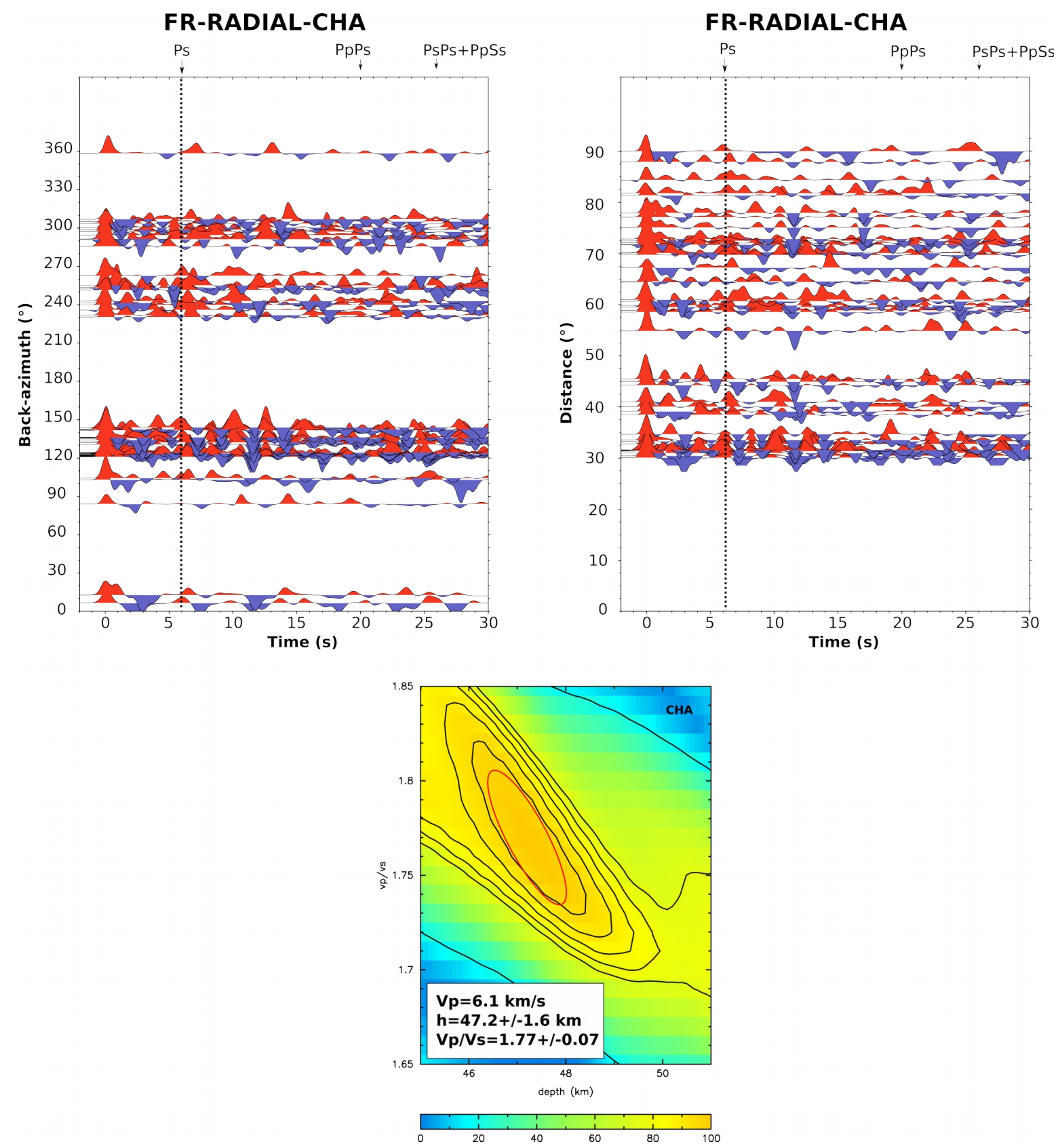

Figura C.19: RF (Radial) e Hk-stacking para a estação CHA. 

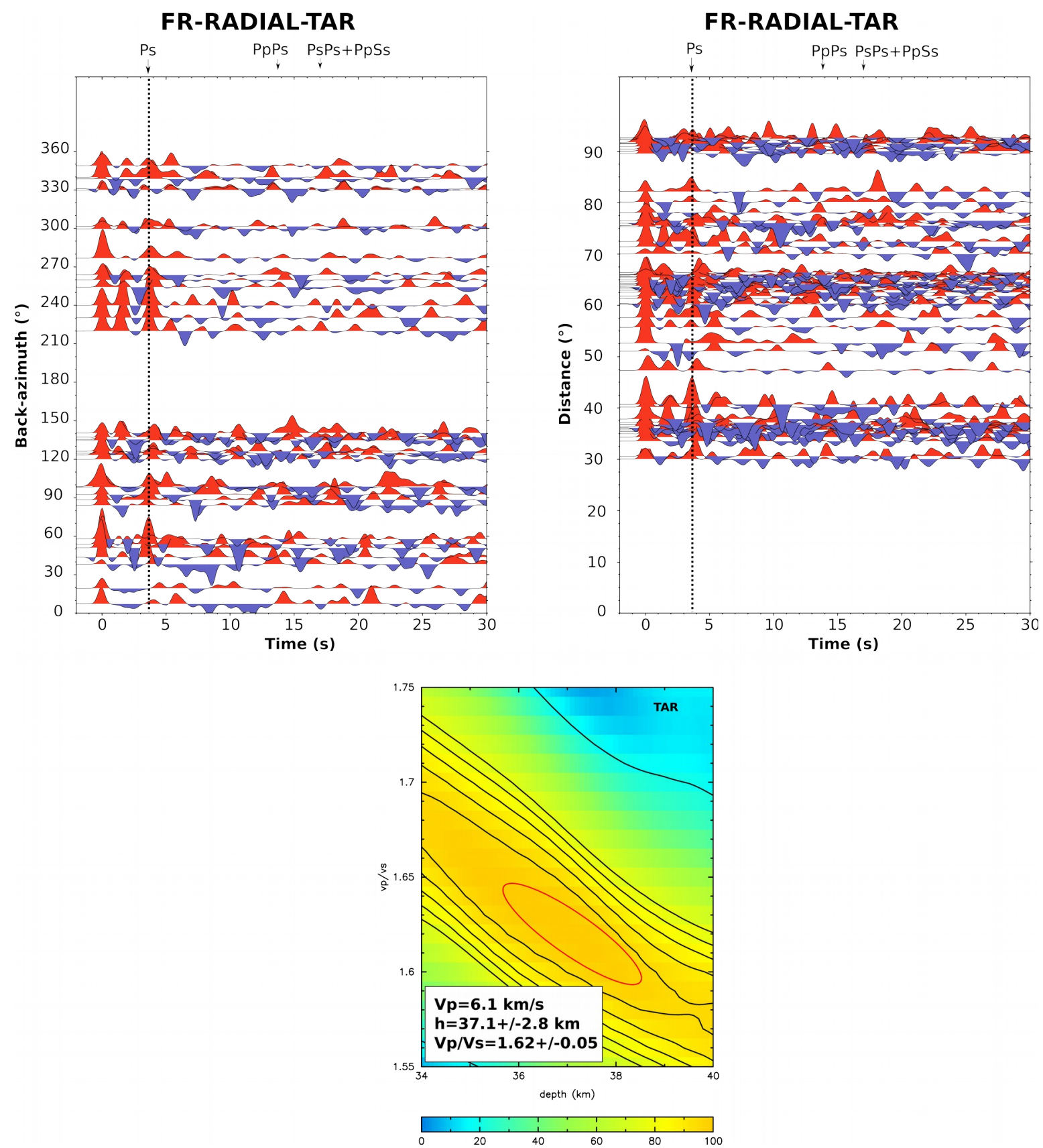

Figura C.20: RF (Radial) e Hk-stacking para a estação TAR. 


\section{FR-RADIAL-TICA}

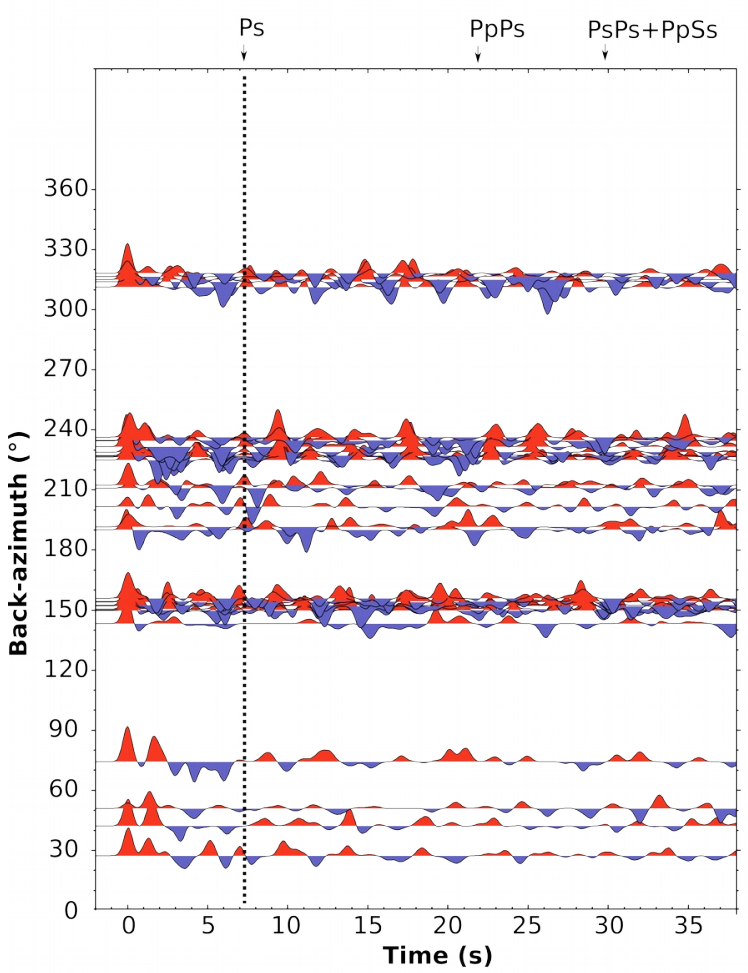

FR-RADIAL-TICA

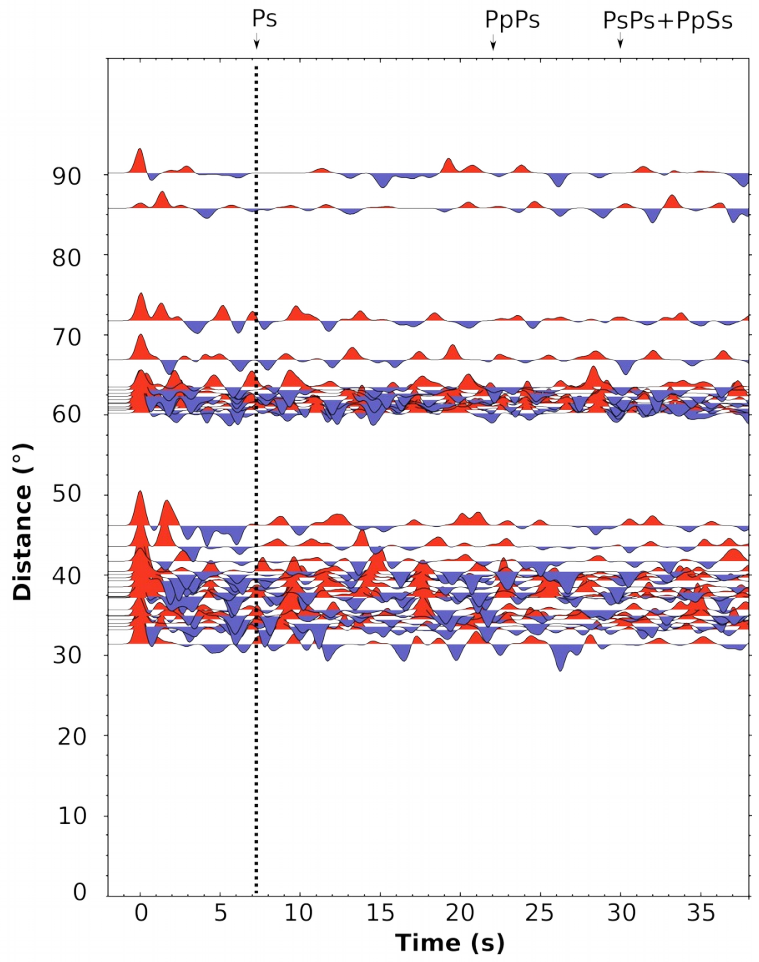

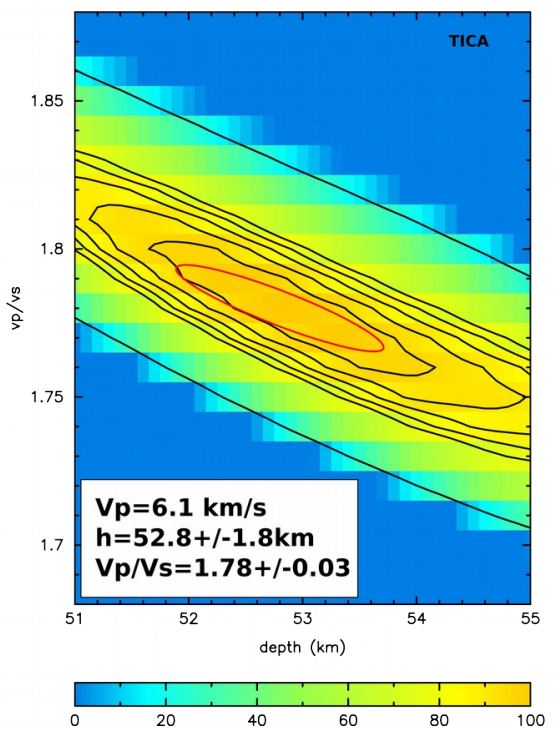

Figura C.21: RF (Radial) e Hk-stacking para a estação TICA. 

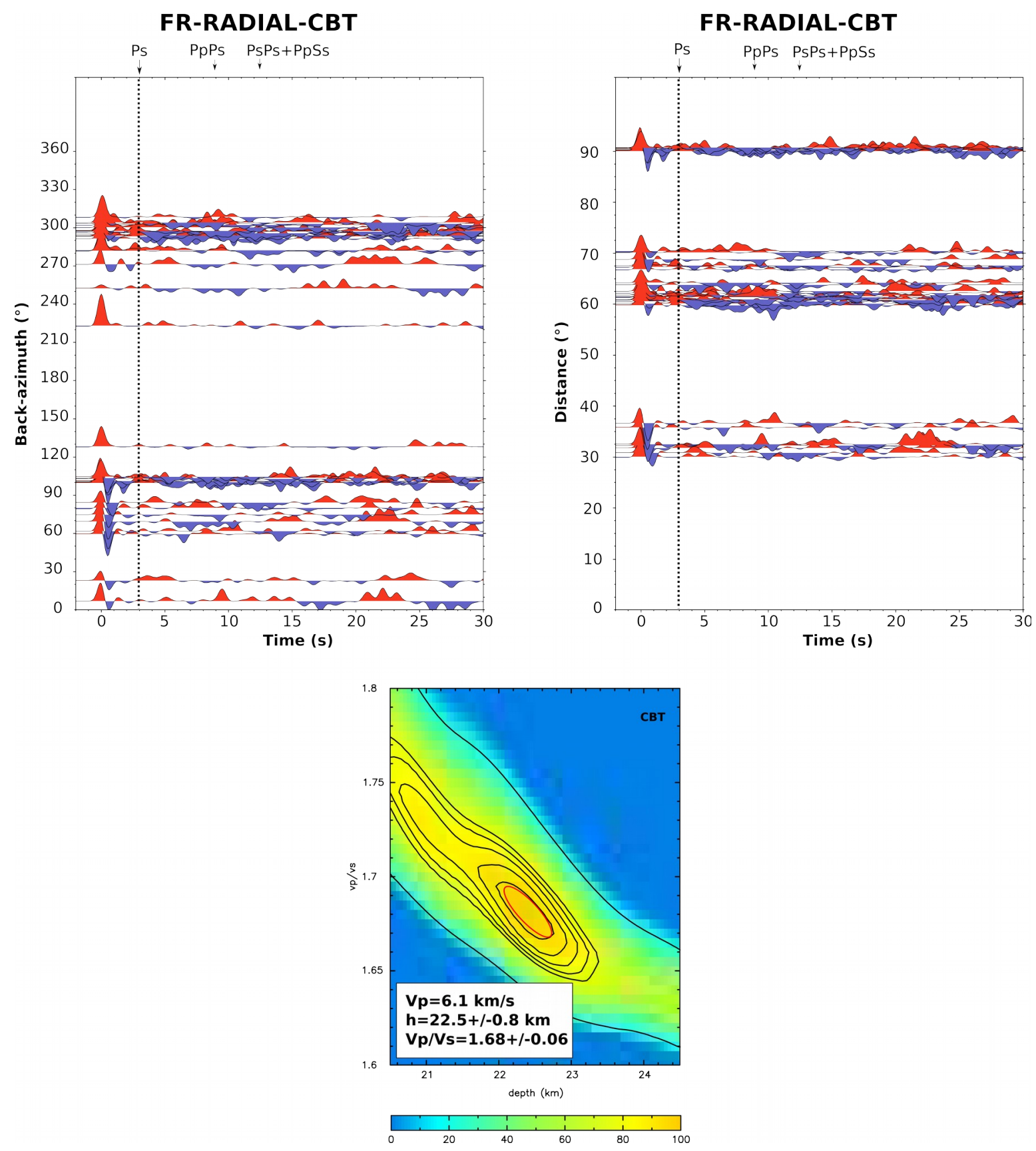

Figura C.22: RF (Radial) e Hk-stacking para a estação CBT. 


\section{FR-RADIAL-YANA}

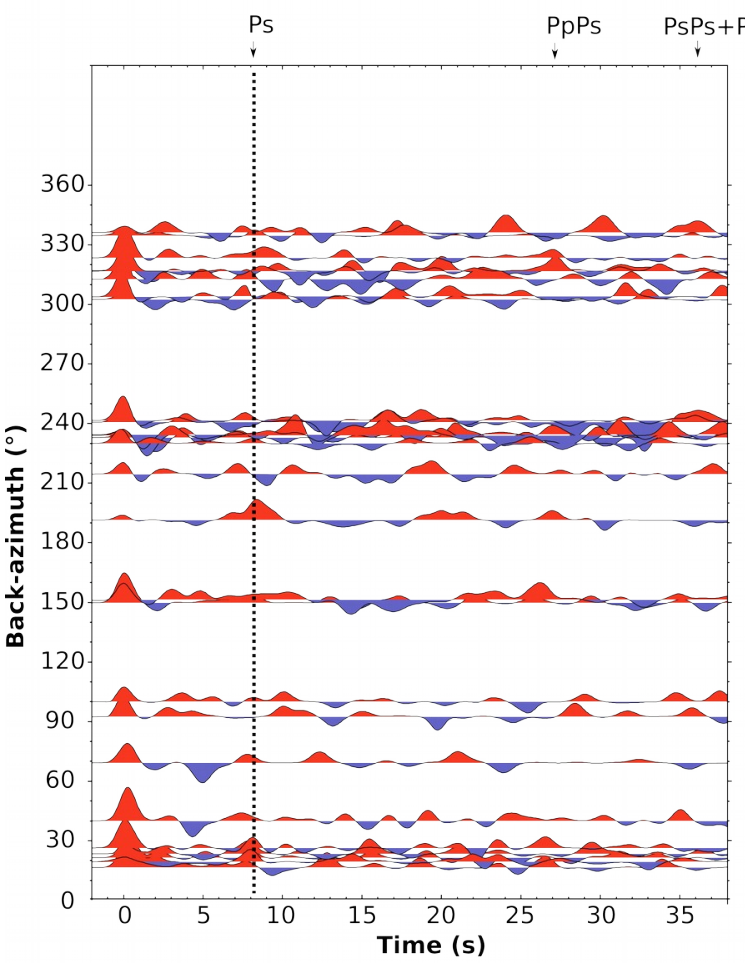

FR-RADIAL-YANA

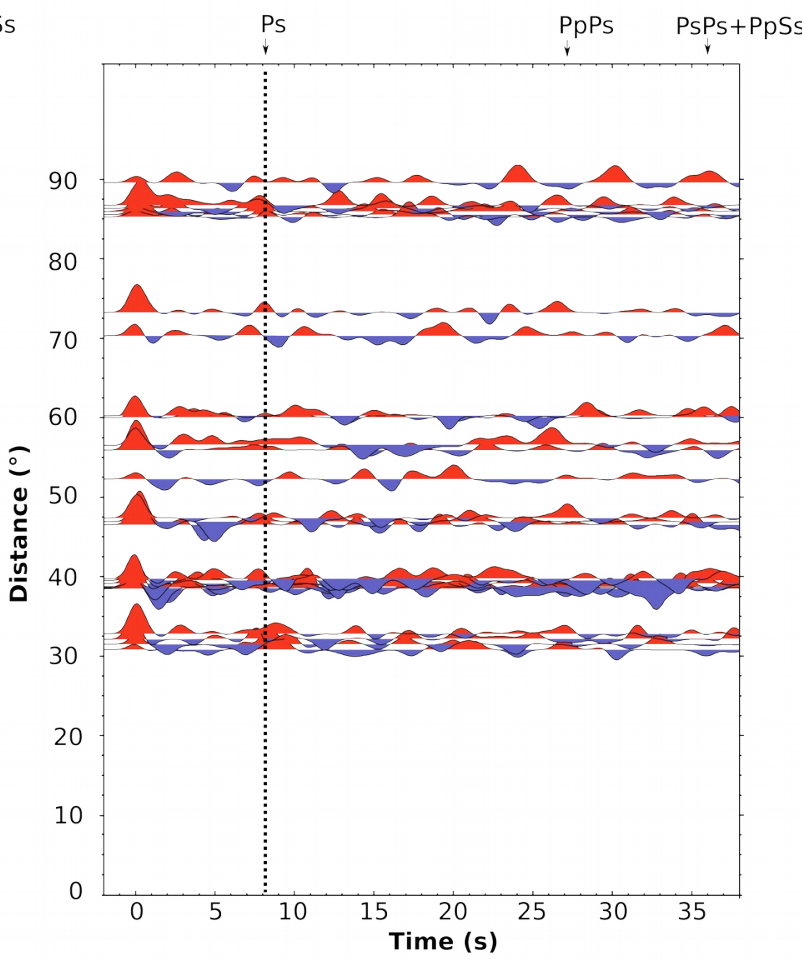

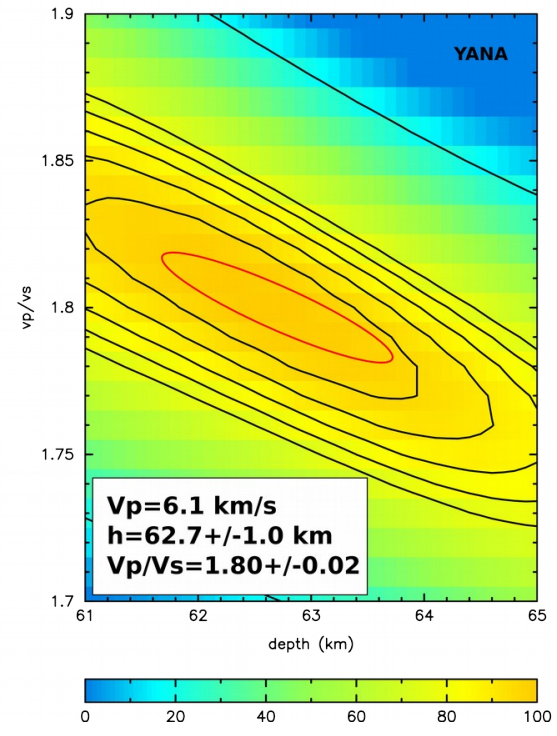

Figura C.23: RF (Radial) e Hk-stacking para a estação YANA. 
FR-RADIAL-OXA

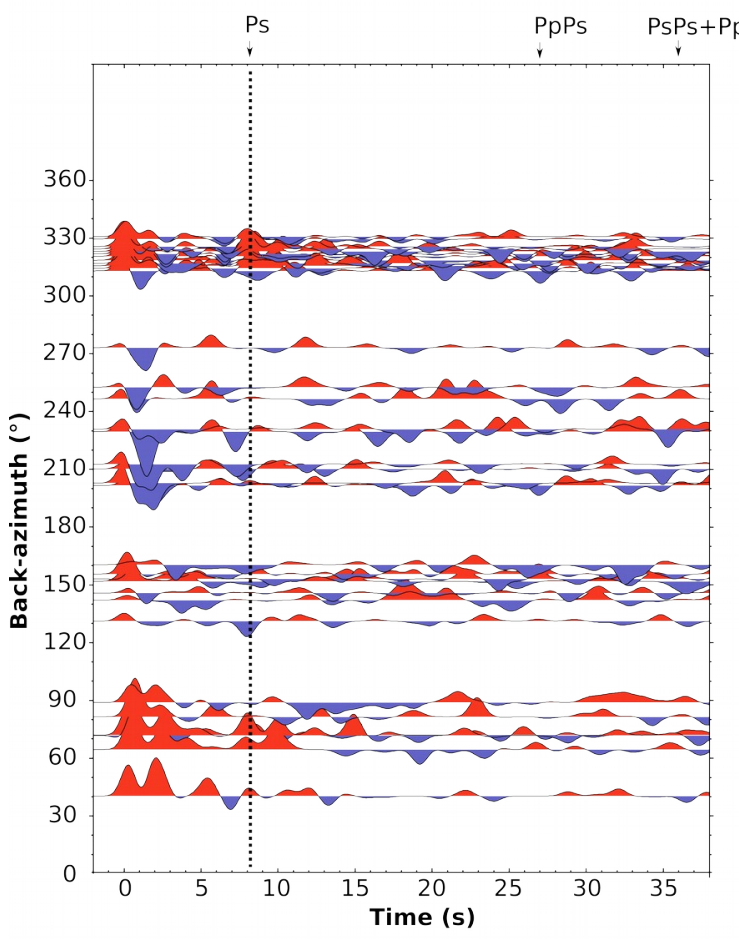

FR-RADIAL-OXA

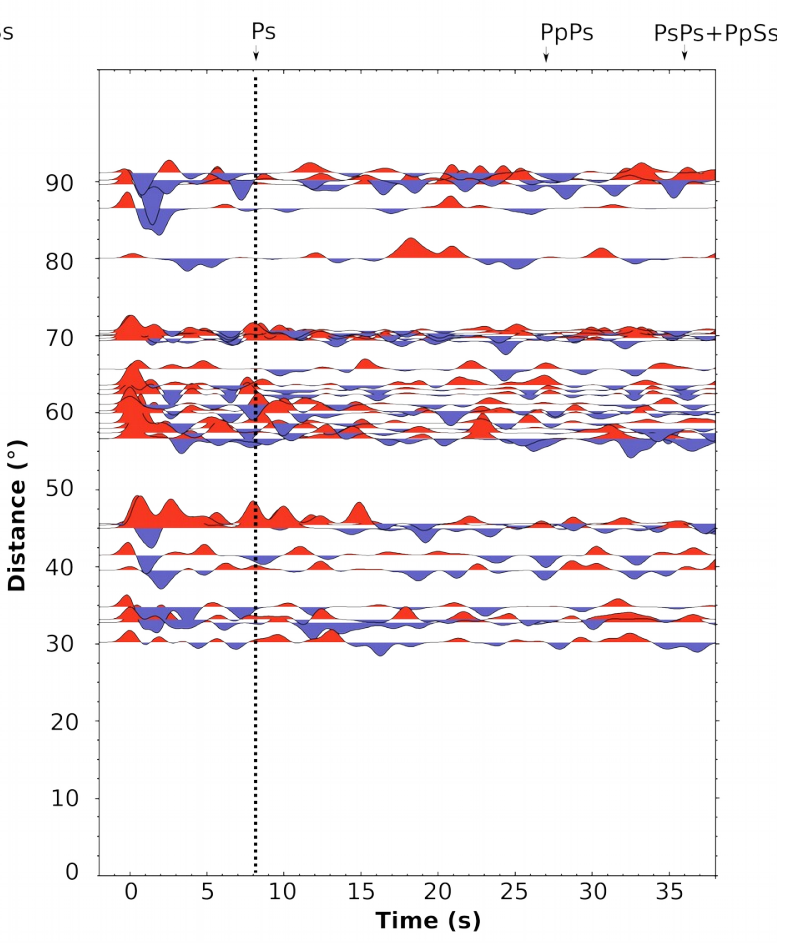

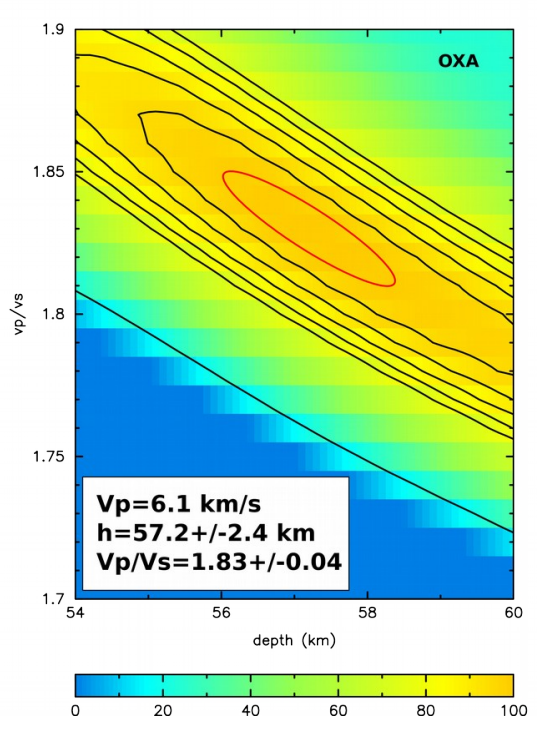

Figura C.24: RF (Radial) e Hk-stacking para a estação OXA. 

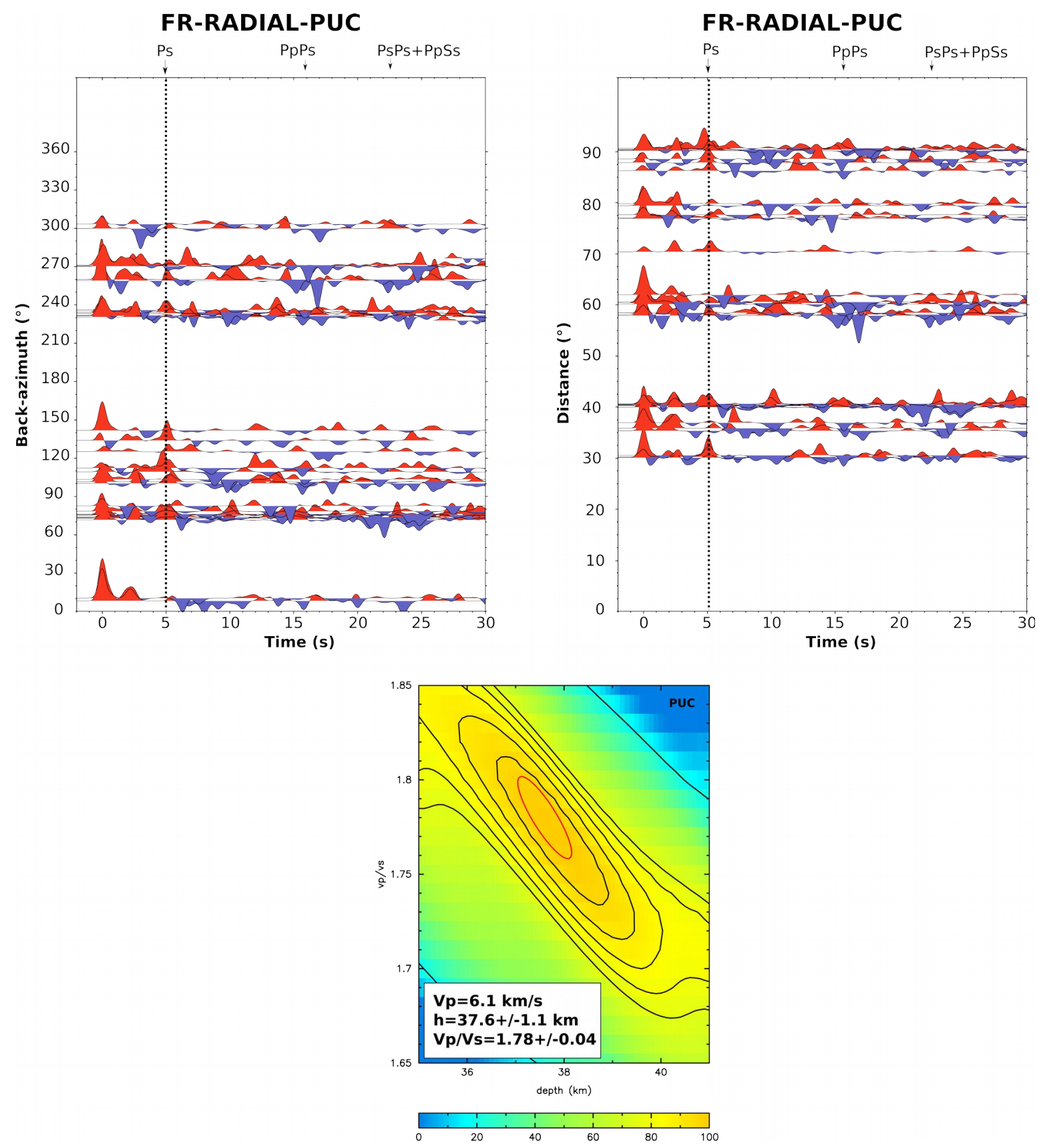

Figura C.25: RF (Radial) e Hk-stacking para a estação PUC. 

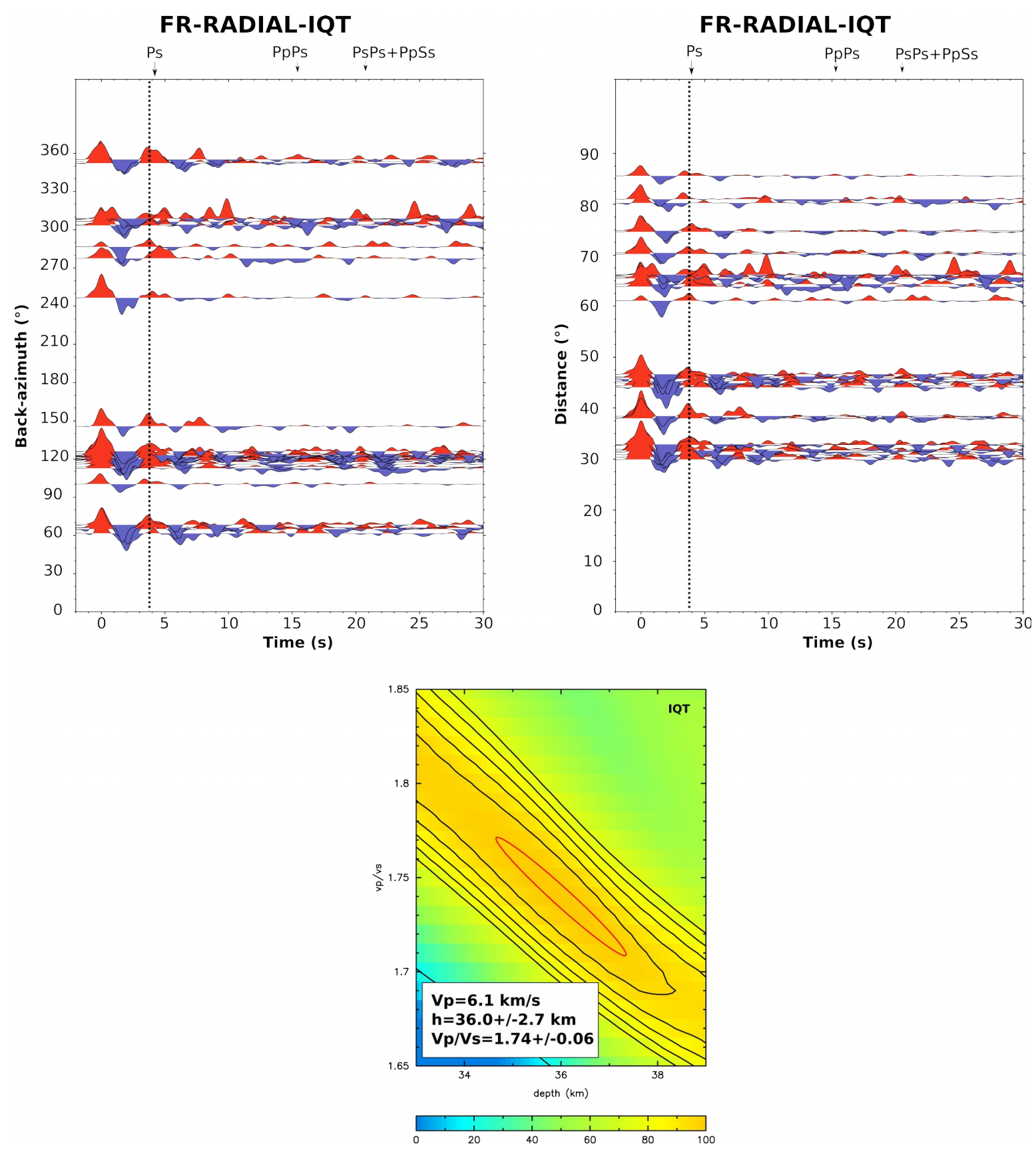

Figura C.26: RF (Radial) e Hk-stacking para a estação IQT. 
FR-RADIAL-HCO

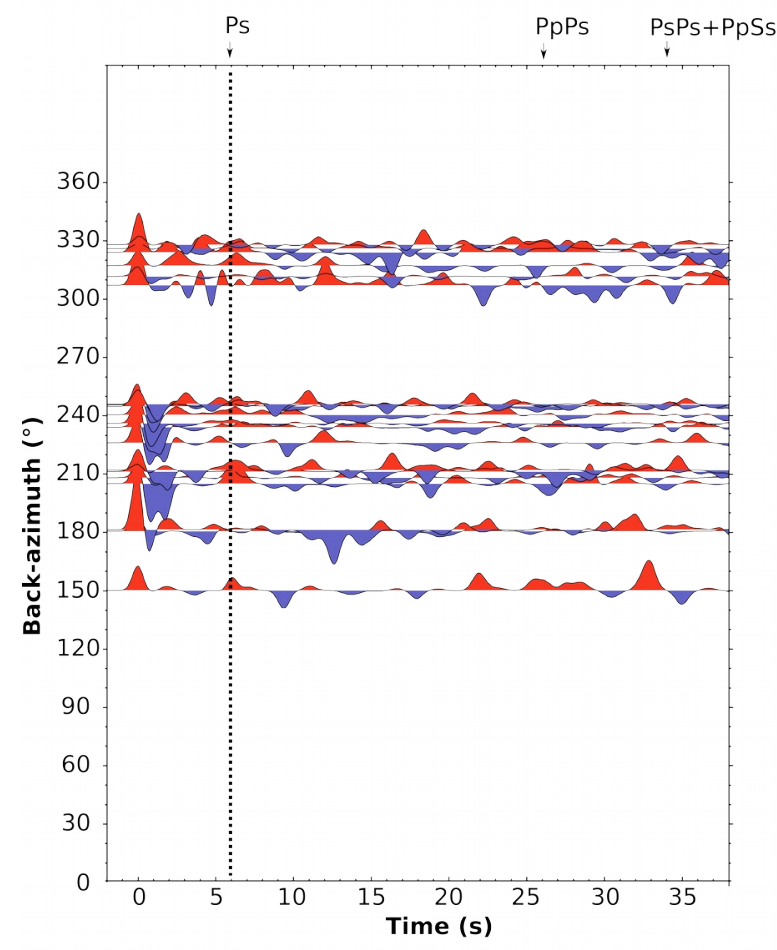

FR-RADIAL-HCO

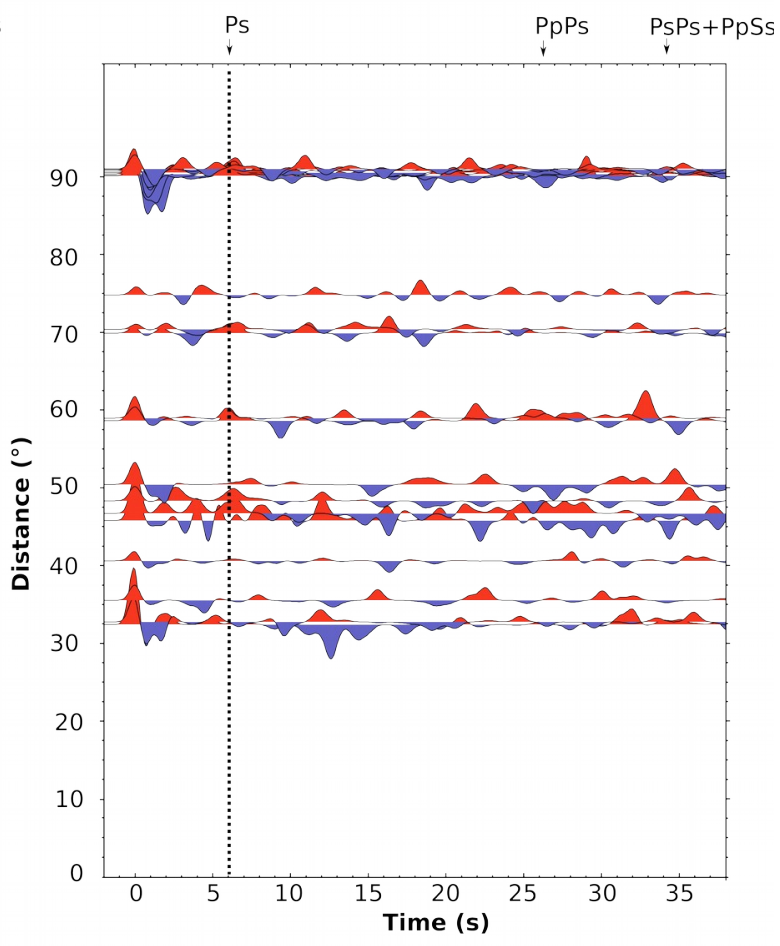

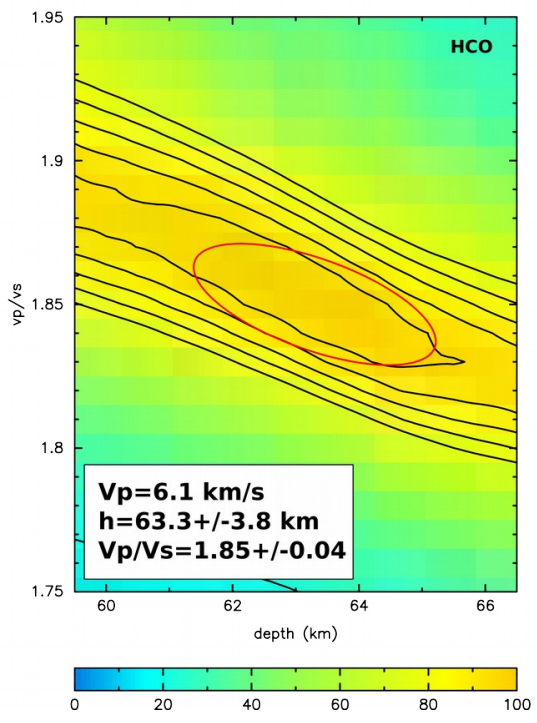

Figura C.27: RF (Radial) e Hk-stacking para a estação HCO. 


\section{FR-RADIAL-HYL}

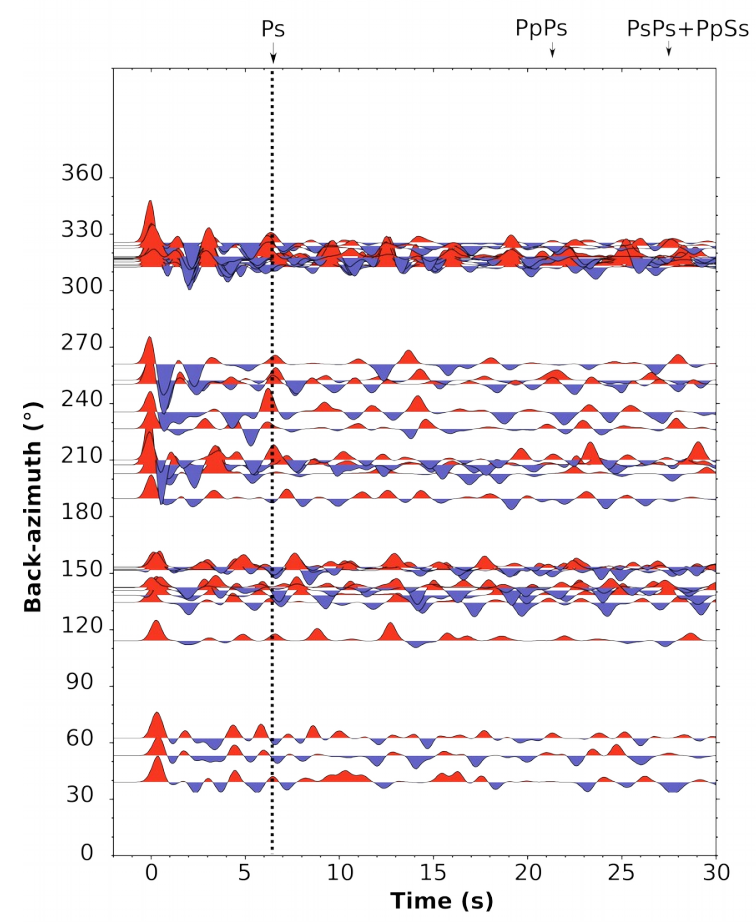

\section{FR-RADIAL-HYL}

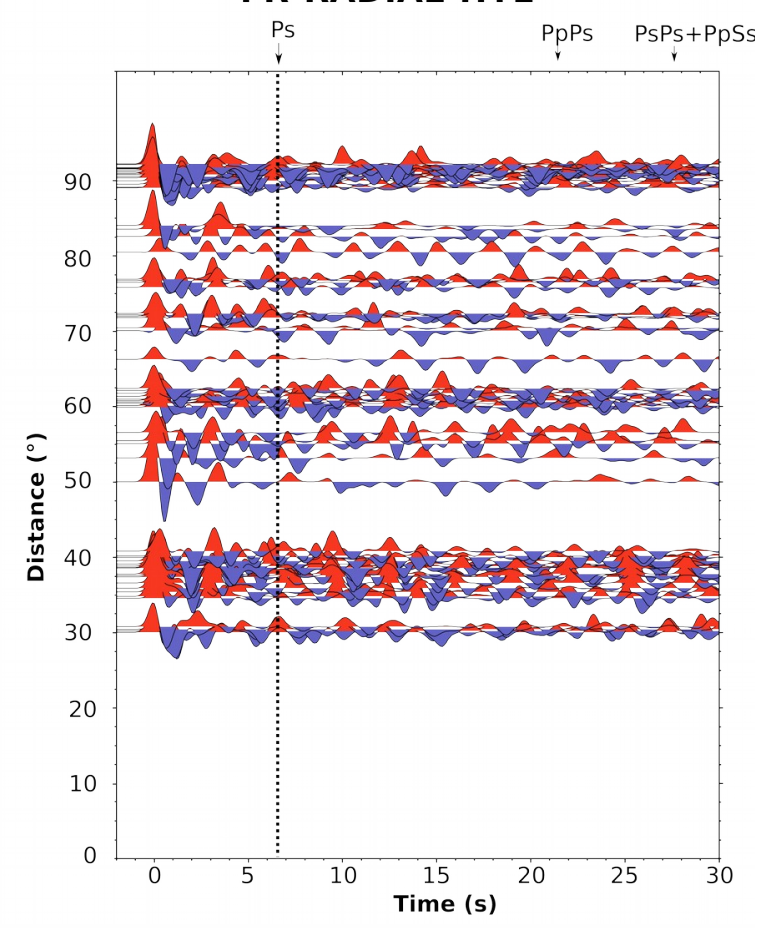

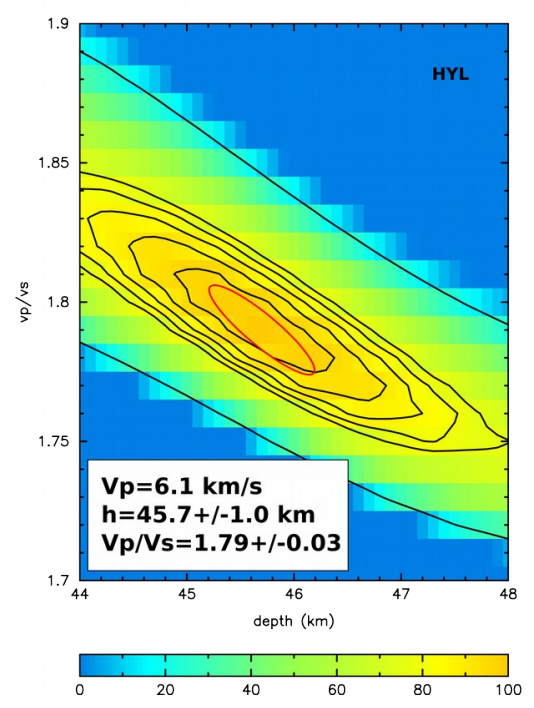

Figura C.28: RF (Radial) e Hk-stacking para a estação HYL. 